WASHINGTON BATISTA VIEIRA

SIMULAÇÃO NUMÉRICA DO COMPORTAMENTO ESTRUTURAL DE VIGAS CASTELADAS DE AÇO COM ÊNFASE NA FLAMBAGEM DO MONTANTE DE ALMA

Dissertação apresentada à Universidade Federal de Viçosa, como parte dos requisitos do Programa de Pós-Graduação em Engenharia Civil, para obtenção do título de Magister Scientiae.

VIÇOSA

MINAS GERAIS - BRASIL 


\section{SIMULAÇÃO NUMÉRICA DO COMPORTAMENTO ESTRUTURAL DE VIGAS CASTELADAS DE AÇO COM ÊNFASE NA FLAMBAGEM DO MONTANTE DE ALMA}

Dissertação apresentada à Universidade Federal de Viçosa, como parte dos requisitos do Programa de Pós-Graduação em Engenharia Civil, para obtenção do título de Magister Scientiae.

APROVADA: 25 de fevereiro de 2011.

Prof. Gustavo de Souza Veríssimo

(Co-orientador)
Prof ${ }^{a}$. Rita de Cássia S. S. Alvarenga

(Co-orientadora)

Prof. José Carlos Lopes Ribeiro

Prof. José Luiz Rangel Paes

(Orientador) 
"Ó profundidade das riquezas, tanto da sabedoria, como da ciência de Deus! Quão insondáveis são os seus juízos, e quão inescrutáveis os teus caminhos! Porque quem compreendeu o intento do Senhor? Ou quem foi seu conselheiro? Ou quem lhe deu primeiro a Ele para que seja recompensado? Porque dEle e por Ele, e para Ele, são todas as coisas; glória pois a Ele eternamente. Amém."

Aos Romanos 11:33-36

À minha esposa, Meiriane 


\section{AGRADECIMENTOS}

Quero expressar a minha gratidão aos que contribuíram direta ou indiretamente para que este trabalho fosse realizado.

Agradeço

Aos meus pais, pelo apoio, amizade e carinho.

Ao Prof. José Luiz Rangel Paes, pela ajuda constante, pela amizade adquirida durante esse tempo de convívio, pelo apoio expressivo, e pela brilhante orientação neste trabalho dentre diversos outros.

Ao Prof. Gustavo de Souza Veríssimo, pela amizade, pelos conselhos, pelas lições de vida e pela participação efetiva durante este trabalho.

À FAPEMIG, pelo apoio financeiro ao desenvolvimento do projeto de pesquisa TEC-APQ 01429-08 e pela bolsa concedida.

Ao Prof. José Carlos Lopes Ribeiro, pelas discussões e compartilhamento de informações sobre o Método dos Elementos Finitos.

Aos colegas do mestrado, Eliane Silveira, Rafael Lopes, Maila Pereira, Carlos Augusto (Cantim), Thiago Albrecht, Giuliana Ferrari, Halley Silva, Luiza Oliveira, Gustavo Irala.

Às minhas queridas irmãs Natally e Anna Cristina Vieira e à minha cunhada Marcilia Guimarães.

Aos meus tios, em especial Washington Viana, Maria das Graças Coelho e Sebastião Viana.

Aos primos, sogro, sogra e demais familiares.

Aos meus amigos e irmãos em Cristo:

Adalvan Daniel Martins, Adão e Fátima Martins, Alexandre e Rita Navarro da Silva, Altair Mendes, Álvaro Alves, Anderson Assis, Anderson e Fabrícia Damasceno, Bruno Lima, Carlos Henrique, Dimas e Maria do Carmo Parreiras, Eberton dos Santos, Eliel Ferreira, Eliseu e Sara Rocha, Elyabe Matos, Filipe Garcia, Henrique e Patrícia Rodrigues, João Mendes e Maria das Graças Gomes, Luiz Carlos e Liete Euclydes, Luiza Nazar, Marcos Leandro, Marcus Euclydes, Maristela Carvalho, Marina Lopes, Nicolas Silva, Ricardo Nazar, Rivelino, Sérgio Rocha e Talita Euclydes, Sílvio e Elisângela Morais, Thiago e Paola Baptista, Patrícia Martins, Thiago Soares e Midhyã Alves, Vanderson de Castro, Vanessa Baglioni, Vilma Soares, Weiner Costa. 
Aos professores do Setor de Estruturas do DEC-UFV: Rita de Cássia Sant'Anna Silva Alvarenga, Reginaldo Carneiro da Silva, Márcio Sampaio Sarmet Moreira, Kléos Magalhães Lenz César Jr, José Maria Franco de Carvalho.

Aos professores do Departamento de Estruturas da Escola de Engenharia da UFMG, em especial Rodrigo Barreto Caldas e Ana Lydia Reis Castro e Silva.

Ao Eduardo Matos Bezerra (Pará), pelo compartilhamento de informações.

À Universidade Federal de Viçosa, e em especial ao Departamento de Engenharia Civil, pela formação e oportunidades.

Agradeço em especial à Meiriane, minha grande parceira nos bons e maus momentos.

Acima de tudo, dou graças a Deus, por ter me dado o privilégio de conhecê-Lo, pelo seu magnífico e grandioso Amor; e a Jesus, o único Homem de verdade, a Quem procuro seguir. 


\section{SUMÁRIO}

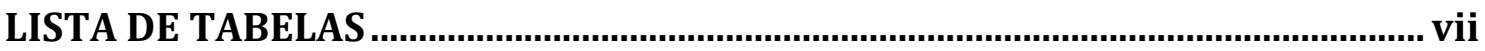

LISTA DE FIGURAS.......................................................................................................ix

LISTA DE SÍMBOLOS E ABREVIATURAS ............................................................

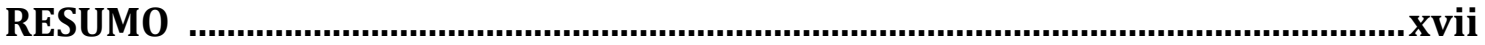

ABSTRACT

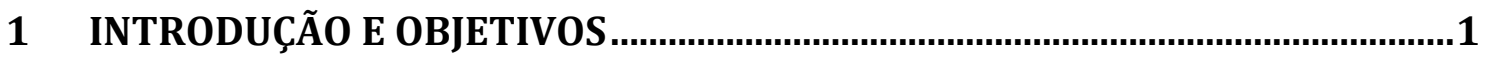

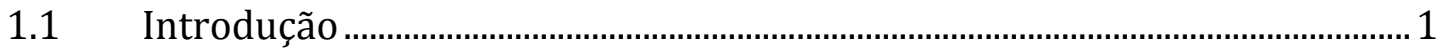

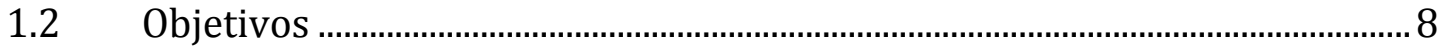

1.3 Organização do documento ……………...........................................................

2 DEFINIÇÃO DAS TIPOLOGIAS E DOS ELEMENTOS.......................................... 10

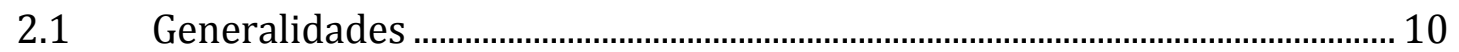

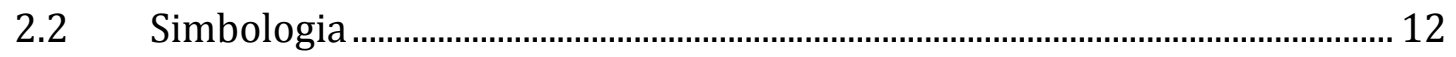

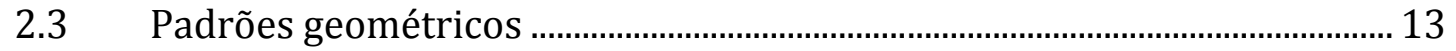

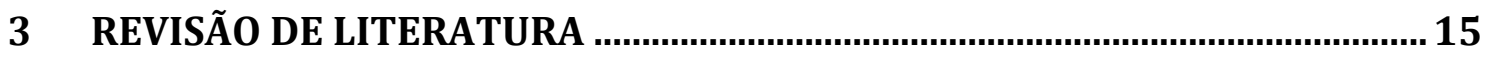

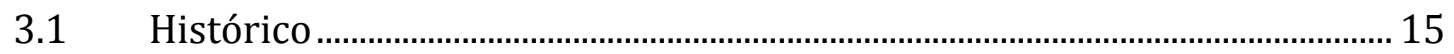

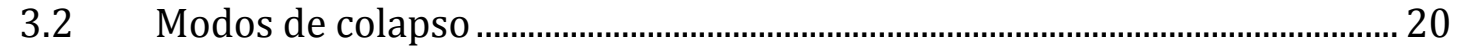

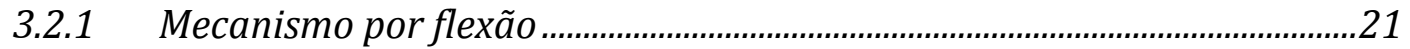

3.2.2 Flambagem lateral com torção ……............................................................21

3.2.3 Mecanismo Vierendeel..................................................................................22

3.2.4 Ruptura do montante de alma por cisalhamento.........................................22

3.2.5 Flambagem do montante de alma ..............................................................23

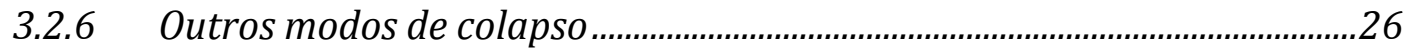

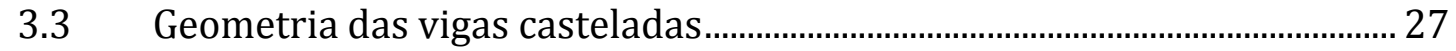

3.4 Comportamento estrutural de vigas alveolares............................................... 28

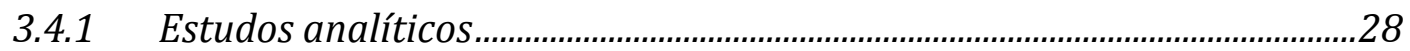

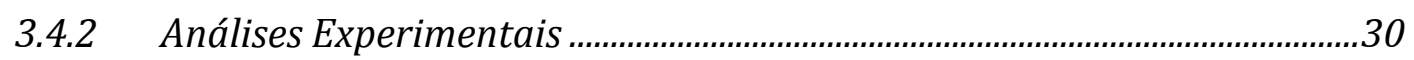

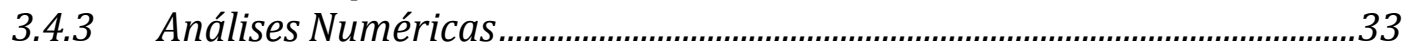

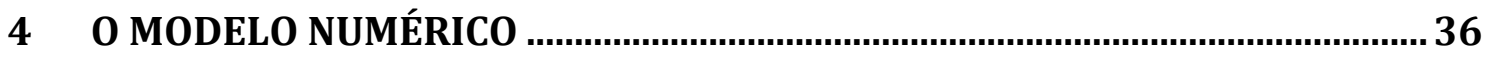

4.1 Considerações iniciais ...................................................................................... 36

4.2 Características do modelo numérico …………...................................................... 37 


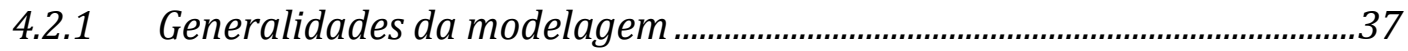

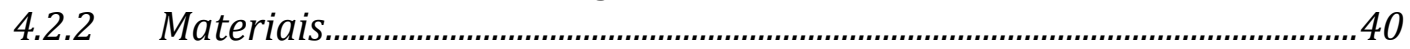

4.2.3 Análise de flambagem elástica..................................................................40

4.2.4 Análise não-linear material e geométrica ..................................................41

4.3 Validação do modelo numérico............................................................................. 46

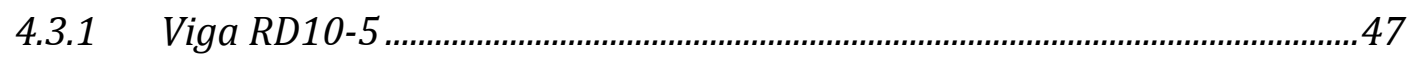

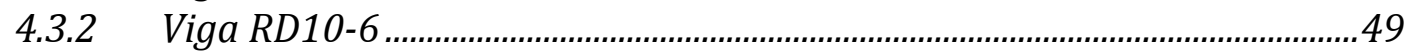

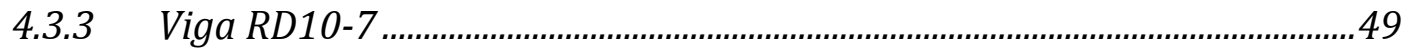

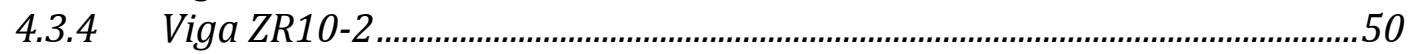

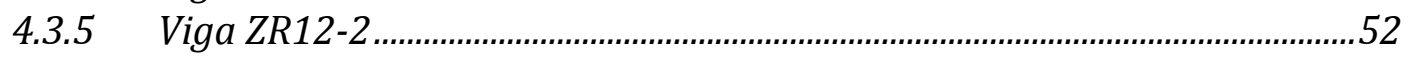

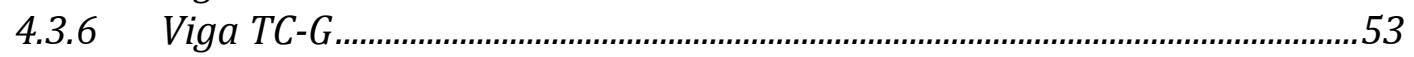

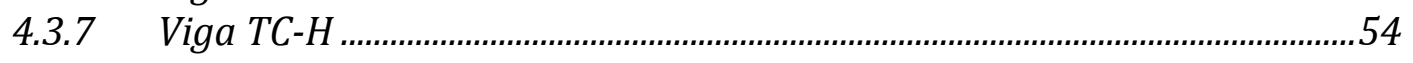

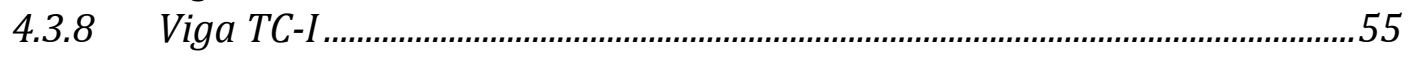

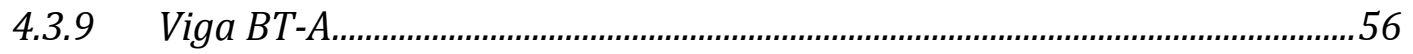

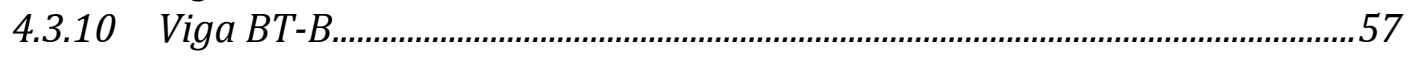

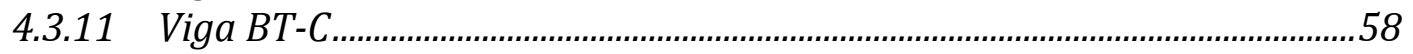

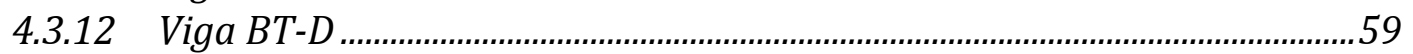

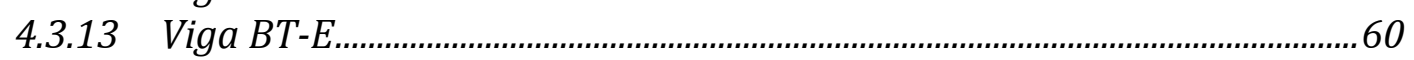

4.3.14 Síntese da validação do modelo numérico.................................................61

\section{AVALIAÇÃO NUMÉRICA DO COMPORTAMENTO ESTRUTURAL DE VIGAS} CASTELADAS: ESTUDO PARAMÉTRICO ................................................ 63

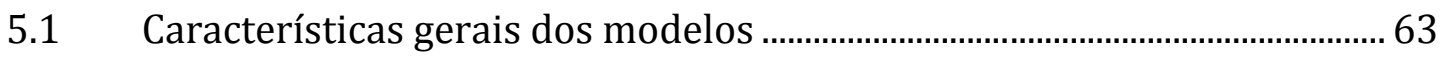

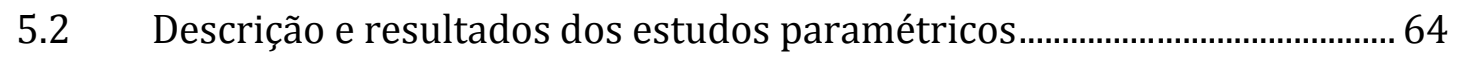

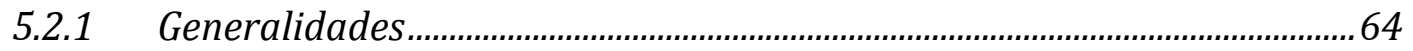

5.2.2 Grupo 1 - Avaliação da influência da esbeltez da alma..............................66

5.2.3 Grupo 2 - Avaliação da influência da relação $L / d_{g}$.....................................69

5.2.4 Grupo 3 - Avaliação da influência do carregamento....................................73

5.2.5 Grupo 4 - Avaliação da influência da geometria dos alvéolos...................74

5.2.6 Grupo 5 - Avaliação do comportamento de vigas de alma cheia ..............78

5.2.7 Grupo 6 - Avaliação da influência da altura da chapa expansora ..........79

5.2.8 Grupo 7 - Avaliação da influência de enrijecedores de alma em vigas casteladas com colapso por FMA por compressão.

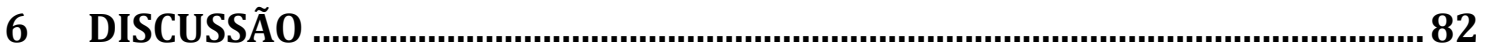

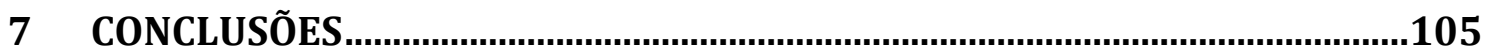

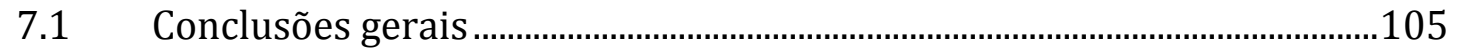

7.2 Sugestões para trabalhos futuros..................................................................... 108

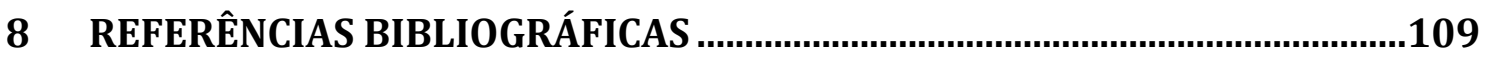




\section{LISTA DE TABELAS}

Tabela 3.1 - Características de ensaios realizados por Zaarour (1995). 32

Tabela 3.2 - Resultados obtidos através de modelagem numérica, em comparação com experimentos (adaptado de ZAAROUR e REDWOOD, 1996).

Tabela 3.3 - Resultados obtidos através de modelagem numérica, em comparação com resultados experimentais (adaptado de REDWOOD e DEMIRDJIAN, 1998).

Tabela 4.1 - Análise da objetividade da malha de elementos finitos. 40

Tabela 4.2 - Modelos experimentais utilizados para validação da modelagem numérica.

Tabela 4.3 - Características e resultados da modelagem numérica da viga RD10-5.... 48

Tabela 4.4 - Características e resultados da modelagem numérica da viga RD10-6..... 49

Tabela 4.5 - Características e resultados da modelagem numérica da viga RD10-7.... 50

Tabela 4.6 - Características e resultados da modelagem numérica da viga ZR10-2 _... 51

Tabela 4.7 - Características e resultados da modelagem numérica da viga ZR12-2. .... 52

Tabela 4.8 - Características e resultados da modelagem numérica da viga TC-G. ....... 53

Tabela 4.9 - Características e resultados da modelagem numérica da viga TC-H. ....... 54

Tabela 4.10 - Características e resultados da modelagem numérica da viga TC-I........ 55

Tabela 4.11 - Características e resultados da modelagem numérica da viga BT-A. ..... 56

Tabela 4.12 - Características e resultados da modelagem numérica da viga BT-B...... 57

Tabela 4.13 - Características e resultados da modelagem numérica da viga BT-C....... 58

Tabela 4.14 - Características e resultados da modelagem numérica da viga BT-D. ..... 59

Tabela 4.15 - Características e resultados da modelagem numérica da viga BT-E....... 60

Tabela 5.1 - Propriedades geométricas dos perfis originais das vigas modeladas......... 66

Tabela 5.2 - Características das vigas analisadas do subgrupo 1.1............................. 67

Tabela 5.3 - Características das vigas modeladas do subgrupo 1.2 ............................. 67

Tabela 5.4 - Resultados das vigas modeladas do Grupo 1............................................. 68

Tabela 5.5 - Características das vigas modeladas do subgrupo 2.1 .............................. 70

Tabela 5.6 - Características das vigas modeladas do subgrupo 2.2 ............................. 71

Tabela 5.7 - Resultados das vigas analisadas do Grupo 2 . ..................................... 72 
Tabela 5.8 - Características das vigas modeladas do Grupo 3 .................................. 73

Tabela 5.9 - Resultados das vigas analisadas do Grupo 3. ......................................... 74

Tabela 5.10 - Características das vigas modeladas do Grupo 4.................................... 76

Tabela 5.11 - Resultados das vigas analisadas do Grupo 4. ........................................ 77

Tabela 5.12 - Características das vigas modeladas do Grupo 5................................... 78

Tabela 5.13 - Resultados das vigas modeladas do Grupo 5....................................... 78

Tabela 5.14 - Características das vigas analisadas do Grupo 6.................................. 79

Tabela 5.15 - Resultados das vigas modeladas do Grupo 6........................................ 79

Tabela 5.16 - Resultados das vigas modeladas do Grupo 7 ....................................... 81 


\section{LISTA DE FIGURAS}

Figura 1.1 - Esquema do procedimento utilizado na fabricação de vigas casteladas (a) sem chapa intermediária e (b) com chapa intermediária (GRÜNBAUER, 2011).

Figura 1.2 - Fabricação de viga castelada: corte com máquinas $\mathrm{CNC}$ e soldagem (GEMPERLE, 2007).

Figura 1.3 - Diversas tipologias de vigas alveolares.

Figura 1.4 - Fabricação de vigas alveolares com aberturas circulares (FELDMANN et al., 2006).

Figura 1.5 - Fabricação de viga celular (FELDMANN et al., 2006).............................. 5

Figura 1.6 - Integração das vigas alveolares com instalações e sistemas de forro

(WESTOK, 2010).

Figura 1.7 - Aspecto estético das vigas alveolares (Centro financeiro da Voest Alpine, em Linz - Áustria; Foto: Dietmar Feichting Architectes).

Figura 1.8 - As vigas alveolares são particularmente apropriadas para grandes vãos (GRÜMBAUER, 2011).

Figura 1.9 - Faixas de variação da esbeltez da alma para perfis europeus, Bantam e laminados brasileiros.

Figura 2.1 - Viga celular.

Figura 2.2 - Viga castelada.

Figura 2.3 - Viga castelada com chapa expansora.

Figura 2.4 - Simbologia relacionada à seção transversal de vigas de alma cheia e alveolares.

Figura 2.5 - Simbologia relacionada às dimensões e espaçamento das aberturas nas vigas alveolares.

Figura 2.6 - Geometria do padrão LITZKA.............................................................. 13

Figura 2.7 - Geometria do padrão PEINER. .................................................................. 13

Figura 2.8 - Geometria do padrão ANGLO-SAXÃO................................................. 14

Figura 3.1 - Viga castelada com colapso por flambagem lateral com torção (TKALČEVIĆ et al., 2007)... 21

Figura 3.2 - Formação do mecanismo Vierendel (DEMIRDJIAN, 1999). 22

Figura 3.3 - Ruptura do montante de alma entre duas aberturas (DEMIRDJIAN, 1999). 
Figura 3.4 - Flambagem do montante de alma de uma viga mista celular (NADJAI et al., 2008).

Figura 3.5 - Flambagem do montante de alma por cisalhamento (adaptado de KERDAL e NETHERCOT, 1984).

Figura 3.6 - Flambagem dos montantes de alma simulada com modelo numérico (adaptado de REDWOOD e DEMIRDJIAN, 1998)... 25

Figura 3.7 - Padrão Anglo-Saxão de vigas casteladas (GIBSON e JENKINS, 1957)... 28

Figura 4.1 - Modelagem de uma viga castelada ensaiada por Redwood e Demirdjian (1998), apresentando a divisão em regiões.

Figura 4.2 - Representação dos elementos (a) S3 e (b) S4R do ABAQUS e (c) dos pontos de integração ao longo da espessura dos elementos pela regra de Simpson.

Figura 4.3 - Representação da malha de elementos finitos em viga ensaiada por Redwood e Demirdjian (1998), com detalhe da região com malha triangular.

Figura 4.4 - Curva adotada para os materiais na modelagem do ABAQUS 40

Figura 4.5 - Modo de flambagem representado no ABAQUS para a viga 10-6 ensaiada por Redwood e Demirdjian (1998)......

Figura 4.6 - Curva carga-deslocamento em problemas de instabilidade (adaptado de Hibbitt et al, 2009).

Figura 4.7 - Algoritmo de Riks modificado (adaptado de Hibbitt et al, 2009). 43

Figura 4.8 - Distribuição de tensões residuais em perfis laminados (GOMES, 2006). . 44

Figura 4.9 - Modelo de distribuição de tensões residuais de Young (GOMES, 2006).. 44

Figura 4.10 - Modelo simplificado de distribuição de tensões residuais adotado: (a) alma e (b) mesas. .... 46

Figura 4.11 - Geometria da Viga RD10-5 (dimensões em mm). 48

Figura 4.12 - Viga RD10-5 modelada no ABAQUS, com indicação do carregamento e das condições de contorno. 48

Figura 4.13 - Geometria da Viga RD10-6 (dimensões em mm). 49

Figura 4.14 - Geometria da Viga RD10-7 (dimensões em mm). 50

Figura 4.15 - Viga ZR10-2, apresentando os travamentos laterais (pontos em vermelho).

Figura 4.16 - Geometria da viga ZR10-2 (dimensões em mm). 51

Figura 4.17 - Geometria da viga ZR12-2 (dimensões em mm). 52

Figura 4.18 - Geometria da viga TC-G (metade esquerda da viga; dimensões em mm), com detalhe dos travamentos laterais (pontos em vermelho). 
Figura 4.19 - Geometria da viga TC-H (metade esquerda da viga; dimensões em mm), com detalhe dos travamentos laterais (pontos em vermelho)......

Figura 4.20 - Geometria da viga TC-I (metade esquerda da viga; dimensões em mm), com detalhe dos travamentos laterais (pontos em vermelho).

Figura 4.21 - Geometria da viga BT-A (metade esquerda da viga; dimensões em mm).

Figura 4.22 - Geometria da viga BT-B (metade esquerda da viga; dimensões em mm).

Figura 4.23 - Geometria da viga BT-C (metade esquerda da viga; dimensões em mm).

Figura 4.24 - Geometria da viga BT-D (metade esquerda da viga; dimensões em mm).

Figura 4.25 - Geometria da viga BT-E (metade esquerda da viga; dimensões em mm).

Figura 4.26 - Comparação entre resultados da modelagem numérica e resultados experimentais correspondentes.

Figura 4.27 - Modos de colapso observados nas simulações numéricas: (a) FMA modelo 10-5 de Redwood e Demirdjian (1998); (b) Vierendeel - modelo G de Toprac e Cooke (1959).

Figura 5.1 - Condições de contorno e travamento lateral nas vigas modeladas. 64

Figura 5.2 - Carga de flambagem elástica dos montantes de alma e carga máxima das vigas casteladas padrão Anglo-Saxão, com (a) $\mathrm{L}=3,2 \mathrm{~d}_{\mathrm{g}}$; (b) $\mathrm{L}=10 \mathrm{~d}_{\mathrm{g}}$.... 68

Figura 5.3 - Correlação entre esbeltez $\left(h_{g} / t_{w}\right)$, relação $P_{\text {máx }} / P_{c r}$ e modos de colapso das vigas modeladas do subgrupo 1.1 .

Figura 5.4 - Geometria das aberturas com ângulo do lado inclinado de $30^{\circ}$, com relação $b_{w} / b$ igual a (a) $1 / 2$ (b) 1 e (c) 2 sem chapa expansora. 75

Figura 5.5 - Geometria das aberturas com ângulo do lado inclinado de $30^{\circ}$, com relação $b_{w} / b$ igual a (a) $1 / 2$ (b) 1 e (c) 2 com chapa expansora..

Figura 5.6 - Geometria das aberturas com ângulo do lado inclinado de $45^{\circ}$, com relação $b_{w} / b$ igual a (a) $1 / 2$ (b) 1 e (c) 2 sem chapa expansora. 75

Figura 5.7 - Geometria das aberturas com ângulo do lado inclinado de $45^{\circ}$, com relação $b_{w} / b$ igual a (a) $1 / 2$ (b) 1 e (c) 2 com chapa expansora.

Figura 5.8 - Geometria das aberturas com ângulo do lado inclinado de $60^{\circ}$, com relação $b_{w} / b$ igual a (a) $1 / 2$ (b) 1 e (c) 2 sem chapa expansora............................. 76

Figura 5.9 - Geometria das aberturas com ângulo do lado inclinado de $60^{\circ}$, com relação $b_{w} / b$ igual a (a) $1 / 2$ (b) 1 e (c) 2 com chapa expansora.............................. 76

Figura 5.10 - Deformada de viga após a FMA por compressão. .................................. 80 
Figura 5.11 - Deformada da viga da Figura 5.10 com enrijecedor adicional no centro do vão.

Figura 6.1 - Carga de FMA elástica das vigas casteladas, com vão de 3000 mm. 83

Figura 6.2 - Capacidade máxima das vigas casteladas, com vão de $3000 \mathrm{~mm}$. 83

Figura 6.3 - Capacidade máxima das vigas casteladas padrão Anglo-Saxão, da série W310, submetidas a carregamento concentrado no centro do vão. 84

Figura 6.4 - Capacidade máxima das vigas casteladas padrão Anglo-Saxão fabricadas a partir do perfil W360x32,9, submetidas a carregamento concentrado no centro do vão.

Figura 6.5 - Capacidade máxima das vigas casteladas padrão Anglo-Saxão fabricadas a partir do perfil W360x32,9, submetidas a duas cargas concentradas nos terços médios do vão. 85

Figura 6.6 - Capacidade máxima das vigas casteladas padrão Anglo-Saxão fabricadas a partir do perfil W360x32,9, submetidas a carregamento uniformemente distribuído.

Figura 6.7 - Correlação entre esbeltez da alma $\left(h_{g} / t_{w}\right)$, relação $P_{\text {máx }} / P_{c r}$ e modos de colapso das vigas de padrão Anglo-Saxão sem chapa expansora, modeladas do subgrupo 2.1 .

Figura 6.8 - Correlação entre esbeltez da alma $\left(h_{g} / t_{w}\right)$, relação $P_{\text {máx }} / P_{c r}$ e modos de colapso das vigas de padrão Anglo-Saxão com chapa expansora, modeladas do subgrupo 2.1 .

Figura 6.9 - Correlação entre esbeltez da alma $\left(h_{g} / t_{w}\right)$, relação $P_{\max x} / P_{c r}$ e modos de colapso das vigas de padrão Peiner sem chapa expansora, modeladas do subgrupo 2.1.

Figura 6.10 - Correlação entre esbeltez da alma $\left(h_{g} / t_{w}\right)$, relação $P_{m a ́ x} / P_{c r}$ e modos de colapso das vigas de padrão Peiner com chapa expansora, modeladas do subgrupo 2.1.

Figura 6.11 - Distribuição de tensões nas vigas: (a) W360x32,9_3000_CC2_AS (ver Tabela 5.8) e (b) W410x38,8_3000_CC1_AS (ver Tabela 5.5).....

Figura 6.12 - Relação entre carga crítica e razão $b_{w} / b$ das vigas casteladas submetidas a carga concentrada no centro do vão, perfil W360 x 32,9 (Grupo 4). . 88

Figura 6.13 - Carga última de vigas casteladas submetidas a carga concentrada no centro do vão em relação à razão $b_{w} / b$, perfil W360 x 32,9 (Grupo 4).

Figura 6.14 - Relação entre carga crítica e razão $b_{w} / b$ das vigas casteladas submetidas a carregamento uniformemente distribuído, perfil W360 x 32,9 (Grupo 4).... 90

Figura 6.15 - Carga última de vigas casteladas submetidas a carregamento uniformemente distribuído em relação à razão $b_{w} / b$, perfil W360 x 32,9 (Grupo 4). 
Figura 6.16 - Relação entre carga crítica e ângulo das aberturas nas vigas casteladas submetidas a carregamento concentrado no centro do vão, perfil W360 × 32,9 (Grupo 4).

Figura 6.17 - Carga última de vigas casteladas submetidas a carregamento concentrado no centro do vão em relação ao ângulo das abertura, perfil W360 x 32,9 (Grupo 4).

Figura 6.18 - Relação entre carga crítica e ângulo das aberturas nas vigas casteladas submetidas a carregamento uniformemente distribuído, perfil W360 x 32,9 (Grupo 4).

Figura 6.19 - Carga última de vigas casteladas submetidas a carregamento uniformemente distribuído em relação ao ângulo das aberturas, perfil W360 x 32,9 (Grupo 4).

Figura 6.20 - Curva carga-deslocamento das vigas com ângulo do lado inclinado do alvéolo igual a $30^{\circ}$ (ver Figura 5.4) e submetidas a uma carga concentrada no centro do vão, perfil W360 x 32,9.

Figura 6.21 - Curva carga-deslocamento das vigas com ângulo do lado inclinado do alvéolo igual a $45^{\circ}$ (ver Figura 5.6) e submetidas a uma carga concentrada no centro do vão, perfil W360 x 32,9.

Figura 6.22 - Curva carga-deslocamento das vigas com ângulo do lado inclinado do alvéolo igual a $60^{\circ}$ (ver Figura 5.8) e submetidas a uma carga concentrada no centro do vão, perfil W360 x 32,9.

Figura 6.23 - Curva carga-deslocamento das vigas relação $b_{w} / b=0,5$ (ver Figura 5.4a, Figura 5.6a, Figura 5.8a) e submetidas a um carregamento concentrado no centro do vão, perfil W360 x 32,9.

Figura 6.24 - Curva carga-deslocamento das vigas relação $b_{w} / b=1,0$ (ver Figura 5.4b, Figura 5.6b, Figura 5.8b) e submetidas a um carregamento concentrado no centro do vão, perfil W360 x 32,9.

Figura 6.25 - Curva carga-deslocamento das vigas relação $b_{w} / b=2,0$ (ver Figura 5.4c, Figura 5.6c, Figura 5.8c) e submetidas a um carregamento concentrado no centro do vão, perfil W360 x 32,9.

Figura 6.26 - Capacidade última das vigas submetidas a carregamento concentrado no centro do vão, perfil W360 x 32,9.

Figura 6.27 - Capacidade última das vigas submetidas a carregamento distribuído, perfil W360 × 32,9. 96

Figura 6.28 - Momento fletor máximo resistente das vigas com diferentes vãos e tipos de carregamento, perfil W360 x 32,9.

Figura 6.29 - Esforço cortante máximo das vigas com diferentes vãos e tipos de carregamento, perfil W360 x 32,9.

Figura 6.30 - Carga máxima nas vigas casteladas, em função da altura da chapa expansora, perfil W360 x 32,9. 
Figura 6.31 - Curva carga-deslocamento das vigas com vão de $3000 \mathrm{~mm}$ e submetidas a um carregamento concentrado no centro do vão, perfil W360 x 32,9.....

Figura 6.32 - Curva carga-deslocamento das vigas com vão de $3000 \mathrm{~mm}$ e submetidas a um carregamento distribuído ao longo do vão, perfil W360 x 32,9.

Figura 6.33 - Curva carga-deslocamento das vigas com vão de $4500 \mathrm{~mm}$ e submetidas a um carregamento concentrado no centro do vão, perfil W360 x 32,9..... 100

Figura 6.34 - Curva carga-deslocamento das vigas com vão de $4500 \mathrm{~mm}$ e submetidas a um carregamento distribuído ao longo do vão, perfil W360 x 32,9. 101

Figura 6.35 - Curva carga-deslocamento para vigas com vão de $6000 \mathrm{~mm}$ submetidas a uma carga concentrada no centro do vão, perfil W360 x 32,9. 101

Figura 6.36 - Curva carga-deslocamento para vigas com vão de $6000 \mathrm{~mm}$ submetidas a carga distribuída ao longo do vão, perfil W360 x 32,9. 102

Figura 6.37 - Razão entre a carga última das vigas com enrijecedor e a carga última das vigas sem enrijecedor adicional (perfil W360 x 32,9)...

Figura 6.38 - Curva carga-deslocamento das vigas W360x32,9_3000_CD_AS (ver Tabela 5.8).

Figura 6.39 - Curva carga-deslocamento das vigas W360x32,9_3000_CD_AS-CH (ver Tabela 5.8). 104

Figura 6.40 - Curva carga-deslocamento das vigas W360x32,9_4500_CD_45;2-CH

(ver Tabela 5.10). 104 


\section{LISTA DE SÍMBOLOS E ABREVIATURAS}

$b \quad$ projeção horizontal do lado inclinado da abertura

$b_{f} \quad$ largura da mesa do perfil original

$b_{w} \quad$ menor largura do montante de alma

d altura total do perfil original

$d_{g} \quad$ altura total da seção da viga alveolar

$f \quad$ deslocamento vertical máximo, flecha

$f_{y} \quad$ tensão de escoamento do aço

$h_{g} \quad$ distância entre os eixos das mesas de viga alveolar

$h_{o} \quad$ altura do alvéolo

$h_{p} \quad$ altura da chapa expansora

$p \quad$ passo $=$ distância entre centros de alvéolos adjacentes

$q \quad$ carregamento distribuído

$t_{f} \quad$ espessura da mesa do perfil original

$t_{w} \quad$ espessura da alma do perfil original

$D_{o} \quad$ diâmetro do alvéolo (no caso de alvéolo circular)

E módulo de elasticidade

$I_{m} \quad$ momento de inércia equivalente de viga castelada

$K_{f} \quad$ coeficiente de majoração da flecha para consideração dos efeitos dos esforços cisalhantes

$L \quad$ vão livre entre apoios

M momento fletor

$N \quad$ quantidade de alvéolos

$V \quad$ força cortante 
$\alpha$ ângulo de inclinação das aberturas, em relação à horizontal

$\lambda \quad$ fator de carga

$\lambda_{w} \quad$ esbeltez da alma

FMA Flambagem dos Montantes de Alma

FLT Flambagem Lateral com Torção

MEF Método dos Elementos Finitos 


\section{RESUMO}

VIEIRA, Washington Batista. M.Sc., Universidade Federal de Viçosa, fevereiro de 2011. Simulação numérica do comportamento estrutural de vigas casteladas de aço com ênfase na flambagem do montante de alma. Orientador: José Luiz Rangel Paes. Coorientadores: Gustavo de Souza Veríssimo e Rita de Cássia Silva Sant'Anna Alvarenga.

Com o início da produção de perfis I de aço laminados no Brasil, a partir de 2002, tem havido um interesse crescente da indústria brasileira pelas vigas casteladas, no segmento das estruturas de aço. As vigas casteladas são fabricadas expandindo-se a alma de perfis de aço I ou $\mathrm{H}$ laminados, de modo que a viga tenha maior rigidez na direção da maior inércia mantendo a mesma massa do perfil original. Neste trabalho, apresenta-se um estudo do comportamento de vigas casteladas de aço, com ênfase na instabilidade do montante de alma, realizado por meio de modelos numéricos utilizando o Método dos Elementos Finitos. Para a análise numérica, as vigas foram analisadas por meio do software ABAQUS, considerando-se o comportamento elastoplástico do material e a não-linearidade geométrica da estrutura. Os resultados numéricos obtidos apresentam excelente concordância com resultados experimentais disponíveis na literatura. Utilizando-se os modelos numéricos desenvolvidos, foi realizado um estudo paramétrico que permitiu avaliar a influência de diversas variáveis sobre a instabilidade do montante de alma em vigas casteladas. Foram modeladas, principalmente, vigas com alma esbelta e pôde-se constatar que, para vãos longos - o que é usual em vigas metálicas - existe pouca possibilidade de ocorrência de flambagem dos montantes de alma e, quando ocorre, na maior parte dos casos esta se dá em regime inelástico. 


\begin{abstract}
VIEIRA, Washington Batista. M.Sc., Universidade Federal de Viçosa, February, 2011. Numerical simulation of structural behavior of castellated beams with emphasis on web-post buckling. Adviser: José Luiz Rangel Paes. Co-advisers: Gustavo de Souza Veríssimo and Rita de Cássia Silva Sant'Anna Alvarenga.
\end{abstract}

With the start of production of hot-rolled structural I shapes in Brazil, since 2002 there has been a growing interest in Brazilian industry by castellated beams in the segment of steel structures. The castellated beams are made expanding the web of rolled I or $\mathrm{H}$ steel sections, so that the beam has greater stifiness keeping the same mass as the original profile. This work presents a study of the behavior of castellated steel beams, with emphasis on the web post instability, performed by means of numerical models using the Finite Element Method. For the numerical analysis, the beams were analyzed using the ABAQUS software, considering the elastoplastic behavior of the material and geometric nonlinearity of the structure. The numerical results show excellent agreement with experimental results available in literature. Using the numerical models developed, a parametric study was performed that allowed to evaluate the influence of several variables on the web post instability for castellated beams. Were modeled mainly beams with slender web and could be seen that for long spans - which is usual for steel beams there is low probability of buckling of the web posts, and when it occurs, inelastic buckling occurs in most cases. 


\section{INTRODUÇÃO E OBJETIVOS}

\subsection{Introdução}

A construção metálica ganhou um grande impulso na primeira metade do século $\mathrm{XX}$, com a invenção da solda elétrica no final dos anos 20 . O advento da solda possibilitou uma série de novas alternativas para elementos estruturais e para ligações entre os elementos. Dentre elas, soluções que viabilizam estruturas leves, capazes de vencer grandes vãos, e com rigidez suficiente para manter os deslocamentos dentro dos limites preconizados pelas normas técnicas vigentes.

Os elementos horizontais das estruturas, notadamente as vigas, têm seu desempenho associado, fundamentalmente à resistência à flexão e à rigidez. Estes dois requisitos estão intimamente relacionados à inércia da seção transversal. Dessa forma, quando se trata de 
desenvolver soluções para vigas, busca-se fazer ajustes na geometria das seções transversais tendo como alvo a maximização da inércia. Adicionalmente existe a preocupação com a economia, já que o aço é um material com alto valor agregado relacionado com seu peso. Assim, procura-se ajustar a geometria da seção transversal de modo a maximizar a relação inércia/peso, ganhando rigidez e capacidade resistente à flexão com o menor consumo de aço possível. Por este motivo, os perfis metálicos para vigas usualmente possuem seção I, onde a maior parte da área da seção transversal se concentra nas mesas; e as treliças de aço, com a área da seção concentrada nos banzos, ambos distantes o máximo possível do baricentro da seção.

Frequentemente na construção metálica, o dimensionamento das peças fletidas é condicionado por limitações de flecha. Neste caso, os perfis trabalham sob tensões relativamente baixas, o que, evidentemente, pressupõe a necessidade maior de rigidez do que de resistência. Considerando-se que as flechas são inversamente proporcionais à inércia da seção, e esta, por sua vez, depende fundamentalmente da área de seus banzos e do quadrado de sua altura, a forma mais econômica de aumentar a inércia e, em consequência, reduzir as deformações é aumentar a altura mantendo a área dos banzos.

Com base nessa premissa surgem soluções como as vigas treliçadas e as vigas alveolares, que são obtidas a partir de perfis I laminados normalmente produzidos pela indústria. Esses perfis são cortados ao meio, longitudinalmente, de modo que as duas metades possam ser reposicionadas mais afastadas uma da outra. Com isso a altura da seção aumenta e conseguem-se peças com uma inércia superior, mantendo-se o mesmo valor da área da seção e, portanto, o mesmo peso da estrutura.

De modo convencional, as vigas alveolares são produzidas por recorte do perfil I em ziguezague, ressoldando-o de forma defasada, formando os alvéolos (AMAYREH e SAKA, 2005; RODRIGUES, 2007). O tipo mais comum dessas vigas fabricadas a partir de recorte e soldagem são aquelas com aberturas hexagonais ou octogonais, denominadas vigas casteladas, devido ao corte lembrar o formato das muralhas dos castelos, conforme mencionado em Boyer (1964). O esquema de fabricação das vigas casteladas é mostrado na Figura 1.1a. Como pode-se notar na figura, as aberturas octogonais são obtidas pela inserção de chapas intermediárias, aumentando a altura total da viga (Figura 1.1b). Na Figura 1.2 mostra-se o processo de corte e soldagem da viga castelada. 

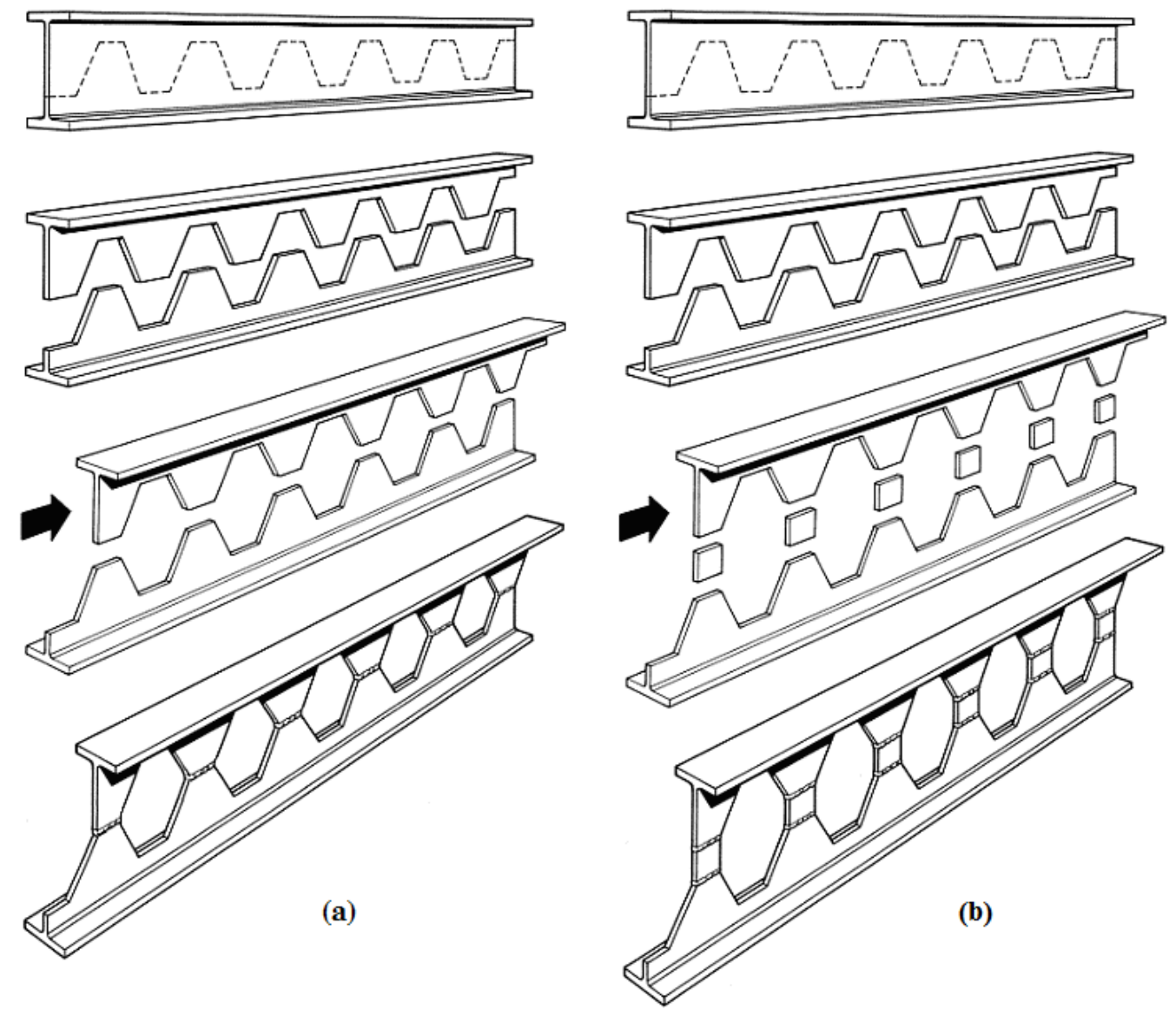

Figura 1.1 - Esquema do procedimento utilizado na fabricação de vigas casteladas (a) sem chapa intermediária e (b) com chapa intermediária (GRÜNBAUER, 2011).

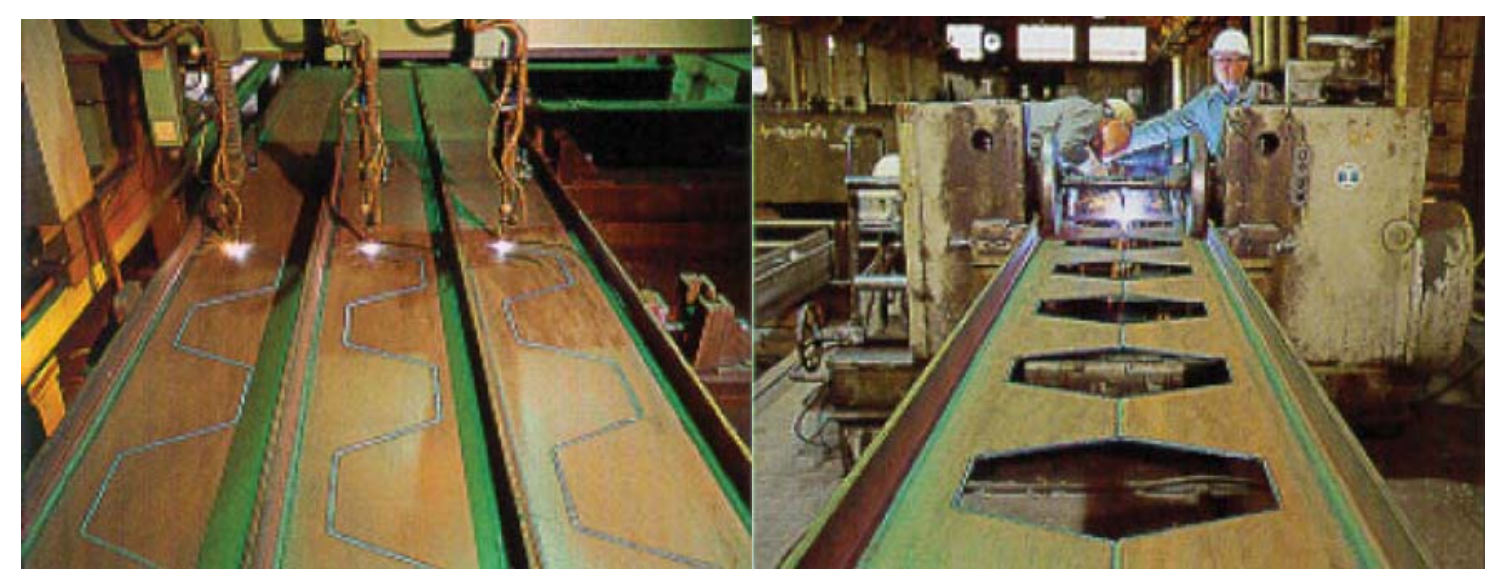

Figura 1.2 - Fabricação de viga castelada: corte com máquinas $\mathrm{CNC}^{1}$ e soldagem (GEMPERLE, 2007).

\footnotetext{
${ }^{1}$ Comando Numérico Computadorizado
} 
A forma dos alvéolos pode variar, dependendo do traçado idealizado para o corte simétrico. Nos anos recentes, o desenvolvimento de novas tecnologias de oxicorte integradas em máquinas $\mathrm{CNC}^{1}$ vem possibilitando diversos padrões de corte, como podem ser vistos na Figura 1.3.
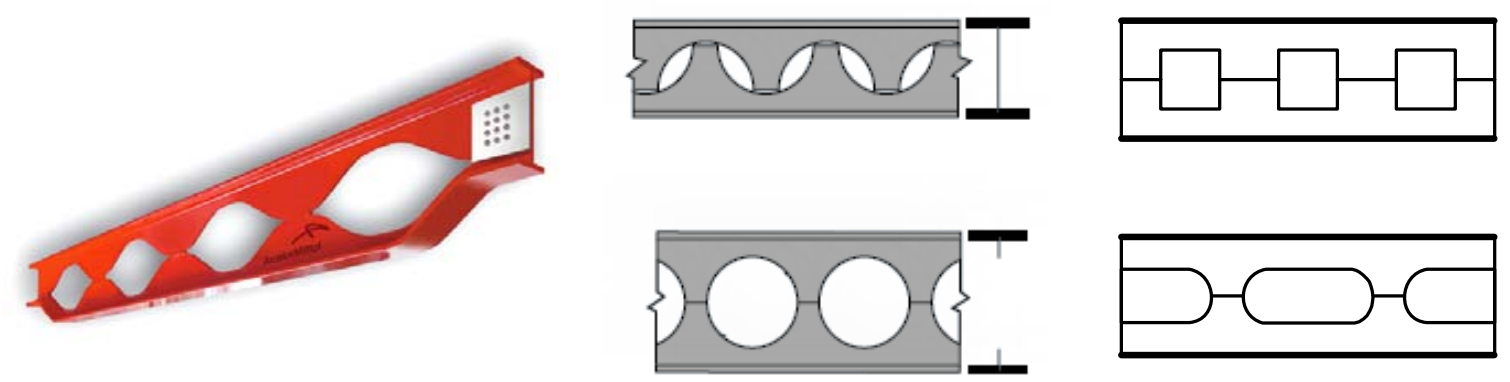

Figura 1.3 - Diversas tipologias de vigas alveolares.

A viga com alvéolos circulares, chamada de viga celular, é um dos tipos de vigas alveolares comumente utilizados nos países desenvolvidos atualmente (Figura 1.4 e Figura $1.5)$.

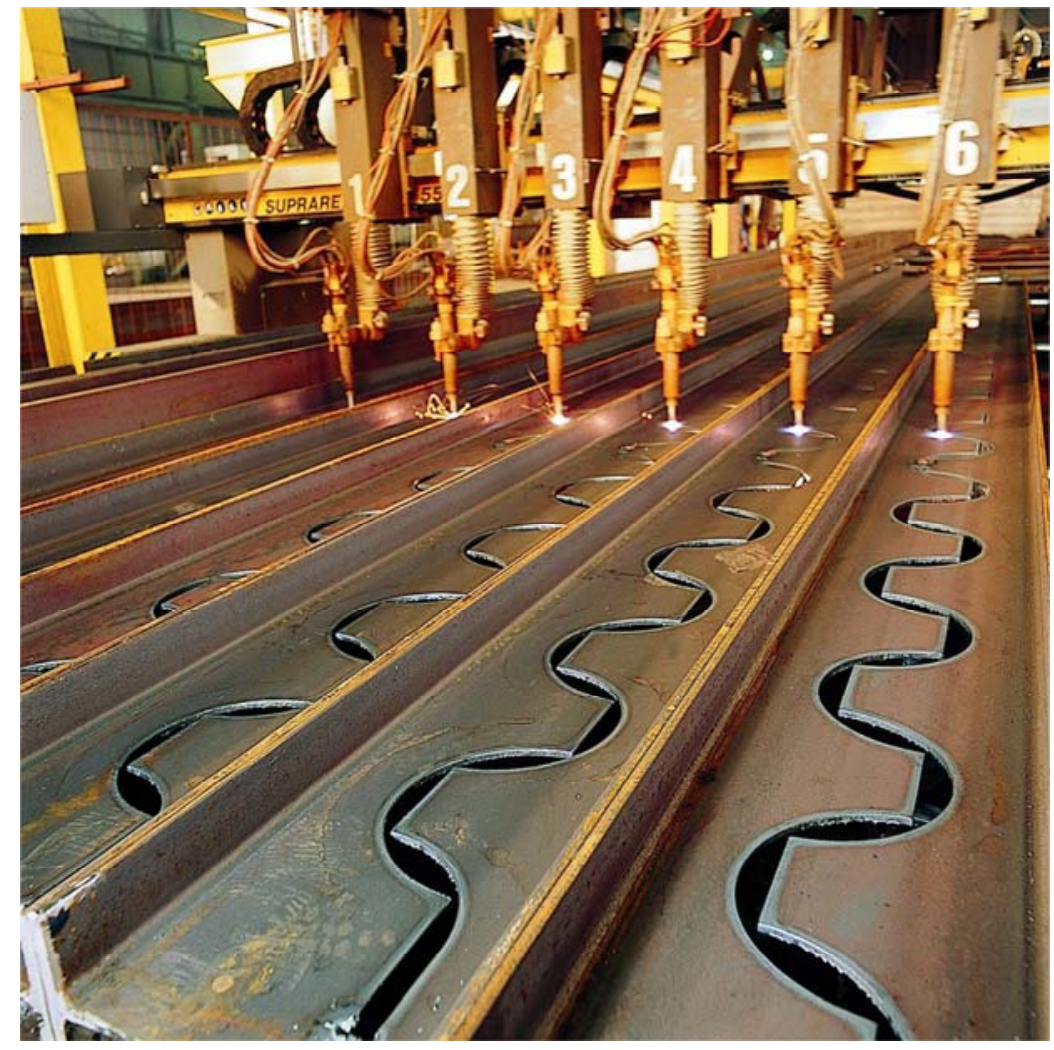

Figura 1.4 - Fabricação de vigas alveolares com aberturas circulares (FELDMANN et al., 2006). 


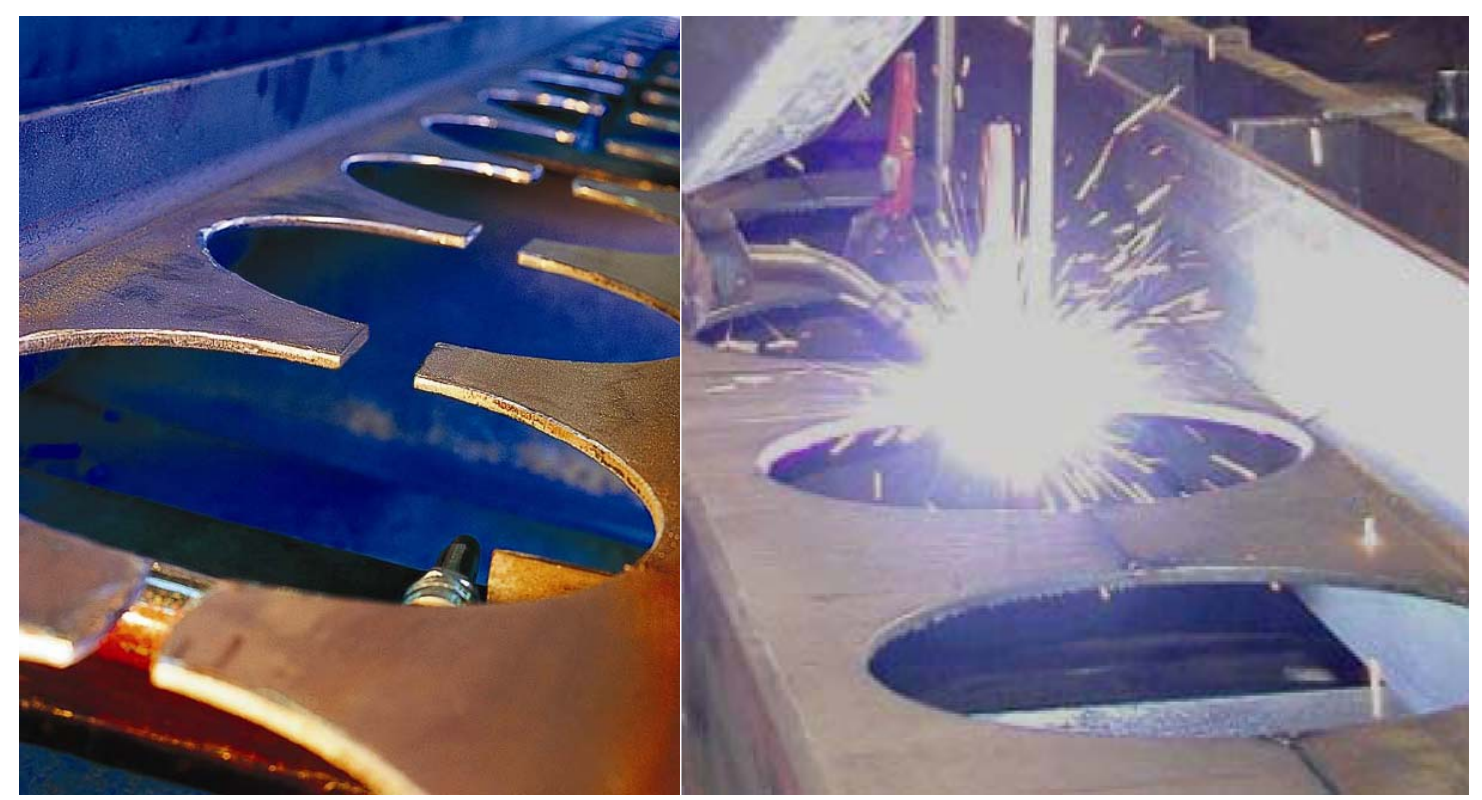

Figura 1.5 - Fabricação de viga celular (FELDMANN et al., 2006).

A presença dos furos na alma, entretanto, faz com que o comportamento estrutural dessas vigas se modifique em diversos aspectos se comparado ao de um perfil convencional de alma cheia. Os furos na alma não apenas modificam a importância relativa dos diferentes modos de colapso possíveis, como também criam a possibilidade de novos modos. Esse comportamento diferenciado deve ser apropriadamente considerado no cálculo estrutural para que se possa usufruir dos benefícios oferecidos pelas vigas alveolares, tais como facilidade de passar os dutos de serviço através da estrutura (Figura 1.6), estética atraente (Figura 1.7) e capacidade de vencer vãos maiores do que os perfís laminados convencionais (Figura 1.8).
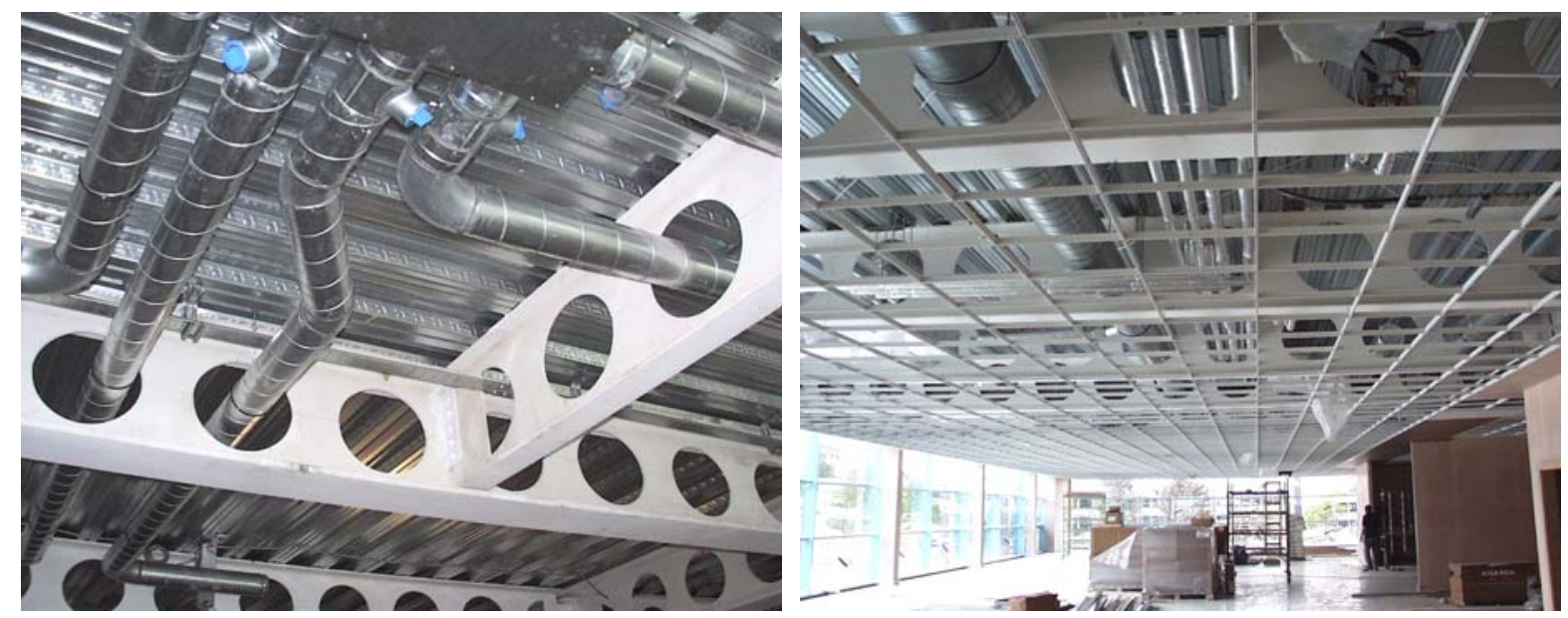

Figura 1.6 - Integração das vigas alveolares com instalações e sistemas de forro (WESTOK, 2010). 


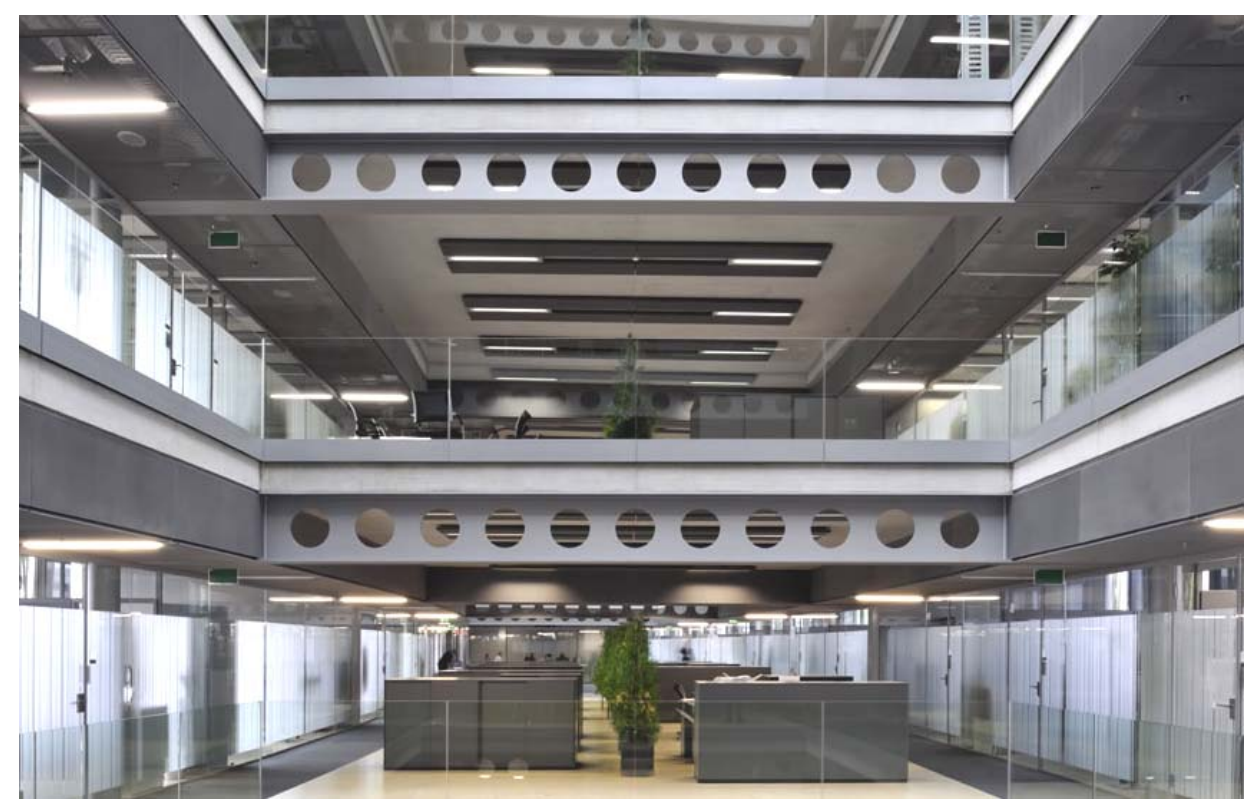

Figura 1.7 - Aspecto estético das vigas alveolares (Centro financeiro da Voest Alpine, em Linz Áustria; Foto: Dietmar Feichting Architectes).

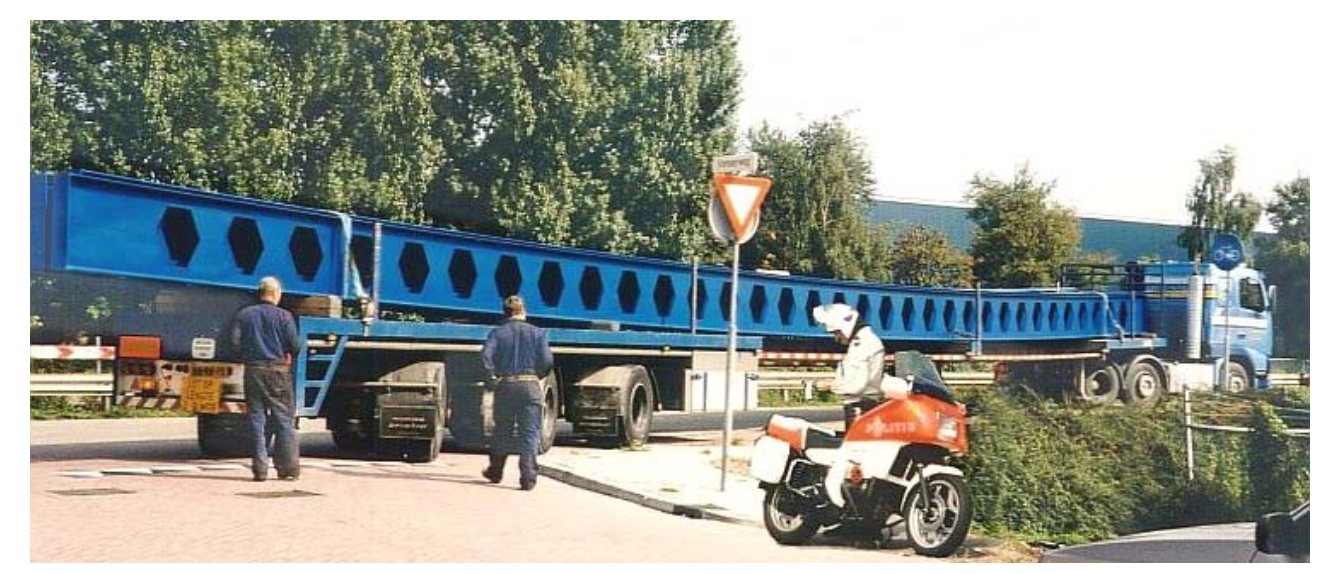

Figura 1.8 - As vigas alveolares são particularmente apropriadas para grandes vãos (GRÜMBAUER, 2011).

O crescimento do mercado da construção metálica no Brasil tem demandado novas soluções construtivas que possibilitem uma aplicação ampla e racional das estruturas de aço, dentre elas perfis de maior altura, capazes de vencer grandes vãos e/ou atender aos limites de deslocamento.

A produção de perfis laminados brasileiros teve início recentemente, a partir de 2002, quando a siderúrgica Gerdau-Açominas ativou sua linha de laminação e, agora, com perfis laminados nacionais disponíveis no mercado, é crescente o interesse por vigas alveolares. 
Embora haja alguns modelos de cálculo para vigas alveolares propostos na literatura americana e europeia, sua aplicação no Brasil era questionada porque esses modelos foram desenvolvidos há muitos anos, quando os aços tinham menor resistência mecânica, e para linhas de perfis com características diferentes dos perfis brasileiros.

Nos estudos experimentais realizados no passado, fora do Brasil, os modelos foram construídos a partir de perfis laminados com seção compacta (chapas com baixa esbeltez). Nesses perfis é comum prevalecer o colapso por plastificação da seção, já que a esbeltez não é suficiente para dar lugar aos fenômenos de instabilidade para tensões abaixo do limite de escoamento do aço (ALTFILLISCH et al., 1957 apud DEMIRDJIAN, 1999; GIBSON e JENKINS, 1957; TOPRAC e COOKE, 1959; KOLOSOWSKI, 1964; LARNACH e PARK, 1964 apud KERDAL e NETHERCOT, 1984; HALLEUX, 1966 apud DELESQUES, 1969; BAZILE e TEXIER, 1968 apud ZAAROUR, 1995; DELESQUES, 1968, 1969; HOSAIN e SPEIRS, 1970, 1973 apud DEMIRDJIAN, 1999; GALAMBOS et al., 1973; NETHERCOT e KERDAL, 1982; DEMIRDJIAN, 1999).

Num programa de ensaios realizado no Canadá com uma série de perfis laminados esbeltos, conhecidos como vigas Bantam, fabricados em determinada época nos Estados Unidos, observou-se que o colapso por instabilidade predominava, notadamente por flambagem do montante de alma (ZAAROUR e REDWOOD, 1996).

Fazendo-se uma análise da série dos perfis laminados produzidos no Brasil, observa-se que a faixa na qual a esbeltez da alma varia extrapola a faixa válida para os perfis europeus, estudados por outros autores, e, ao mesmo tempo, se sobrepõe à faixa de esbeltez das vigas Bantam (Figura 1.9).

Para os perfis laminados produzidos no Brasil, a esbeltez da alma varia numa faixa mais ampla do que aquela considerada quando os modelos mais antigos foram desenvolvidos, alcançando valores para os quais o comportamento das vigas alveolares ainda não é bem conhecido. Além disso, nas últimas décadas a resistência mecânica dos aços aumentou consideravelmente e esse fator também influencia na questão da instabilidade dos elementos estruturais comprimidos. Assim, um estudo dos modos de colapso por instabilidade torna-se oportuno e necessário no contexto atual. 


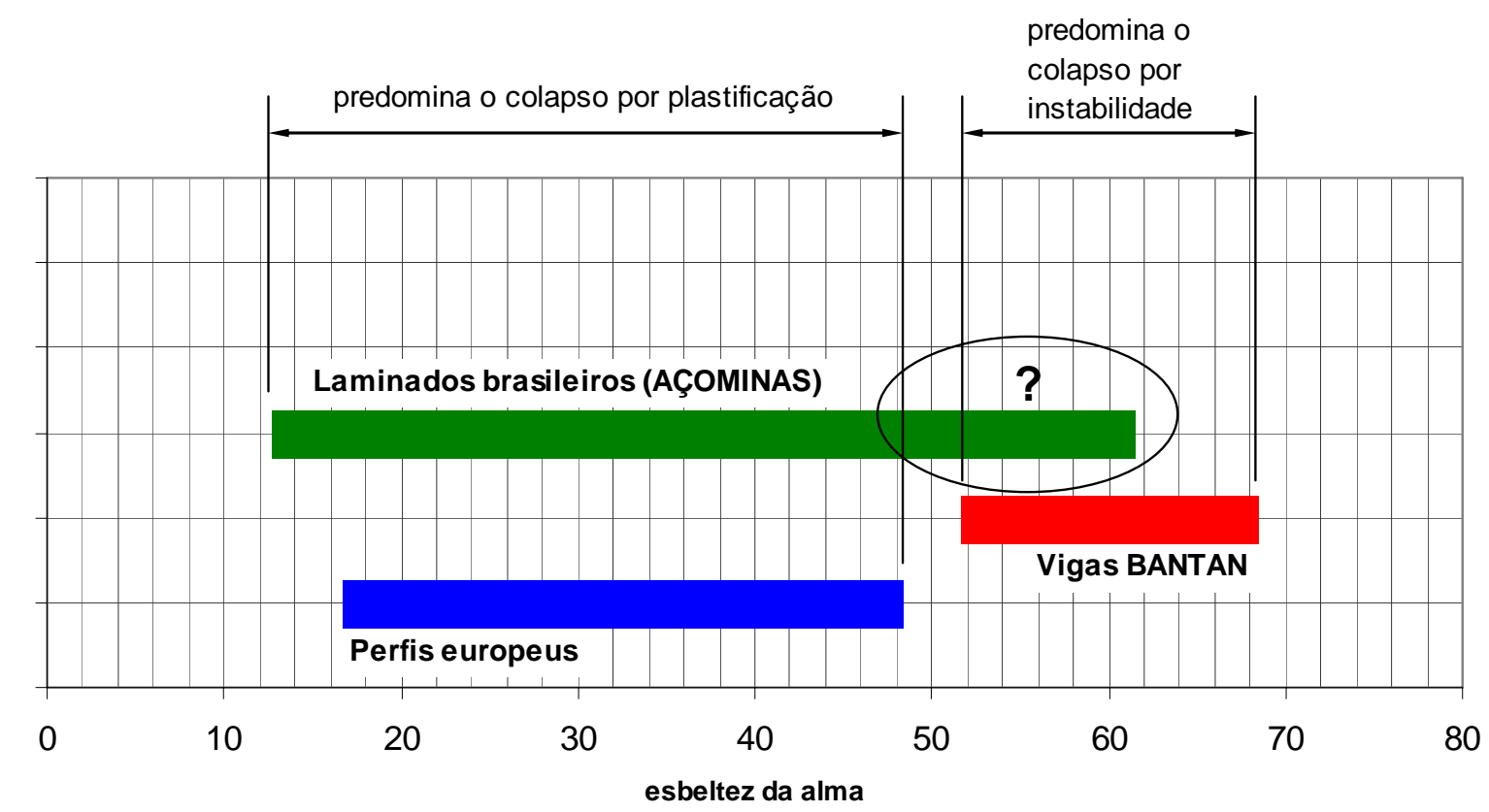

Figura 1.9 - Faixas de variação da esbeltez da alma para perfis europeus, Bantam e laminados brasileiros.

Conclui-se então que há uma necessidade de um estudo específico do comportamento de vigas alveolares constituídas por perfis brasileiros, bem como da adequação dos modelos de cálculo propostos por autores estrangeiros.

Neste trabalho apresenta-se um estudo sobre a instabilidade do montante de alma em vigas casteladas, realizado por meio de modelos numéricos utilizando o Método dos Elementos Finitos. Para a análise numérica foi utilizado o software ABAQUS. Os resultados numéricos obtidos apresentam excelente concordância com resultados experimentais disponíveis na literatura. Utilizando-se os modelos numéricos desenvolvidos, foi realizado um estudo paramétrico que permitiu avaliar a influência de diversas variáveis sobre a instabilidade do montante de alma em vigas casteladas.

\subsection{Objetivos}

O objetivo geral desse trabalho é avaliar o comportamento das vigas casteladas com ênfase no modo de colapso por flambagem dos montantes de alma (FMA), por meio de análise numérica, para perfis nacionais e estrangeiros. Para isso, os seguintes objetivos específicos devem ser atingidos: 
- validar um modelo numérico pelo Método dos Elementos Finitos, através do software ABAQUS, tendo como parâmetros os resultados experimentais encontrados na literatura;

- identificar modos de colapso na modelagem numérica, concordantes com os resultados experimentais;

- investigar as situações em que configurações de geometria e carregamento podem favorecer ou não o colapso de uma viga alveolar por FMA.

\subsection{Organização do documento}

O presente trabalho foi estruturado em sete capítulos, sendo que no Capítulo 2 são apresentadas as definições das tipologias de vigas alveolares e dos componentes constituintes desses elementos estruturais.

No Capítulo 3, apresenta-se uma extensa revisão bibliográfica, sendo que no subitem 3.1 é mostrado um histórico geral das publicações relacionadas às vigas alveolares em geral. No subitem 3.2 são apresentados os diversos modos de colapso possíveis em vigas alveolares, encontrados na literatura. O subitem 3.3 reúne as abordagens dos trabalhos relacionados à geometria das vigas alveolares e no subitem 3.4 são apresentados resultados de diversos trabalhos (experimentais, analíticos e numéricos) realizados com vigas alveolares.

No Capítulo 4 são apresentados a metodologia utilizada no desenvolvimento do trabalho e o modelo numérico utilizado, bem como sua validação, com base nos resultados encontrados na literatura.

Após a validação do modelo numérico, foram analisadas as vigas do estudo paramétrico. A abrangência deste estudo paramétrico e os resultados obtidos nas análises são apresentados no Capítulo 5.

No Capítulo 6 é apresentada uma discussão dos resultados das modelagens referentes ao estudo paramétrico. No Capítulo 7, apresentam-se as conclusões gerais deste trabalho, bem como sugestões para futuras investigações. 


\section{DEFINIÇÃO DAS TIPOLOGIAS E DOS ELEMENTOS}

\subsection{Generalidades}

As vigas alveolares podem ser fabricadas em diversas tipologias, como visto na Figura 1.1 e na Figura 1.3. As mais comuns são as vigas casteladas e as vigas celulares. As vigas celulares possuem aberturas circulares, como se pode ver na Figura 2.1, enquanto as vigas casteladas têm aberturas hexagonais, como mostrado na Figura 2.2; ou octogonais como mostrado na Figura 2.3. 


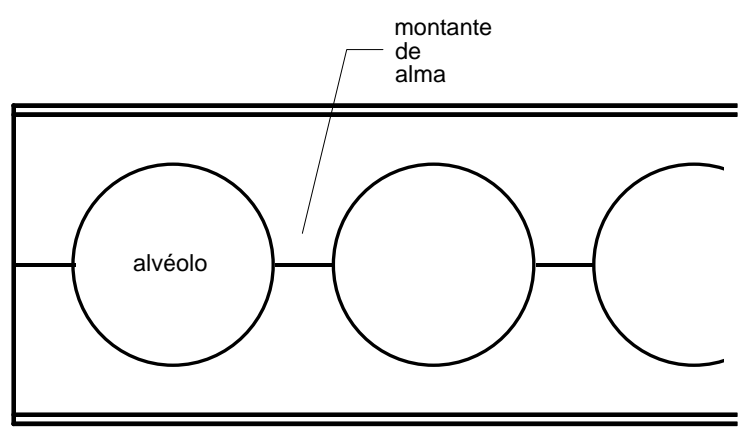

Figura 2.1 - Viga celular.

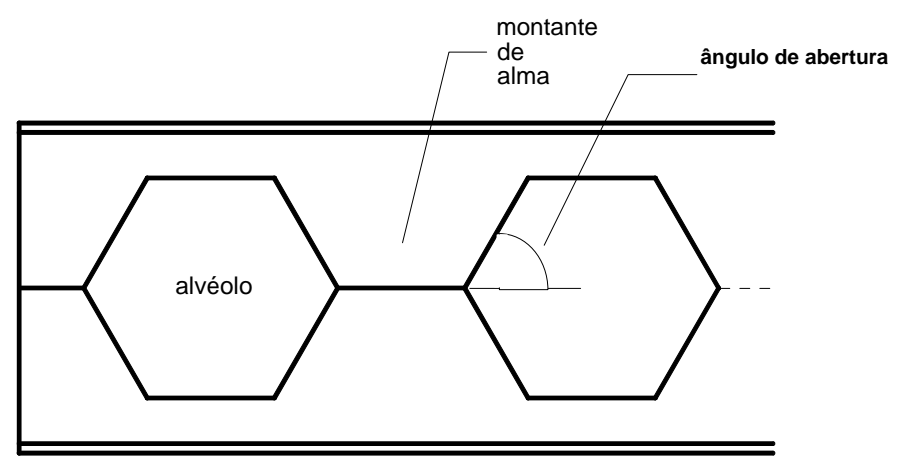

Figura 2.2 - Viga castelada.

Havendo a necessidade de aumentar ainda mais a inércia das vigas, podem-se utilizar vigas casteladas com chapas expansoras, como mostrado na Figura 2.3.

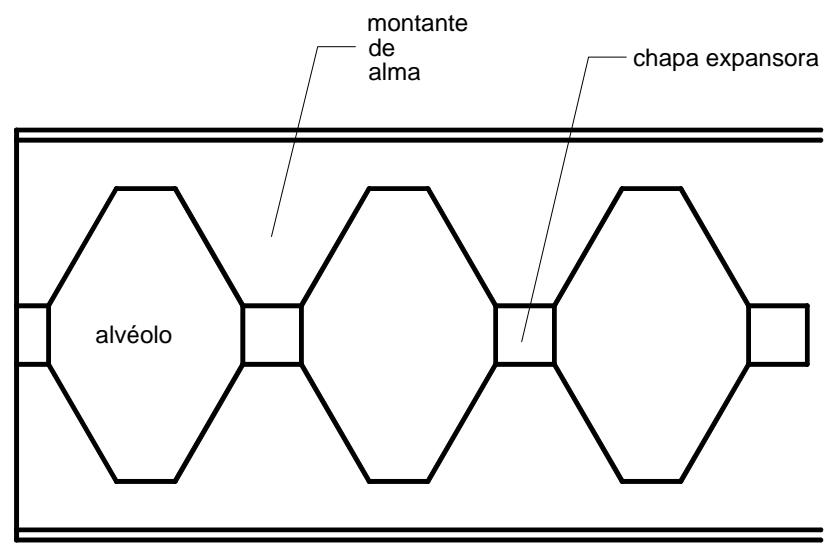

Figura 2.3 - Viga castelada com chapa expansora. 


\subsection{Simbologia}

Na Figura 2.4 é apresentada a simbologia relacionada às dimensões da seção transversal de vigas de alma cheia e de vigas alveolares. Na Figura 2.5 é mostrada a simbologia relacionada às dimensões das aberturas das vigas alveolares.

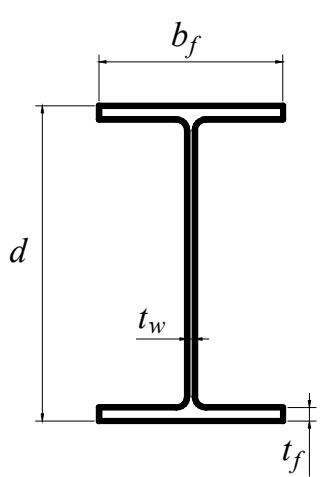

seção original

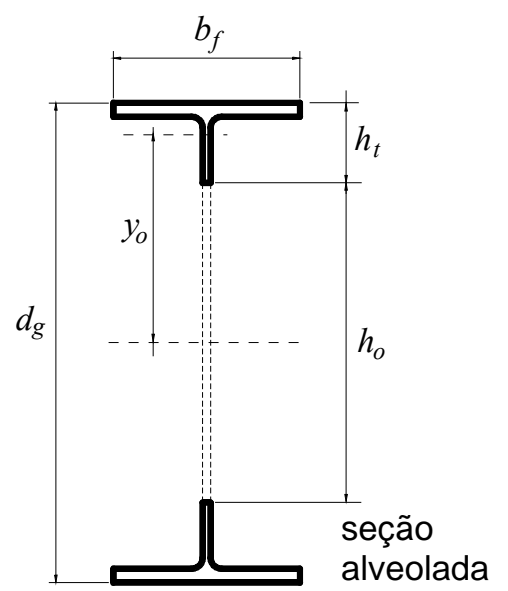

Figura 2.4 - Simbologia relacionada à seção transversal de vigas de alma cheia e alveolares.

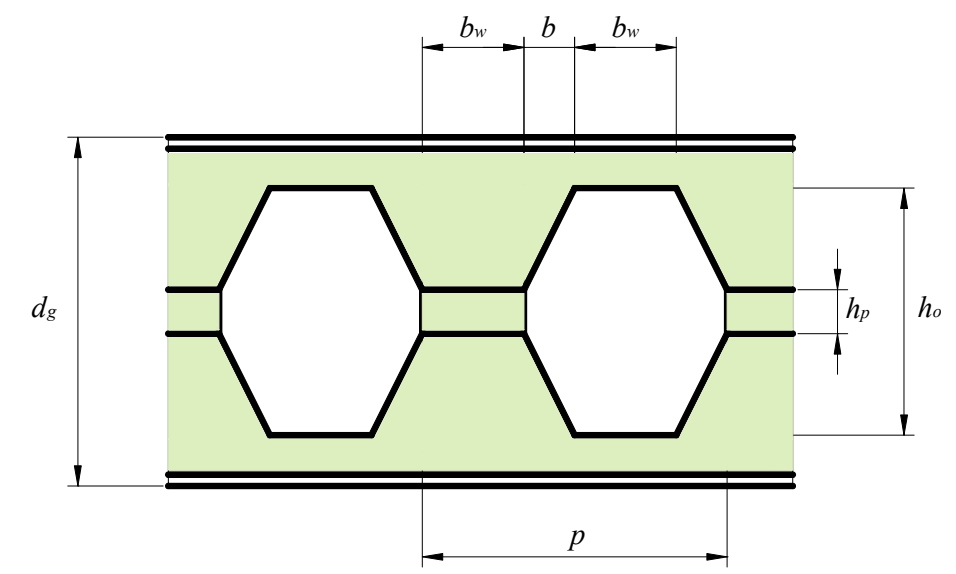

Figura 2.5 - Simbologia relacionada às dimensões e espaçamento das aberturas nas vigas alveolares. 


\subsection{Padrões geométricos}

Existem diversas possibilidades de geometria dos alvéolos nas vigas casteladas, sendo que os padrões de fabricação mais usuais são o Litzka (Figura 2.6), o Peiner (Figura 2.7) e o Anglo-Saxão (Figura 2.8).

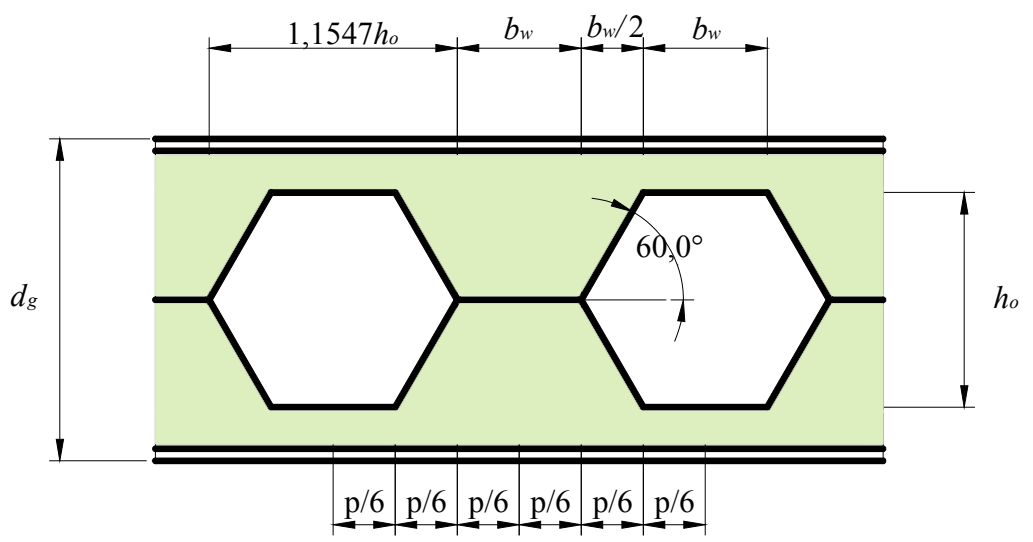

Figura 2.6 - Geometria do padrão LITZKA.

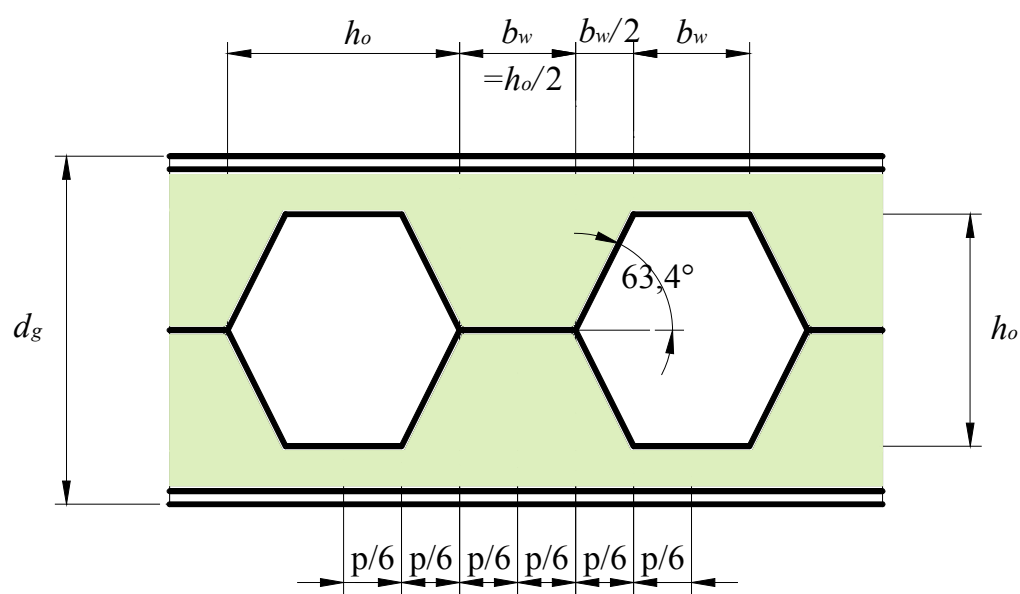

Figura 2.7 - Geometria do padrão PEINER. 


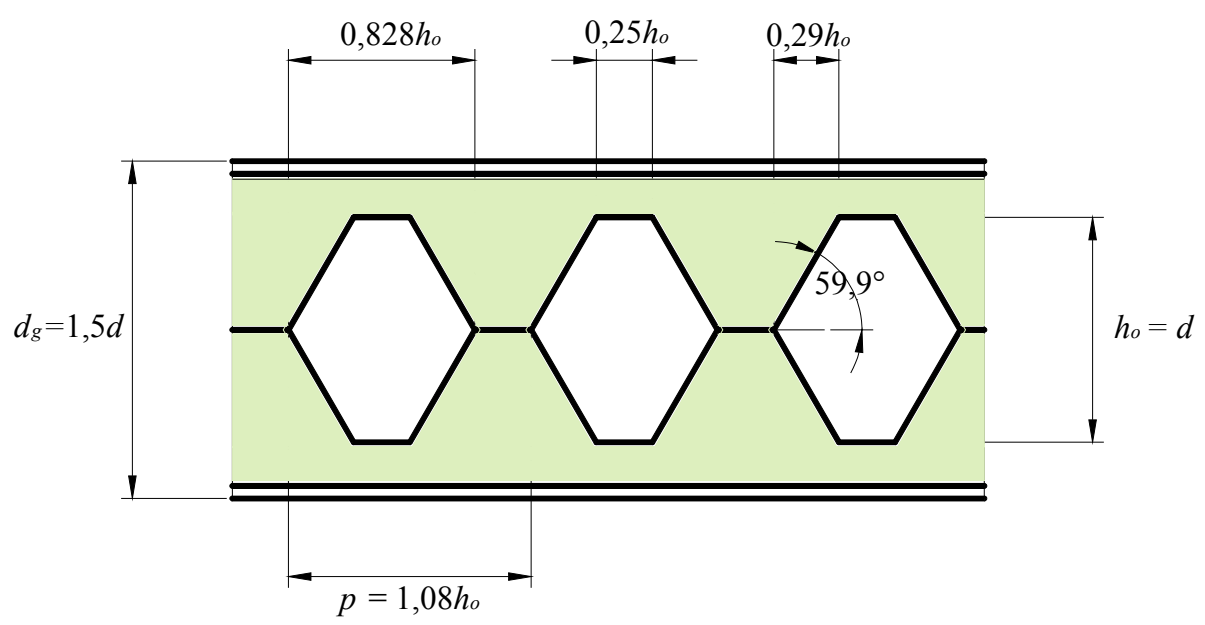

Figura 2.8 - Geometria do padrão ANGLO-SAXÃO.

No padrão Litzka, o alvéolo é um hexágono regular. O padrão Peiner é similar ao Litzka, porém com a diferença que o alvéolo possui a largura igual à altura e não é propriamente regular. No padrão Anglo-Saxão os alvéolos são mais estreitos, tendo largura igual a 0,828 vezes a altura do alvéolo. 


\section{REVISÃO DE LITERATURA}

\subsection{Histórico}

Uma ampla revisão bibliográfica foi realizada sobre as vigas alveolares e vigas com aberturas na alma durante este trabalho, reunindo documentos desde meados do século passado até os trabalhos mais recentes.

O primeiro estudo experimental encontrado na literatura foi realizado por Altfillisch et al. (1957 apud DEMIRDJIAN, 1999), que estudou o comportamento da solda nas vigas casteladas.

Gibson e Jenkins (1957) realizaram um estudo analítico em vigas casteladas, considerando vigas do padrão Anglo-Saxão, simplesmente apoiadas nas extremidades e submetidas a uma carga concentrada no centro do vão. Após o estudo analítico foi realizada uma 
investigação fotoelástica com modelos reduzidos a fim de estudar as regiões onde ocorrem as tensões críticas, para o planejamento de um futuro programa experimental. Os autores concluíram que as vigas casteladas, em domínio elástico, têm comportamento semelhante à teoria das vigas Vierendeel.

Toprac e Cooke (1959) realizaram um programa experimental com dez vigas, sendo nove delas casteladas, para estudar o comportamento dessas vigas e comparar com estudos analíticos anteriores.

Boyer (1964) apresenta a fabricação das vigas casteladas e faz um estudo de tensões. É apresentado também um estudo de custo dessas vigas.

Kolosowski (1964) apresenta uma análise dos métodos de dimensionamento de vigas casteladas. $\mathrm{O}$ autor também realizou um programa experimental.

Faltus (1966) também realizou um estudo analítico de vigas casteladas, apresentando uma série de expressões para a determinação das tensões máximas nas vigas em função do tipo de carregamento aplicado.

Halleux (1966 apud DELESQUES, 1969) realizou um programa experimental com onze vigas casteladas, variando a geometria dos alvéolos.

Bazile e Texier (1968 apud DELESQUES, 1969) realizaram um programa experimental com vigas de chapas compactas, mas com alta razão de expansão, levando-as à ocorrência da flambagem inelástica dos montantes.

Humphrey e Sunley (1968 apud NETHERCOT e KERDAL, 1982) foi o primeiro trabalho encontrado no qual se utilizou o Método dos Elementos Finitos (MEF) em vigas alveolares.

Um dos primeiros trabalhos sobre a instabilidade dos montantes de alma foi realizado por Delesques (1968), que apresenta uma formulação analítica para a determinação da carga crítica de flambagem dos montantes. Posteriormente, Delesques (1969) apresenta um trabalho analítico para o cálculo da capacidade resistente de vigas casteladas.

Hope e Sheikh (1969 apud GALAMBOS et al., 1973) também publicaram um trabalho sobre projeto de vigas casteladas. 
Hosain e Speirs (1971 apud GALAMBOS et al., 1973) estudaram o colapso de vigas casteladas por ruptura do montante de alma por cisalhamento. Hosain e Speirs (1973 apud GALAMBOS et al., 1973) realizaram também um programa experimental com dez vigas casteladas, variando o comprimento da solda, para estudar o problema da ruptura dos montantes por cisalhamento.

Galambos et al. (1973), publicaram um importante trabalho para obtenção da razão ótima de expansão das vigas casteladas. Os resultados mostraram que essa razão ótima é função da geometria das aberturas e da relação momento/cortante.

Aglan e Redwood (1974 apud REDWOOD e DEMIRDJIAN, 1998) também realizaram um estudo sobre a flambagem dos montantes de alma nas vigas casteladas.

Um dos primeiros estudos sobre a flambagem lateral de vigas casteladas encontrado foi presentado por Pattanayak e Chesson (1974 apud NETHERCOT e KERDAL, 1982).

Dougherty (1981) realizou um estudo da flambagem dos montantes de alma em vigas com aberturas na alma. Aglan e Qaqish (1982) estudaram a distribuição de tensões em vigas com abertura na alma. Ambos os trabalhos não abrangem as vigas alveolares.

Nethercot e Kerdal (1982) realizaram um programa experimental com vigas casteladas em tamanho reduzido e em tamanho real, para estudar a flambagem lateral com torção. Segundo os autores, o comportamento das vigas casteladas e não-casteladas é o mesmo, quando se refere à flambagem lateral com torção.

Com uma compilação de dezoito programas experimentais realizados anteriormente, Kerdal e Nethercot (1984) relataram os diversos modos de colapso observados nesses ensaios, apresentando relações entre os modos de colapso e a geometria da viga castelada.

Lam (1984) estudou o problema da flambagem lateral em vigas com aberturas na alma. $\mathrm{Na}$ mesma época, Redwood e Pombouras (1984) investigaram o comportamento de vigas mistas com aberturas na alma. Ambos os trabalhos não abrangeram as vigas alveolares.

Das e Srimani (1986) publicaram um trabalho voltado para o projeto de vigas casteladas a partir de vigas laminadas nos padrões indianos. 
Lleonart (1988) apresentou um trabalho propondo critérios de projeto de vigas casteladas em função da geometria.

No início da década de 1990 alguns poucos trabalhos foram publicados, sendo que a maior parte destes referia-se ao comportamento de vigas com aberturas retangulares na alma.

Na segunda metade da década, importantes trabalhos com vigas de chapas esbeltas foram publicados por Zaarour (1995) e Zaarour e Redwood (1996). O estudo consistiu de etapas experimental, analítica e numérica, tendo como foco o estudo da flambagem do montante de alma.

Megharief (1997) realizou, na Universidade McGill, no Canadá, um estudo experimental e numérico com vigas mistas casteladas.

Ainda no final da década de 1990, outro importante trabalho foi realizado, abordando a flambagem do montante de alma por cisalhamento. Nesse trabalho, realizado por Redwood e Demirdjian (1998), os autores realizaram experimentos com quatro vigas casteladas. Todas tiveram sua capacidade limitada pela flambagem do montante de alma.

Demirdjian (1999) realizou um estudo de vigas casteladas com base em resultados de ensaios. Para isso, o autor descreveu os experimentos conduzidos por Altfillisch et al. (1957), Toprac e Cooke (1959), Sherbourne (1966), Halleux (1967), Bazile e Texier (1968), Husein e Speirs (1971, 1973), Galambos et al. (1975), Zaarour e Redwood (1996) e Redwood e Demirdjian (1998).

$\mathrm{Na}$ última década, diversos trabalhos foram publicados no mundo, relacionados com o comportamento, análise e desenvolvimento de novas tipologias de vigas alveolares.

Cimadevilla (2000) realizou um estudo analítico, propondo equações de resistência para vigas casteladas.

Redwood (2000) investigou o comportamento estrutural de vigas mistas casteladas. Dabaon et al. (2003) estudou o comportamento de vigas casteladas mistas e de eixo curvo.

Bailey (2004) realizou um trabalho de investigação do comportamento de vigas celulares em condição de incêndio. 
Hennessey et al. (2004) estudaram a influência da geometria dos montantes de extremidade, no comportamento das vigas alveolares.

Em um estudo realizado por Mohebkhah (2004), questionou-se a conclusão antiga de que o comportamento das vigas casteladas quanto à FLT é semelhante ao comportamento das vigas de alma cheia. Mohebkhah (2005) apresenta critérios de projeto para o travamento das vigas, para se evitar o estado limite da flambagem lateral com torção.

Amayreh e Saka (2005) utilizaram redes neurais artificiais para predição da capacidade máxima de vigas casteladas.

Uma análise comparativa de custo foi realizada nos EUA, por Estrada et al.(2006). Os autores concluíram que, para vãos curtos, as vigas casteladas são menos econômicas, enquanto que, para vãos longos, elas têm um custo vantajoso em relação às vigas de alma cheia.

Um estudo numérico pelo MEF foi realizado por Hoffman et al. (2006), no qual foi estudado o comportamento e a distribuição de tensões em vigas celulares.

Raftoyiannis e Ioannidis (2006) realizaram um estudo numérico e analítico para avaliação dos deslocamentos verticais nas vigas casteladas submetidas a carregamento transversal.

Um dos primeiros estudos sobre a flambagem lateral com distorção em vigas casteladas foi realizado por Zirakian e Showkati (2006).

Em um trabalho realizado na Suíça, Gemperle (2007) apresentou um método de cálculo de vigas casteladas.

Nadjai et al. (2007) realizou um estudo do comportamento estrutural de pisos mistos com vigas celulares em situação de incêndio.

Radić e Markulak (2007) investigaram o comportamento à flambagem lateral com torção em vigas casteladas em relação à geometria e às condições de contorno das vigas.

Nadjai et al. (2008) propôs uma metodologia simplificada de cálculo de vigas celulares mistas em situação de incêndio. $\mathrm{O}$ mesmo grupo de pesquisa propôs também um modelo 
analítico para a flambagem dos montantes de alma de vigas celulares em situação de incêndio, apresentado em Vassart et al. (2008).

Outro trabalho relacionado ao comportamento estrutural das vigas celulares em situação de incêndio foi realizado por Wong et al. (2009).

Mais recentemente foram publicados dois trabalhos brasileiros, realizados na UFMG, referentes ao estudo da flambagem lateral com torção em vigas celulares e em vigas casteladas, desenvolvidos respectivamente por Abreu et al. (2010) e por Bezerra et al. (2010).

\subsection{Modos de colapso}

A presença das aberturas nas vigas alveolares faz com que seu comportamento estrutural seja diferente daquele observado nas vigas de aço de alma cheia. A viga alveolar obtida de um perfil laminado original fica com a alma mais alta, porém, com a mesma espessura, o que implica num aumento de esbeltez da alma, além dos furos cujas bordas não se apoiam em nenhum outro elemento, ficando, assim, muito mais susceptíveis a fenômenos de instabilidade localizada.

Estudos experimentais recentes identificaram diversos modos de colapso nas vigas alveolares (DOUGHERTY, 1981; KERDAL e NETHERCOT, 1984; REDWOOD e DEMIRDJIAN, 1998; DEMIRDJIAN, 1999; CHUNG et al., 2001; HOFFMAN, 2006). Os furos na alma não apenas alteram a importância relativa dos diferentes modos de colapso possíveis como também criam a possibilidade de novos modos. Os modos de colapso conhecidos até o momento para as vigas alveolares são os seguintes:

- formação de mecanismo por flexão;

- flambagem lateral com torção do vão;

- formação de um mecanismo Vierendeel;

- ruptura do montante de alma por cisalhamento;

- flambagem do montante de alma por cisalhamento;

- flambagem do montante de alma por compressão. 


\subsubsection{Mecanismo por flexão}

Segundo Demirdjian (1999), em seções de Classe 1 ou 2, as vigas alveolares atingem a carga máxima pela plastificação dos tês formados acima e abaixo das aberturas, submetidos a esforços de compressão e tração, respectivamente, para vigas biapoiadas. Toprac e Cook (1957) e Halleux (1967 apud DEMIRDJIAN, 1999) apresentaram casos de vigas casteladas que sofreram colapso por formação de mecanismo de flexão.

\subsubsection{Flambagem lateral com torção}

As vigas alveolares com comprimento destravado insuficiente para conter o tê comprimido podem sofrer a flambagem lateral com torção, de modo muito semelhante às vigas de alma cheia. Alguns autores asseguram que a influência das aberturas é insignificante no comportamento da viga à flambagem lateral com torção (DEMIRDJIAN, 1999; NETHERCOT e KERDAL, 1982). Entretanto, outros autores têm estudado esse modo de colapso, mais recentemente, em vigas alveolares, notando que existe influência das aberturas no comportamento das vigas à flambagem lateral com torção (MOHEBKHAH, 2004; TKALČEVIĆ et al., 2007; RADIĆ e MARKULAK, 2007; SHOWKATI, 2008; RADIĆ et al., 2009; BEZERRA et al., 2010; ABREU et al., 2010). Na Figura 3.1 mostrase o ensaio de uma viga castelada em que ocorre o colapso por flambagem lateral com torção.
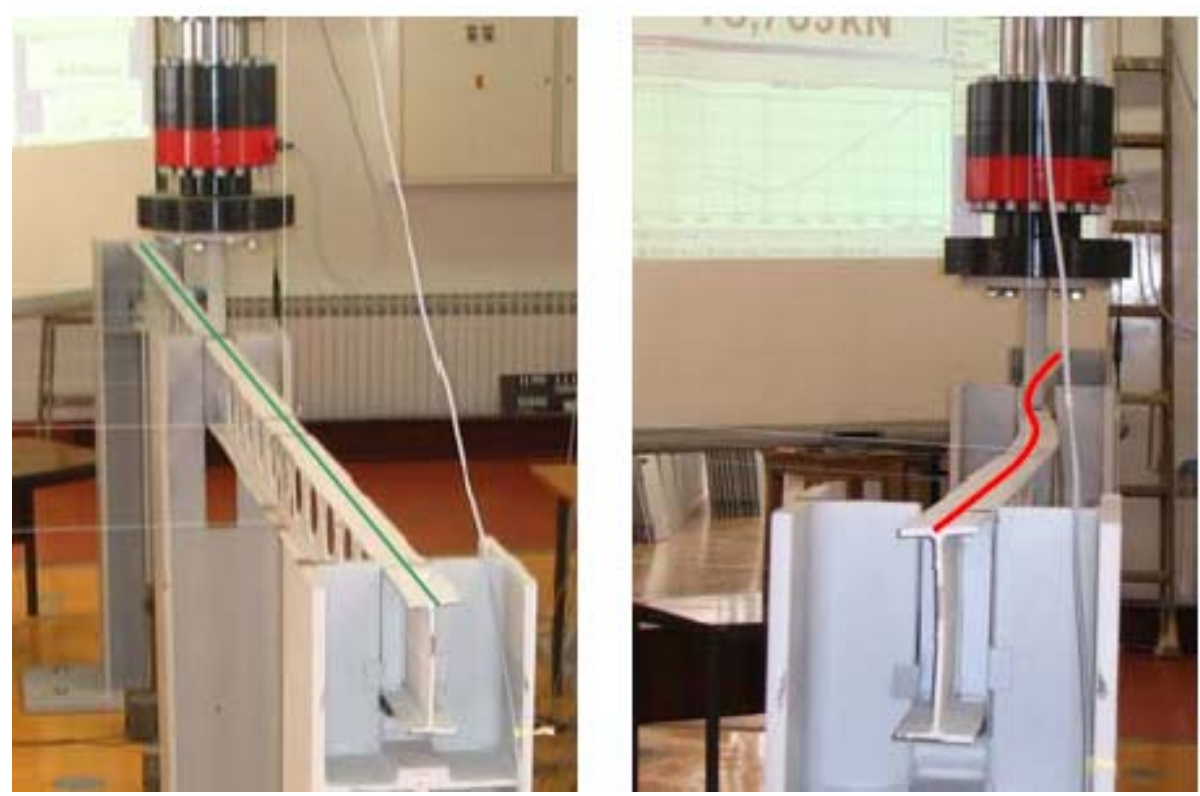

Figura 3.1 - Viga castelada com colapso por flambagem lateral com torção (TKALČEVIĆ et al., 2007). 


\subsubsection{Mecanismo Vierendeel}

No modo de colapso conhecido como mecanismo Vierendeel, ocorre a formação de quatro rótulas plásticas nos cantos das aberturas e os painéis se deformam formando um paralelogramo na região de variação do momento fletor. A partir do estudo do mecanismo Vierendeel, pode-se afirmar que este modo de colapso ocorre preferencialmente em vigas com vãos pequenos, comprimento de solda grande e baixa altura das seções $T$ formadas acima e abaixo das aberturas em relação à altura expandida do perfil (KERDAL e NETHERCOT, 1984). Na Figura 3.2 é apresentada a caracterização do mecanismo Vierendeel. Altifillisch et al. (1957 apud DEMIRDJIAN, 1999) e Toprac e Cooke (1959) foram os primeiros a observarem esse modo de falha nas vigas alveolares.

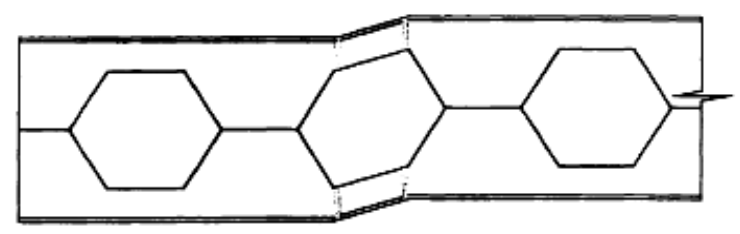

Figura 3.2 - Formação do mecanismo Vierendel (DEMIRDJIAN, 1999).

\subsubsection{Ruptura do montante de alma por cisalhamento}

Algumas vigas têm sua capacidade limitada pela ruptura do montante de alma por cisalhamento, na região da solda. Esse modo de ruptura ocorre normalmente quando as tensões cisalhantes no metal base, na região da solda, atingem o valor da tensão de escoamento do material, o que acontece mais frequentemente em vigas onde a relação entre o comprimento da solda e a distância entre as aberturas é pequena (KERDAL e NETHERCOT, 1984). Na Figura 3.3, apresenta-se um esquema da ruptura do montante por cisalhamento. Em ensaios realizados por Husain e Speirs (1971 apud DEMIRDJIAN, 1999), observou-se este modo de colapso.

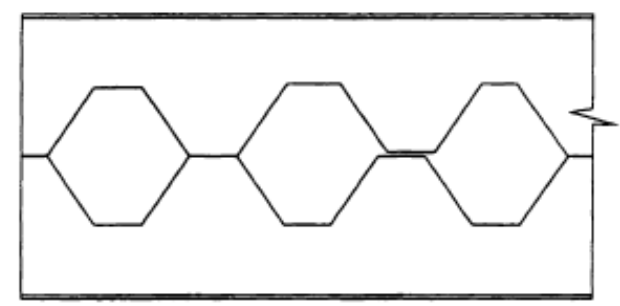

Figura 3.3 - Ruptura do montante de alma entre duas aberturas (DEMIRDJIAN, 1999). 


\subsubsection{Flambagem do montante de alma}

\section{Generalidades}

Nos últimos anos, com o avanço da indústria siderúrgica, a resistência mecânica dos aços aumentou consideravelmente, o que influencia na questão da instabilidade dos elementos estruturais comprimidos. A carga de flambagem é reduzida com o aumento da resistência mecânica (ABNT NBR 8800:2008). Além disso, a esbeltez das chapas dos perfis laminados atinge uma faixa em que a instabilidade governa o dimensionamento dos elementos estruturais. Essa esbeltez é ainda maior nas vigas alveolares fabricadas a partir desses perfis.

Na Figura 3.4 mostra-se um detalhe de uma viga celular ensaiada por Nadjai et al. (2008), que sofreu colapso por instabilidade do montante de alma.

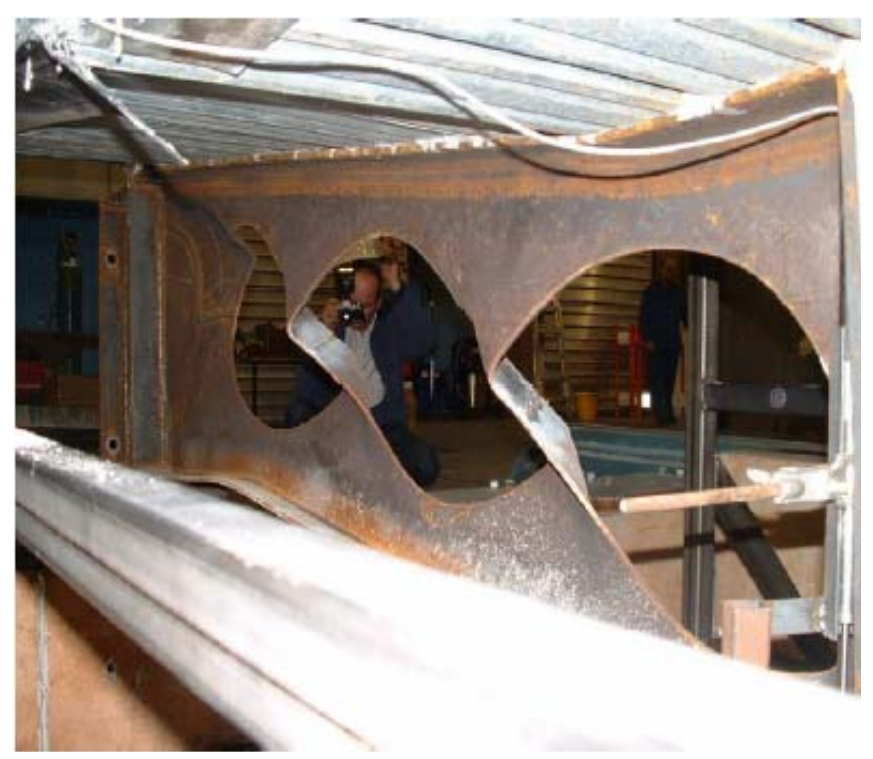

Figura 3.4 - Flambagem do montante de alma de uma viga mista celular (NADJAI et al., 2008).

De um modo geral, a flambagem das vigas pode ser inelástica, quando a flambagem ocorre após o início da plastificação, ou elástica, quando não acontece plastificação (DOUGHERTY, 1981; NETHERCOT e KERDAL, 1982; MOHEBKHAH, 2004).

\section{Flambagem do montante de alma por cisalhamento}

Por analogia com uma viga Vierendeel, o montante de alma de uma viga alveolar possui forças internas como se mostra na Figura 3.5. A força cisalhante $F$ ao longo da junta 
soldada solicita o montante de alma à flexão. $\mathrm{A}$ borda $\mathrm{AB}$ do montante é solicitada por tensões de tração, enquanto a borda CD está sujeita a tensões de compressão, podendo ocasionar a flambagem do montante. Ocorrendo a flambagem do montante de alma, o deslocamento lateral será acompanhado de torção da linha diagonal xx' (Figura 3.5). Esse modo de colapso é denominado flambagem do montante de alma por cisalhamento.

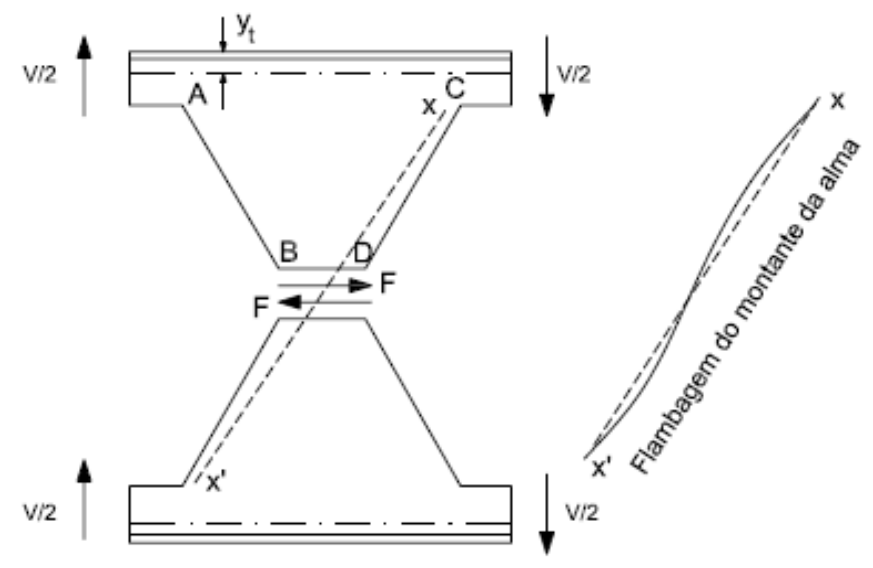

Figura 3.5 - Flambagem do montante de alma por cisalhamento (adaptado de KERDAL A NETHERCOT, 1984).

A flambagem do montante de alma por cisalhamento é influenciada pelas relações geométricas a seguir (ZAAROUR e REDWOOD, 1996; REDWOOD e DEMIRDJIAN, 1998):

- altura da abertura em relação à altura total da seção;

- altura da abertura em relação à largura mínima do montante de alma;

- largura mínima do montante de alma em relação à espessura da chapa;

- altura da chapa intermediária em relação à altura da abertura;

- altura da chapa intermediária em relação à espessura da chapa.

Diversos autores reportam casos de colapso de vigas alveolares por flambagem do montante de alma por cisalhamento, sendo que a maioria ocorreu em regime inelástico, com significativa plastificação das seções (KERDAL e NETHERCOT, 1984).

Delesques (1968) investigou a flambagem do montante de alma assumindo comportamento indefinidamente elástico, mas, em concordância com outros autores, concluiu que a flambagem elástica dificilmente ocorre. 
Aglan e Redwood (1974 apud REDWOOD e DEMIRDJIAN, 1998) analisaram o problema da flambagem do montante de alma por cisalhamento, através de uma aproximação por diferenças finitas para um material elastoplástico com encruamento. Constatou-se que os montantes de alma estariam num estágio avançado de escoamento antes da ocorrência da flambagem. Embora o modelo utilizado pelos autores assumisse a flambagem da linha vertical do montante de alma, as curvas propostas para dimensionamento parecem dar resultados razoáveis.

Zaarour e Redwood (1996) ensaiaram 12 modelos de vigas casteladas a partir de uma série de perfis laminados leves, denominadas vigas Bantam, fabricados numa determinada época pela Chaparral Steel, cuja esbeltez de alma varia na faixa $53 \leq \lambda_{w} \leq 67$. As vigas foram ensaiadas, com o objetivo de investigar a flambagem do montante de alma. Das 12 vigas ensaiadas, 10 sofreram colapso por flambagem do montante de alma. Os autores também conduziram uma análise numérica, utilizando o Método dos Elementos Finitos, com o objetivo de prever a carga de flambagem dos montantes de alma considerando comportamento inelástico. Com base nos resultados, propuseram alguns gráficos como ferramenta auxiliar para estimativa da resistência de vigas casteladas.

Redwood e Demirdjian (1998) estudaram a flambagem local da alma por cisalhamento em vigas casteladas, ensaiando vigas com esbeltez alta $\left(\lambda_{w}=74,8\right)$. Foi utilizado um modelo de elementos finitos para a realização de uma análise de bifurcação elástica (Figura 3.6). Os resultados deste trabalho mostraram que a capacidade estimada pelo modelo de elementos finitos foi sempre menor que a experimental. Apesar do alto índice de esbeltez, os autores constataram que o montante de alma ainda sofreu a flambagem em regime inelástico.

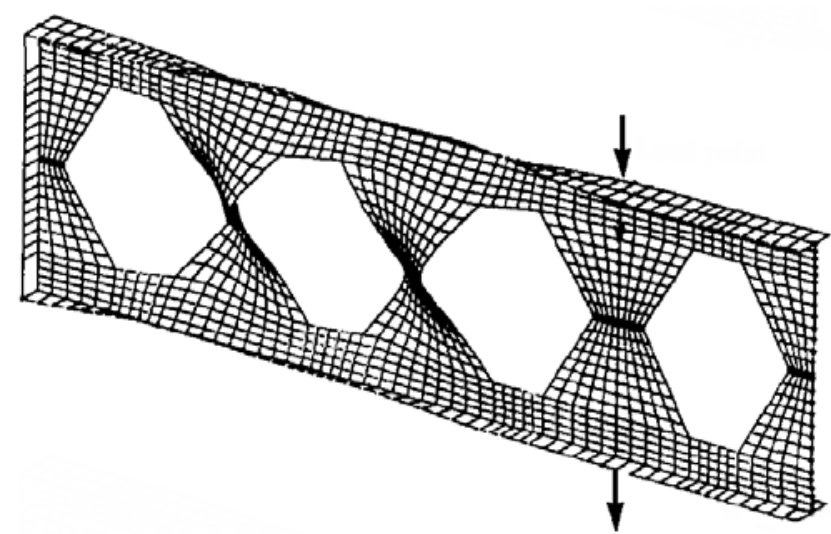

Figura 3.6 - Flambagem dos montantes de alma simulada com modelo numérico (adaptado de REDWOOD e DEMIRDJIAN, 1998). 
Além dessas publicações, Kerdal e Nethercot (1984) apresentaram uma síntese de outros trabalhos que relataram a ocorrência da flambagem do montante de alma por cisalhamento, realizados por Sherbourne (1966), Halleux (1967), Bazile e Texier (1968) e Stark (1982).

\section{Flambagem do montante de alma por compressão}

Este modo de colapso acontece normalmente em pontos de carga concentrada sobre o montante ou em apoios, principalmente quando não existem enrijecedores. Nesses pontos, esse modo de falha é similar ao enrugamento da alma que se observa numa viga de alma cheia submetida a uma carga concentrada. Ao contrário do que ocorre num montante de alma que flamba por cisalhamento, o deslocamento lateral do montante que flamba por compressão não é acompanhado de torção. Embora seja consenso que o comportamento deste elemento sob o efeito da flambagem seria o de uma coluna com seção transversal igual à seção mínima (seção da solda) e comprimento igual à altura da abertura, não existe ainda uma sugestão consistente para o coeficiente de flambagem a ser adotado (KERDAL e NETHERCOT, 1984).

\subsubsection{Outros modos de colapso}

Outros modos de colapso de vigas alveolares são apresentados em alguns trabalhos encontrados na literatura.

Zaarour e Redwood (1996) relatam que no programa experimental realizado duas vigas sofreram colapso por flambagem local dos tês. Amayreh e Saka (2005) também citaram esse modo de colapso em seu trabalho.

Zirakian e Showkati (2006) estudaram o modo de colapso conhecido como flambagem lateral com distorção.

Cimadevilla (2000) apresenta em seu estudo analítico a verificação para o modo de colapso denominado ruptura do montante de alma por flexão. 


\subsection{Geometria das vigas casteladas}

Segundo Lleonart (1988), as vigas casteladas em que o lado inclinado das aberturas possui menor ângulo têm maior resistência do que aquelas em que esse ângulo é maior, desde que as tensões normais sejam mais significantes que as tensões cisalhantes.

Apesar de o ângulo do lado inclinado da abertura ter pequena influência na rigidez elástica da viga castelada, a capacidade à rotação e a ductilidade da viga é melhorada para aberturas em que esse ângulo é maior. De modo geral, têm-se adotado com maior frequência aberturas cujo lado inclinado possui ângulo da ordem de $60^{\circ}$ (DOUGHERTY, 1993 apud AMAYREH e SAKA, 2005).

A largura mínima do montante de alma influencia no colapso da viga dependendo de suas dimensões. Para um comprimento muito pequeno, a viga terá sua capacidade restringida pela ruptura do montante de alma por cisalhamento; por outro lado, se a solda possui um comprimento elevado, facilita o colapso da viga pelo mecanismo Vierendeel. Knowles (1985 apud AYMAREH e SAKA, 2005) sugere que, para que haja um equilíbrio, deve-se utilizar um comprimento de solda com um quarto da altura da abertura. Essa sugestão também é apresentada por Dougherty (1993 apud DEMIRDJIAN, 1999) e por Gibson e Jenkins (1957). Esses autores também sugerem que o ângulo das aberturas seja próximo de $60^{\circ}$. Desse modo, a projeção horizontal da parte inclinada da abertura mede aproximadamente 0,29 vezes a altura da abertura. Vigas casteladas com esse padrão são muito utilizadas, principalmente nos Estados Unidos, Canadá e Inglaterra (GRÜNBAUER, 2011), sendo denomidado padrão Anglo-Saxão (LLEONART, 1988). Um esquema dessa tipologia é apresentado na Figura 3.7.

Outro parâmetro geométrico importante das vigas casteladas, é a razão de expansão, dada pela relação entre a altura total da viga castelada e altura do perfil original. Nos padrões mais usuais, adota-se uma razão de expansão de 1,5 (GRÜNBAUER, 2011; AYMAREH e SAKA, 2005), como pode ser visto na Figura 3.7. 


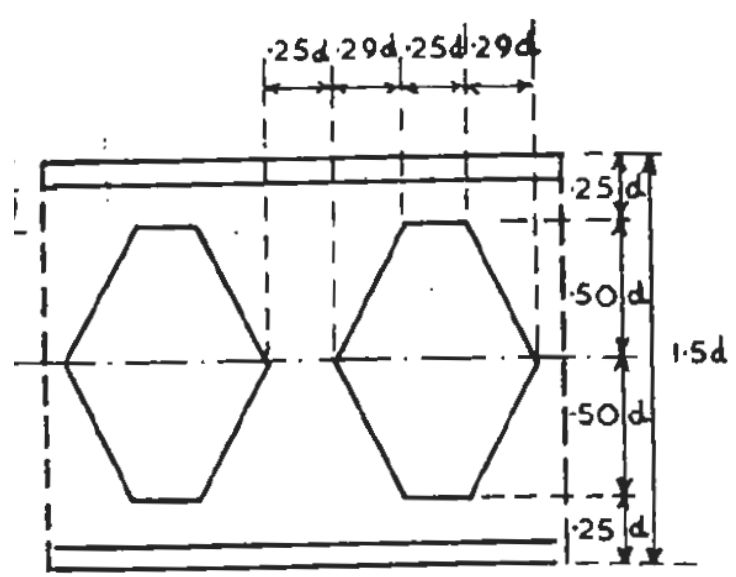

Figura 3.7 - Padrão Anglo-Saxão de vigas casteladas (GIBSON e JENKINS, 1957).

Uma viga com maior expansão terá um momento de inércia maior, para o mesmo peso de aço. Entretanto, a capacidade da viga se reduzirá devido à maior susceptibilidade de um colapso por instabilidade, a partir de certa razão. Galambos et al. (1973) investigou esses aspectos e propôs parâmetros para obtenção da razão de expansão ótima de vigas casteladas. Destaca-se nas suas conclusões que, para propiciar uma razão de expansão ótima maior, o comprimento da solda entre as aberturas deve ser o mínimo necessário para garantir que a ruptura não se dê por cisalhamento do montante. A razão ótima de expansão da viga também é maior quanto maior for sua relação momento-cortante.

\subsection{Comportamento estrutural de vigas alveolares}

\subsubsection{Estudos analíticos}

Diversos autores estudaram analiticamente o comportamento estrutural das vigas alveolares, especificamente, das vigas casteladas.

Um dos primeiros estudos sobre o comportamento estrutural de vigas casteladas foi realizado por Gibson e Jenkins (1957), a partir da teoria das vigas Vierendeel. Os autores apresentam uma aplicação particular às vigas casteladas no padrão anglo-saxão.

Kolosowski (1964) realizou um estudo teórico-experimental para avaliação das tensões e deformações nas vigas casteladas. O trabalho apresenta basicamente dois métodos de análise de vigas casteladas - o método clássico da teoria das vigas e o método com base na 
teoria das vigas Vierendeel. Comparando-se com resultados experimentais, o segundo modelo de cálculo é mais realista. Observou-se que a distribuição de tensões ao longo das mesas se dá em ziguezague, como nas vigas Vierendeel.

Delesques (1968) estudou o comportamento de instabilidade dos montantes de alma das vigas casteladas e propôs uma expressão para o cálculo da força cortante crítica correspondente à instabilidade do montante de alma (ver Figura 3.5).

Em outro estudo analítico, Delesques (1969) apresenta o comportamento estrutural das vigas casteladas. Foram estudados separadamente os comportamentos dos tês e dos montantes de alma. São propostas equações que estimam a capacidade desses elementos submetidos a esforços cortantes, a momentos fletores e à combinação desses esforços. É apresentado também um estudo de estabilidade dos montantes. Segundo Delesques (1969), no comportamento estrutural das vigas casteladas a hipótese de Navier-Bernoulli não é válida; a hipótese que pode ser considerada com melhor aproximação é a de distribuição uniforme de tensões na altura do perfil.

Lleonart (1988) realizou um estudo sobre vigas alveolares submetidas a carregamento uniformemente distribuído, assumindo que o comportamento resistente desses elementos estruturais é similar ao de uma viga Vierendeel com cargas aplicadas nos nós. Com essa hipótese, são apresentadas equações para o cálculo das tensões e para obtenção da seção crítica, que sofrerá plastificação.

Gemperle (2007) apresenta um estudo analítico de vigas casteladas, mostrando o comportamento dessas vigas quando submetidas ao cisalhamento e à flexão. A elaboração de diagramas de interação momento-cortante é apresentada, tendo em vista o prédimensionamento dessas vigas.

Delesques (1969) realizou também um estudo das deformações das vigas casteladas. As expressões para previsão dos deslocamentos também foram desenvolvidas separadamente para os montantes e os tês. Essas equações são formadas por duas parcelas, correspondentes às deformações por flexão e por cisalhamento. As deformações por cisalhamento, que são desprezíveis em vigas de alma cheia, são significativas nas vigas casteladas, e, por esse motivo, devem sempre ser consideradas no cálculo dos deslocamentos. 
Lleonart (1988) também realizou um estudo das deformações nas vigas casteladas, chegando à conclusão que os deslocamentos devidos ao cisalhamento são uma fração daqueles devidos à flexão. Deste modo, a flecha total de uma viga castelada submetida a carregamento uniformemente distribuído pode ser dada por:

$$
f=\frac{5}{384} K_{f} \frac{q L^{4}}{E I_{m}}
$$

onde:

$q$ é o valor do carregamento distribuído;

$I_{m}$ é o momento de inércia equivalente da viga castelada;

$K_{f}$ é um coeficiente de majoração da flecha para consideração dos efeitos dos esforços cisalhantes.

$L$ é o vão livre da viga biapoiada

Esse coeficiente de majoração é função do tipo de carregamento e do comprimento do vão. Segundo Lleonart (1988), para vãos usuais recomenda-se a utilização de $K_{f}=1,10$. Assim, a flecha nessas vigas pode ser escrita como apresentado na equação (3-2).

$$
f=\frac{5,5}{384} \frac{q L^{4}}{E I_{m}}
$$

Segundo Gemperle (2007), o valor do coeficiente de majoração para os deslocamentos depende da relação vão/altura da viga, e recomenda que se utilize o valor de 1,35 para vigas submetidas a carregamento uniformemente distribuído e de 1,5 para vigas com carga concentrada no centro do vão.

\subsubsection{Análises Experimentais}

Diversos programas experimentais têm sido realizados, desde meados do século passado, com o objetivo de estudar o comportamento estrutural de vigas alveolares.

Altifillisch et al. (1957 apud DEMIRDJIAN, 1999) realizaram ensaios em vigas casteladas, com o objetivo de avaliar o comportamento nos domínios elástico e plástico dessas vigas. 
Em um programa experimental realizado por Toprac e Cooke (1959) foram ensaiadas nove vigas casteladas, com o objetivo de realizar um estudo do comportamento nos domínios elástico e plástico, dos modos de colapso e da capacidade de carga. Realizou-se também uma análise comparativa entre os modelos analíticos de cálculo. Nas vigas ensaiadas, foram observadas falhas por mecanismo Vierendeel e por flambagem da mesa.

Sherbourne (1966 apud DEMIRDJIAN, 1999) ensaiou diversas vigas casteladas, com o objetivo de investigar a relação entre a interação momento-cortante nas vigas e suas condições de carregamento. Nos modelos ensaiados ocorreram colapsos por mecanismo de flexão, mecanismo Vierendeel, flambagem do montante de alma e flambagem lateral com torção.

Halleux (1967 apud DEMIRDJIAN, 1999) realizou um programa experimental com vigas casteladas, originadas de uma mesma seção, variando-se a razão de expansão, o comprimento da solda, o ângulo da abertura e a presença de chapa intermediária. Algumas vigas ruíram por mecanismo Vierendeel e outras por mecanismo de flexão.

Um programa experimental com sete vigas casteladas a partir de duas classes de perfis foi ensaiado por Bazile e Texier (1968 apud ZAAROUR, 1995), para estudar o comportamento dessas vigas em relação a diversas características geométricas. Essas vigas eram biapoiadas e submetidas a oito cargas concentradas. Todos os modelos tiveram sua capacidade determinada pela instabilidade do montante de alma.

Outro programa experimental com seis vigas casteladas foi realizado por Husain e Speirs (1971 apud DEMIRDJIAN, 1999), com o objetivo de estudar o comportamento das vigas susceptíveis à ruptura do montante de alma por cisalhamento. Husain e Speirs (1973 apud DEMIRDJIAN, 1999) estudaram a contribuição da geometria das aberturas no comportamento e na carga última das vigas. Ocorreram colapsos por mecanismo Vierendeel e por flambagem do montante de alma. Em ambos os programas experimentais as vigas eram biapoiadas submetidas a uma ou duas cargas concentradas.

Galambos et al. (1975 apud DEMIRDJIAN, 1999) também ensaiaram vigas casteladas, com o objetivo de determinar a melhor razão de expansão. No entanto, não foram publicados detalhes sobre os modos de colapso. 
Zaarour (1995) ensaiou quatorze vigas da série Bantam (fabricadas pela Chaparral Steel Company), com o objetivo de estudar a flambagem do montante de alma. Destas, dez vigas sofreram ruína por instabilidade do montante de alma. Na Tabela 3.1, apresenta-se as propriedades geométricas, a carga última e o modo de colapso sofrido pelas vigas casteladas ensaiadas.

Tabela 3.1 - Características de ensaios realizados por Zaarour (1995).

\begin{tabular}{cccccccccccc}
\hline Ensaio & $\begin{array}{c}\mathrm{d}_{\mathrm{g}} \\
\mathrm{mm}\end{array}$ & $\begin{array}{c}\mathrm{b}_{\mathrm{f}} \\
\mathrm{mm}\end{array}$ & $\begin{array}{c}\mathrm{t}_{\mathrm{w}} \\
\mathrm{mm}\end{array}$ & $\begin{array}{c}\mathrm{t}_{\mathrm{f}} \\
\mathrm{mm}\end{array}$ & $\begin{array}{c}\mathrm{b}_{\mathrm{w}} \\
\mathrm{mm}\end{array}$ & $\begin{array}{c}\mathrm{h}_{0} \\
\mathrm{~mm}\end{array}$ & $\begin{array}{c}\mathrm{p} \\
\mathrm{mm}\end{array}$ & $\begin{array}{c}\mathrm{h}_{\mathrm{p}} \\
\mathrm{mm}\end{array}$ & $\begin{array}{c}\text { Vão } \\
\mathrm{m}\end{array}$ & $\begin{array}{c}\text { Carga } \\
\text { kN }\end{array}$ & $\begin{array}{c}\text { Modo de } \\
\text { ruína }\end{array}$ \\
\hline $8-1 \mathrm{a}$ & 307,34 & 59,44 & 3,43 & 4,70 & 47,75 & 222,25 & 222,25 & - & 3,070 & 56,94 & FTS \\
$8-2 a$ & 359,66 & 58,42 & 3,48 & 4,72 & 47,75 & 270,76 & 222,25 & 50,80 & 3,072 & 49,82 & FMA \\
$8-3$ & 307,34 & 59,69 & 3,51 & 4,57 & 57,15 & 222,25 & 342,90 & - & 3,045 & 57,83 & FTS \\
$8-4$ & 358,90 & 58,42 & 3,48 & 4,72 & 57,15 & 270,00 & 342,90 & 50,80 & 3,051 & 39,59 & FMA \\
$10-1$ & 370,59 & 69,09 & 3,58 & 4,39 & 57,15 & 245,87 & 254,00 & - & 3,043 & 79,18 & FMA \\
$10-2$ & 417,83 & 69,85 & 3,61 & 3,99 & 57,15 & 295,15 & 254,00 & 50,80 & 3,048 & 58,72 & FMA \\
$10-3$ & 376,43 & 70,61 & 3,61 & 4,45 & 57,15 & 260,35 & 368,30 & - & 3,045 & 73,84 & FMA \\
$10-4$ & 425,45 & 70,61 & 3,68 & 4,27 & 57,15 & 308,10 & 368,30 & 50,80 & 3,044 & 50,26 & FMA \\
$12-1$ & 476,25 & 78,49 & 4,70 & 5,33 & 76,20 & 352,81 & 355,60 & - & 3,048 & 114,76 & FMA \\
$12-2$ & 527,81 & 77,98 & 4,60 & 5,36 & 76,20 & 403,86 & 355,60 & 50,80 & 3,048 & 98,31 & FMA \\
$12-3$ & 449,58 & 78,23 & 4,62 & 5,36 & 69,85 & 302,51 & 438,15 & - & 3,051 & 116,54 & FMA \\
$12-4$ & 501,65 & 77,98 & 4,70 & 5,33 & 69,85 & 349,76 & 438,15 & 50,80 & 3,053 & 93,41 & FMA \\
\hline Legenda
\end{tabular}

Simbologia
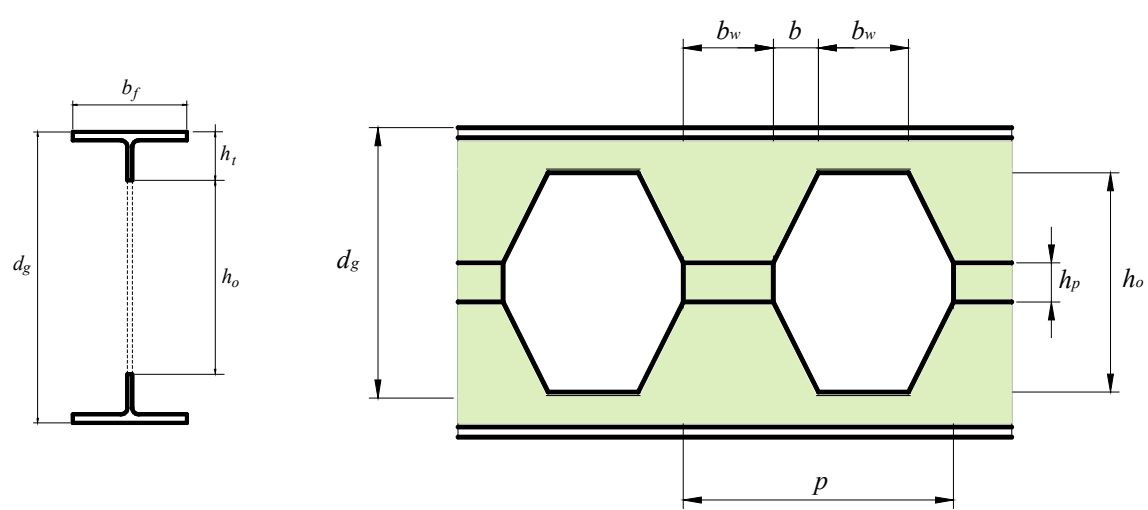

Redwood e Demirdjian (1998) ensaiaram quatro vigas casteladas, variando-se apenas o comprimento do vão. Os objetivos principais do programa experimental foram investigar o modo de colapso por flambagem do montante de alma e observar os efeitos da relação momento-cortante com o modo de ruína das vigas.

Dabaon et al. (2003) realizaram um programa experimental no Egito com vigas casteladas mistas de eixo curvo, para estudarem o comportamento misto e os efeitos da torção. 
Diversos outros programas experimentais foram realizados com vigas celulares, para estudar seu comportamento estrutural em temperatura ambiente e em situação de incêndio (BAILEY, 2004; HOFFMAN et al., 2006; LAWSON et al., 2006; NADJAI et al., 2007; NADJAI et al., 2008; VASSART et al., 2008).

\subsubsection{Análises Numéricas}

Nas últimas décadas tem sido cada vez mais frequente a utilização do Método dos Elementos Finitos (MEF) para o estudo do comportamento de elementos estruturais, com a finalidade de prever a carga em ensaios ou para a realização de estudos paramétricos. Diversos autores têm realizado modelagens numéricas pelo MEF, de diferentes formas, para o estudo do comportamento de vigas alveolares.

Zaarour e Redwood (1996) apresentam resultados de uma análise de flambagem pelo MEF, realizado através do software NASTRAN, para obtenção da carga crítica. Foram modeladas as vigas ensaiadas pelos autores e de outros programas experimentais. $\mathrm{Na}$ Tabela 3.2, são apresentados os resultados experimentais e numéricos das vigas que sofreram colapso por instabilidade do montante de alma, ensaiadas por Zaarour e Redwood (1996) e Bazile e Texier (1968 apud ZAAROUR, 1995).

Tabela 3.2 - Resultados obtidos através de modelagem numérica, em comparação com experimentos (adaptado de ZAAROUR e REDWOOD, 1996).

\begin{tabular}{ccccc}
\hline \multirow{2}{*}{ Ensaio } & \multicolumn{2}{c}{$\begin{array}{c}\text { Resultado Experimental } \\
\mathrm{kN}\end{array}$} & $\begin{array}{c}\text { Resultado Numérico } \\
\mathrm{kN}\end{array}$ & \multirow{2}{*}{ Erro } \\
& & 49,82 & 49,38 & $-0,9 \%$ \\
& $8-2^{\mathrm{a}}$ & 39,59 & 44,04 & $11,2 \%$ \\
& $8-4$ & 79,18 & 67,61 & $-14,6 \%$ \\
Zaarour e & $10-1$ & 58,72 & 61,83 & $5,3 \%$ \\
Redwood & $10-2$ & 73,84 & 65,39 & $-11,4 \%$ \\
& $10-3$ & 50,26 & 63,61 & $26,5 \%$ \\
& $10-4$ & 114,76 & 125,88 & $9,7 \%$ \\
& $12-1$ & 98,31 & 94,75 & $-3,6 \%$ \\
& $12-2$ & 116,54 & 109,87 & $-5,7 \%$ \\
& $12-3$ & 93,41 & 107,20 & $14,8 \%$ \\
\hline \multirow{5}{*}{ Bazile e Texier } & $12-4$ & 805,13 & 705,04 & $-12,4 \%$ \\
& A & 685,03 & 701,93 & $2,5 \%$ \\
& B & 600,07 & 663,67 & $10,6 \%$ \\
& C & 620,08 & 644,99 & $4,0 \%$ \\
& D & 279,79 & 304,26 & $8,7 \%$ \\
\hline
\end{tabular}


Redwood e Demirdjian (1998) também realizaram uma análise numérica com os modelos ensaiados. A análise foi realizada através do software NASTRAN visando obter a carga crítica. Na Tabela 3.3, apresenta-se os resultados experimentais e os resultados obtidos numericamente pelo Método dos Elementos Finitos.

Tabela 3.3 - Resultados obtidos através de modelagem numérica, em comparação com resultados experimentais (adaptado de REDWOOD e DEMIRDJIAN, 1998).

\begin{tabular}{|c|c|c|c|}
\hline Ensaio & $\begin{array}{l}\text { Resultado Experimental } \\
\qquad \mathrm{kN}\end{array}$ & $\begin{array}{l}\text { Resultado Numérico } \\
\text { kN }\end{array}$ & Erro \\
\hline $10-5 a$ & 92,7 & 88,6 & $-4,4 \%$ \\
\hline $10-5 b$ & 100,9 & 88,6 & $-12,2 \%$ \\
\hline $10-6$ & 94,8 & 84,1 & $-11,3 \%$ \\
\hline $10-7$ & 84,4 & 81,3 & $-3,7 \%$ \\
\hline
\end{tabular}

Dabaon et al. (2003) modelaram seus ensaios de vigas casteladas mistas com eixo curvo, através do software ANSYS. Os autores utilizaram elementos sólidos para a modelagem e consideraram a não-linearidade material e geométrica. Foi utilizada a técnica de iteração de Newton para solução da análise não-linear.

Outra análise numérica em vigas casteladas através do ANSYS foi realizada por Hennessey et al. (2004), com o objetivo de estudar a flambagem dos montantes e o comportamento da ligação, variando-se a forma desta. Foram consideradas, nessa análise, as não-linearidades material e geométrica.

Mohebkhah (2004) também realizou modelagem por elementos finitos pelo ANSYS. Em estudo da flambagem lateral com torção inelástica em vigas casteladas, o autor utilizou elementos de casca e material elastoplástico trilinear com endurecimento. $\mathrm{O}$ carregamento foi aplicado nas mesas superior e inferior, dividido igualmente entre estas.

Mohebkhah e Showkati (2005) realizaram um estudo sobre o travamento lateral de vigas casteladas em comportamento inelástico. Os autores realizaram a análise através do software COSMOS/M, utilizando um material elastoplástico trilinear com endurecimento. Na aplicação do carregamento foi utilizado o procedimento de Newton-Raphson completo. Através do estudo numérico, os autores apresentaram uma correlação entre a rigidez do travamento lateral e a carga crítica de flambagem lateral com torção.

Cavalcante (2005) também modelou vigas casteladas mistas com o ANSYS, utilizando elementos sólidos de oito nós (lineares) para o estudo do comportamento da solda. 
Chai (2005), em um estudo de torção em vigas com abertura na alma, realizou uma análise numérica com o software LUSAS, utilizando elementos quadrilaterais de casca de quatro nós.

Hoffman et al. (2006) modelaram vigas celulares com elementos sólidos no ANSYS, para o estudo do comportamento estrutural dessas vigas.

Rini (2006) também fez um estudo numérico de vigas celulares, analisando o comportamento em incêndio. A análise foi realizada com o ABAQUS, utilizando-se elementos de casca lineares.

Lotfollahi-Yaghin e Ahmadi (2008) estudaram o comportamento dinâmico de vigas casteladas em balanço utilizando o ANSYS.

Diversos outros autores têm utilizado modelagem numérica para o estudo de vigas de aço com aberturas na alma, vigas casteladas e celulares (LIAN e SHANMUGAM, 2004; LIU e CHUNG, 2003; RAFTOYIANNIS e IOANNIDIS, 2006; RADIĆ e MARKULAK, 2007; NADJAI et al., 2007; RODRIGUES et al., 2007; LAGAROS et al., 2008; KOHNEHPOOSHI e SHOWKATI, 2009; RADIĆ et al., 2009; BEZERRA et al., 2010; ABREU et al., 2010). 


\section{O MODELO NUMÉRICO}

\subsection{Considerações iniciais}

A metodologia adotada para atingir os objetivos propostos foi desenvolvida basicamente em três etapas, a saber: construção de um modelo numérico com base no Método dos Elementos Finitos (MEF); validação do modelo com base em resultados experimentais disponíveis; realização de um estudo paramétrico utilizando-se o modelo numérico desenvolvido.

O modelo numérico elaborado foi construído no ABAQUS, um software avançado para análises por elementos finitos que oferece muitos recursos para a elaboração de modelos. $\mathrm{O}$ ABAQUS permite análises lineares ou não-lineares, estáticas ou dinâmicas e também oferece recursos para a realização de análises de flambagem e de pós-flambagem, quesito 
importante, uma vez que o objeto de estudo deste trabalho envolve fenômenos de instabilidade.

Uma vez que os elementos estruturais a serem modelados são constituídos por perfís de aço compostos por chapas de pequena espessura, optou-se por discretizá-los utilizando os elementos finitos de casca disponíveis na biblioteca do ABAQUS.

Para cada viga, foram realizadas duas análises: uma análise linear de flambagem, para seleção do modo de flambagem e para obtenção de uma estimativa da carga crítica, e, posteriormente, uma análise completa, considerando as não-linearidades material e geométrica, as imperfeições iniciais e as tensões residuais existentes nos perfis. Essas análises são descritas nos itens 4.2.3 e 4.2.4, respectivamente.

A fim de verificar a validade do modelo numérico, foram modeladas 13 vigas casteladas, ensaiadas por Redwood e Demirdjian (1998), Zaarour e Redwood (1996), Bazile e Texier (1968) e Toprac e Cooke (1959). As características físicas e geométricas das vigas ensaiadas e os resultados experimentais e numéricos são apresentados no item 4.3.

\subsection{Características do modelo numérico}

\subsubsection{Generalidades da modelagem}

A primeira etapa para elaboração de um modelo de elementos finitos no ABAQUS consiste na definição de um modelo geométrico que represente de maneira adequada o problema físico. Neste caso optou-se pela criação de um modelo geométrico tridimensional formado por elementos de casca fina do tipo deformável, representando a superfície média das chapas de aço que compõem a viga alveolar.

Para cada região definida no modelo devem ser atribuídas as seções. A cada seção criada no ABAQUS é atribuída uma espessura e um material que pode ter comportamento elástico-linear ou que considere a plasticidade (ver item 4.2.2).

Existem no ABAQUS as opções de se realizar a integração das seções antes ou durante a análise. Quando os materiais associados às seções têm comportamento linear, pode-se 
realizar a integração antes da análise (Hibbitt et al, 2009). Entretanto, como se considerou o comportamento não-linear dos materiais, a integração nas seções foi realizada durante a análise.

Foram atribuídas seções do tipo casca, com integração realizada pela regra de Simpson com cinco pontos de integração ao longo da espessura.

Os modelos foram divididos em regiões para facilitar a criação das malhas, conforme se mostra na Figura 4.1.

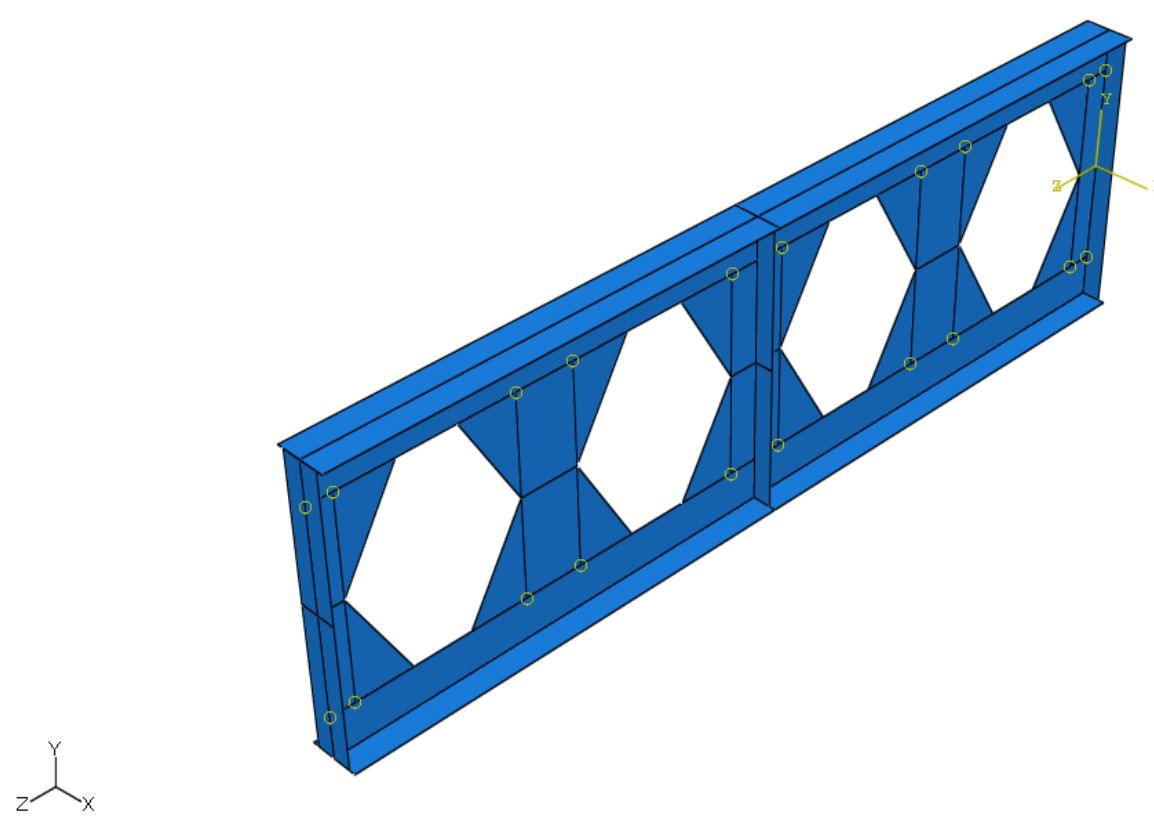

Figura 4.1 - Modelagem de uma viga castelada ensaiada por Redwood e Demirdjian (1998), apresentando a divisão em regiões.

Nas regiões triangulares formadas nas proximidades das aberturas foi gerada uma malha com elementos triangulares e nas demais regiões utilizaram-se elementos quadrilaterais.

Os elementos triangulares são do tipo S3 da biblioteca do ABAQUS/Standard, que são elementos de casca lineares com três nós e seis graus de liberdade por nó.

Para a malha quadrilateral foram escolhidos os elementos S4R do ABAQUS/Standard, que são elementos de casca lineares, com quatro nós, seis graus de liberdade por nó e utilização de integração reduzida. A integração reduzida permite uma diminuição do tempo de análise (CUNHA, 2005) e melhora a qualidade dos resultados em relação aos deslocamentos. 
Na Figura 4.2 apresentam-se os elementos S3 e S4R do ABAQUS. Na Figura 4.3 mostrase uma viga modelada com a malha de elementos finitos utilizada.

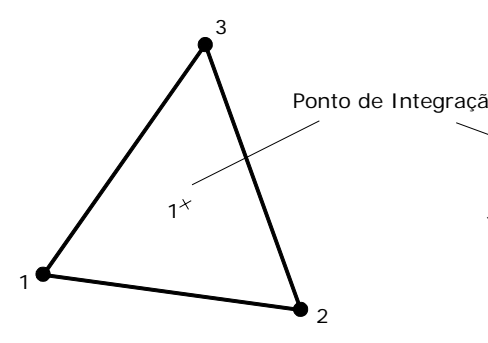

S3

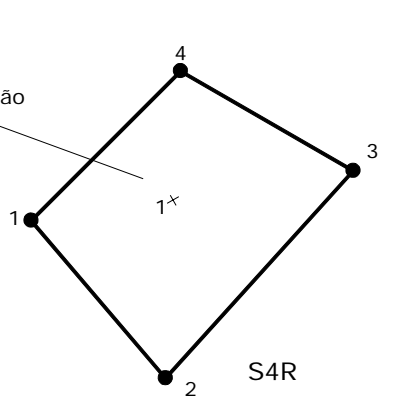

(b)

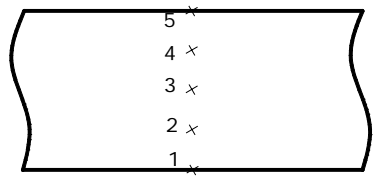

(c)

Figura 4.2 - Representação dos elementos (a) S3 e (b) S4R do ABAQUS e (c) dos pontos de integração ao longo da espessura dos elementos pela regra de Simpson.
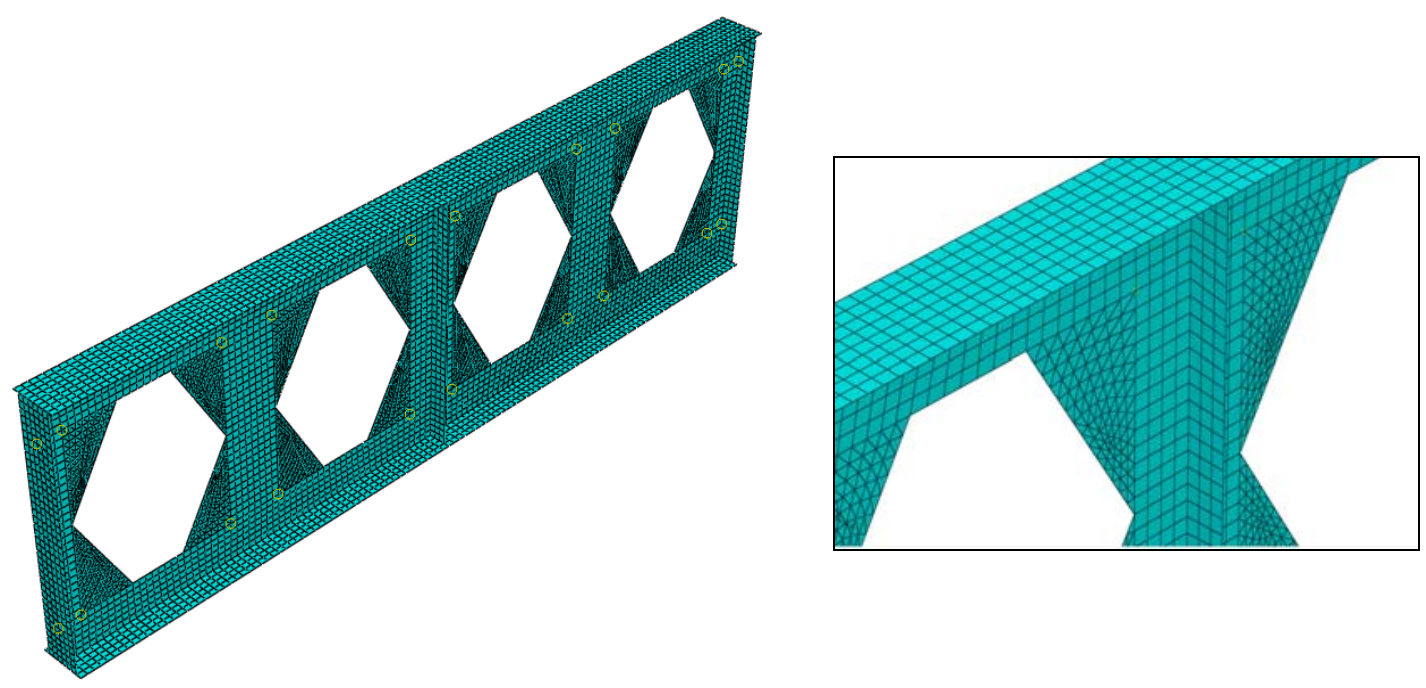

Figura 4.3 - Representação da malha de elementos finitos em viga ensaiada por Redwood e Demirdjian (1998), com detalhe da região com malha triangular.

Para avaliação da objetividade da malha foram realizadas algumas análises preliminares variando-se a dimensão dos elementos. Como se mostra na Tabela 4.1, a variação dos resultados para malhas com elementos com lados menores que $1 \mathrm{~cm}$ é muito pequena, tendo em vista a diferença do tempo de processamento. Por esse motivo, decidiu-se utilizar malhas formadas por elementos com lados de $1 \mathrm{~cm}$. 
Tabela 4.1 - Análise da objetividade da malha de elementos finitos.

\begin{tabular}{ccccc}
\hline Ensaio & $\begin{array}{c}\text { Dimensão dos } \\
\text { lados dos } \\
\text { elementos }\end{array}$ & $\begin{array}{c}\text { Diferença } \\
\frac{P_{\text {mum }}-P_{\text {exp }}}{P_{\text {exp }}}\end{array}$ & $\begin{array}{c}\text { Tempo de } \\
\text { processamento }\end{array}$ & $\begin{array}{c}\text { Espaço em } \\
\text { disco }\end{array}$ \\
\hline \multirow{2}{*}{ Redwood e Demirdjian (1998) - Viga 10-5 } & $0,6 \mathrm{~cm}$ & $6 \%$ & $61^{\prime \prime} 41^{\prime \prime}$ & $620 \mathrm{MB}$ \\
& $0,8 \mathrm{~cm}$ & $6 \%$ & $39^{\prime} 25^{\prime \prime}$ & $370 \mathrm{MB}$ \\
\hline \multirow{2}{*}{ Redwood e Demirdjian (1998) - Viga 10-6 } & $1,0 \mathrm{~cm}$ & $6 \%$ & $27^{\prime} 18^{\prime \prime}$ & $254 \mathrm{MB}$ \\
\hline \multirow{2}{*}{ Redwood e Demirdjian (1998) - Viga 10-7 } & $0,6 \mathrm{~cm}$ & $-6 \%$ & $141^{\prime} 29^{\prime \prime}$ & $955 \mathrm{MB}$ \\
& $1,0 \mathrm{~cm}$ & $-5 \%$ & $35^{\prime} 18^{\prime \prime}$ & $341 \mathrm{MB}$ \\
\hline
\end{tabular}

\subsubsection{Materiais}

No modelo de elementos finitos desenvolvido neste trabalho, considera-se o comportamento não-linear dos materiais (plasticidade). Para o aço admite-se uma lei constitutiva elastoplástica sem encruamento e o critério de escoamento de Von Mises.

Utilizou-se, no modelo numérico adotado, um material elastoplástico perfeito, como apresentado no diagrama da Figura 4.4.

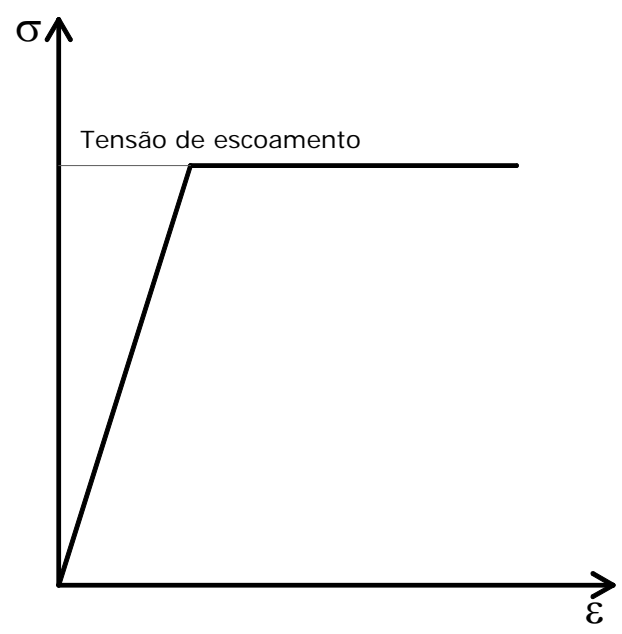

Figura 4.4 - Curva adotada para os materiais na modelagem do ABAQUS.

\subsubsection{Análise de flambagem elástica}

Antes da análise não-linear, realiza-se uma análise de flambagem elástica para estimativa da carga crítica de flambagem elástica.

O carregamento é aplicado à estrutura como perturbação linear do tipo buckle e a solução é obtida pelo método de iteração Subspace (ver BATHE, 1996). 
Como resultados da análise de flambagem obtêm-se os autovalores e autovetores correspondentes. Os autovalores representam o fator de carga para o qual ocorre a instabilidade e os autovetores definem o modo de flambagem. Na Figura 4.5 apresenta-se um dos modos de flambagem de um dos modelos elaborados no ABAQUS. Neste modelo deformado, os deslocamentos estão normalizados (o valor máximo é igual à unidade) para posterior utilização na análise não-linear material e geométrica.

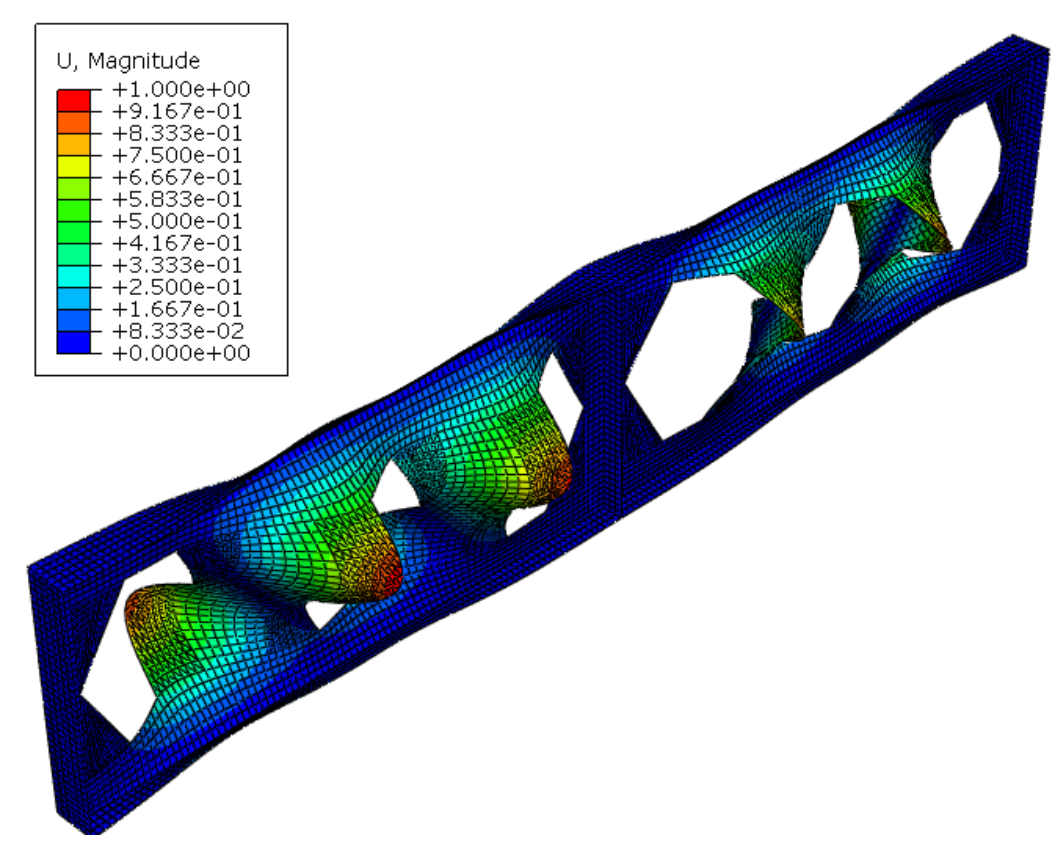

Figura 4.5 - Modo de flambagem representado no ABAQUS para a viga 10-6 ensaiada por Redwood e Demirdjian (1998).

\subsubsection{Análise não-linear material e geométrica}

Após a análise de instabilidade, procede-se a uma análise não-linear material e geométrica que simula o comportamento da estrutura durante todo o carregamento, inclusive na fase pós-flambagem. Para realização desse tipo de análise, considera-se a não-linearidade geométrica da estrutura e o comportamento elastoplástico do material.

O carregamento é aplicado por incrementos e o equilíbrio para cada incremento de carga é obtido pelo algoritmo de Riks modificado. 


\section{Método de Riks modificado}

O método de Riks modificado, disponível no ABAQUS é capaz de descrever uma trajetória de equilíbrio que permite ir além da carga máxima alcançada pela estrutura e simular o comportamento de estruturas com resposta carga-deslocamento semelhante à apresentada na Figura 4.6.

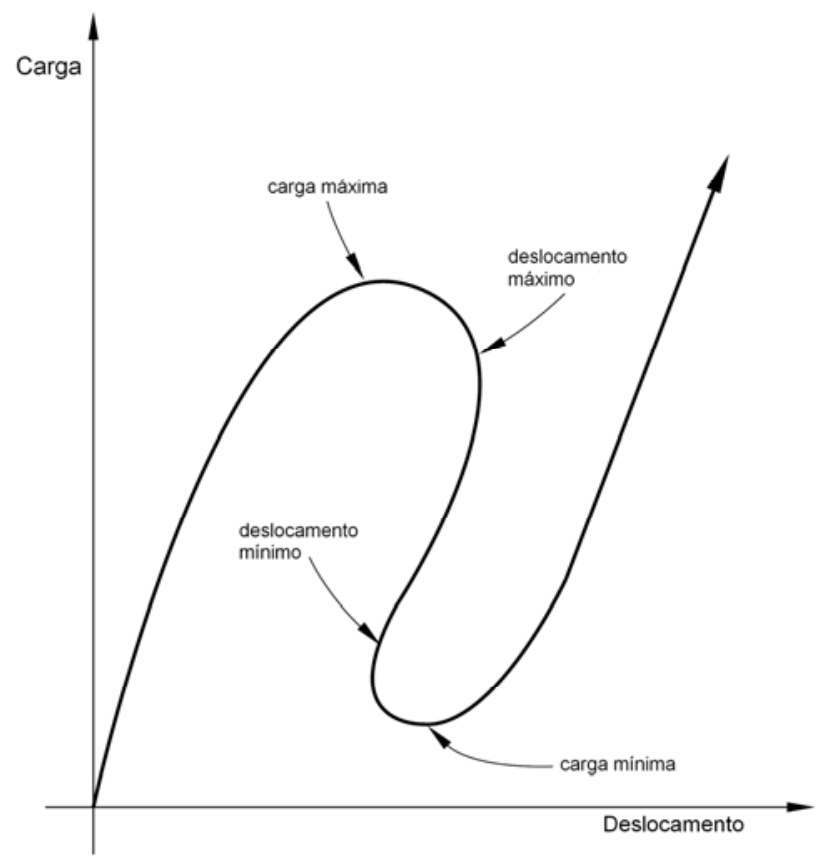

Figura 4.6 - Curva carga-deslocamento em problemas de instabilidade (adaptado de Hibbitt et al, 2009).

No algoritmo de Riks modificado implementado no ABAQUS, o tamanho do incremento é limitado movendo-se ao longo da linha tangente à curva no ponto corrente da solução e a procura pelo equilíbrio é realizada em um plano ortogonal à linha tangente e que passa pelo ponto obtido. Na Figura 4.7 ilustra-se esse procedimento, onde $\lambda$ é o fator de carga e $\bar{u}^{\mathrm{N}}$ é o vetor deslocamento. 


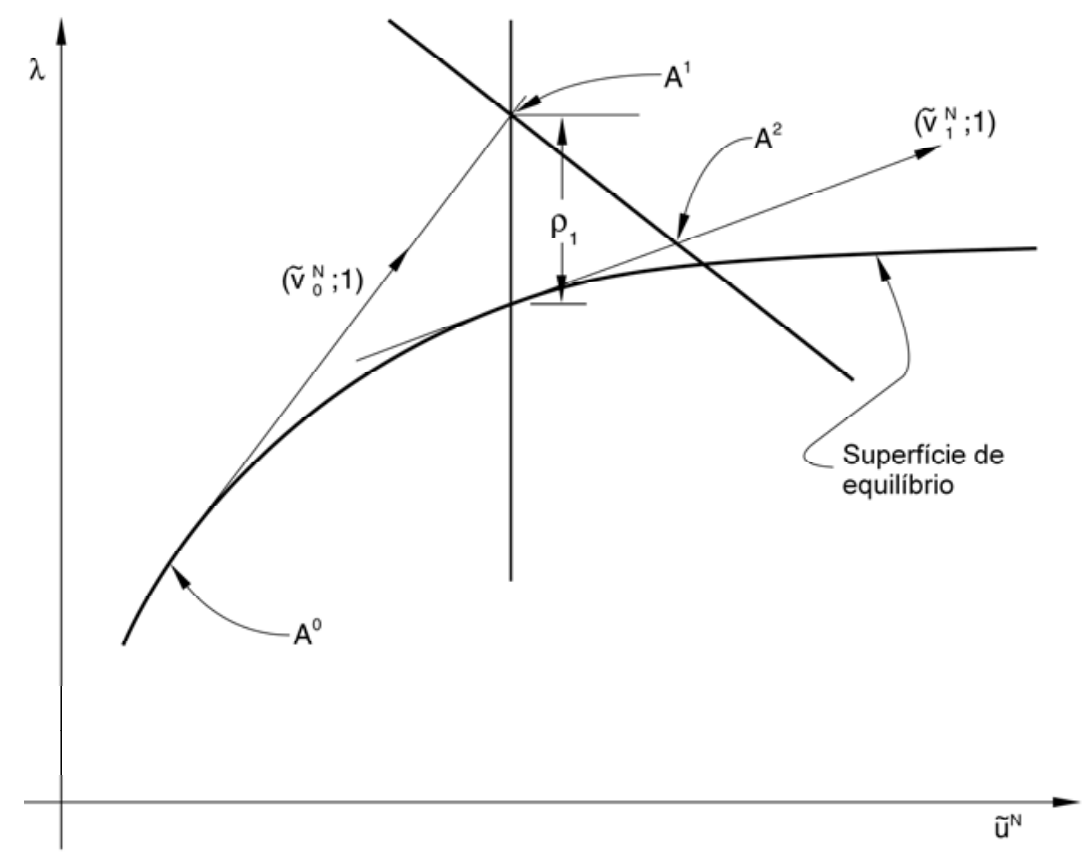

Figura 4.7 - Algoritmo de Riks modificado (adaptado de Hibbitt et al, 2009).

Para iniciar a análise, deve-se fornecer um incremento inicial do comprimento de arco (que é equivalente a uma fração do carregamento) e os incrementos seguintes são ajustados automaticamente, aumentando ou diminuindo, dependendo do número de iterações realizadas para convergência do incremento.

\section{Imperfeições iniciais}

Utilizando-se o método de Riks é necessário aplicar uma imperfeição inicial ao modelo, correspondente ao modo de flambagem selecionado na análise de flambagem elástica (ver Figura 4.5), para que seja possível caracterizar o ponto de carga máxima (crítica) da estrutura.

Para análise de instabilidade dos montantes de alma das vigas alveolares, por exemplo, a imperfeição inicial a ser utilizada na análise não-linear, deve ser uma fração da altura do perfil. Por meio de diversas análises realizadas neste trabalho, verificou-se que utilizar uma imperfeição igual a 1/2000 da altura total da viga alveolar conduzia à melhor concordância com resultados experimentais. 


\section{Tensões Residuais}

Após a laminação, os perfis metálicos passam por um processo de resfriamento, que não acontece de maneira homogênea para todas as regiões do perfil. A velocidade de resfriamento será maior nas partes mais expostas (extremidades das mesas e centro da alma) que nas outras regiões da seção transversal. Esse resfriamento diferencial, associado à solidificação do metal, é responsável pelo aparecimento das tensões residuais ao longo da seção.

Diversos modelos têm sido propostos para representar a distribuição das tensões residuais nas seções transversais dos perfis de aço, como pode ser visto na Figura 4.8.

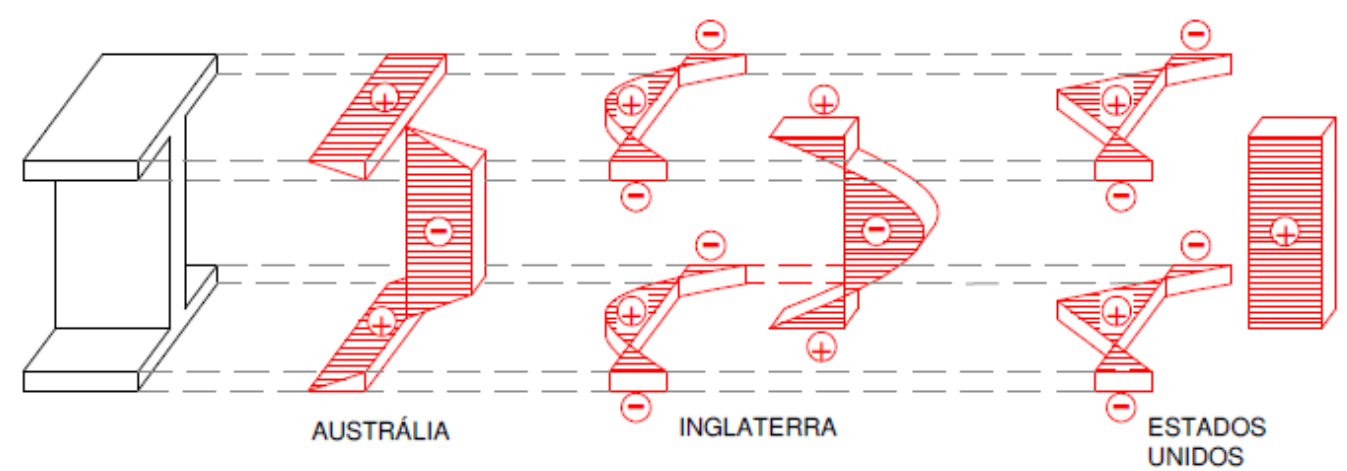

Figura 4.8 - Distribuição de tensões residuais em perfis laminados (GOMES, 2006).

O modelo de distribuição inglês foi desenvolvido por Young (1972 apud SZALAI e PAPP, 2005) e tem as características apresentadas na Figura 4.9.

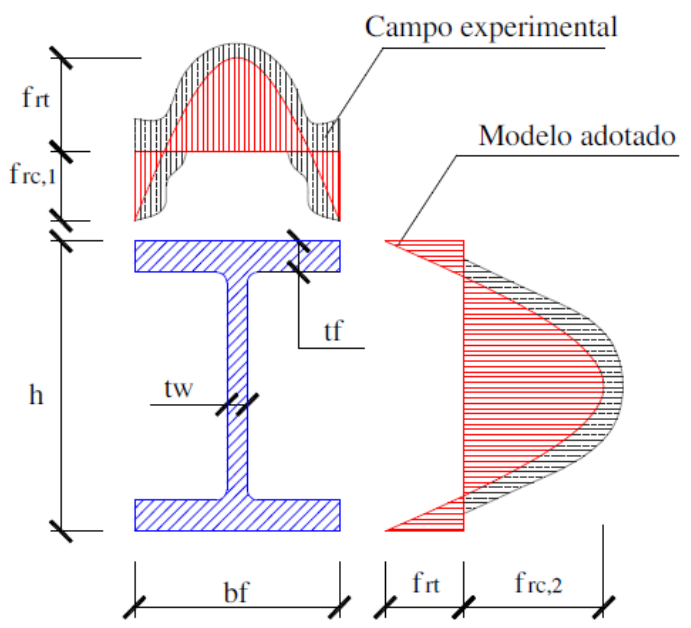

Figura 4.9 - Modelo de distribuição de tensões residuais de Young (GOMES, 2006). 
Os valores máximos das tensões residuais atuantes na direção longitudinal do perfil são dados por (SZALAI e PAPP, 2006; GOMES, 2006):

$$
\begin{aligned}
& f_{r c, 1}=165\left(1-\frac{\chi}{2,4 \beta}\right)(\mathrm{MPa}) \\
& f_{r c, 2}=100\left(1,5+\frac{\chi}{2,4 \beta}\right)(\mathrm{MPa}) \\
& f_{r t}=100\left(0,7+\frac{\chi}{2 \beta}\right)(\mathrm{MPa})
\end{aligned}
$$

onde:

$$
\begin{aligned}
& \chi=\frac{t_{w}}{t_{f}} \\
& \beta=\frac{b_{f}}{h-t_{f}}
\end{aligned}
$$

Apesar de ser possível a obtenção das curvas de distribuição das tensões residuais, como mostrado nas equações (4-1) a (4-3) a utilização de uma distribuição simplificada pode ser justificada por alguns fatores:

- para a geometria da maioria das vigas estudadas neste trabalho, têm-se a alma submetida predominantemente a tensões residuais de compressão e a mesa a tensões residuais de tração, conforme o modelo de Young (1972 apud SZALAI e PAPP, 2005);

- após o corte e a soldagem para fabricação dos perfis alveolares, a distribuição das tensões residuais ao longo da alma será alterada; deste modo, não se justifica a utilização de qualquer distribuição precisa com formulação para vigas não casteladas;

- foram realizadas análises de vigas reais utilizando-se a distribuição simplificada, descrita a seguir, e obtiveram-se bons resultados.

No modelo de elementos finitos desenvolvido neste trabalho admite-se uma distribuição simplificada de tensões residuais, adotando-se uma tensão uniforme de compressão para a alma e uma tensão uniforme de tração para as mesas, de modo que a força resultante na alma e nas mesas seja equivalente à força resultante da distribuição parabólica de 
Young (1972 apud SZALAI e PAPP, 2005). Na Figura 4.10 é apresentada a distribuição simplificada de tensões residuais.

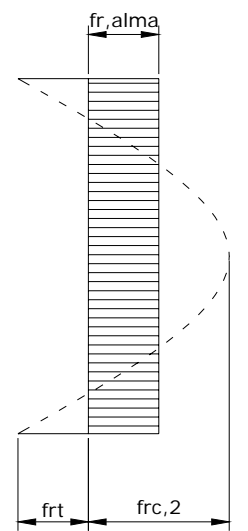

(a)
- - - Distribuiçao de Young

एाण Distribuiçao utilizada

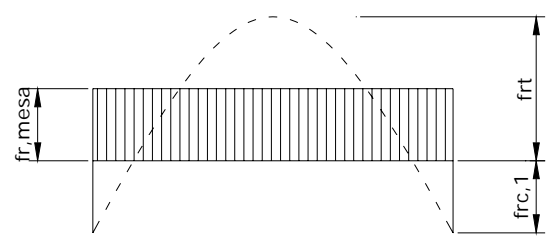

(b)

Figura 4.10 - Modelo simplificado de distribuição de tensões residuais adotado: (a) alma e (b) mesas.

As tensões uniformes utilizadas para a alma e para as mesas, propostas a partir dos valores máximos da distribuição de Young (1972 apud SZALAI e PAPP, 2005), podem ser calculadas pelas equações (4-4) e (4-5), respectivamente.

$$
\begin{aligned}
& f_{r, a l m a}=\frac{100}{9} \frac{\chi}{\beta}+\frac{230}{3}(\mathrm{MPa}) ;(\text { compressão) } \\
& f_{r, \text { mesa }}=\frac{225}{4} \frac{\chi}{\beta}+\frac{25}{3}(\mathrm{MPa}) ;(\text { tração })
\end{aligned}
$$

\subsection{Validação do modelo numérico}

Para a validação do modelo numérico a ser utilizado, foram analisadas algumas vigas casteladas cujas características geométricas e de ensaio estão relatadas na literatura. $\mathrm{Na}$ Tabela 4.2 apresenta-se a relação das vigas utilizadas para a validação do modelo numérico. 
Tabela 4.2 - Modelos experimentais utilizados para validação da modelagem numérica.

\begin{tabular}{ccc}
\hline Autor & Nome da viga ensaiada & Identificação neste trabalho \\
\hline \multirow{2}{*}{ Redwood e Demirdjian (1998) } & $10-5$ & RD10-5 \\
& $10-6$ & RD10-6 \\
Zaarour e Redwood (1996) & $10-7$ & RD10-7 \\
\hline \multirow{2}{*}{ Toprac e Cooke (1959) } & $10-2$ & ZR10-2 \\
& $12-2$ & ZR12-2 \\
\hline \multirow{2}{*}{ Bazile e Texier (1968) } & G & TC-G \\
& H & TC-H \\
& I & TC-I \\
\hline & B & BT-A \\
& C & BT-B \\
& B & BT-C \\
& E & BT-D \\
\end{tabular}

\subsubsection{Viga RD10-5}

A viga 10-5, ensaiada por Redwood e Demirdjian (1998), tem as seguintes características:

- $\quad$ altura do perfil original - 247,4 mm;

- razão de expansão - 1,54 ;

- distância entre os planos médios das mesas - 375,91 mm;

- viga biapoiada;

- carga aplicada no centro do vão;

- enrijecedores localizados no ponto de aplicação da carga e nos apoios, com largura de $25 \mathrm{~mm}$ e espessura de $9,53 \mathrm{~mm}$;

- travamento lateral na seção de aplicação da carga (apenas mesa superior) e nos apoios;

- deslocamento longitudinal impedido (na modelagem foi utilizada uma restrição longitudinal no apoio esquerdo - ver Figura 4.12);

- aço da mesa $\operatorname{com} f_{y}=345,6 \mathrm{MPa}$;

- $\quad$ aço da alma com fy = 352,9 MPa;

- demais informações presentes na Figura 4.11 e na Figura 4.12. 


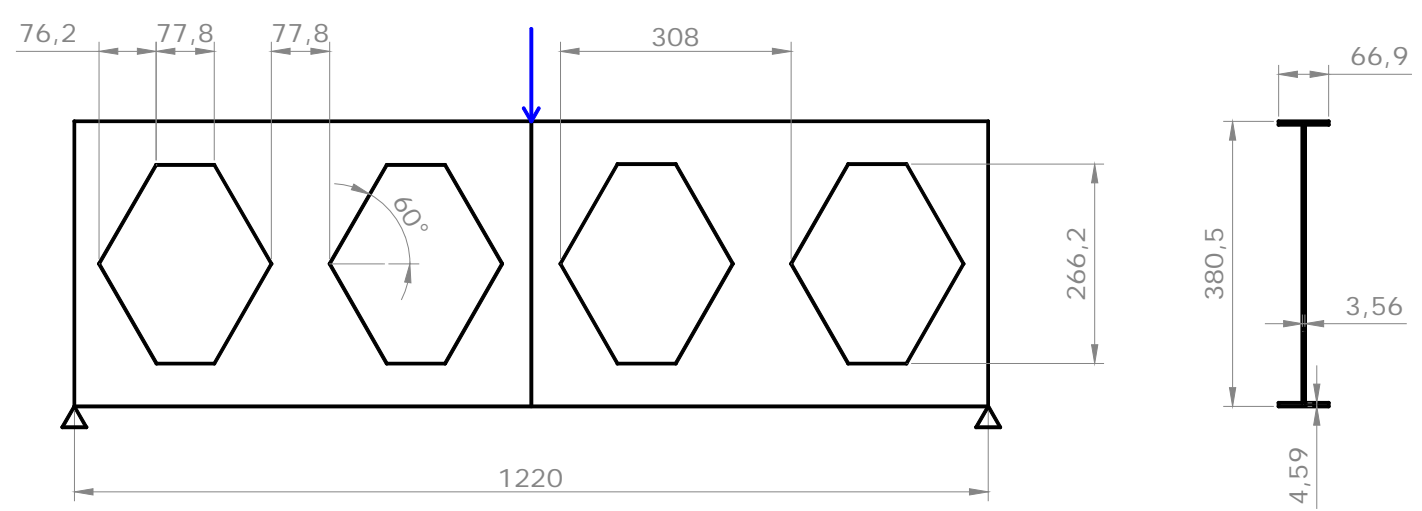

Figura 4.11 - Geometria da Viga RD10-5 (dimensões em mm).

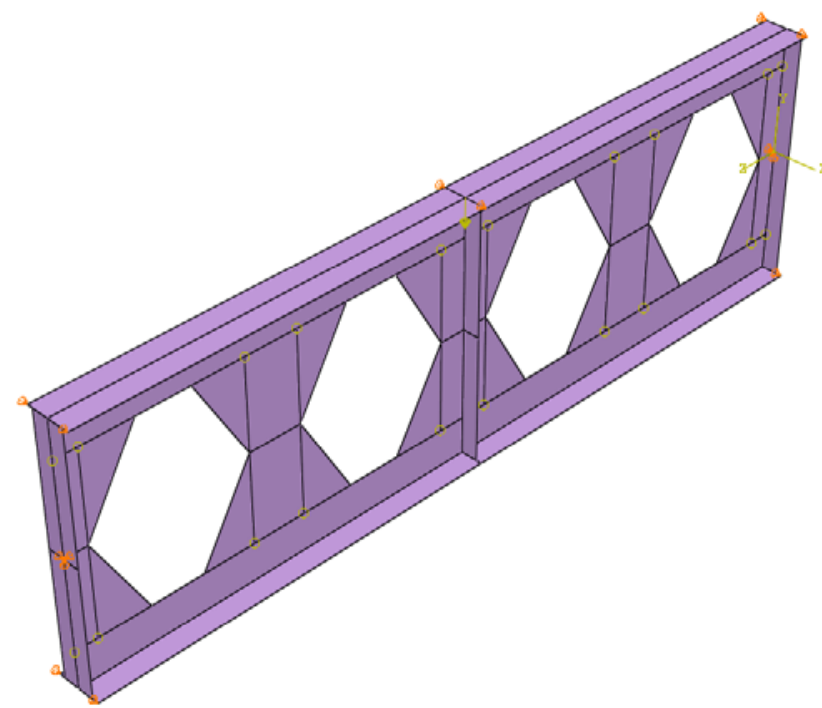

Figura 4.12 - Viga RD10-5 modelada no ABAQUS, com indicação do carregamento e das condições de contorno.

Redwood e Demirdjian ensaiaram dois modelos idênticos com as características da viga RD10-5. A carga máxima nesses ensaios foram respectivamente $92,7 \mathrm{kN}$ e $100,9 \mathrm{kN}$. Na Tabela 4.3, apresenta-se as características e resultados da modelagem numérica realizada em comparação com o resultado experimental.

Tabela 4.3 - Características e resultados da modelagem numérica da viga RD10-5.

\begin{tabular}{lll}
\hline & Dimensão da malha & $10 \mathrm{~mm}$ \\
& Número de elementos & 7764 \\
Características da modelagem & Número de nós & 6625 \\
& Imperfeição inicial & $0,19 \mathrm{~mm}$ \\
& Tensão residual na alma (compressão) & $107,94 \mathrm{MPa}$ \\
& Tensão residual na mesa (tração) & $150,01 \mathrm{MPa}$ \\
\hline \multirow{3}{*}{ Resultados } & Carga máxima experimental (valor médio) $-P_{\text {exp }}$ & $96,8 \mathrm{kN}$ \\
& Carga máxima da modelagem numérica $-P_{\text {num }}$ & $103 \mathrm{kN}$ \\
\hline
\end{tabular}




\subsubsection{Viga RD10-6}

A viga 10-6, ensaiada por Redwood e Demirdjian (1998) tem as mesmas características gerais da viga RD10-5 (item 4.3.1). As demais características estão apresentadas na Figura 4.13 .

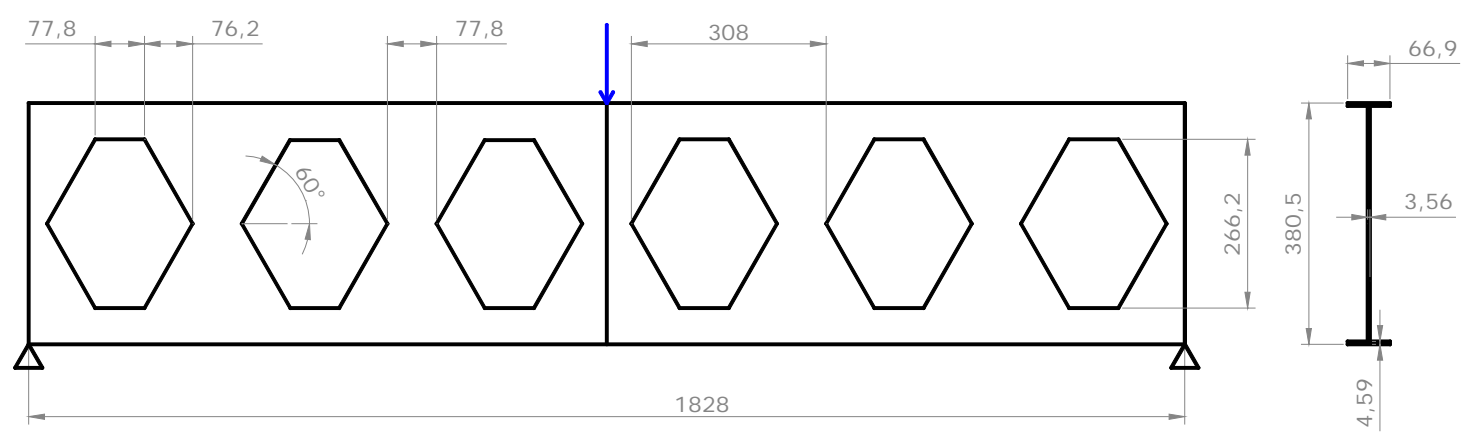

Figura 4.13 - Geometria da Viga RD10-6 (dimensões em mm).

$\mathrm{Na}$ Tabela 4.4, apresenta-se as características e resultados da modelagem numérica realizada em comparação com o resultado experimental.

Tabela 4.4 - Características e resultados da modelagem numérica da viga RD10-6.

\begin{tabular}{lll}
\hline & Dimensão da malha & $10 \mathrm{~mm}$ \\
& Número de elementos & 10630 \\
Características da modelagem & Número de nós & 8891 \\
& Imperfeição inicial & $0,19 \mathrm{~mm}$ \\
& Tensão residual na alma (compressão) & $107,94 \mathrm{MPa}$ \\
& Tensão residual na mesa (tração) & $150,01 \mathrm{MPa}$ \\
\hline \multirow{3}{*}{ Resultados } & Carga máxima experimental (valor médio) $-P_{\text {exp }}$ & $94,8 \mathrm{kN}$ \\
& Carga máxima da modelagem numérica $-P_{\text {num }}$ & $89,7 \mathrm{kN}$ \\
& Erro $\left(P_{\text {num }} / P_{\exp }-1\right)$ & $-5,4 \%$ \\
\hline
\end{tabular}

\subsubsection{Viga RD10-7}

A viga 10-7, ensaiada por Redwood e Demirdjian (1998), tem as mesmas características gerais da viga RD10-5 (item 4.3.1). As demais características estão apresentadas na Figura 4.14 . 


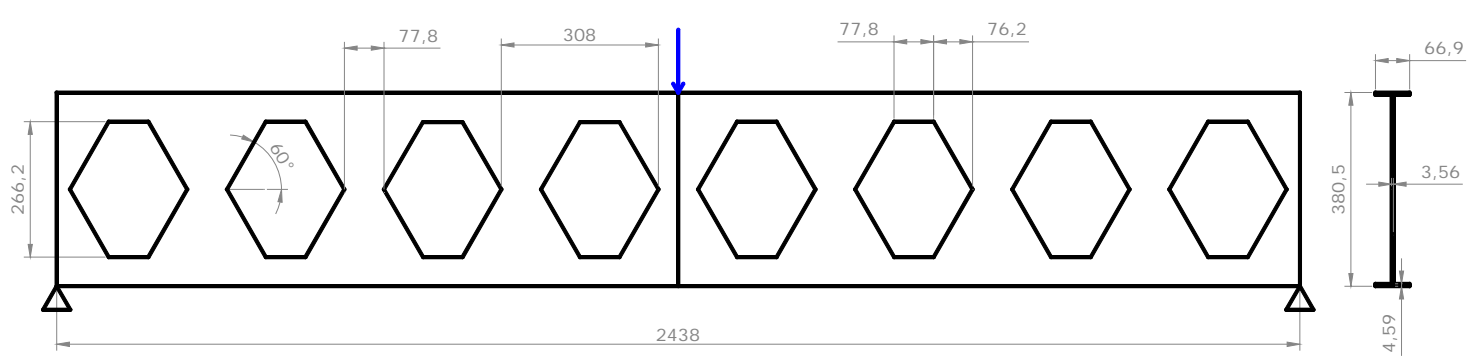

Figura 4.14 - Geometria da Viga RD10-7 (dimensões em mm).

$\mathrm{Na}$ Tabela 4.5, apresenta-se as características e resultados da modelagem numérica realizada em comparação com o resultado experimental.

Tabela 4.5 - Características e resultados da modelagem numérica da viga RD10-7.

\begin{tabular}{lll}
\hline & Dimensão da malha & $10 \mathrm{~mm}$ \\
& Número de elementos & 15600 \\
Características da modelagem & Número de nós & 13235 \\
& Imperfeição inicial & $0,19 \mathrm{~mm}$ \\
& Tensão residual na alma (compressão) & $107,94 \mathrm{MPa}$ \\
& Tensão residual na mesa (tração) & $150,01 \mathrm{MPa}$ \\
\hline \multirow{3}{*}{ Resultados } & Carga máxima experimental (valor médio) $-P_{\text {exp }}$ & $84,4 \mathrm{kN}$ \\
& Carga máxima da modelagem numérica $-P_{\text {num }}$ & $85,3 \mathrm{kN}$ \\
& Erro $\left(P_{\text {num }} / P_{\exp }-1\right)$ & $1,0 \%$ \\
\hline
\end{tabular}

\subsubsection{Viga ZR10-2}

A viga 10-2 ensaiada por Zaarour e Redwood (1996), tem as seguintes características:

- altura do perfil original - 219,5 mm;

- $\quad$ razão de expansão - 1,67;

- chapa expansora - 50,8 mm;

- distância entre os planos médios das mesas - 413,84 mm;

- viga biapoiada;

- carga aplicada no centro do vão;

- enrijecedores localizados no ponto de aplicação da carga e nos apoios, com largura de $25,4 \mathrm{~mm}$ e espessura de $6,35 \mathrm{~mm}$;

- travamento lateral na seção de aplicação da carga, nas seções distantes de 76,2 mm dos apoios e nas seções a 635 mm do centro do vão (ver Figura 4.15);

- deslocamento longitudinal impedido;

- aço da mesa $\operatorname{com} f_{y}=342,0 \mathrm{MPa}$;

- aço da alma $\operatorname{com} f_{y}=357,2 \mathrm{MPa}$; 
- demais informações presentes na Figura 4.15 e na Figura 4.16.

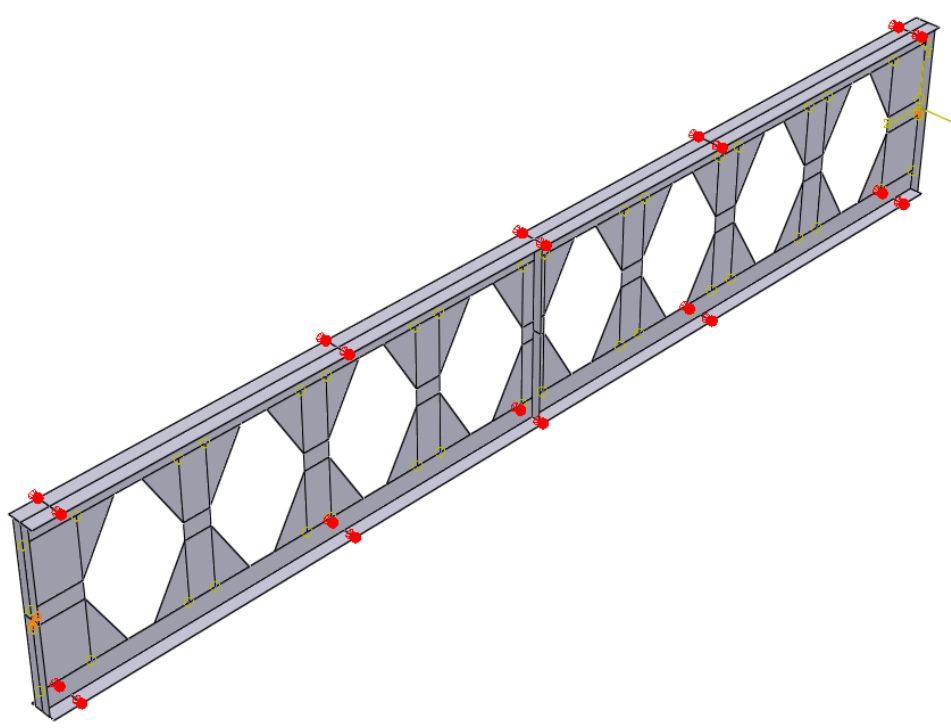

Figura 4.15 - Viga ZR10-2, apresentando os travamentos laterais (pontos em vermelho).

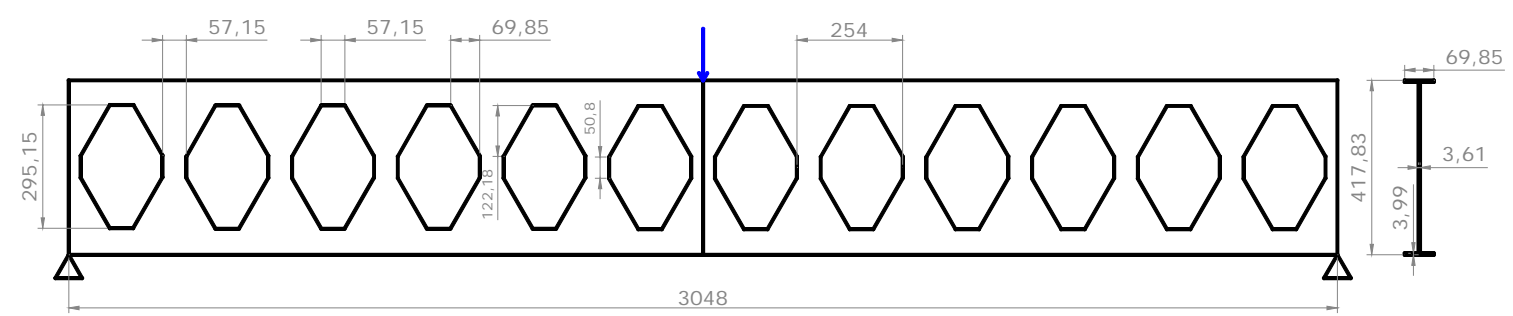

Figura 4.16 - Geometria da viga ZR10-2 (dimensões em mm).

$\mathrm{Na}$ Tabela 4.6, apresenta-se as características e resultados da modelagem numérica realizada em comparação com o resultado experimental.

Tabela 4.6 - Características e resultados da modelagem numérica da viga ZR10-2.

\begin{tabular}{lll}
\hline & Dimensão da malha & $10 \mathrm{~mm}$ \\
& Número de elementos & 19112 \\
Características da modelagem & Número de nós & 16147 \\
& Imperfeição inicial & $0,21 \mathrm{~mm}$ \\
& Tensão residual na alma (compressão) & $107,68 \mathrm{MPa}$ \\
& Tensão residual na mesa (tração) & $148,66 \mathrm{MPa}$ \\
\hline \multirow{3}{*}{ Resultados } & Carga máxima experimental (valor médio) $-P_{\text {exp }}$ & $58,7 \mathrm{kN}$ \\
& Carga máxima da modelagem numérica $-P_{\text {num }}$ & $66,1 \mathrm{kN}$ \\
& Erro $\left(P_{\text {num }} / P_{\exp }-1\right)$ & $-12,6 \%$ \\
\hline
\end{tabular}




\subsubsection{Viga ZR12-2}

A viga 12-2, ensaiada por Zaarour e Redwood (1996), tem as seguintes características:

- altura do perfil original - 275,08 mm;

- razão de expansão - 1,73 ;

- chapa expansora - 50,8 mm;

- distância entre os planos médios das mesas - 522,45 mm;

- viga biapoiada com carga aplicada no centro do vão;

- enrijecedores localizados no ponto de aplicação da carga e nos apoios, com largura de $25,4 \mathrm{~mm}$ e espessura de $6,35 \mathrm{~mm}$;

- travamento lateral na seção de aplicação da carga, nas seções distantes de 76,2 $\mathrm{mm}$ dos apoios e nas seções a $635 \mathrm{~mm}$ do centro do vão;

- deslocamento longitudinal impedido;

- aço da mesa $\operatorname{com} f_{y}=307,5 \mathrm{MPa}$;

- aço da alma $\operatorname{com} f_{y}=311,7 \mathrm{MPa}$;

- demais informações, na Figura 4.17.

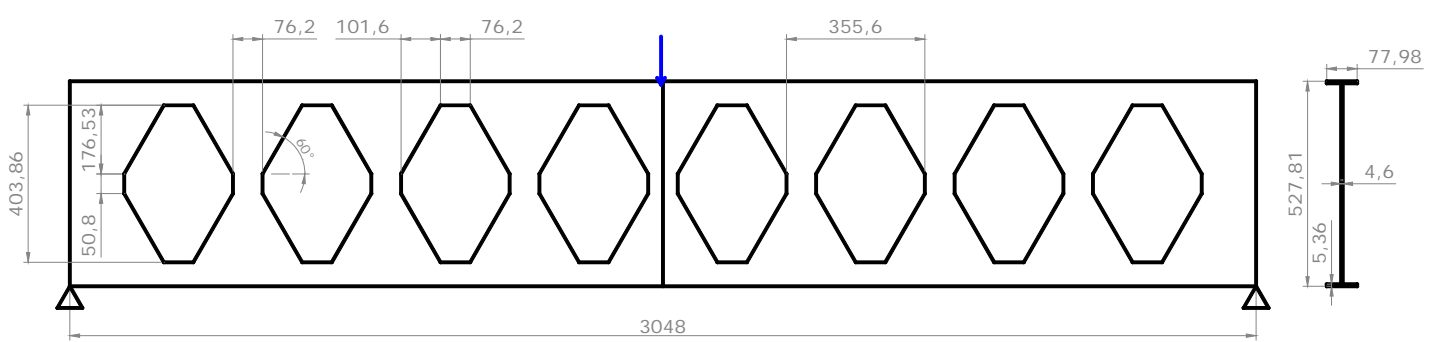

Figura 4.17 - Geometria da viga ZR12-2 (dimensões em mm).

$\mathrm{Na}$ Tabela 4.7, apresenta-se as características e resultados da modelagem numérica realizada em comparação com o resultado experimental.

Tabela 4.7 - Características e resultados da modelagem numérica da viga ZR12-2.

\begin{tabular}{lll}
\hline & Dimensão da malha & $10 \mathrm{~mm}$ \\
& Número de elementos & 23572 \\
Características da modelagem & Número de nós & 19103 \\
& Imperfeição inicial & $0,26 \mathrm{~mm}$ \\
& Tensão residual na alma (compressão) & $109,65 \mathrm{MPa}$ \\
& Tensão residual na mesa (tração) & $158,64 \mathrm{MPa}$ \\
\hline \multirow{3}{*}{ Resultados } & Carga máxima experimental (valor médio) $-P_{\text {exp }}$ & $98,3 \mathrm{kN}$ \\
& Carga máxima da modelagem numérica $-P_{\text {num }}$ & $105,0 \mathrm{kN}$ \\
\hline
\end{tabular}




\subsubsection{Viga TC-G}

A viga G, ensaiada por Toprac e Cooke (1959), tem as seguintes características:

- altura do perfil original - 198,12 mm;

- razão de expansão - 1,67;

- distância entre os planos médios das mesas - 325,02 mm;

- $\quad$ viga biapoiada, vão de $4235 \mathrm{~mm}$;

- quatro cargas concentradas aplicadas simetricamente e distantes de $419 \mathrm{~mm}$ e $1257 \mathrm{~mm}$ do centro do vão (Figura 4.18);

- enrijecedores localizados nos pontos de aplicação das cargas e nos apoios, com espessura de 4,70 mm e largura das mesas;

- travamento lateral em seis seções, simétricas em relação ao centro do vão e distantes de 609,6 mm, 1219,2 $\mathrm{mm}$ e 1828,8 mm do meio da viga (Figura 4.18);

- deslocamento longitudinal impedido;

- $\quad$ aço $\operatorname{com} f_{y}=296,4 \mathrm{MPa}$;

- demais informações, na Figura 4.18.
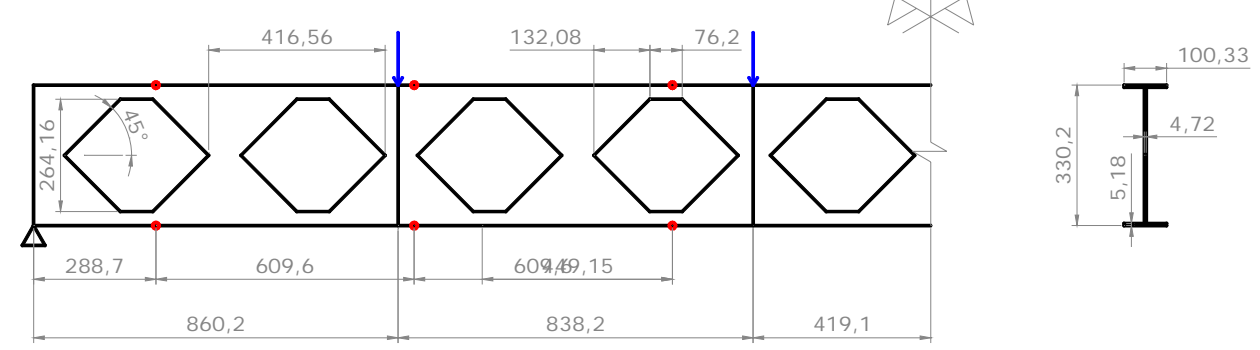

Figura 4.18 - Geometria da viga TC-G (metade esquerda da viga; dimensões em $\mathrm{mm}$ ), com detalhe dos travamentos laterais (pontos em vermelho).

$\mathrm{Na}$ Tabela 4.8, apresenta-se as características e resultados da modelagem numérica realizada em comparação com o resultado experimental.

Tabela 4.8 - Características e resultados da modelagem numérica da viga TC-G.

\begin{tabular}{lll}
\hline & Dimensão da malha & $10 \mathrm{~mm}$ \\
& Número de elementos & 28072 \\
Características da modelagem & Número de nós & 22551 \\
& Imperfeição inicial & $0,17 \mathrm{~mm}$ \\
& Tensão residual na alma (compressão) & $96,14 \mathrm{MPa}$ \\
& Tensão residual na mesa (tração) & $90,23 \mathrm{MPa}$ \\
\hline \multirow{3}{*}{ Resultados } & Carga máxima experimental (valor médio) $-P_{\text {exp }}$ & $90,6 \mathrm{kN}(4 \times 22,65 \mathrm{kN})$ \\
& Carga máxima da modelagem numérica $-P_{\text {num }}$ & $85,9 \mathrm{kN}$ \\
& Erro $\left(P_{\text {num }} / P_{\exp }-1\right)$ & $-5,2 \%$ \\
\hline
\end{tabular}




\subsubsection{Viga TC-H}

A viga H, ensaiada por Toprac e Cooke (1959), tem as seguintes características:

- altura do perfil original - 197,95 mm;

- razão de expansão - 1,50;

- distância entre os planos médios das mesas - 290,75 mm;

- $\quad$ viga biapoiada com vão de $4102 \mathrm{~mm}$;

- quatro cargas concentradas aplicadas simetricamente e distantes de $410 \mathrm{~mm}$ e $1229 \mathrm{~mm}$ do centro do vão;

- enrijecedores localizados nos pontos de aplicação das cargas e nos apoios, com espessura de 4,42 mm e largura das mesas;

- travamento lateral em quatro seções, simétricas em relação ao centro do vão e distantes de 609,6 mm e 1828,8 $\mathrm{mm}$ do meio da viga;

- deslocamento longitudinal impedido;

- $\quad$ aço $\operatorname{com} f_{y}=296,4 \mathrm{MPa}$;

- demais informações, na Figura 4.19.

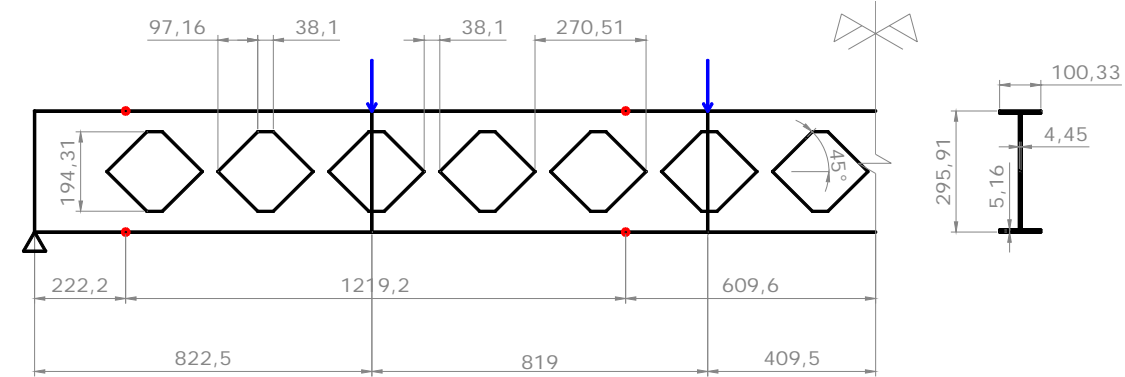

Figura 4.19 - Geometria da viga TC-H (metade esquerda da viga; dimensões em mm), com detalhe dos travamentos laterais (pontos em vermelho).

$\mathrm{Na}$ Tabela 4.9, apresenta-se as características e resultados da modelagem numérica realizada em comparação com o resultado experimental.

Tabela 4.9 - Características e resultados da modelagem numérica da viga TC-H.

\begin{tabular}{lll}
\hline & Dimensão da malha & $10 \mathrm{~mm}$ \\
& Número de elementos & 26312 \\
Características da modelagem & Número de nós & 22135 \\
& Imperfeição inicial & $0,15 \mathrm{~mm}$ \\
& Tensão residual na alma (compressão) & $95,16 \mathrm{MPa}$ \\
& Tensão residual na mesa (tração) & $85,27 \mathrm{MPa}$ \\
\hline \multirow{3}{*}{ Resultados } & Carga máxima experimental (valor médio) $-P_{\text {exp }}$ & $98,1 \mathrm{kN}(4 \times 24,53 \mathrm{kN})$ \\
& Carga máxima da modelagem numérica $-P_{\text {num }}$ & $96,8 \mathrm{kN}$ \\
& Erro $\left(P_{\text {num }} / P_{\exp }-1\right)$ & $-1,3 \%$ \\
\hline
\end{tabular}




\subsubsection{Viga TC-I}

A viga I, ensaiada por Toprac e Cooke (1959), tem as seguintes características:

- altura do perfil original - 199,52 mm;

- razão de expansão - 1,78 ;

- distância entre os planos médios das mesas - 349,20 mm;

- viga biapoiada, vão de $4277 \mathrm{~mm}$;

- quatro cargas concentradas aplicadas simetricamente e distantes de $583 \mathrm{~mm}$ e 1357 mm do centro do vão;

- enrijecedores localizados nos pontos de aplicação das cargas e nos apoios, com espessura de 4,75 mm e largura das mesas;

- travamento lateral em seis seções, simétricas em relação ao centro do vão e distantes de $609,6 \mathrm{~mm}, 1219,2 \mathrm{~mm}$ e 1828,8 $\mathrm{mm}$ do meio da viga;

- deslocamento longitudinal impedido;

- $\quad$ aço $\operatorname{com} f_{y}=296,4 \mathrm{MPa}$;

- demais informações, na Figura 4.20.

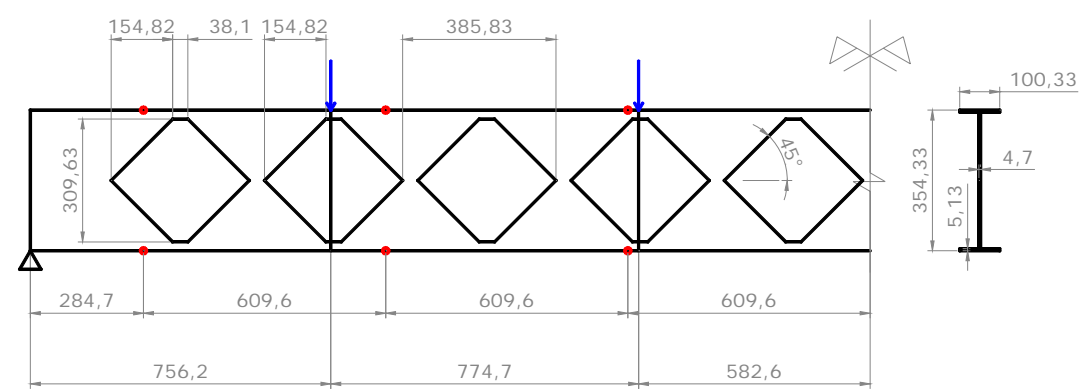

Figura 4.20 - Geometria da viga TC-I (metade esquerda da viga; dimensões em mm), com detalhe dos travamentos laterais (pontos em vermelho).

$\mathrm{Na}$ Tabela 4.10, apresenta-se as características e resultados da modelagem numérica realizada em comparação com o resultado experimental.

Tabela 4.10 - Características e resultados da modelagem numérica da viga TC-I.

\begin{tabular}{lll}
\hline & Dimensão da malha & $10 \mathrm{~mm}$ \\
& Número de elementos & 31492 \\
Características da modelagem & Número de nós & 24147 \\
& Imperfeição inicial & $0,18 \mathrm{~mm}$ \\
& Tensão residual na alma (compressão) & $96,39 \mathrm{MPa}$ \\
& Tensão residual na mesa (tração) & $91,52 \mathrm{MPa}$ \\
\hline \multirow{3}{*}{ Resultados } & Carga máxima experimental (valor médio) $-P_{\text {exp }}$ & $84,7 \mathrm{kN}(4 \times 21,18 \mathrm{kN})$ \\
& Carga máxima da modelagem numérica $-P_{\text {num }}$ & $90,4 \mathrm{kN}$ \\
& Erro $\left(P_{\text {num }} / P_{\exp }-1\right)$ & $7,0 \%$ \\
\hline
\end{tabular}




\subsubsection{Viga BT-A}

A viga A, ensaiada por Bazile e Texier (1968), tem as seguintes características:

- altura do perfil original $-350 \mathrm{~mm}$;

- razão de expansão - 1,43 ;

- distância entre os planos médios das mesas - 482,5 mm;

- viga biapoiada com vão de $8064 \mathrm{~mm}$;

- oito cargas concentradas aplicadas, sendo as das extremidades distantes de $504 \mathrm{~mm}$ dos apoios e as demais, distantes de $1008 \mathrm{~mm}$ entre si;

- enrijecedores nos apoios;

- travamento lateral contínuo ao longo do vão;

- deslocamento longitudinal livre;

- aço da mesa $\operatorname{com} f_{y}=299 \mathrm{MPa}$;

- aço da alma $\operatorname{com} f_{y}=370 \mathrm{MPa}$;

- demais informações, na Figura 4.21.
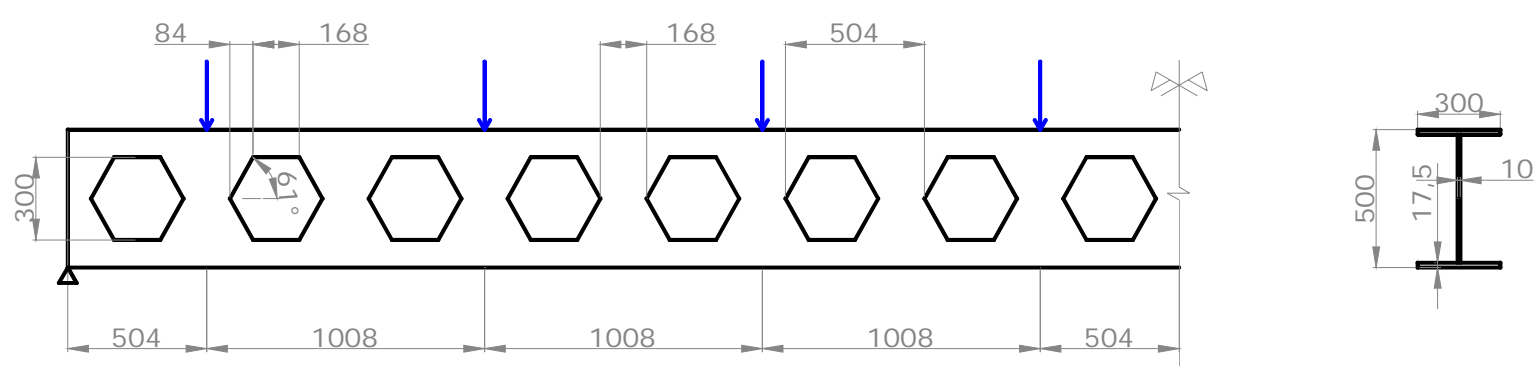

Figura 4.21 - Geometria da viga BT-A (metade esquerda da viga; dimensões em mm).

Na Tabela 4.11, apresenta as características e resultados da modelagem numérica realizada em comparação com o resultado experimental.

Tabela 4.11 - Características e resultados da modelagem numérica da viga BT-A.

\begin{tabular}{lll}
\hline & Dimensão da malha & $10 \mathrm{~mm}$ \\
& Número de elementos & 87820 \\
Características da modelagem & Número de nós & 82346 \\
& Imperfeição inicial & $0,25 \mathrm{~mm}$ \\
& Tensão residual na alma (compressão) & $83,70 \mathrm{MPa}$ \\
& Tensão residual na mesa (tração) & $27,29 \mathrm{MPa}$ \\
\hline \multirow{3}{*}{ Resultados } & Carga máxima experimental (valor médio) $-P_{\text {exp }}$ & $805 \mathrm{kN}(8 \times 100,6 \mathrm{kN})$ \\
& Carga máxima da modelagem numérica $-P_{\text {num }}$ & $904 \mathrm{kN}$ \\
& Erro $\left(P_{\text {num }} / P_{\exp }-1\right)$ & $12,3 \%$ \\
\hline
\end{tabular}




\subsubsection{Viga BT-B}

A viga B, ensaiada por Bazile e Texier (1968), tem as seguintes características:

- altura do perfil original $-415 \mathrm{~mm}$;

- $\quad$ razão de expansão - 1,45;

- distância entre os planos médios das mesas - 582,5 mm;

- viga biapoiada com vão de $8064 \mathrm{~mm}$;

- oito cargas concentradas aplicadas, sendo as das extremidades distantes de $504 \mathrm{~mm}$ dos apoios e as demais, distantes de $1008 \mathrm{~mm}$ entre si;

- enrijecedores nos apoios;

- travamento lateral contínuo ao longo do vão;

- deslocamento longitudinal livre;

- aço da mesa $\operatorname{com} f_{y}=245 \mathrm{MPa}$;

- aço da alma com $f_{y}=302 \mathrm{MPa}$;

- demais informações, na Figura 4.22.
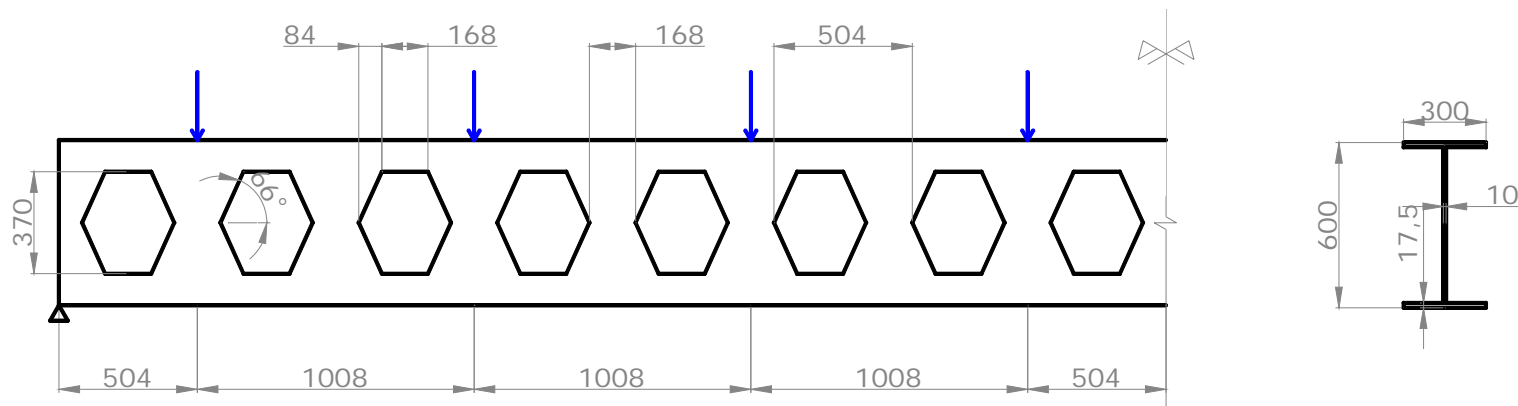

Figura 4.22 - Geometria da viga BT-B (metade esquerda da viga; dimensões em mm).

$\mathrm{Na}$ Tabela 4.12, apresenta-se as características e resultados da modelagem numérica realizada em comparação com o resultado experimental.

Tabela 4.12 - Características e resultados da modelagem numérica da viga BT-B.

\begin{tabular}{lll}
\hline & Dimensão da malha & $10 \mathrm{~mm}$ \\
& Número de elementos & 91837 \\
Características da modelagem & Número de nós & 87608 \\
& Imperfeição inicial & $0,30 \mathrm{~mm}$ \\
& Tensão residual na alma (compressão) & $82,33 \mathrm{MPa}$ \\
& Tensão residual na mesa (tração) & $20,33 \mathrm{MPa}$ \\
\hline \multirow{3}{*}{ Resultados } & Carga máxima experimental (valor médio) $-P_{\text {exp }}$ & $685 \mathrm{kN}(8 \times 85,6 \mathrm{kN})$ \\
& Carga máxima da modelagem numérica $-P_{\text {num }}$ & $689,6 \mathrm{kN}$ \\
& Erro $\left(P_{\text {num }} / P_{\exp }-1\right)$ & $0,7 \%$ \\
\hline
\end{tabular}




\subsubsection{Viga BT-C}

A viga C, ensaiada por Bazile e Texier (1968), tem as seguintes características:

- altura do perfil original $-450 \mathrm{~mm}$;

- razão de expansão - 1,56 ;

- chapa expansora-200 mm;

- distância entre os planos médios das mesas - 682,5 mm;

- $\quad$ viga biapoiada com vão de 8064 mm;

- oito cargas concentradas aplicadas, sendo as das extremidades distantes de $504 \mathrm{~mm}$ dos apoios e as demais, distantes de $1008 \mathrm{~mm}$ entre si;

- enrijecedores nos apoios;

- travamento lateral contínuo ao longo do vão;

- deslocamento longitudinal livre;

- aço da mesa $\operatorname{com} f_{y}=256 \mathrm{MPa}$;

- aço da alma com $f_{y}=315 \mathrm{MPa}$;

- demais informações, na Figura 4.23.

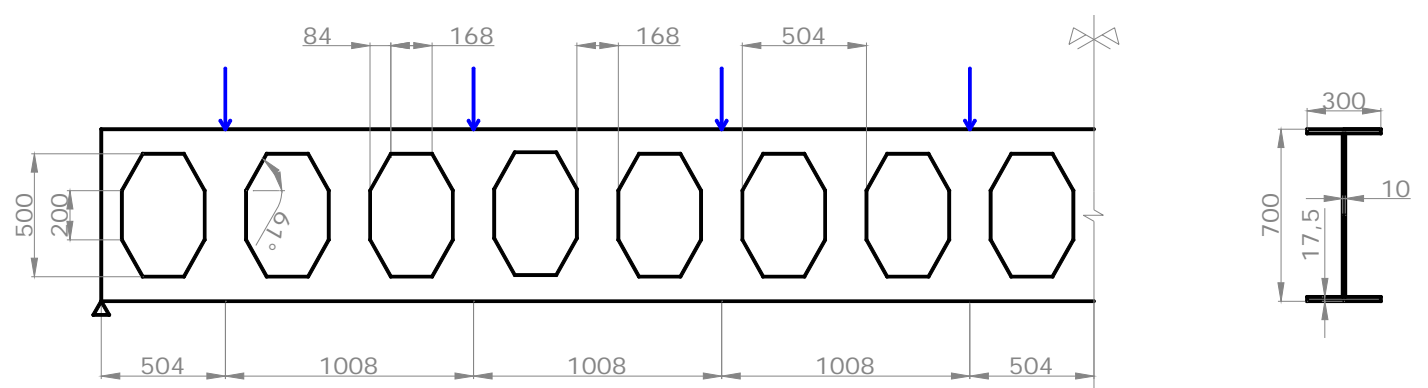

Figura 4.23 - Geometria da viga BT-C (metade esquerda da viga; dimensões em mm).

$\mathrm{Na}$ Tabela 4.13, apresenta-se as características e resultados da modelagem numérica realizada em comparação com o resultado experimental.

Tabela 4.13 - Características e resultados da modelagem numérica da viga BT-C.

\begin{tabular}{lll} 
& Dimensão da malha & $10 \mathrm{~mm}$ \\
& Número de elementos & 94394 \\
Características da modelagem & Número de nós & 89284 \\
& Imperfeição inicial & $0,35 \mathrm{~mm}$ \\
& Tensão residual na alma (compressão) & $81,59 \mathrm{MPa}$ \\
& Tensão residual na mesa (tração) & $16,58 \mathrm{MPa}$ \\
\hline \multirow{3}{*}{ Resultados } & Carga máxima experimental (valor médio) $-P_{\text {exp }}$ & $600 \mathrm{kN}(8 \times 75,0 \mathrm{kN})$ \\
& Carga máxima da modelagem numérica $-P_{\text {num }}$ & $620,8 \mathrm{kN}$ \\
\hline
\end{tabular}




\subsubsection{Viga $B T-D$}

A viga D, ensaiada por Bazile e Texier (1968), tem as seguintes características:

- altura do perfil original - $465 \mathrm{~mm}$;

- $\quad$ razão de expansão - 1,51;

- distância entre os planos médios das mesas - 682,5 mm;

- viga biapoiada com vão de 8064 mm;

- oito cargas concentradas aplicadas, sendo as das extremidades distantes de $504 \mathrm{~mm}$ dos apoios e as demais, distantes de $1008 \mathrm{~mm}$ entre si;

- enrijecedores nos apoios;

- travamento lateral contínuo ao longo do vão;

- deslocamento longitudinal livre;

- aço da mesa $\operatorname{com} f_{y}=272 \mathrm{MPa}$;

- aço da alma com $f_{y}=315 \mathrm{MPa}$;

- demais informações, na Figura 4.24.
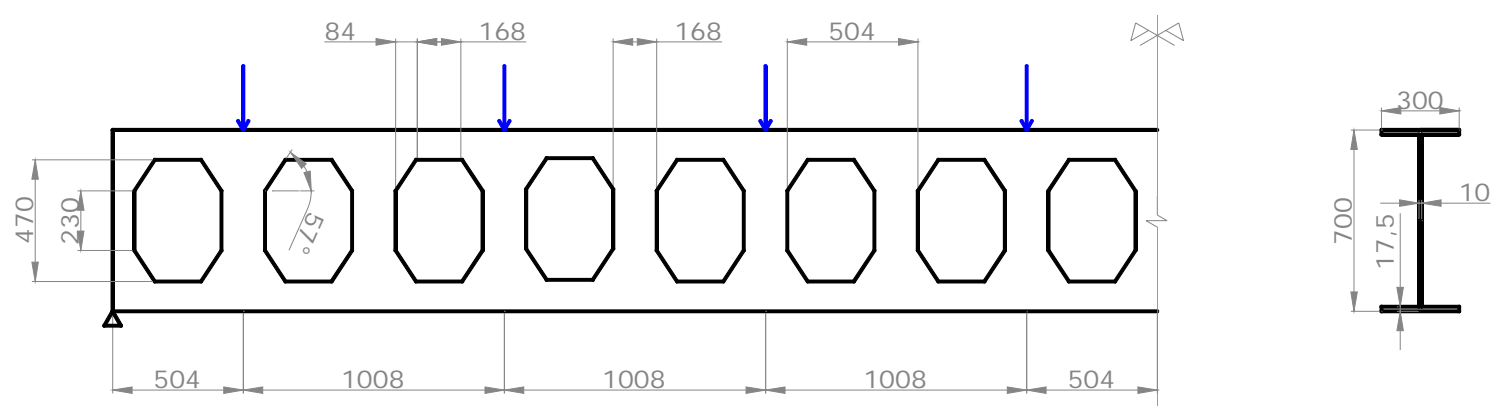

Figura 4.24 - Geometria da viga BT-D (metade esquerda da viga; dimensões em mm).

$\mathrm{Na}$ Tabela 4.14, apresenta-se as características e resultados da modelagem numérica realizada em comparação com o resultado experimental.

Tabela 4.14 - Características e resultados da modelagem numérica da viga BT-D.

\begin{tabular}{lll}
\hline & Dimensão da malha & $10 \mathrm{~mm}$ \\
& Número de elementos & 95265 \\
Características da modelagem & Número de nós & 91198 \\
& Imperfeição inicial & $0,35 \mathrm{~mm}$ \\
& Tensão residual na alma (compressão) & $81,27 \mathrm{MPa}$ \\
& Tensão residual na mesa (tração) & $14,97 \mathrm{MPa}$ \\
\hline \multirow{3}{*}{ Resultados } & Carga máxima experimental (valor médio) $-P_{\text {exp }}$ & $620 \mathrm{kN}(8 \times 77,5 \mathrm{kN})$ \\
& Carga máxima da modelagem numérica $-P_{\text {num }}$ & $601,9 \mathrm{kN}$ \\
& Erro $\left(P_{\text {num }} / P_{\exp }-1\right)$ & $-2,9 \%$ \\
\hline
\end{tabular}




\subsubsection{Viga BT-E}

A viga E, ensaiada por Bazile e Texier (1968), tem as seguintes características:

- altura do perfil original $-340 \mathrm{~mm}$;

- $\quad$ razão de expansão - 1,47;

- distância entre os planos médios das mesas - 489,8 mm;

- viga biapoiada com vão de $6624 \mathrm{~mm}$;

- oito cargas concentradas aplicadas, sendo as das extremidades distantes de $414 \mathrm{~mm}$ dos apoios e as demais, distantes de $828 \mathrm{~mm}$ entre si;

- enrijecedores nos apoios;

- travamento lateral contínuo ao longo do vão;

- deslocamento longitudinal livre;

- aço da mesa $\operatorname{com} f_{y}=249 \mathrm{MPa}$;

- aço da alma $\operatorname{com} f_{y}=336 \mathrm{MPa}$;

- demais informações, na Figura 4.25.

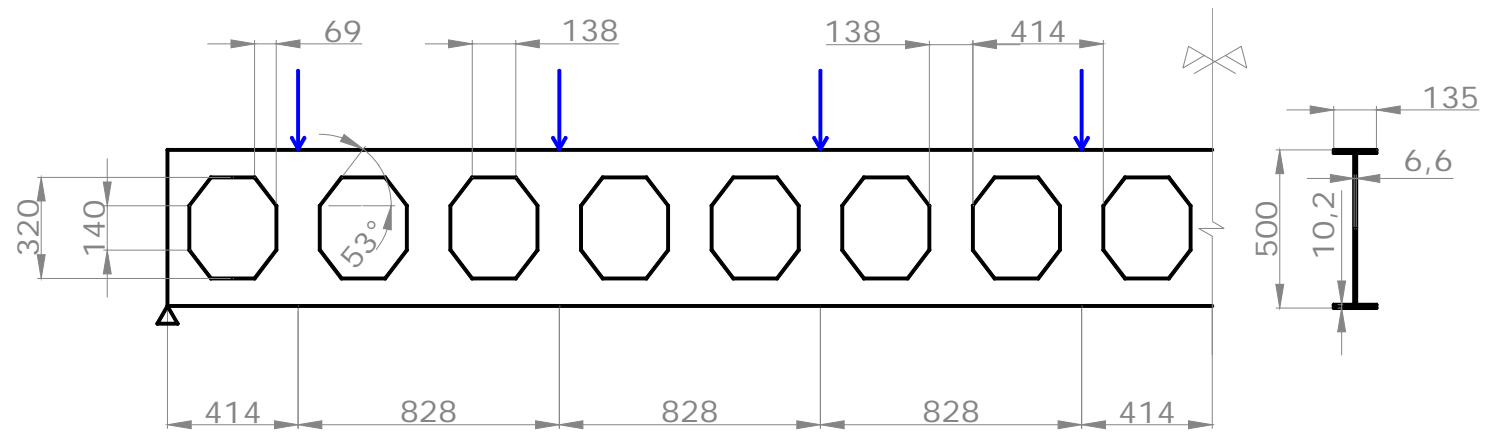

Figura 4.25 - Geometria da viga BT-E (metade esquerda da viga; dimensões em mm).

$\mathrm{Na}$ Tabela 4.15, apresenta-se as características e resultados da modelagem numérica realizada em comparação com o resultado experimental.

Tabela 4.15 - Características e resultados da modelagem numérica da viga BT-E.

\begin{tabular}{lll}
\hline & Dimensão da malha & $10 \mathrm{~mm}$ \\
& Número de elementos & 45674 \\
Características da modelagem & Número de nós & 43369 \\
& Imperfeição inicial & $0,25 \mathrm{~mm}$ \\
& Tensão residual na alma (compressão) & $86,78 \mathrm{MPa}$ \\
& Tensão residual na mesa (tração) & $42,84 \mathrm{MPa}$ \\
\hline \multirow{3}{*}{ Resultados } & Carga máxima experimental (valor médio) $-P_{\text {exp }}$ & $280,0 \mathrm{kN}(8 \times 35 \mathrm{kN})$ \\
& Carga máxima da modelagem numérica $-P_{\text {num }}$ & $287,2 \mathrm{kN}$ \\
& Erro $\left(P_{\text {num }} / P_{\text {exp }}-1\right)$ & $2,6 \%$ \\
\hline
\end{tabular}




\subsubsection{Síntese da validação do modelo numérico}

$\mathrm{Na}$ Figura 4.26 são mostrados os resultados obtidos com o modelo numérico em comparação com os resultados experimentais correspondentes.

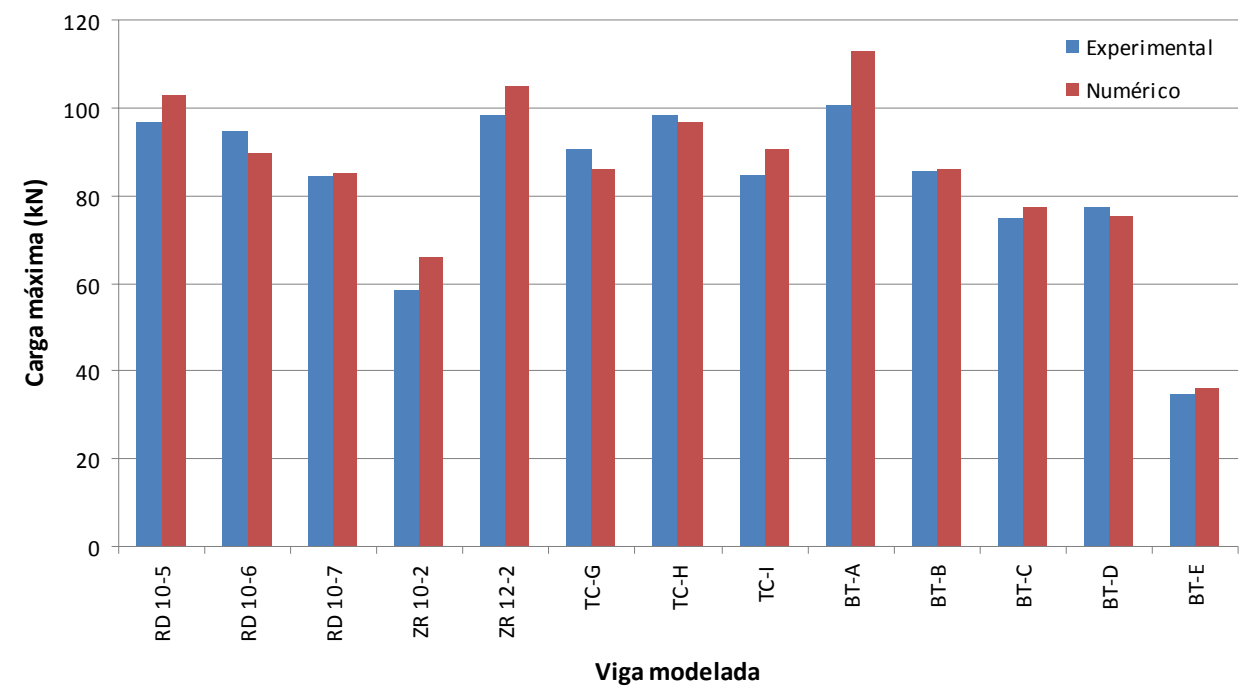

Figura 4.26 - Comparação entre resultados da modelagem numérica e resultados experimentais correspondentes.

Como se pode observar, os resultados numéricos apresentam boa correlação com os resultados experimentais.

Em todos os casos simulados numericamente, o modelo numérico apresentou o mesmo modo de colapso observado nos modelos experimentais. Na Figura 4.27(a), por exemplo, mostra-se o colapso por FMA obtido da simulação numérica para o modelo 10-5 de Redwood e Demirdjian (1998). Na Figura 4.27(b), mostra-se o colapso por mecanismo Vierendeel, resultante da simulação numérica do modelo G de Toprac e Cooke (1959). 


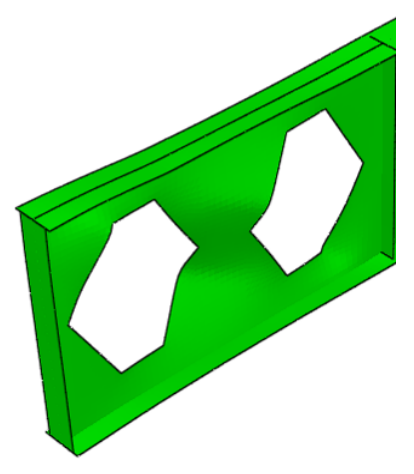

(a)

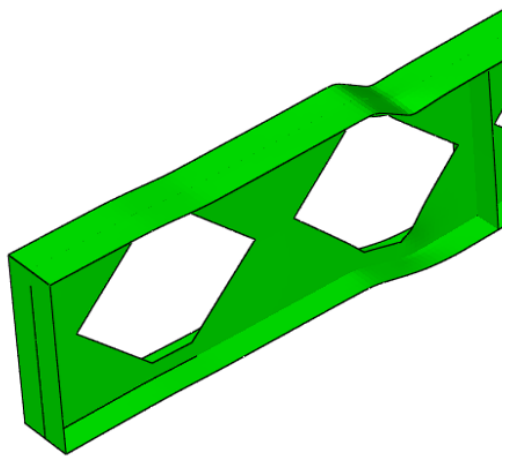

(b)

Figura 4.27 - Modos de colapso observados nas simulações numéricas: (a) FMA - modelo 10-5 de Redwood e Demirdjian (1998); (b) Vierendeel - modelo G de Toprac e Cooke (1959).

Com base nos resultados obtidos, considera-se o modelo numérico válido para as análises subsequentes, alvo deste estudo. 


\section{AVALIAÇÃO NUMÉRICA DO COMPORTAMENTO ESTRUTURAL DE VIGAS CASTELADAS: ESTUDO PARAMÉTRICO}

\subsection{Características gerais dos modelos}

Após a validação do modelo numérico, apresentada no capítulo 4, foi realizado um estudo paramétrico, modelando-se diversas vigas, conforme apresentado neste capítulo.

Para efeito de comparação entre os diversos elementos modelados, alguns parâmetros foram fixados:

- a razão de expansão de todas as vigas é de 1,5 (relação entre altura da viga alveolar e a altura do perfil original);

- as vigas são simplesmente apoiadas; 
- o deslocamento longitudinal foi restringido em um dos apoios;

- foi adotado travamento lateral contínuo ao longo do eixo das mesas, como apresentado na Figura 5.1;

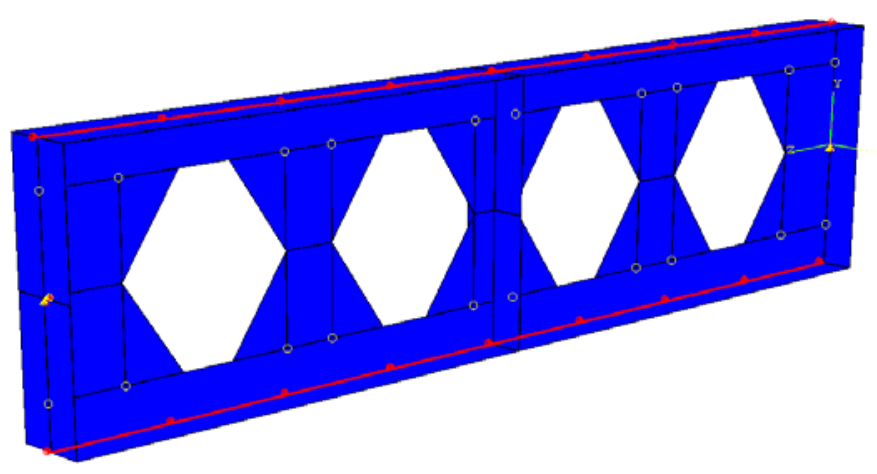

Figura 5.1 - Condições de contorno e travamento lateral nas vigas modeladas.

- a distribuição das aberturas ao longo da viga foi realizada de modo que a largura dos montantes de extremidade seja no mínimo igual à largura dos demais montantes;

- foram colocados enrijecedores em todos os pontos de aplicação de carga concentrada e nos apoios.

\subsection{Descrição e resultados dos estudos paramétricos}

\subsubsection{Generalidades}

Os estudos paramétricos deste trabalho foram organizados em grupos em função dos parâmetros selecionados para avaliação. No Quadro 5.1 apresentam-se as características gerais dos estudos paramétricos, e a seguir são apresentadas as descrições e os respectivos resultados para cada estudo. No Quadro 5.2 é apresentada uma legenda da nomenclatura das vigas analisadas neste estudo paramétrico 
Quadro 5.1 - Características dos grupos do estudo paramétrico

\begin{tabular}{c|l}
\hline Grupo & \multicolumn{1}{c}{ Descrição } \\
\hline 1 & $\begin{array}{l}\text { Avaliação da influência da variação da esbeltez da alma } \\
1.1 \text { - vigas casteladas com predominância de esforço cortante }\left(L / d_{g}=3,2\right) \\
1.2 \text { - vigas casteladas com predominância de momento fletor }\left(L / d_{g}=10\right)\end{array}$ \\
\hline 2 & $\begin{array}{l}\text { Avaliação da influência da relação } L / d_{g} \\
2.1 \text { - vigas casteladas com diferentes relações } L / d_{g} \text { com vão fixo } \\
2.2 \text { - vigas casteladas com diferentes relações } L / d_{g} \text { com esbeltez de alma fixa }\end{array}$ \\
\hline 3 & Avaliação da influência do carregamento \\
\hline 4 & Avaliação da influência da geometria dos alvéolos \\
\hline 5 & Avaliação do comportamento de vigas de alma cheia \\
\hline 7 & Avaliação da influência da altura da chapa expansora \\
\hline \multirow{2}{*}{$\begin{array}{l}\text { Avaliação da influência de enrijecedores de alma em vigas casteladas com } \\
\text { colapso por FMA por compressão }\end{array}$}
\end{tabular}

Quadro 5.2 - Legenda da nomenclatura das vigas

Os nomes dos modelos seguem ao seguinte critério:

PERFIL_VÃO_CARREGAMENTO_PADRÃO_CHAPA

Perfil: Nome do perfil original da viga

Vão: Comprimento do vão livre da viga entre apoios da viga

Carregamento: Tipo de carregamento, que pode ser:

- CC1 - uma carga concentrada no centro do vão

- CC2 - duas cargas concentradas nos terços médios do vão

- $\quad C D$ - carga uniformemente distribuída ao longo do vão

Padrão: Padrão das aberturas da viga castelada, que pode ser:

- $\quad$ AS - Padrão Anglo-Saxão

- $\quad P N$ - Padrão Peiner

- $\theta ; x$ - Abertura com ângulo de abertura igual a $\theta$ e relação $b_{w} / b=x$

Chapa: presença de chapa expansora

$\mathrm{CHN}$ - a viga tem chapa expansora de $\mathrm{N} \mathrm{mm}$

Exemplos:

W360x32,9_4500_CC1_AS

Perfil W360×32,9, com vão de 4500 mm, carga concentrada no centro do vão, castelada no padrão Anglo-Saxão.

W360×32,9_4500_CD_45;0.5-CH100

Perfil W360×32,9, com vão livre de 4500 mm, carga distribuída, castelada com ângulo de abertura de $45^{\circ}$, relação $b_{w} / b=0,5$ e com chapa expansora de $100 \mathrm{~mm}$ 


\subsubsection{Grupo 1 - Avaliação da influência da esbeltez da alma}

\section{Objetivo}

Este grupo de vigas foi analisado com o objetivo de verificar o comportamento das vigas casteladas quanto ao modo de colapso, para diversos valores de esbeltez de alma.

\section{Descrição}

Subgrupo 1.1 - Vigas com predominância de esforço cortante $\left(L / d_{g}=3,2\right)$

Foram modeladas nove vigas, fixando a relação $L / d_{g}$ em 3,2. Essa relação é a mesma do modelo 10-5 ensaiado por Redwood e Demirdjian (1998).

As vigas foram selecionadas do catálogo da Açominas, tomando-se o perfil de menor esbeltez, o de maior esbeltez e o intermediário de cada uma das três séries de perfís selecionadas (W310, W360 e W410). As propriedades geométricas dos perfis originais são apresentadas na Tabela 5.1.

Tabela 5.1 - Propriedades geométricas dos perfis originais das vigas modeladas.

\begin{tabular}{|c|c|c|c|c|c|c|c|}
\hline & \multirow{2}{*}{ bf } & Designação & $\mathrm{d}(\mathrm{mm})$ & bf (mm) & $\mathrm{tf}(\mathrm{mm})$ & $\mathrm{tw}(\mathrm{mm})$ & $\mathrm{R}(\mathrm{mm})$ \\
\hline & & W310x21,0 & 303 & 101 & 5,7 & 5,1 & 10 \\
\hline \multirow{8}{*}{ d } & \multirow{8}{*}{$\rightarrow \leftrightarrow$ tw } & W310x28,3 & 309 & 102 & 8,9 & 6,0 & 10 \\
\hline & & W310x52,0 & 317 & 167 & 13,2 & 7,6 & 10 \\
\hline & & W360×32,9 & 349 & 127 & 8,5 & 5,8 & 12 \\
\hline & & W360x51,0 & 355 & 171 & 11,6 & 7,2 & 12 \\
\hline & & W360x79,0 & 354 & 205 & 16,8 & 9,4 & 12 \\
\hline & & W410x38,8 & 399 & 140 & 8,8 & 6,4 & 12 \\
\hline & & W410x60,0 & 407 & 178 & 12,8 & 7,7 & 12 \\
\hline & & W410x85,0 & 417 & 181 & 18,2 & 10,9 & 12 \\
\hline
\end{tabular}

Todas as vigas foram casteladas no padrão Anglo-Saxão, com carga concentrada no centro do vão. Na Tabela 5.2, apresenta-se as características das vigas casteladas do subgrupo 1.1. 
Tabela 5.2 - Características das vigas analisadas do subgrupo 1.1.

\begin{tabular}{|c|c|c|c|c|c|c|c|}
\hline Modelo & Perfil Original & $\begin{array}{l}\mathrm{L} \\
\mathrm{m}\end{array}$ & $\begin{array}{c}h_{0} \\
\mathrm{~mm}\end{array}$ & $\begin{array}{c}h_{p} \\
\mathrm{~mm}\end{array}$ & $\begin{array}{l}b_{w} \\
\mathrm{~mm}\end{array}$ & $\begin{array}{c}p \\
\mathrm{~mm}\end{array}$ & $N$ \\
\hline W310x21,0_1454_CC1_AS & $W 310 \times 21,0$ & 1,454 & 303 & - & 75,8 & 327,2 & 4 \\
\hline W310x28,3_1483_CC1_AS & $W 310 \times 28,3$ & 1,483 & 309 & - & 77,3 & 333,7 & 4 \\
\hline W310x52,0_1522_CC1_AS & $W 310 \times 52,0$ & 1,522 & 317 & - & 79,3 & 342,4 & 4 \\
\hline W360x32,9_1675_CC1_AS & W360 x 32,9 & 1,675 & 349 & - & 87,3 & 376,9 & 4 \\
\hline W360x51,0_1704_CC1_AS & $W 360 \times 51,0$ & 1,704 & 355 & - & 88,8 & 383,4 & 4 \\
\hline W360x79,0_1699_CC1_AS & W360 x 79,0 & 1,699 & 354 & - & 88,5 & 382,3 & 4 \\
\hline W410x38,8_1915_CC1_AS & W410 x 38,8 & 1,915 & 399 & - & 99,8 & 430,9 & 4 \\
\hline W410x60,0_1954_CC1_AS & $W 410 \times 60,0$ & 1,954 & 407 & - & 101,8 & 439,6 & 4 \\
\hline W410x85,0_2002_CC1_AS & $W 410 \times 85,0$ & 2,002 & 417 & - & 104,3 & 450,4 & 4 \\
\hline
\end{tabular}

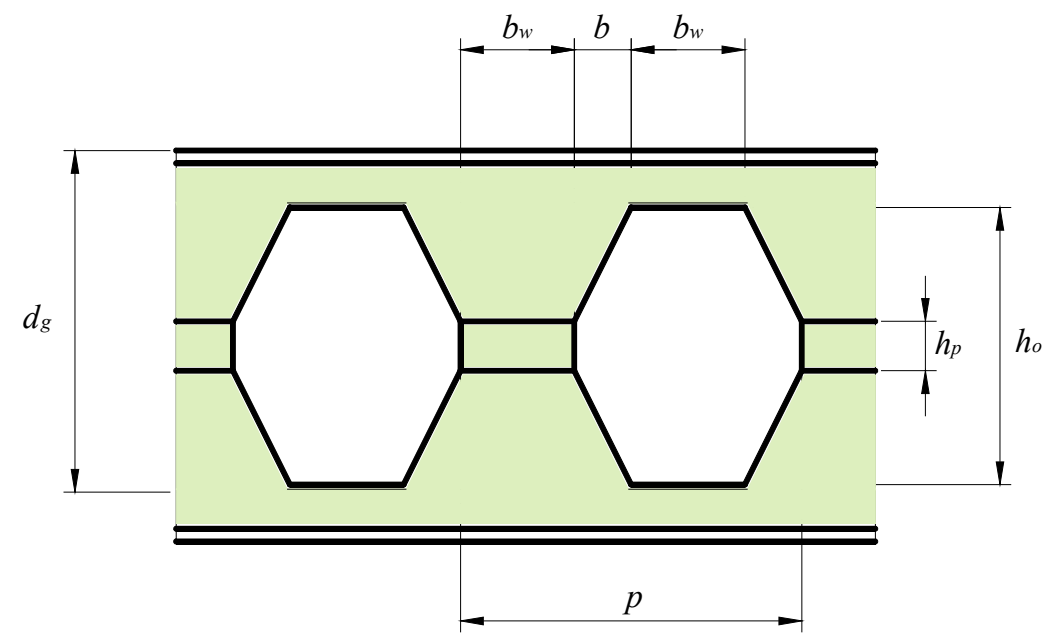

Figura 2.5 - Simbologia relacionada às dimensões e espaçamento das aberturas nas vigas alveolares.

Subgrupo 1.2 - Vigas com predominância de momento fletor $\left(L / d_{g}=10\right)$

Este subgrupo seria uma repetição do subgrupo 1.1, porém com razão $L / d_{g}=10$. Entretanto, como se observou que a flambagem do montante de alma é improvável para essa relação $L / d_{g}$, modelaram-se vigas apenas da série W310. Todas as vigas foram casteladas no padrão Anglo-Saxão, com carga concentrada no centro do vão. As características das vigas casteladas modeladas neste subgrupo são mostradas na Tabela 5.3.

Tabela 5.3 - Características das vigas modeladas do subgrupo 1.2.

\begin{tabular}{lccccccc}
\hline Modelo & Perfil Original & $\begin{array}{c}\mathrm{L} \\
\mathrm{m}\end{array}$ & $\begin{array}{c}h_{0} \\
\mathrm{~mm}\end{array}$ & $\begin{array}{c}h_{\mathrm{p}} \\
\mathrm{mm}\end{array}$ & $\begin{array}{c}b_{w} \\
\mathrm{~mm}\end{array}$ & $\begin{array}{c}p \\
\mathrm{~mm}\end{array}$ & $N$ \\
\hline W310x21,0_4545_CC1_AS & W310 21,0 & 4,545 & 303 & - & 75,8 & 327,2 & 4 \\
W310x28,3_4635_CC1_AS & W310 28,3 & 4,635 & 309 & - & 77,3 & 333,7 & 4 \\
W310x52,0_4755_CC1_AS & W310 52,0 & 4,755 & 317 & - & 79,3 & 342,4 & 4 \\
\hline
\end{tabular}




\section{Resultados}

$\mathrm{Na}$ Tabela 5.4, apresenta-se os resultados obtidos a partir das simulações numéricas realizadas para os modelos do Grupo 1.

Tabela 5.4 - Resultados das vigas modeladas do Grupo 1.

\begin{tabular}{|c|c|c|c|c|c|}
\hline Nome da Viga & $\begin{array}{c}\text { Carga de } \\
\text { Flambagem } \\
\text { Elástica }\left(P_{\mathrm{cr}}\right) \\
\text { kN }\end{array}$ & $\begin{array}{c}\text { Carga } \\
\text { máxima } \\
\left(P_{\text {máx }}\right) \\
\text { kN }\end{array}$ & $\mathrm{P}_{\text {máx }} / \mathrm{P}_{\mathrm{cr}}$ & Modo de Colapso & $\begin{array}{c}\text { Tempo gasto } \\
\text { na análise } \\
\text { hh:mm:ss }\end{array}$ \\
\hline W310x21,0_1454_CC1_AS & 227,9 & 214,5 & 0,94 & FMA & $1: 07: 55$ \\
\hline W310x28,3_1483_CC1_AS & 397,0 & 305,2 & 0,77 & FMA & $0: 40: 08$ \\
\hline W310x52,0_1522_CC1_AS & 864,9 & 462,4 & 0,53 & Flexão; FMA & $0: 29: 27$ \\
\hline W360x32,9_1675_CC1_AS & 322,1 & 289,6 & 0,90 & FMA & $0: 50: 01$ \\
\hline W360x51,0_1704_CC1_AS & 641,4 & 455,0 & 0,71 & FMA & $2: 32: 08$ \\
\hline W360x79,0_1699_CC1_AS & 1481,2 & 670,0 & 0,45 & Flexão; Falha do montante (cis.) & $0: 39: 45$ \\
\hline W410x38,8_1915_CC1_AS & 369,4 & 353,4 & 0,96 & FMA & $0: 38: 57$ \\
\hline W410x60,0_1954_CC1_AS & 682,8 & 529,0 & 0,77 & FMA & $1: 02: 57$ \\
\hline W410x85,0_2002_CC1_AS & 1868,7 & 886,0 & 0,47 & Flexão; Falha do montante (cis.) & $0: 54: 00$ \\
\hline W310x21,0_4545_CC1_AS & 193,5 & 119,7 & 0,62 & Flexão & $0: 53: 47$ \\
\hline W310x28,3_4635_CC1_AS & 339,8 & 170,1 & 0,50 & Flexão & $0: 57: 26$ \\
\hline W310x52,0_4755_CC1_AS & 723,4 & 354,0 & 0,49 & Flexão & $0: 46: 28$ \\
\hline
\end{tabular}

Na Figura 5.2 mostra-se a carga de flambagem elástica e a capacidade máxima dos modelos simulados no Grupo 1. Os resultados da Figura 5.2(a) correspondem às vigas do subgrupo $1.1 \mathrm{e}$ os da Figura 5.2(b) correspondem às vigas do subgrupo 1.2.

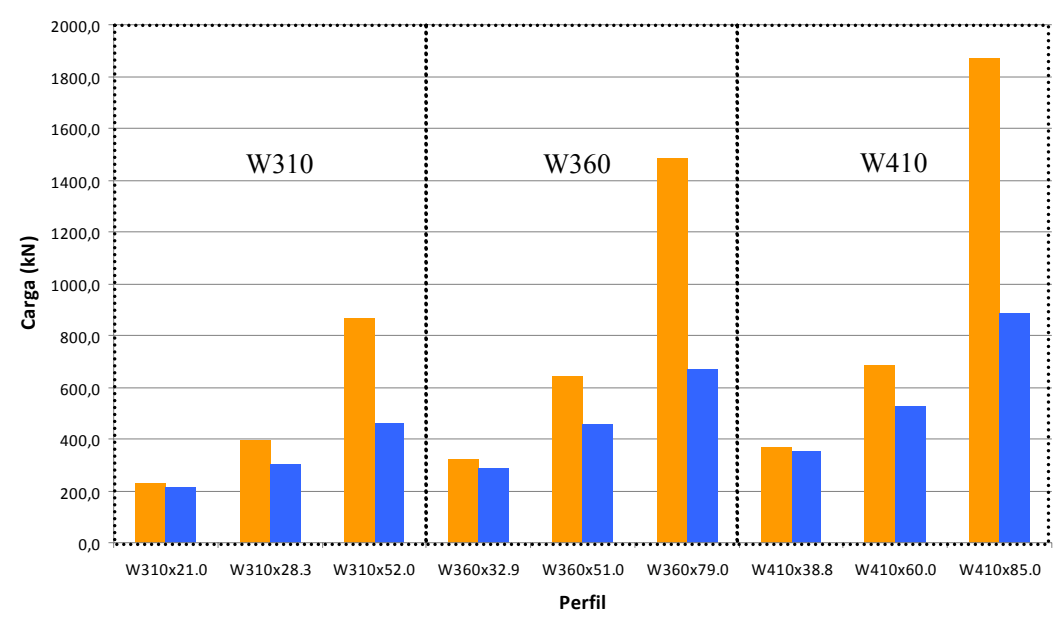

(a)

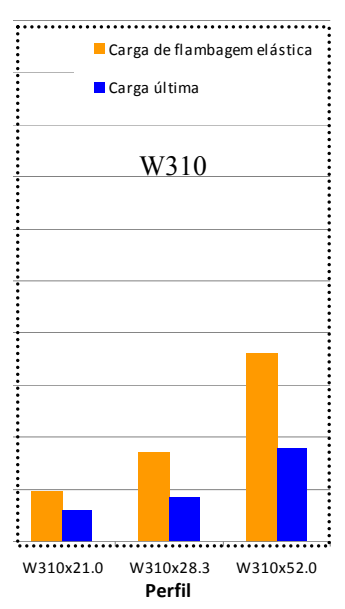

(b)

Figura 5.2 - Carga de flambagem elástica dos montantes de alma e carga máxima das vigas casteladas padrão Anglo-Saxão, com (a) $L=3,2 \mathrm{~d}_{\mathrm{g}} ;$ (b) $L=10 \mathrm{~d}_{\mathrm{g}}$.

Na Figura 5.3 é apresentada uma relação entre a esbeltez da alma castelada $\left(h_{g} / t_{w}\right)$ e a razão $P_{\text {máx }} / P_{c r}$ para as vigas modeladas do Grupo 1.1 do estudo paramétrico, separando-se as vigas que sofreram colapso pela FMA das que tiveram outros modos de ruína. As vigas 
com menor índice de esbeltez da alma (W360 x 79,0 e W410 x 85,0) apresentaram colapso por mecanismo de flexão concomitantemente com falha do montante por cisalhamento, enquanto as demais tiveram a capacidade resistente limitada pela instabilidade dos montantes de alma. Pode-se observar também, que, mesmo para as vigas com alma esbelta, a ocorrência da flambagem dos montantes de alma se deu em regime inelástico.

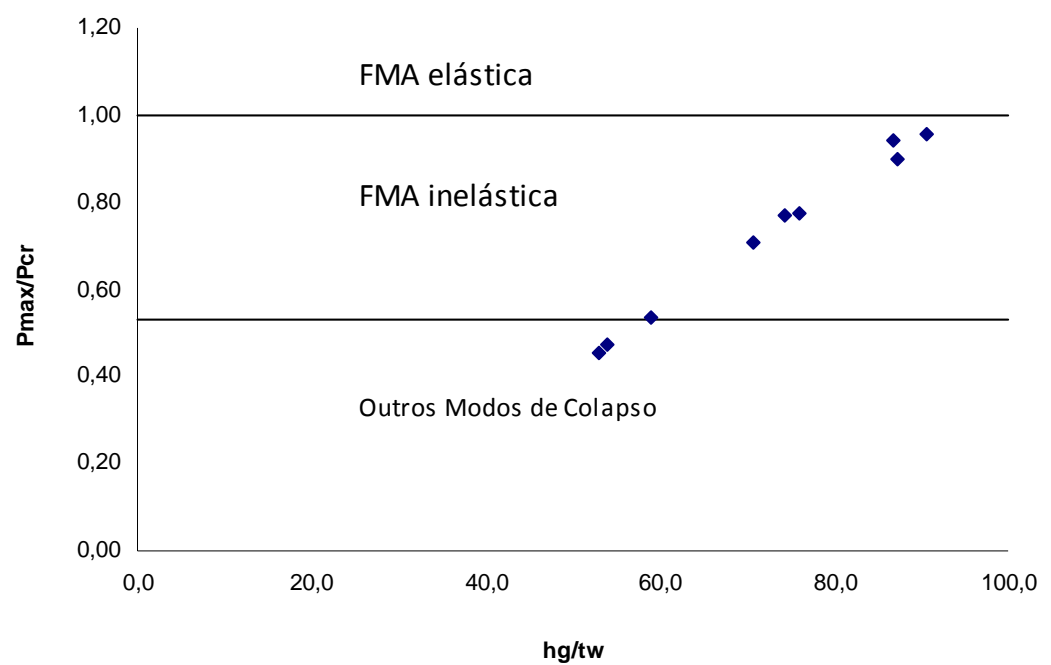

Figura 5.3 - Correlação entre esbeltez $\left(h_{g} / t_{w}\right)$, relação $P_{\text {máx }} / P_{c r}$ e modos de colapso das vigas modeladas do subgrupo 1.1.

\subsubsection{Grupo 2 - Avaliação da influência da relação $L / d_{g}$}

\section{Objetivos}

Este grupo de vigas foi modelado com os objetivos de examinar a mudança dos modos de colapso em função da relação $L / d_{g}$ e verificar a diferença no comportamento das vigas casteladas nos padrões Anglo-Saxão e Peiner, com e sem chapa expansora.

\section{Descrição}

Subgrupo 2.1 - Vigas com vão fixo

Este subgrupo é composto por 36 vigas casteladas, formadas a partir dos nove perfis do subgrupo 1.1, e utilizando-se, para cada perfil, os padrões de fabricação Anglo-Saxão e Peiner. Essas vigas foram modeladas sem chapa expansora e com uma chapa expansora de $100 \mathrm{~mm}$ de altura. 
Todas as vigas deste subgrupo foram modeladas com um vão de $3000 \mathrm{~mm}$ e com uma carga concentrada no centro do vão. O objetivo principal deste grupo foi selecionar um dentre os nove perfis, para o qual ocorresse o colapso por flambagem do montante de alma, a ser utilizado nas análises seguintes. Na Tabela 5.5 são apresentadas as características geométricas das vigas casteladas deste subgrupo.

Tabela 5.5 - Características das vigas modeladas do subgrupo 2.1.

\begin{tabular}{|c|c|c|c|c|c|c|c|}
\hline Modelo & Perfil Original & $\begin{array}{l}\mathrm{L} \\
\mathrm{m}\end{array}$ & $\begin{array}{l}h_{0} \\
\mathrm{~mm}\end{array}$ & $\begin{array}{l}h_{p} \\
\mathrm{~mm}\end{array}$ & $\begin{array}{l}b_{w} \\
\mathrm{~mm}\end{array}$ & $\underset{\mathrm{mm}}{p}$ & $N$ \\
\hline W310x21,0_3000_CC1_AS & $W 310 \times 21,0$ & 3,000 & 303 & - & 75,8 & 327,2 & 8 \\
\hline W310x21,0_3000_CC1_AS_CH100 & $W 310 \times 21,0$ & 3,000 & 403 & 100 & 75,8 & 327,2 & 8 \\
\hline W310x21,0_3000_CC1_PN & $W 310 \times 21,0$ & 3,000 & 303 & - & 75,8 & 327,2 & 6 \\
\hline W310x21,0_3000_CC1_PN_CH100 & $W 310 \times 21,0$ & 3,000 & 403 & 100 & 75,8 & 327,2 & 6 \\
\hline W310x28,3_3000_CC1_AS & $W 310 \times 28,3$ & 3,000 & 309 & - & 77,3 & 333,7 & 8 \\
\hline W310x28,3_3000_CC1_AS_CH100 & $W 310 \times 28,3$ & 3,000 & 409 & 100 & 77,3 & 333,7 & 8 \\
\hline W310x28,3_3000_CC1_PN & $W 310 \times 28,3$ & 3,000 & 309 & - & 77,3 & 333,7 & 6 \\
\hline W310x28,3_3000_CC1_PN_CH100 & $W 310 \times 28,3$ & 3,000 & 409 & 100 & 77,3 & 333,7 & 6 \\
\hline W310x52,0_3000_CC1_AS & $W 310 \times 52,0$ & 3,000 & 317 & - & 79,3 & 342,4 & 8 \\
\hline W310x52,0_3000_CC1_AS_CH100 & $W 310 \times 52,0$ & 3,000 & 417 & 100 & 79,3 & 342,4 & 8 \\
\hline W310x52,0_3000_CC1_PN & $W 310 \times 52,0$ & 3,000 & 317 & - & 79,3 & 342,4 & 5 \\
\hline W310x52,0_3000_CC1_PN_CH100 & $W 310 \times 52,0$ & 3,000 & 417 & 100 & 79,3 & 342,4 & 5 \\
\hline W360x32,9_3000_CC1_AS & W360 $\times 32,9$ & 3,000 & 349 & - & 87,3 & 376,9 & 7 \\
\hline W360x32,9_3000_CC1_AS_CH100 & W360 $\times 32,9$ & 3,000 & 449 & 100 & 87,3 & 376,9 & 7 \\
\hline W360x32,9_3000_CC1_PN & W360 x 32,9 & 3,000 & 349 & - & 87,3 & 376,9 & 5 \\
\hline W360x32,9_3000_CC1_PN_CH100 & W360 $\times 32,9$ & 3,000 & 449 & 100 & 87,3 & 376,9 & 5 \\
\hline W360x51,0_3000_CC1_AS & $W 360 \times 51,0$ & 3,000 & 355 & - & 88,8 & 383,4 & 7 \\
\hline W360x51,0_3000_CC1_AS_CH100 & W360 x 51,0 & 3,000 & 455 & 100 & 88,8 & 383,4 & 7 \\
\hline W360x51,0_3000_CC1_PN & $W 360 \times 51,0$ & 3,000 & 355 & - & 88,8 & 383,4 & 5 \\
\hline W360x51,0_3000_CC1_PN_CH100 & $W 360 \times 51,0$ & 3,000 & 455 & 100 & 88,8 & 383,4 & 5 \\
\hline W360x79,0_3000_CC1_AS & W360 x 79,0 & 3,000 & 354 & - & 88,5 & 382,3 & 7 \\
\hline W360x79,0_3000_CC1_AS_CH100 & W360 x 79,0 & 3,000 & 454 & 100 & 88,5 & 382,3 & 7 \\
\hline W360x79,0_3000_CC1_PN & W360 x 79,0 & 3,000 & 354 & - & 88,5 & 382,3 & 5 \\
\hline W360x79,0_3000_CC1_PN_CH100 & W360 x 79,0 & 3,000 & 454 & 100 & 88,5 & 382,3 & 5 \\
\hline W410x38,8_3000_CC1_AS & $W 410 \times 38,8$ & 3,000 & 399 & - & 99,8 & 430,9 & 6 \\
\hline W410x38,8_3000_CC1_AS_CH100 & $W 410 \times 38,8$ & 3,000 & 499 & 100 & 99,8 & 430,9 & 6 \\
\hline W410x38,8_3000_CC1_PN & $W 410 \times 38,8$ & 3,000 & 399 & - & 99,8 & 430,9 & 4 \\
\hline W410x38,8_3000_CC1_PN_CH100 & $W 410 \times 38,8$ & 3,000 & 499 & 100 & 99,8 & 430,9 & 4 \\
\hline W410x60,0_3000_CC1_AS & $W 410 \times 60,0$ & 3,000 & 407 & - & 101,8 & 439,6 & 6 \\
\hline W410x60,0_3000_CC1_AS_CH100 & $W 410 \times 60,0$ & 3,000 & 507 & 100 & 101,8 & 439,6 & 6 \\
\hline W410x60,0_3000_CC1_PN & $W 410 \times 60,0$ & 3,000 & 407 & - & 101,8 & 439,6 & 4 \\
\hline W410x60,0_3000_CC1_PN_CH100 & $W 410 \times 60,0$ & 3,000 & 507 & 100 & 101,8 & 439,6 & 4 \\
\hline W410x85,0_3000_CC1_AS & $W 410 \times 85,0$ & 3,000 & 417 & - & 104,3 & 450,4 & 6 \\
\hline W410x85,0_3000_CC1_AS_CH100 & $W 410 \times 85,0$ & 3,000 & 517 & 100 & 104,3 & 450,4 & 6 \\
\hline W410x85,0_3000_CC1_PN & $W 410 \times 85,0$ & 3,000 & 417 & - & 104,3 & 450,4 & 4 \\
\hline W410x85,0_3000_CC1_PN_CH100 & $W 410 \times 85,0$ & 3,000 & 517 & 100 & 104,3 & 450,4 & 4 \\
\hline
\end{tabular}


Subgrupo 2.2 - Vigas com esbeltez de alma fixa

Neste grupo de vigas do estudo paramétrico fixou-se o perfil W360x32,9 e admitiram-se vãos de 4500 e 6000 mm. Foram modeladas oito vigas nos padrões Anglo-Saxão e Peiner, sem chapa expansora e com chapa expansora de $100 \mathrm{~mm}$. Todas as vigas foram submetidas a uma carga concentrada no centro do vão. Na Tabela 5.6 são apresentadas as características geométricas das vigas casteladas deste grupo.

Tabela 5.6 - Características das vigas modeladas do subgrupo 2.2.

\begin{tabular}{|c|c|c|c|c|c|c|c|}
\hline Modelo & Perfil Original & $\begin{array}{l}\mathrm{L} \\
\mathrm{m}\end{array}$ & $\begin{array}{l}h_{0} \\
\mathrm{~mm}\end{array}$ & $\begin{array}{l}h_{p} \\
\mathrm{~mm}\end{array}$ & $\begin{array}{l}b_{w} \\
\mathrm{~mm}\end{array}$ & $\begin{array}{c}p \\
\mathrm{~mm}\end{array}$ & $N$ \\
\hline W360x32,9_4500_CC1_AS & W360 $\times 32,9$ & 4,500 & 349 & - & 87,3 & 376,9 & 11 \\
\hline W360x32,9_4500_CC1_AS_CH100 & $W 360 \times 32,9$ & 4,500 & 449 & 100 & 87,3 & 376,9 & 11 \\
\hline W360x32,9_4500_CC1_PN & W360 x 32,9 & 4,500 & 349 & - & 174,5 & 523,5 & 8 \\
\hline W360x32,9_4500_CC1_PN_CH100 & W360 x 32,9 & 4,500 & 449 & 100 & 174,5 & 523,5 & 8 \\
\hline W360x32,9_6000_CC1_AS & W360 x 32,9 & 6,000 & 349 & - & 87,3 & 376,9 & 15 \\
\hline W360x32,9_6000_CC1_AS_CH100 & W360 $\times 32,9$ & 6,000 & 449 & 100 & 87,3 & 376,9 & 15 \\
\hline W360x32,9_6000_CC1_PN & W360 x 32,9 & 6,000 & 349 & - & 174,5 & 523,5 & 11 \\
\hline W360x32,9_6000_CC1_PN_CH100 & W360 $\times 32,9$ & 6,000 & 449 & 100 & 174,5 & 523,5 & 11 \\
\hline
\end{tabular}

\section{Resultados}

$\mathrm{Na}$ Tabela 5.7, apresenta-se os resultados obtidos a partir das simulações numéricas realizadas para os modelos do Grupo 2. 
Tabela 5.7 - Resultados das vigas analisadas do Grupo 2.

\begin{tabular}{|c|c|c|c|c|c|}
\hline Nome da Viga & $\begin{array}{c}\text { Carga de } \\
\text { Flambagem } \\
\left.\text { Elástica ( } P_{c r}\right) \\
\text { kN } \\
\end{array}$ & $\begin{array}{c}\text { Carga } \\
\text { máxima } \\
\left(P_{\text {máx }}\right) \\
\text { kN }\end{array}$ & $\mathrm{P}_{\text {máx }} / \mathrm{P}_{\mathrm{cr}}$ & Modo de Colapso & $\begin{array}{c}\text { Tempo gasto } \\
\text { na análise } \\
\text { hh:mm:ss } \\
\end{array}$ \\
\hline W310x21,0_3000_CC1_AS & 206,0 & 168,6 & 0,82 & Flexão & $0: 42: 00$ \\
\hline W310x21,0_3000_CC1_AS_CH100 & 138,3 & 125,3 & 0,91 & FMA & 0:40:08 \\
\hline W310x21,0_3000_CC1_PN & 192,5 & 154,4 & 0,80 & Vierendeel & $0: 38: 41$ \\
\hline W310x21,0_3000_CC1_PN_CH100 & 140,0 & 146,6 & 1,05 & FMA & $0: 46: 48$ \\
\hline W310x28,3_3000_CC1_AS & 356,3 & 242,2 & 0,68 & Vierendeel & $0: 50: 16$ \\
\hline W310x28,3_3000_CC1_AS_CH100 & 235,6 & 180,3 & 0,77 & FMA & $2: 17: 31$ \\
\hline W310x28,3_3000_CC1_PN & 350,1 & 220,9 & 0,63 & Vierendeel & 2:11:48 \\
\hline W310x28,3_3000_CC1_PN_CH100 & 245,6 & 225,8 & 0,92 & FMA & 2:17:11 \\
\hline W310x52,0_3000_CC1_AS & 768,5 & 415,5 & 0,54 & Flexão & $3: 05: 27$ \\
\hline W310x52,0_3000_CC1_AS_CH100 & 509,8 & 281,5 & 0,55 & Falha do montante (cis.) & $1: 27: 48$ \\
\hline W310x52,0_3000_CC1_PN & 806,4 & 409,6 & 0,51 & Vierendeel & $0: 27: 49$ \\
\hline W310x52,0_3000_CC1_PN_CH100 & 567,5 & 408,5 & 0,72 & Vierendeel; FMA & $0: 28: 27$ \\
\hline W360x32,9_3000_CC1_AS & 296,5 & 266,7 & 0,90 & FMA & $0: 33: 27$ \\
\hline W360x32,9_3000_CC1_AS_CH100 & 206,3 & 182,2 & 0,88 & FMA & $0: 37: 34$ \\
\hline W360x32,9_3000_CC1_PN & 294,2 & 269,1 & 0,91 & FMA & $0: 26: 57$ \\
\hline W360x32,9_3000_CC1_PN_CH100 & 216,1 & 222,0 & 1,03 & FMA & $0: 27: 47$ \\
\hline W360x51,0_3000_CC1_AS & 586,9 & 418,3 & 0,71 & Falha do montante (cis.) & 0:47:00 \\
\hline W360x51,0_3000_CC1_AS_CH100 & 408,6 & 280,8 & 0,69 & FMA & $0: 44: 48$ \\
\hline W360x51,0_3000_CC1_PN & 595,3 & 407,0 & 0,68 & Vierendeel & 0:34:04 \\
\hline W360x51,0_3000_CC1_PN_CH100 & 435,0 & 370,9 & 0,85 & FMA & $1: 12: 25$ \\
\hline W360x79,0_3000_CC1_AS & 1356,0 & 604,0 & 0,45 & Plastificação; Falha do montante & $0: 48: 23$ \\
\hline W360x79,0_3000_CC1_AS_CH100 & 941,1 & 445,6 & 0,47 & Falha do montante (cis.) & $0: 36: 59$ \\
\hline W360x79,0_3000_CC1_PN & 1399,9 & 608,0 & 0,43 & Vierendeel & $0: 37: 44$ \\
\hline W360x79,0_3000_CC1_PN_CH100 & 1015,6 & 605,0 & 0,60 & Vierendeel & $0: 34: 30$ \\
\hline W410x38,8_3000_CC1_AS & 344,9 & 320,6 & 0,93 & FMA & $4: 42: 34$ \\
\hline W410x38,8_3000_CC1_AS_CH100 & 254,2 & 235,8 & 0,93 & FMA & $1: 42: 02$ \\
\hline W410x38,8_3000_CC1_PN & 334,4 & 325,7 & 0,97 & FMA & $0: 50: 54$ \\
\hline W410x38,8_3000_CC1_PN_CH100 & 257,3 & 236,3 & 0,92 & FMA & 9:08:45 \\
\hline W410x60,0_3000_CC1_AS & 636,1 & 493,4 & 0,78 & FMA & $10: 38: 03$ \\
\hline W410x60,0_3000_CC1_AS_CH100 & 468,4 & 355,5 & 0,76 & FMA & $10: 43: 20$ \\
\hline W410x60,0_3000_CC1_PN & 638,6 & 476,8 & 0,75 & Vierendeel & $10: 33: 34$ \\
\hline W410x60,0_3000_CC1_PN_CH100 & 486,6 & 434,9 & 0,89 & FMA & $0: 55: 59$ \\
\hline W410x85,0_3000_CC1_AS & 1743,5 & 809,0 & 0,46 & Flexão & 0:58:06 \\
\hline W410x85,0_3000_CC1_AS_CH100 & 1290,6 & 631,0 & 0,49 & Falha do montante (cis.) & 1:12:46 \\
\hline W410x85,0_3000_CC1_PN & 1761,0 & 727,0 & 0,41 & Vierendeel & $1: 05: 23$ \\
\hline W410x85,0_3000_CC1_PN_CH100 & 1348,1 & 744,0 & 0,55 & Vierendeel & 1:03:36 \\
\hline W360x32,9_4500_CC1_AS & 278,7 & 229,6 & 0,82 & Flexão & 0:58:06 \\
\hline W360x32,9_4500_CC1_AS_CH100 & 189,2 & 169,2 & 0,89 & FMA & $0: 49: 53$ \\
\hline W360x32,9_4500_CC1_PN & 275,2 & 205,5 & 0,75 & Vierendeel & 0:46:40 \\
\hline W360x32,9_4500_CC1_PN_CH100 & 199,1 & 202,0 & 1,01 & FMA & $0: 40: 29$ \\
\hline W360x32,9_6000_CC1_AS & 271,0 & 175,0 & 0,65 & Flexão & $11: 36: 40$ \\
\hline W360x32,9_6000_CC1_AS_CH100 & 184,0 & 166,3 & 0,90 & FMA & $2: 35: 44$ \\
\hline W360x32,9_6000_CC1_PN & 268,9 & 168,7 & 0,63 & Flexão & 2:09:20 \\
\hline W360x32,9_6000_CC1_PN_CH100 & 194,6 & 193,8 & 1,00 & FMA & $1: 02: 36$ \\
\hline
\end{tabular}




\subsubsection{Grupo 3 - Avaliação da influência do carregamento}

\section{Objetivos}

Este grupo foi criado para estudar a influência dos diferentes tipos de carregamento no comportamento das vigas casteladas.

\section{Descrição}

Foram modeladas 24 vigas, utilizando-se dois tipos de carregamento:

- duas cargas concentradas aplicadas nos terços médios do vão;

- carregamento distribuído ao longo do vão.

Para cada tipo de carregamento, foram modeladas vigas com vãos de 3000, 4500 e $6000 \mathrm{~mm}$ nos padrões Anglo-Saxão e Peiner, sem chapa expansora e com chapa expansora de $100 \mathrm{~mm}$. As características geométricas dos modelos deste grupo estão apresentadas na Tabela 5.8.

Tabela 5.8 - Características das vigas modeladas do Grupo 3.

\begin{tabular}{|c|c|c|c|c|c|c|c|c|}
\hline & Modelo & Perfil Original & $\begin{array}{l}\mathrm{L} \\
\mathrm{m}\end{array}$ & $\begin{array}{l}h_{0} \\
\mathrm{~mm}\end{array}$ & $\begin{array}{c}h_{p} \\
\mathrm{~mm}\end{array}$ & $\begin{array}{l}b_{w} \\
\mathrm{~mm}\end{array}$ & $\underset{\mathrm{mm}}{p}$ & $N$ \\
\hline \multirow{12}{*}{ 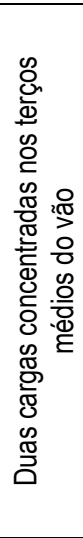 } & W360x32,9_3000_CC2_AS & W360 $\times 32,9$ & 3,000 & 349 & - & 87,3 & 376,9 & 7 \\
\hline & W360x32,9_3000_CC2_AS_CH100 & W360 $\times 32,9$ & 3,000 & 449 & 100 & 87,3 & 376,9 & 7 \\
\hline & W360x32,9_3000_CC2_PN & $W 360 \times 32,9$ & 3,000 & 349 & - & 174,5 & 523,5 & 5 \\
\hline & W360x32,9_3000_CC2_PN_CH100 & W360 $\times 32,9$ & 3,000 & 449 & 100 & 174,5 & 523,5 & 5 \\
\hline & W360x32,9_4500_CC2_AS & $W 360 \times 32,9$ & 4,500 & 349 & - & 87,3 & 376,9 & 11 \\
\hline & W360x32,9_4500_CC2_AS_CH100 & W360 $\times 32,9$ & 4,500 & 449 & 100 & 87,3 & 376,9 & 11 \\
\hline & W360x32,9_4500_CC2_PN & W360 x 32,9 & 4,500 & 349 & - & 174,5 & 523,5 & 8 \\
\hline & W360x32,9_4500_CC2_PN_CH100 & W360 x 32,9 & 4,500 & 449 & 100 & 174,5 & 523,5 & 8 \\
\hline & W360x32,9_6000_CC2_AS & W360 x 32,9 & 6,000 & 349 & - & 87,3 & 376,9 & 15 \\
\hline & W360x32,9_6000_CC2_AS_CH100 & W360 x 32,9 & 6,000 & 449 & 100 & 87,3 & 376,9 & 15 \\
\hline & W360x32,9_6000_CC2_PN & W360 x 32,9 & 6,000 & 349 & - & 174,5 & 523,5 & 11 \\
\hline & W360x32,9_6000_CC2_PN_CH100 & W360 x 32,9 & 6,000 & 449 & 100 & 174,5 & 523,5 & 11 \\
\hline \multirow{12}{*}{ 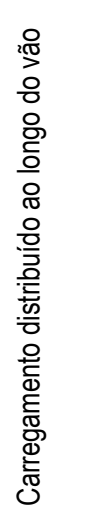 } & W360x32,9_3000_CD_AS & W360 x 32,9 & 3,000 & 349 & - & 87,3 & 376,9 & 7 \\
\hline & W360x32,9_3000_CD_AS_CH100 & W360 x 32,9 & 3,000 & 449 & 100 & 87,3 & 376,9 & 7 \\
\hline & W360x32,9_3000_CD_PN & W360 x 32,9 & 3,000 & 349 & - & 174,5 & 523,5 & 5 \\
\hline & W360x32,9_3000_CD_PN_CH100 & W360 $\times 32,9$ & 3,000 & 449 & 100 & 174,5 & 523,5 & 5 \\
\hline & W360x32,9_4500_CD_AS & W360 x 32,9 & 4,500 & 349 & - & 87,3 & 376,9 & 11 \\
\hline & W360×32,9_4500_CD_AS_CH100 & W360 x 32,9 & 4,500 & 449 & 100 & 87,3 & 376,9 & 11 \\
\hline & W360×32,9_4500_CD_PN & W360 x 32,9 & 4,500 & 349 & - & 174,5 & 523,5 & 8 \\
\hline & W360×32,9_4500_CD_PN_CH100 & W360 x 32,9 & 4,500 & 449 & 100 & 174,5 & 523,5 & 8 \\
\hline & W360×32,9_6000_CD_AS & W360 x 32,9 & 6,000 & 349 & - & 87,3 & 376,9 & 15 \\
\hline & W360x32,9_6000_CD_AS_CH100 & W360 x 32,9 & 6,000 & 449 & 100 & 87,3 & 376,9 & 15 \\
\hline & W360x32,9_6000_CD_PN & W360 x 32,9 & 6,000 & 349 & - & 174,5 & 523,5 & 11 \\
\hline & W360x32,9_6000_CD_PN_CH100 & W360 x 32,9 & 6,000 & 449 & 100 & 174,5 & 523,5 & 11 \\
\hline
\end{tabular}




\section{Resultados}

$\mathrm{Na}$ Tabela 5.9, apresenta-se os resultados obtidos a partir das simulações numéricas realizadas para os modelos do Grupo 3.

Tabela 5.9 - Resultados das vigas analisadas do Grupo 3.

\begin{tabular}{|c|c|c|c|c|c|}
\hline Nome da Viga & $\begin{array}{c}\text { Carga de } \\
\text { Flambagem } \\
\text { Elástica }\left(P_{c r}\right) \\
k N\end{array}$ & $\begin{array}{c}\text { Carga } \\
\text { máxima } \\
\left(P_{\text {máx }}\right) \\
\mathrm{kN}\end{array}$ & $P_{\text {máx }} / P_{c r}$ & Modo de Colapso & $\begin{array}{c}\text { Tempo gasto } \\
\text { na análise } \\
\text { hh:mm:ss }\end{array}$ \\
\hline W360x32,9_3000_CC2_AS & 160,7 & 144,9 & 0,90 & FMA & $0: 50: 50$ \\
\hline W360x32,9_3000_CC2_AS_CH100 & 116,1 & 120,0 & 1,03 & FMA & 0:38:59 \\
\hline W360x32,9_3000_CC2_PN & 159,1 & 144,0 & 0,91 & FMA & $0: 59: 48$ \\
\hline W360x32,9_3000_CC2_PN_CH100 & 117,2 & 124,8 & 1,06 & FMA & $0: 40: 30$ \\
\hline W360x32,9_4500_CC2_AS & 147,1 & 133,2 & 0,91 & FMA & 1:13:02 \\
\hline W360x32,9_4500_CC2_AS_CH100 & 101,7 & 90,5 & 0,89 & FMA & 0:44:08 \\
\hline W360x32,9_4500_CC2_PN & 145,5 & 134,0 & 0,92 & FMA & $0: 50: 50$ \\
\hline W360x32,9_4500_CC2_PN_CH100 & 106,2 & 108,0 & 1,02 & FMA & 0:41:06 \\
\hline W360x32,9_6000_CC2_AS & 140,8 & 119,3 & 0,85 & Vierendeel & $1: 08: 21$ \\
\hline W360x32,9_6000_CC2_AS_CH100 & 95,8 & 85,6 & 0,89 & FMA & $1: 35: 25$ \\
\hline W360x32,9_6000_CC2_PN & 139,9 & 115,1 & 0,82 & Vierendeel & $2: 29: 02$ \\
\hline W360x32,9_6000_CC2_PN_CH100 & 101,1 & 103,0 & 1,02 & FMA & 3:13:21 \\
\hline W360x32,9_3000_CD_AS & 114,7 & 107,8 & 0,94 & FMA por compressão & 1:48:18 \\
\hline W360x32,9_3000_CD_AS_CH100 & 75,0 & 70,7 & 0,94 & FMA por compressão & 3:19:02 \\
\hline W360x32,9_3000_CD_PN & 123,5 & 118,6 & 0,96 & FMA por compressão & $3: 10: 56$ \\
\hline W360x32,9_3000_CD_PN_CH100 & 87,4 & 84,3 & 0,96 & FMA por compressão & 3:00:11 \\
\hline W360x32,9_4500_CD_AS & 80,5 & 75,4 & 0,94 & FMA; FMA por compressão & 0:54:01 \\
\hline W360x32,9_4500_CD_AS_CH100 & 54,7 & 51,8 & 0,95 & FMA; FMA por compressão & $1: 37: 56$ \\
\hline W360x32,9_4500_CD_PN & 82,1 & 77,7 & 0,95 & FMA & $1: 49: 33$ \\
\hline W360x32,9_4500_CD_PN_CH100 & 59,3 & 61,8 & 1,04 & FMA; FMA por compressão & $2: 57: 17$ \\
\hline W360x32,9_6000_CD_AS & 58,0 & 53,7 & 0,93 & FMA; FMA por compressão & 2:09:19 \\
\hline W360x32,9_6000_CD_AS_CH100 & 40,3 & 37,5 & 0,93 & FMA; FMA por compressão & $2: 09: 54$ \\
\hline W360x32,9_6000_CD_PN & 57,1 & 54,2 & 0,95 & FMA & $4: 37: 13$ \\
\hline W360x32,9_6000_CD_PN_CH100 & 41,5 & 43,3 & 1,04 & FMA & $4: 45: 28$ \\
\hline
\end{tabular}

\subsubsection{Grupo 4 - Avaliação da influência da geometria dos alvéolos}

\section{Objetivo}

Neste grupo, foram modeladas vigas casteladas com diferentes padrões de corte, com a finalidade de estudar a influência dos diferentes traçados geométricos das aberturas no comportamento estrutural dessas vigas.

\section{Descrição}

Foram modeladas 36 vigas, variando-se o ângulo do lado inclinado das aberturas, em 30, 45 e 60 graus. Variou-se também a relação entre o comprimento da solda e o comprimento 
da projeção horizontal da parte inclinada da abertura, tomando-se relações 1/2, 1/1 e 2/1. Para cada uma das geometrias apresentadas, modelaram-se as vigas sem chapa e com chapa intermediária de $100 \mathrm{~mm}$. Também foram modeladas vigas com carga concentrada no centro do vão e carregamento uniformemente distribuído. Todas as vigas foram modeladas com um vão de $4500 \mathrm{~mm}$.

$\mathrm{Na}$ Figura 5.4 à Figura 5.9 apresentam-se os esquemas da geometria das aberturas modeladas neste grupo. As características geométricas deste grupo de vigas estão apresentadas na Tabela 5.10.

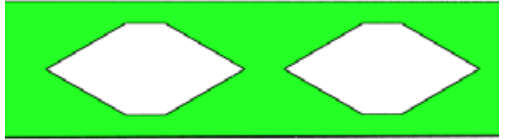

(a)

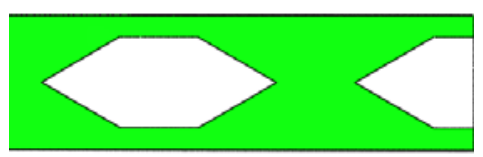

(b)

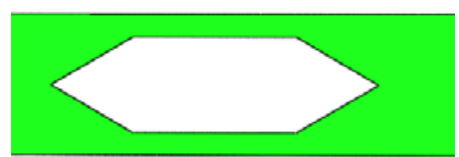

(c)

Figura 5.4 - Geometria das aberturas com ângulo do lado inclinado de $30^{\circ}$, com relação $b_{w} / b$ igual a (a) 1/2 (b) 1 e (c) 2 sem chapa expansora.

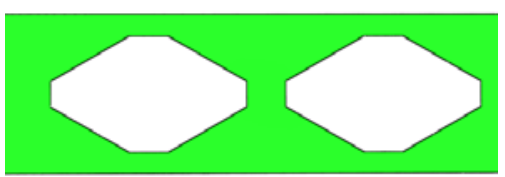

(a)

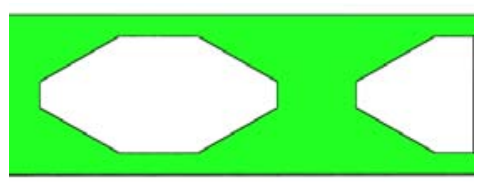

(b)

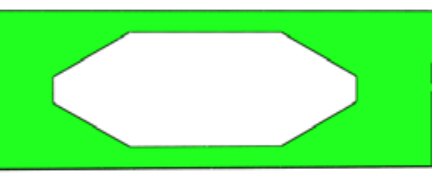

(c)

Figura 5.5 - Geometria das aberturas com ângulo do lado inclinado de $30^{\circ}$, com relação $b_{w} / b$ igual a (a) 1/2 (b) 1 e (c) 2 com chapa expansora.

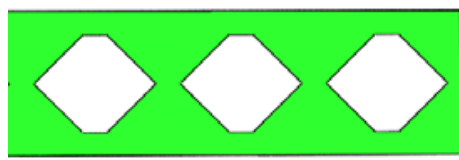

(a)

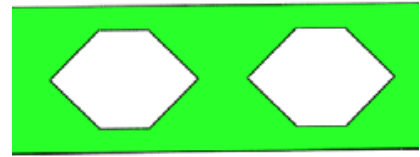

(b)

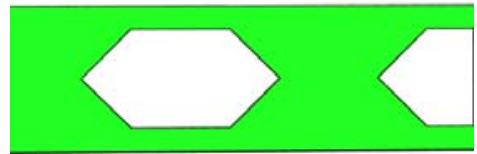

(c)

Figura 5.6 - Geometria das aberturas com ângulo do lado inclinado de $45^{\circ}$, com relação $b_{w} / b$ igual a (a) 1/2 (b) 1 e (c) 2 sem chapa expansora.

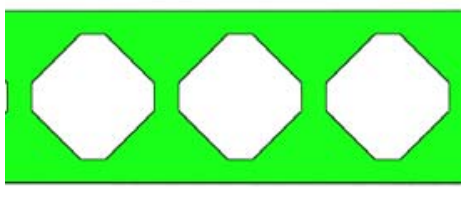

(a)

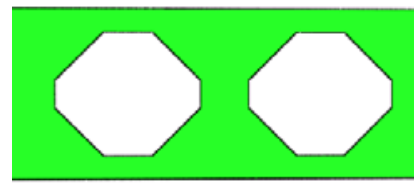

(b)

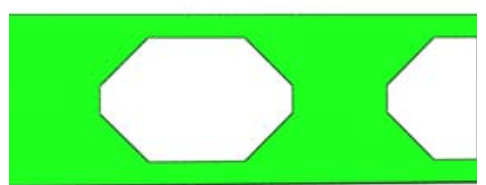

(c)

Figura 5.7 - Geometria das aberturas com ângulo do lado inclinado de $45^{\circ}$, com relação $b_{w} / b$ igual a (a) 1/2 (b) 1 e (c) 2 com chapa expansora. 


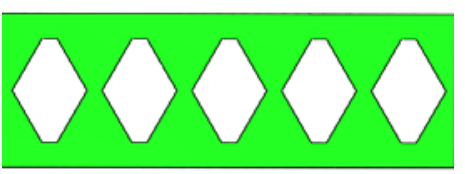

(a)

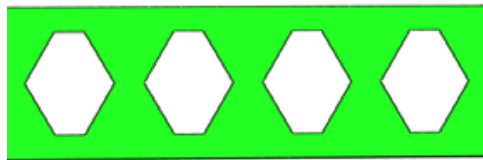

(b)

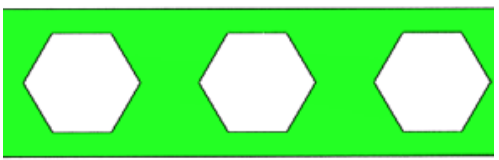

(c)

Figura 5.8 - Geometria das aberturas com ângulo do lado inclinado de $60^{\circ}$, com relação $b_{w} / b$ igual a (a) 1/2 (b) 1 e (c) 2 sem chapa expansora.

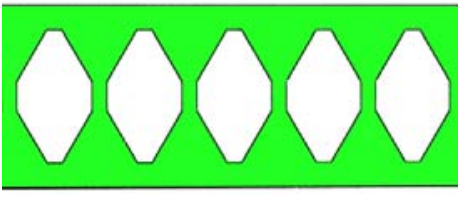

(a)

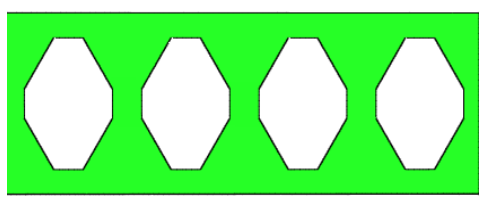

(b)

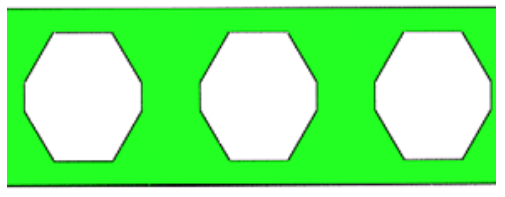

(c)

Figura 5.9 - Geometria das aberturas com ângulo do lado inclinado de $60^{\circ}$, com relação $b_{w} / b$ igual a (a) 1/2 (b) 1 e (c) 2 com chapa expansora.

Tabela 5.10 - Características das vigas modeladas do Grupo 4.

\begin{tabular}{|c|c|c|c|c|c|c|c|c|}
\hline Modelo & Perfil Original & $\begin{array}{l}L \\
\mathrm{~m}\end{array}$ & $\begin{array}{l}h_{0} \\
\mathrm{~mm}\end{array}$ & $\begin{array}{l}h_{p} \\
\mathrm{~mm}\end{array}$ & $\begin{array}{l}b_{w} \\
\mathrm{~mm}\end{array}$ & $\begin{array}{c}p \\
\mathrm{~mm}\end{array}$ & $\alpha$ & $N$ \\
\hline W360x32,9_4500_CC1_30;0.5 & $W 360 \times 32,9$ & 4,500 & 349 & - & 151,1 & 906,7 & 30 & 4 \\
\hline W360x32,9_4500_CC1_30;0.5_CH100 & W360 x 32,9 & 4,500 & 449 & 100 & 151,1 & 906,7 & 30 & 4 \\
\hline W360x32,9_4500_CC1_30;1 & W360 x 32,9 & 4,500 & 349 & - & 302,2 & 1209,0 & 30 & 3 \\
\hline W360x32,9_4500_CC1_30;1_CH100 & $W 360 \times 32,9$ & 4,500 & 449 & 100 & 302,2 & 1209,0 & 30 & 3 \\
\hline W360x32,9_4500_CC1_30;2 & W360 $\times 32,9$ & 4,500 & 349 & - & 604,5 & 1813,5 & 30 & 2 \\
\hline W360x32,9_4500_CC1_30;2_CH100 & W360 x 32,9 & 4,500 & 449 & 100 & 604,5 & 1813,5 & 30 & 2 \\
\hline W360x32,9_4500_CC1_45;0.5 & $W 360 \times 32,9$ & 4,500 & 349 & - & 87,3 & 523,5 & 45 & 8 \\
\hline W360x32,9_4500_CC1_45;0.5_CH100 & W360 $\times 32,9$ & 4,500 & 449 & 100 & 87,3 & 523,5 & 45 & 8 \\
\hline W360x32,9_4500_CC1_45;1 & W360 x 32,9 & 4,500 & 349 & - & 174,5 & 698,0 & 45 & 6 \\
\hline W360x32,9_4500_CC1_45;1_CH100 & $W 360 \times 32,9$ & 4,500 & 449 & 100 & 174,5 & 698,0 & 45 & 6 \\
\hline W360x32,9_4500_CC1_45;2 & W360 $\times 32,9$ & 4,500 & 349 & - & 349,0 & 1047,0 & 45 & 3 \\
\hline W360x32,9_4500_CC1_45;2_CH100 & W360 $\times 32,9$ & 4,500 & 449 & 100 & 349,0 & 1047,0 & 45 & 3 \\
\hline W360x32,9_4500_CC1_60;0.5 & $W 360 \times 32,9$ & 4,500 & 349 & - & 50,4 & 302,2 & 60 & 14 \\
\hline W360x32,9_4500_CC1_60;0.5_CH100 & W360 $\times 32,9$ & 4,500 & 449 & 100 & 50,4 & 302,2 & 60 & 14 \\
\hline W360x32,9_4500_CC1_60;1 & W360 $\times 32,9$ & 4,500 & 349 & - & 100,7 & 403,0 & 60 & 10 \\
\hline W360x32,9_4500_CC1_60;1_CH100 & $W 360 \times 32,9$ & 4,500 & 449 & 100 & 100,7 & 403,0 & 60 & 10 \\
\hline W360x32,9_4500_CC1_60;2 & W360 $\times 32,9$ & 4,500 & 349 & - & 201,5 & 604,5 & 60 & 7 \\
\hline W360x32,9_4500_CC1_60;2_CH100 & W360 $\times 32,9$ & 4,500 & 449 & 100 & 201,5 & 604,5 & 60 & 7 \\
\hline W360x32,9_4500_CD_30;0.5 & W360 $\times 32,9$ & 4,500 & 349 & - & 151,1 & 906,7 & 30 & 4 \\
\hline W360x32,9_4500_CD_30;0.5_CH100 & W360 $\times 32,9$ & 4,500 & 449 & 100 & 151,1 & 906,7 & 30 & 4 \\
\hline W360x32,9_4500_CD_30;1 & $W 360 \times 32,9$ & 4,500 & 349 & - & 302,2 & 1209,0 & 30 & 3 \\
\hline W360x32,9_4500_CD_30;1_CH100 & $W 360 \times 32,9$ & 4,500 & 449 & 100 & 302,2 & 1209,0 & 30 & 3 \\
\hline W360x32,9_4500_CD_30;2 & W360 $\times 32,9$ & 4,500 & 349 & - & 604,5 & 1813,5 & 30 & 2 \\
\hline W360x32,9_4500_CD_30;2_CH100 & $W 360 \times 32,9$ & 4,500 & 449 & 100 & 604,5 & 1813,5 & 30 & 2 \\
\hline W360×32,9_4500_CD_45;0.5 & W360 $\times 32,9$ & 4,500 & 349 & - & 87,3 & 523,5 & 45 & 8 \\
\hline W360x32,9_4500_CD_45;0.5_CH100 & $W 360 \times 32,9$ & 4,500 & 449 & 100 & 87,3 & 523,5 & 45 & 8 \\
\hline W360x32,9_4500_CD_45;1 & $W 360 \times 32,9$ & 4,500 & 349 & - & 174,5 & 698,0 & 45 & 6 \\
\hline W360x32,9_4500_CD_45;1_CH100 & W360 $\times 32,9$ & 4,500 & 449 & 100 & 174,5 & 698,0 & 45 & 6 \\
\hline W360x32,9_4500_CD_45;2 & W360 $\times 32,9$ & 4,500 & 349 & - & 349,0 & 1047,0 & 45 & 3 \\
\hline W360x32,9_4500_CD_45;2_CH100 & W360 $\times 32,9$ & 4,500 & 449 & 100 & 349,0 & 1047,0 & 45 & 3 \\
\hline W360×32,9_4500_CD_60;0.5 & W360 $\times 32,9$ & 4,500 & 349 & - & 50,4 & 302,2 & 60 & 14 \\
\hline W360x32,9_4500_CD_60;0.5_CH100 & W360 $\times 32,9$ & 4,500 & 449 & 100 & 50,4 & 302,2 & 60 & 14 \\
\hline W360x32,9_4500_CD_60;1 & $W 360 \times 32,9$ & 4,500 & 349 & - & 100,7 & 403,0 & 60 & 10 \\
\hline W360x32,9_4500_CD_60;1_CH100 & $W 360 \times 32,9$ & 4,500 & 449 & 100 & 100,7 & 403,0 & 60 & 10 \\
\hline W360×32,9_4500_CD_60;2 & $W 360 \times 32,9$ & 4,500 & 349 & - & 201,5 & 604,5 & 60 & 7 \\
\hline W360x32,9_4500_CD_60;2_CH100 & W360 $\times 32,9$ & 4,500 & 449 & 100 & 201,5 & 604,5 & 60 & 7 \\
\hline
\end{tabular}




\section{Resultados}

$\mathrm{Na}$ Tabela 5.11, apresenta-se os resultados obtidos a partir das simulações numéricas realizadas para os modelos do Grupo 4.

Tabela 5.11 - Resultados das vigas analisadas do Grupo 4.

\begin{tabular}{|c|c|c|c|c|c|}
\hline Nome da Viga & $\begin{array}{c}\text { Carga de } \\
\text { Flambagem } \\
\text { Elástica }\left(P_{c r}\right) \\
k N\end{array}$ & $\begin{array}{c}\text { Carga } \\
\text { máxima } \\
\left(P_{\text {máx }}\right) \\
\mathrm{kN}\end{array}$ & $\mathrm{P}_{\text {máx }} / \mathrm{P}_{\mathrm{cr}}$ & Modo de Colapso & $\begin{array}{c}\text { Tempo } \\
\text { gasto na } \\
\text { análise } \\
\text { hh:mm:ss }\end{array}$ \\
\hline W360x32,9_4500_CC1_30;0.5 & 205,4 & 210,0 & 1,02 & Vierendeel & $0: 58: 46$ \\
\hline W360x32,9_4500_CC1_30;0.5_CH100 & 144,6 & 156,0 & 1,08 & FMA & 1:05:01 \\
\hline W360x32,9_4500_CC1_30;1 & 189,9 & 176,4 & 0,93 & Vierendeel & $1: 12: 28$ \\
\hline W360x32,9_4500_CC1_30;1_CH100 & 165,0 & 180,0 & 1,09 & Vierendeel & 2:02:00 \\
\hline W360x32,9_4500_CC1_30;2 & 136,8 & 101,6 & 0,74 & Vierendeel & 1:13:36 \\
\hline W360x32,9_4500_CC1_30;2_CH100 & 128,8 & 100,0 & 0,78 & Vierendeel & $0: 53: 12$ \\
\hline W360x32,9_4500_CC1_45;0.5 & 255,6 & 225,5 & 0,88 & Flexão; Vierendeel & $1: 17: 48$ \\
\hline W360x32,9_4500_CC1_45;0.5_CH100 & 167,2 & 144,3 & 0,86 & FMA & 1:13:03 \\
\hline W360x32,9_4500_CC1_45;1 & 258,1 & 209,5 & 0,81 & Vierendeel; Flexão & $2: 48: 21$ \\
\hline W360x32,9_4500_CC1_45;1_CH100 & 181,3 & 192,2 & 1,06 & FMA & $1: 42: 18$ \\
\hline W360x32,9_4500_CC1_45;2 & 234,0 & 169,5 & 0,72 & Vierendeel & $0: 44: 58$ \\
\hline W360x32,9_4500_CC1_45;2_CH100 & 200,8 & 168,4 & 0,84 & Vierendeel & $1: 23: 20$ \\
\hline W360x32,9_4500_CC1_60;0.5 & 287,8 & 222,3 & 0,77 & Flexão; Vierendeel & $4: 41: 41$ \\
\hline W360x32,9_4500_CC1_60;0.5_CH100 & 184,0 & 119,8 & 0,65 & FMA & $4: 41: 45$ \\
\hline W360x32,9_4500_CC1_60;1 & 277,1 & 219,3 & 0,79 & Flexão; Vierendeel & $1: 57: 44$ \\
\hline W360x32,9_4500_CC1_60;1_CH100 & 191,1 & 178,0 & 0,93 & FMA & $1: 30: 34$ \\
\hline W360x32,9_4500_CC1_60;2 & 278,8 & 216,3 & 0,78 & Flexão; Vierendeel & 3:30:04 \\
\hline W360x32,9_4500_CC1_60;2_CH100 & 202,0 & 210,0 & 1,04 & FMA & $1: 40: 42$ \\
\hline W360x32,9_4500_CD_30;0.5 & 64,1 & 67,9 & 1,06 & FMA por compressão & $1: 56: 50$ \\
\hline W360x32,9_4500_CD_30;0.5_CH100 & 45,3 & 44,5 & 0,98 & FMA por compressão & $2: 50: 02$ \\
\hline W360x32,9_4500_CD_30;1 & 57,7 & 67,1 & 1,16 & Vierendeel & $0: 35: 49$ \\
\hline W360x32,9_4500_CD_30;1_CH100 & 47,5 & 54,9 & 1,16 & FMA por compressão & $1: 28: 23$ \\
\hline W360x32,9_4500_CD_30;2 & 47,5 & 49,3 & 1,04 & Vierendeel & $1: 41: 03$ \\
\hline W360x32,9_4500_CD_30;2_CH100 & 40,8 & 49,3 & 1,21 & Vierendeel & $5: 31: 34$ \\
\hline W360x32,9_4500_CD_45;0.5 & 73,6 & 69,5 & 0,94 & FMA por compressão & $0: 47: 05$ \\
\hline W360x32,9_4500_CD_45;0.5_CH100 & 46,4 & 42,9 & 0,92 & FMA por compressão & $1: 28: 16$ \\
\hline W360x32,9_4500_CD_45;1 & 77,8 & 77,0 & 0,99 & Vierendeel & $2: 10: 44$ \\
\hline W360x32,9_4500_CD_45;1_CH100 & 54,7 & 56,7 & 1,04 & FMA por compressão & $2: 18: 37$ \\
\hline W360x32,9_4500_CD_45;2 & 79,3 & 72,8 & 0,92 & Vierendeel & $0: 39: 42$ \\
\hline W360x32,9_4500_CD_45;2_CH100 & 63,4 & 70,2 & 1,11 & FMA por compressão & $1: 27: 06$ \\
\hline W360×32,9_4500_CD_60;0.5 & 79,7 & 69,2 & 0,87 & FMA por compressão & 1:15:14 \\
\hline W360x32,9_4500_CD_60;0.5_CH100 & 49,0 & 39,4 & 0,81 & FMA por compressão & 1:22:07 \\
\hline W360x32,9_4500_CD_60;1 & 82,7 & 78,9 & 0,95 & FMA por compressão & $0: 57: 06$ \\
\hline W360x32,9_4500_CD_60;1_CH100 & 56,7 & 55,3 & 0,98 & FMA por compressão & $0: 53: 45$ \\
\hline W360x32,9_4500_CD_60;2 & 82,9 & 73,9 & 0,89 & Vierendeel & $0: 38: 51$ \\
\hline W360x32,9_4500_CD_60;2_CH100 & 67,0 & 63,1 & 0,94 & FMA; FMA por compressão & $0: 40: 27$ \\
\hline
\end{tabular}




\subsubsection{Grupo 5 - Avaliação do comportamento de vigas de alma cheia}

\section{Objetivo}

Este grupo de vigas foi modelado com a finalidade de comparar o comportamento das vigas casteladas modeladas com as vigas originais de alma cheia.

\section{Descrição}

Para efeito de comparação com as vigas casteladas modeladas, os modelos deste grupo têm vãos de 3000, 4500 e $6000 \mathrm{~mm}$, com carga concentrada no centro do vão e carga uniformemente distribuída. Na Tabela 5.12 são mostradas as características destas vigas modeladas.

Tabela 5.12 - Características das vigas modeladas do Grupo 5.

\begin{tabular}{|c|c|c|c|}
\hline Modelo & Tipo de Carregamento & Perfil Original & $\begin{array}{l}\mathrm{L} \\
\mathrm{m}\end{array}$ \\
\hline W360x32,9_3000_CC1 & & & 3,000 \\
\hline W360x32,9_4500_CC1 & Carga concentrada no centro do vão & W360x32,9 & 4,500 \\
\hline W360x32,9_6000_CC1 & & & 6,000 \\
\hline W360x32,9_3000_CD & & & 3,000 \\
\hline W360x32,9_4500_CD & Carga uniformemente distribuída & W360x32,9 & 4,500 \\
\hline W360×32,9_6000_CD & & & 6,000 \\
\hline
\end{tabular}

\section{Resultados}

$\mathrm{Na}$ Tabela 5.13, apresenta-se os resultados obtidos a partir das simulações numéricas realizadas para os modelos do Grupo 5. Em todos esses casos, o modo de colapso se deu por flexão

Tabela 5.13 - Resultados das vigas modeladas do Grupo 5

\begin{tabular}{lcc}
\hline Nome da Viga & $\begin{array}{c}\text { Carga máxima } \\
\text { kN }\end{array}$ & $\begin{array}{c}\text { Tempo gasto na análise } \\
\text { hh:mm:ss }\end{array}$ \\
\hline W360x32,9_3000_CC1 & 258,0 & $0: 14: 09$ \\
W360x32,9_4500_CC1 & 171,2 & $0: 16: 47$ \\
W360x32,9_6000_CC1 & 127,2 & $0: 20: 53$ \\
W360x32,9_3000_CD & 164,3 & $0: 10: 53$ \\
W360x32,9_4500_CD & 73,3 & $0: 17: 01$ \\
W360x32,9_6000_CD & 41,3 & $0: 18: 03$ \\
\hline
\end{tabular}




\subsubsection{Grupo 6 - Avaliação da influência da altura da chapa expansora}

\section{Objetivo}

As modelagens deste grupo foram realizadas com o objetivo de verificar a influência da altura da chapa expansora nas vigas casteladas selecionadas.

\section{Descrição}

Este grupo consiste de vigas similares com variação da altura da chapa expansora. Foram modeladas vigas nos padrões Anglo-Saxão e Peiner. Na Tabela 5.14, apresenta-se as características das vigas modeladas.

Tabela 5.14 - Características das vigas analisadas do Grupo 6.

\begin{tabular}{lccccccc}
\hline Modelo & Perfil Original & $\begin{array}{c}\mathrm{L} \\
\mathrm{m}\end{array}$ & $\begin{array}{c}h_{0} \\
\mathrm{~mm}\end{array}$ & $\begin{array}{c}h_{p} \\
\mathrm{~mm}\end{array}$ & $\begin{array}{c}b_{w} \\
\mathrm{~mm}\end{array}$ & $\begin{array}{c}p \\
\mathrm{~mm}\end{array}$ & $N$ \\
\hline W360x32,9_3000_CC1_AS_CH50 & W360 x 32,9 & 3,000 & 399 & 50 & 87,3 & 376,9 & 7 \\
W360x32,9_3000_CC1_AS_CH200 & W360 x 32,9 & 3,000 & 549 & 200 & 87,3 & 376,9 & 7 \\
W360x32,9_3000_CC1_AS_CH300 & W360 x 32,9 & 3,000 & 649 & 300 & 87,3 & 376,9 & 7 \\
W360x32,9_3000_CC1_PN_CH50 & W360 X 32,9 & 3,000 & 399 & 50 & 174,5 & 523,5 & 5 \\
W360x32,9_3000_CC1_PN_CH200 & W360 x 32,9 & 3,000 & 549 & 200 & 174,5 & 523,5 & 5 \\
W360x32,9_3000_CC1_PN_CH300 & W360 x 32,9 & 3,000 & 649 & 300 & 174,5 & 523,5 & 5 \\
\hline
\end{tabular}

\section{Resultados}

$\mathrm{Na}$ Tabela 5.15, apresenta-se os resultados obtidos a partir das simulações numéricas realizadas para os modelos do Grupo 6.

Tabela 5.15 - Resultados das vigas modeladas do Grupo 6.

\begin{tabular}{|c|c|c|c|c|c|}
\hline Nome da Viga & $\begin{array}{c}\text { Carga de } \\
\text { Flambagem } \\
\text { Elástica }\left(\mathrm{P}_{\mathrm{cr}}\right) \\
\mathrm{kN}\end{array}$ & $\begin{array}{c}\text { Carga máxima } \\
\left(P_{\text {máx }}\right) \\
\text { kN }\end{array}$ & $\mathrm{P}_{\text {máx }} / \mathrm{P}_{\mathrm{cr}}$ & $\begin{array}{l}\text { Modo de } \\
\text { Colapso }\end{array}$ & $\begin{array}{c}\text { Tempo gasto } \\
\text { na análise } \\
\text { hh:mm:ss }\end{array}$ \\
\hline W360x32,9_3000_CC1_AS_CH50 & 245,0 & 222,5 & 0,91 & FMA & $0: 24: 41$ \\
\hline W360x32,9_3000_CC1_AS_CH200 & 155,0 & 135,6 & 0,88 & FMA & $0: 28: 50$ \\
\hline W360x32,9_3000_CC1_AS_CH300 & 125,6 & 115,7 & 0,92 & FMA & 0:28:02 \\
\hline W360x32,9_3000_CC1_PN_CH50 & 250,3 & 246,3 & 0,98 & FMA & $0: 24: 45$ \\
\hline W360x32,9_3000_CC1_PN_CH2O0 & 168,0 & 181,2 & 1,08 & FMA & 1:08:07 \\
\hline W360x32,9_3000_CC1_PN_CH300 & 137,0 & 157,8 & 1,15 & FMA & $0: 54: 39$ \\
\hline
\end{tabular}




\subsubsection{Grupo 7 - Avaliação da influência de enrijecedores de alma em vigas casteladas com colapso por FMA por compressão}

\section{Objetivos}

Observou-se, a partir dos resultados das análises numéricas anteriores, que as vigas com vãos curtos submetidas a carga distribuída ao longo do vão sofrem colapso predominantemente por flambagem do montante de alma por compressão, sendo que os montantes mais próximos do centro do vão são os que sofrem mais o efeito da flambagem. Na Figura 5.10, ilustra-se um caso em que a viga sofreu flambagem por compressão nos montantes.

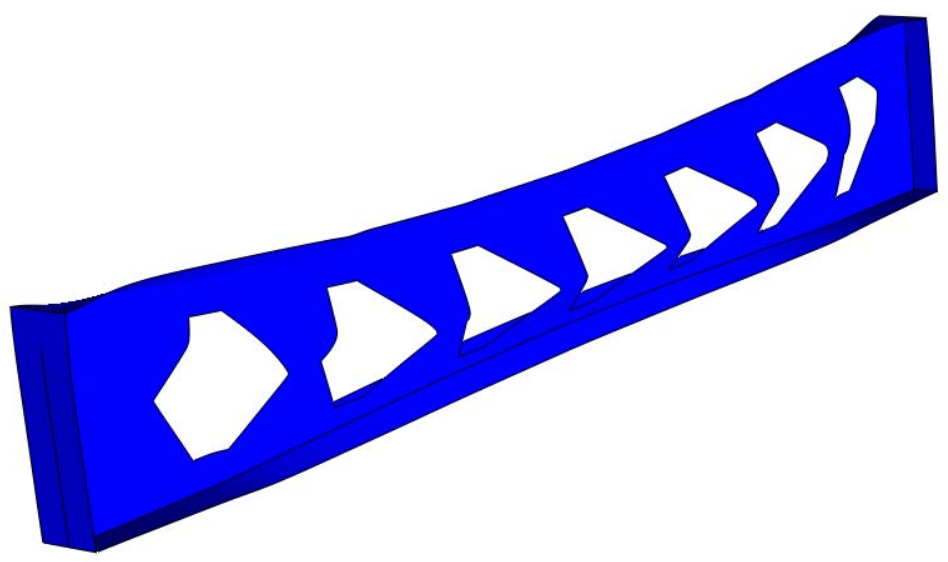

Figura 5.10 - Deformada de viga após a FMA por compressão.

\section{Descrição}

Uma vez que o efeito é mais crítico no centro do vão, foram analisadas novamente algumas vigas já processadas anteriormente, adicionando-se um enrijecedor nessa região com a finalidade de avaliar o ganho de capacidade resistente, uma vez que o deslocamento lateral dos montantes centrais torna-se impedido.

\section{Resultados}

$\mathrm{Na}$ Tabela 5.16, apresenta-se os resultados obtidos a partir das simulações numéricas realizadas com os modelos do Grupo 7. 
Tabela 5.16 - Resultados das vigas modeladas do Grupo 7.

\begin{tabular}{|c|c|c|c|c|c|}
\hline Nome da Viga & $\begin{array}{c}\text { Carga de } \\
\text { Flambagem } \\
\text { Elástica }\left(P_{c r}\right) \\
\text { kN } \\
\end{array}$ & $\begin{array}{l}\text { Carga máxima } \\
\left(P_{\text {máx }}\right) \\
k N \\
\end{array}$ & $\mathrm{P}_{\operatorname{máx}} / \mathrm{P}_{\text {cr }}$ & $\begin{array}{l}\text { Modo de } \\
\text { Colapso }\end{array}$ & $\begin{array}{c}\text { Tempo gasto } \\
\text { na análise } \\
\text { hh:mm:ss } \\
\end{array}$ \\
\hline W360x32,9_3000_CD_AS & 138,9 & 128,3 & 0,92 & FMA & $0: 50: 58$ \\
\hline W360x32,9_3000_CD_AS_CH100a & 98,9 & 99,1 & 1,00 & FMA & $0: 44: 43$ \\
\hline W360x32,9_4500_CD_45;2_CH100b & 68,6 & 75,4 & 1,10 & FMA & 1:21:01 \\
\hline $\begin{array}{l}\text { Nota: } \\
\text { a As características do modelo estão a } \\
\text { b As características do modelo estão a }\end{array}$ & $\begin{array}{l}\text { entadas na } \\
\text { entadas na }\end{array}$ & $\begin{array}{l} \\
5.5 \\
5.10\end{array}$ & & & \\
\hline
\end{tabular}

Na Figura 5.10 mostrou-se uma viga cujo colapso se deu por flambagem do montante de alma por compressão. A mesma viga foi modelada adicionando-se um enrijecedor de alma no centro do vão, como mostrado na Figura 5.11. Pode-se notar que a flambagem dos montantes de alma por compressão é impedida e o colapso passa a se dar por flambagem dos montantes de alma por cisalhamento, na região de esforço cortante máximo.

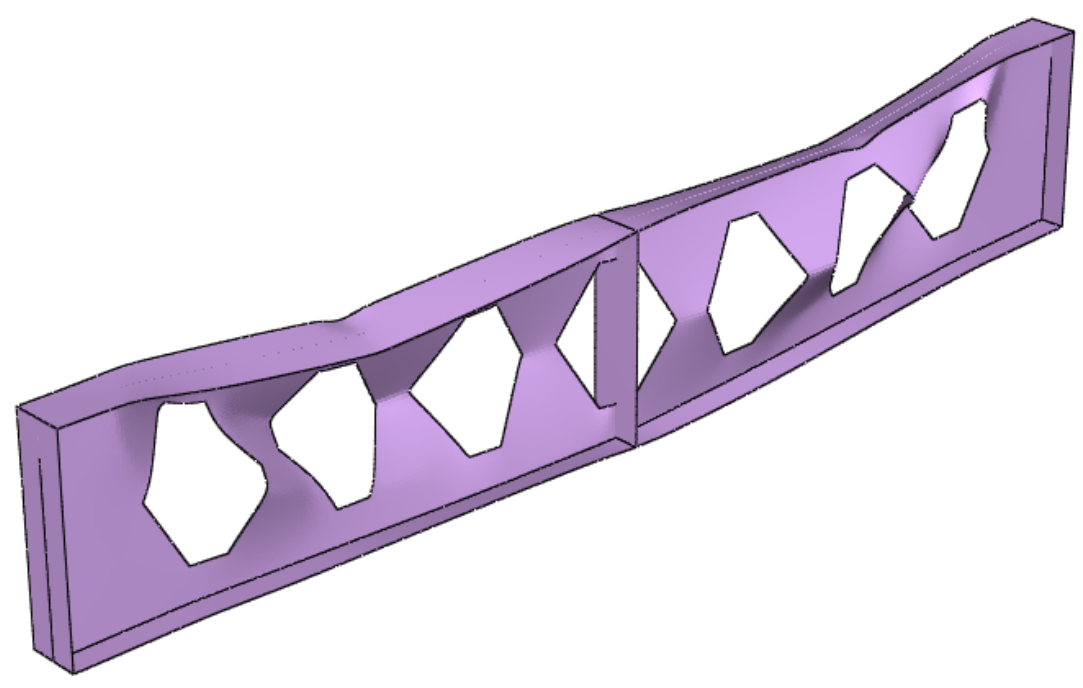

Figura 5.11 - Deformada da viga da Figura 5.10 com enrijecedor adicional no centro do vão. 


\section{DISCUSSÃO}

Neste capítulo são discutidos os resultados obtidos a partir das simulações realizadas no estudo paramétrico.

Na Figura 6.1 apresenta-se a carga de flambagem elástica dos montantes de alma das vigas analisadas no subgrupo 2.1 do estudo paramétrico e na Figura 6.2, a capacidade máxima dessas mesmas vigas. São mostrados os resultados para as vigas de máxima, média e mínima esbeltez da alma, de cada uma das três séries de perfis utilizados (W310, W360 e W410). Na figura são mostrados os resultados obtidos numericamente para os padrões de fabricação Anglo-Saxão e Peiner, com e sem chapa expansora. 


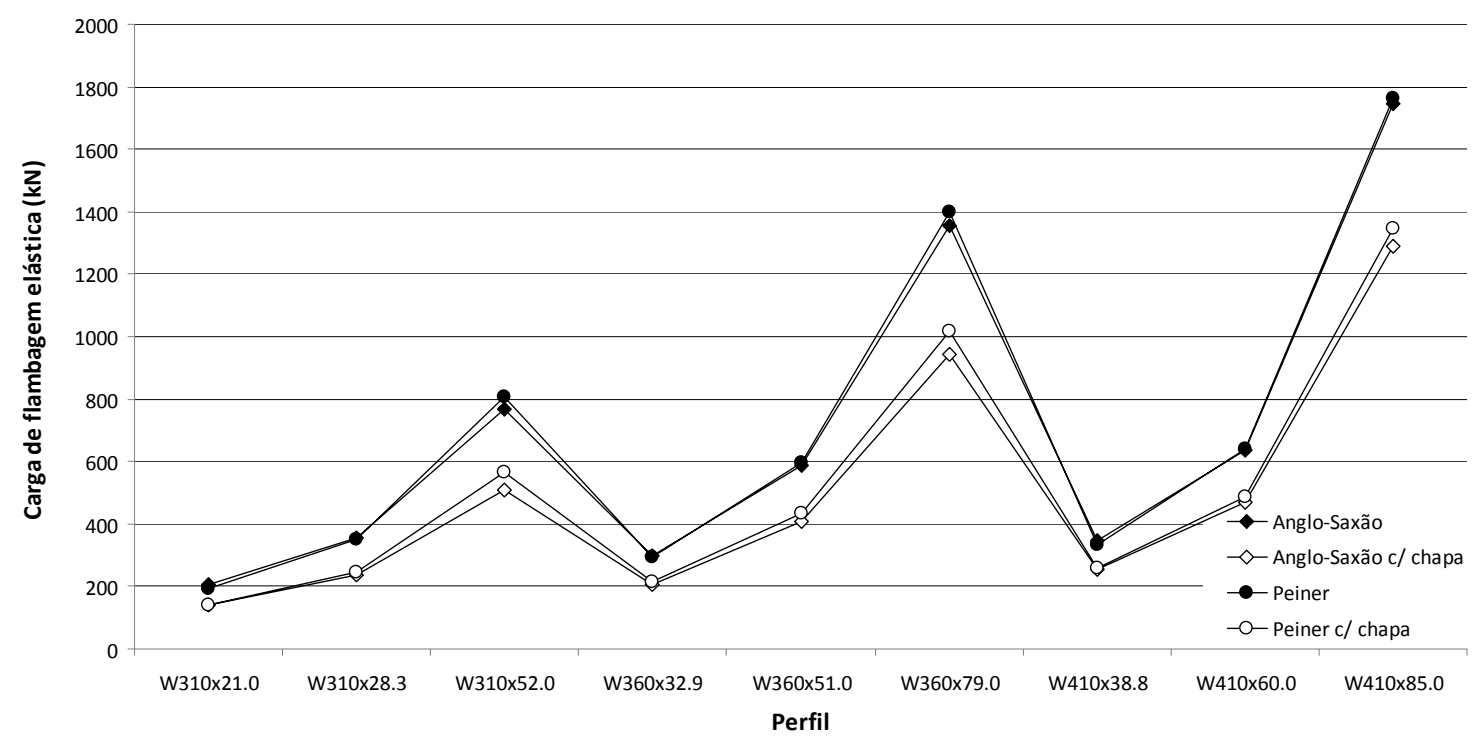

Figura 6.1 - Carga de FMA elástica das vigas casteladas, com vão de 3000 mm.

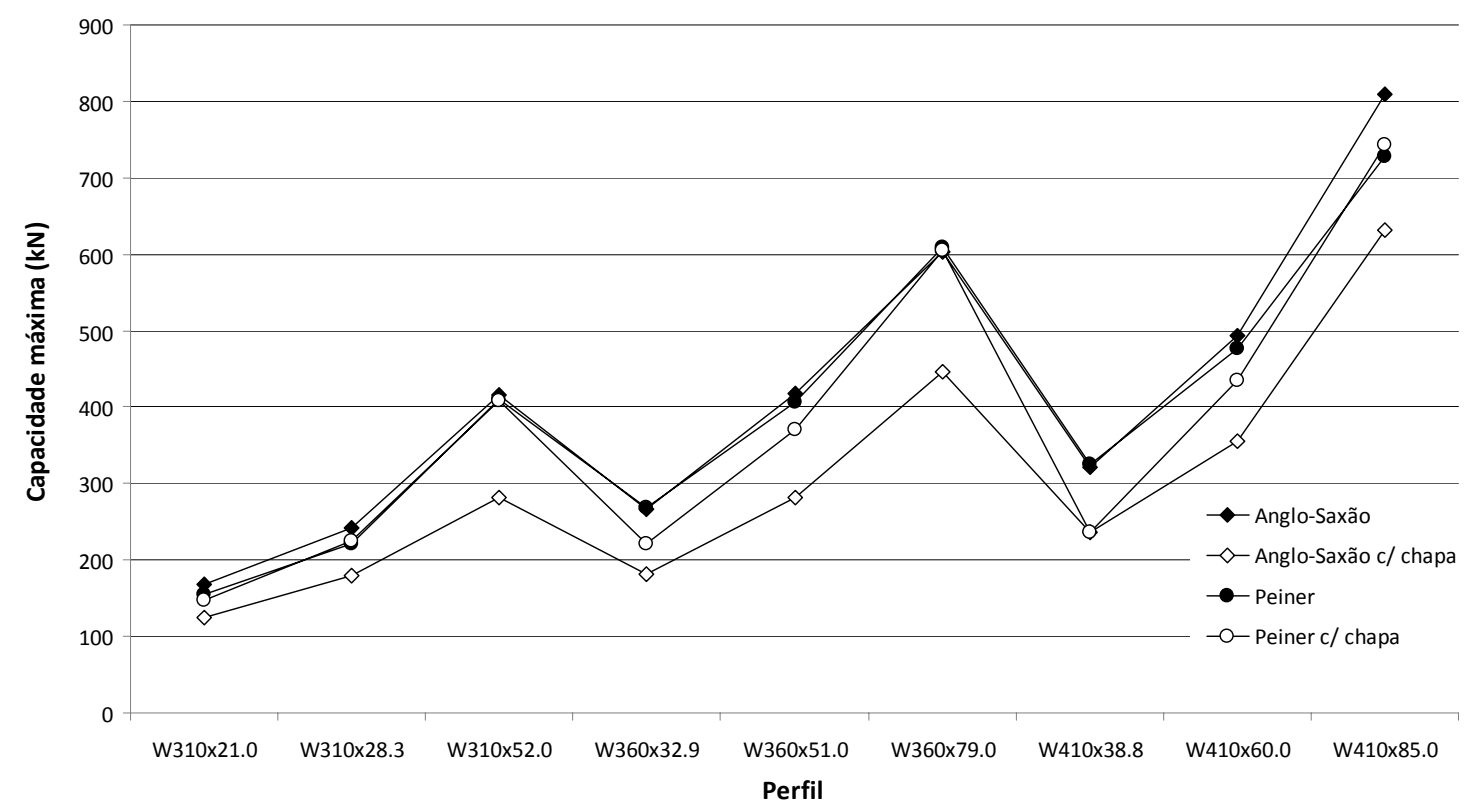

Figura 6.2 - Capacidade máxima das vigas casteladas, com vão de 3000 mm.

Nota-se que, para os perfis com alma mais esbelta, a utilização da chapa expansora deixa a viga mais susceptível à flambagem, havendo um decréscimo de capacidade resistente em relação às vigas sem chapa expansora. Observa-se também que a carga limite mais baixa se dá para as vigas casteladas no padrão Anglo-Saxão com chapa expansora. Isto se deve ao fato de que os montantes nesse padrão possuem largura mínima menor do que no padrão Peiner, devido à sua forma, o que facilita a flambagem do montante de alma (ver 
item 3.2.5). Percebe-se também, nos gráficos, que as vigas com baixa esbeltez da alma sofrem pequena influência do padrão de fabricação, uma vez que as propriedades geométricas relacionadas à flexão são similares tanto num padrão como no outro.

Na Figura 6.3, mostra-se uma correlação entre a relação altura/vão e a capacidade resistente das vigas casteladas no padrão Anglo-Saxão para a série W310 da Açominas, modeladas nos grupos 1 e 2 do estudo paramétrico.

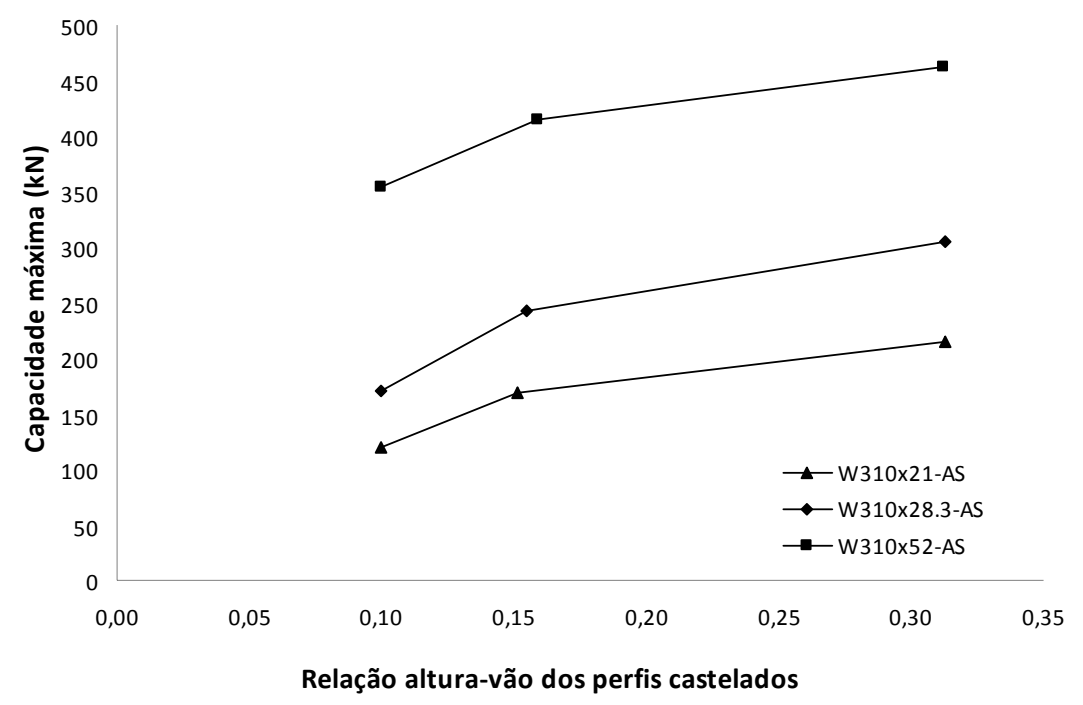

Figura 6.3 - Capacidade máxima das vigas casteladas padrão Anglo-Saxão, da série W310, submetidas a carregamento concentrado no centro do vão.

A mesma correlação é apresentada a seguir, na Figura 6.4, na Figura 6.5 e na Figura 6.6, para as vigas casteladas produzidas a partir do perfil W360 × 32,9, do Grupo 2 do estudo paramétrico. Na Figura 6.4, apresenta-se o gráfico para as vigas submetidas a carregamento concentrado no centro do vão; na Figura 6.5, mostram-se os resultados das vigas com duas cargas concentradas nos terços médios do vão e na Figura 6.6 têm-se a representação para as vigas submetidas a uma carga uniformemente distribuída. 


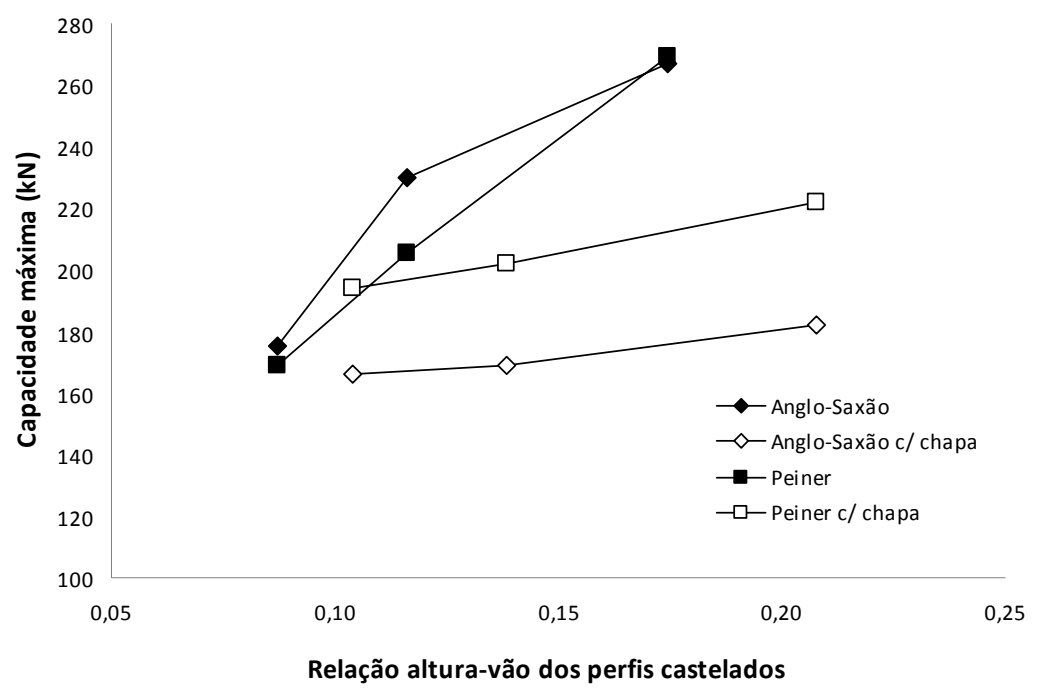

Figura 6.4 - Capacidade máxima das vigas casteladas padrão Anglo-Saxão fabricadas a partir do perfil W360x32,9, submetidas a carregamento concentrado no centro do vão.

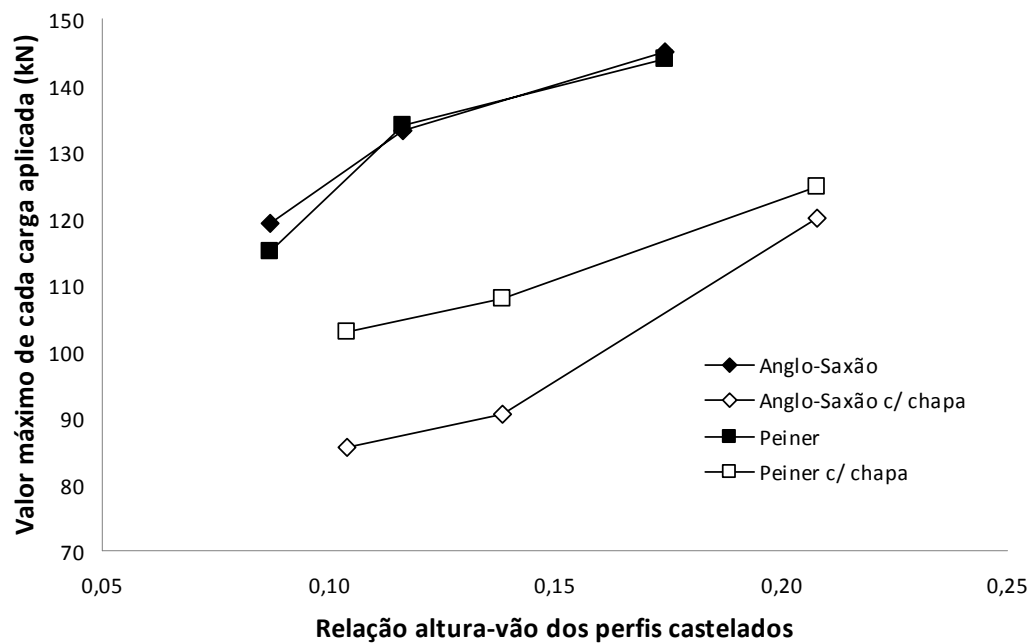

Figura 6.5 - Capacidade máxima das vigas casteladas padrão Anglo-Saxão fabricadas a partir do perfil W360x32,9, submetidas a duas cargas concentradas nos terços médios do vão.

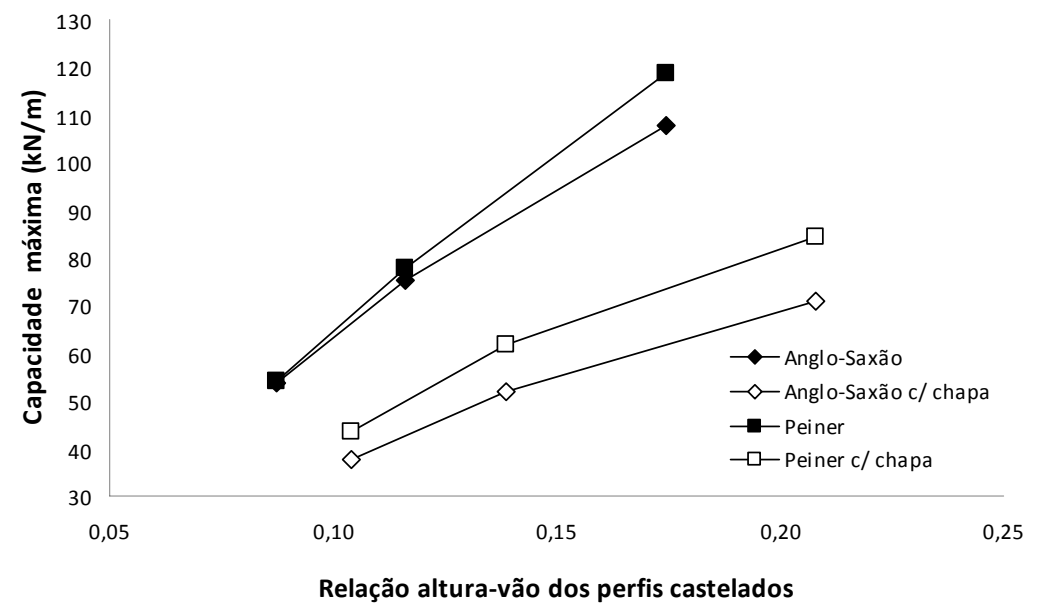

Figura 6.6 - Capacidade máxima das vigas casteladas padrão Anglo-Saxão fabricadas a partir do perfil W360x32,9, submetidas a carregamento uniformemente distribuído. 
Na Figura 6.7, Figura 6.8, Figura 6.9 e Figura 6.10 são apresentadas as correlações entre a esbeltez da alma castelada $\left(h_{g} / t_{w}\right)$ e a razão $P_{\text {máx }} / P_{c r}$ para as vigas modeladas do subgrupo 2.1 do estudo paramétrico, separando-se as vigas que falharam por FMA daquelas que sofreram outros modos de colapso.

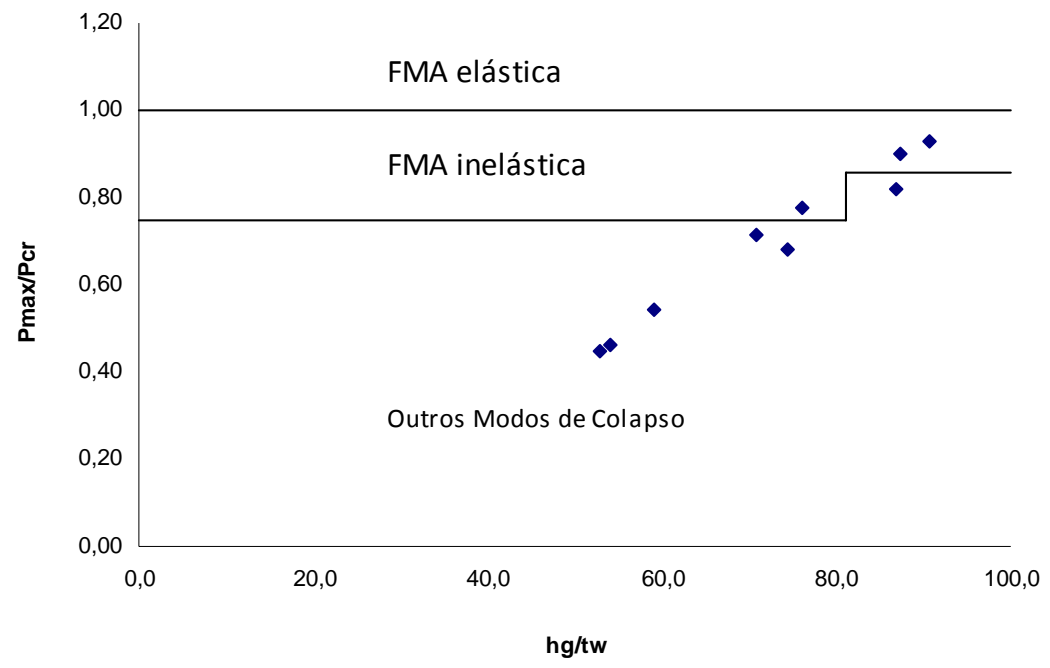

Figura 6.7 - Correlação entre esbeltez da alma $\left(h_{g} / t_{w}\right)$, relação $P_{\text {máx }} / P_{c r}$ e modos de colapso das vigas de padrão Anglo-Saxão sem chapa expansora, modeladas do subgrupo 2.1.

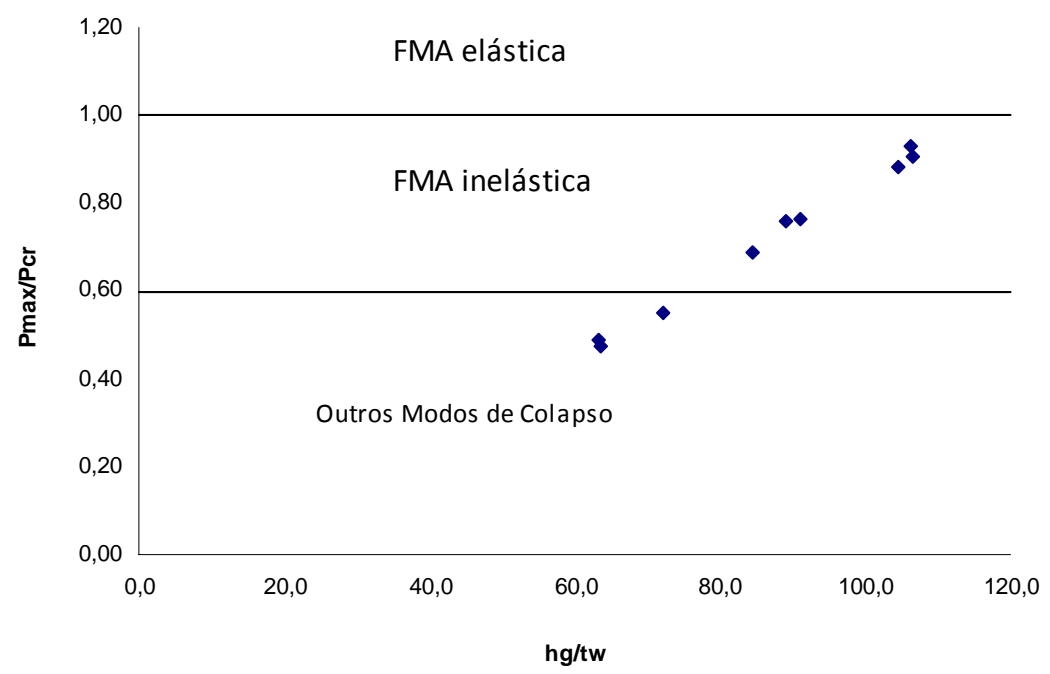

Figura 6.8 - Correlação entre esbeltez da alma $\left(h_{g} / t_{w}\right)$, relação $P_{\text {máx }} / P_{c r}$ e modos de colapso das vigas de padrão Anglo-Saxão com chapa expansora, modeladas do subgrupo 2.1. 


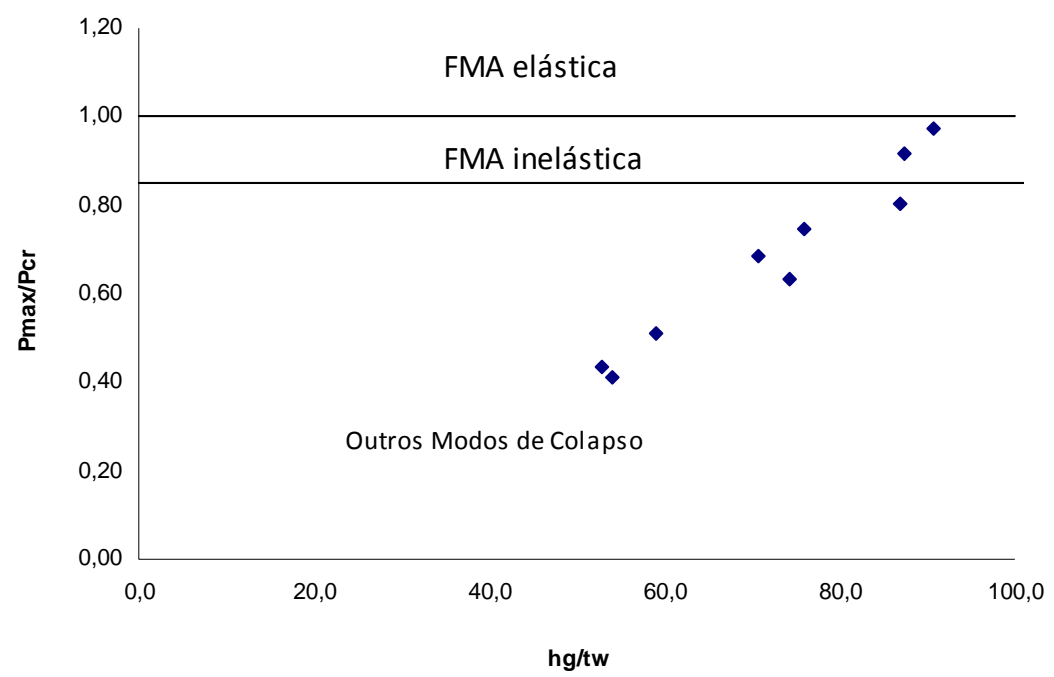

Figura 6.9 - Correlação entre esbeltez da alma $\left(h_{g} / t_{w}\right)$, relação $P_{\text {máx }} / P_{c r}$ e modos de colapso das vigas de padrão Peiner sem chapa expansora, modeladas do subgrupo 2.1.

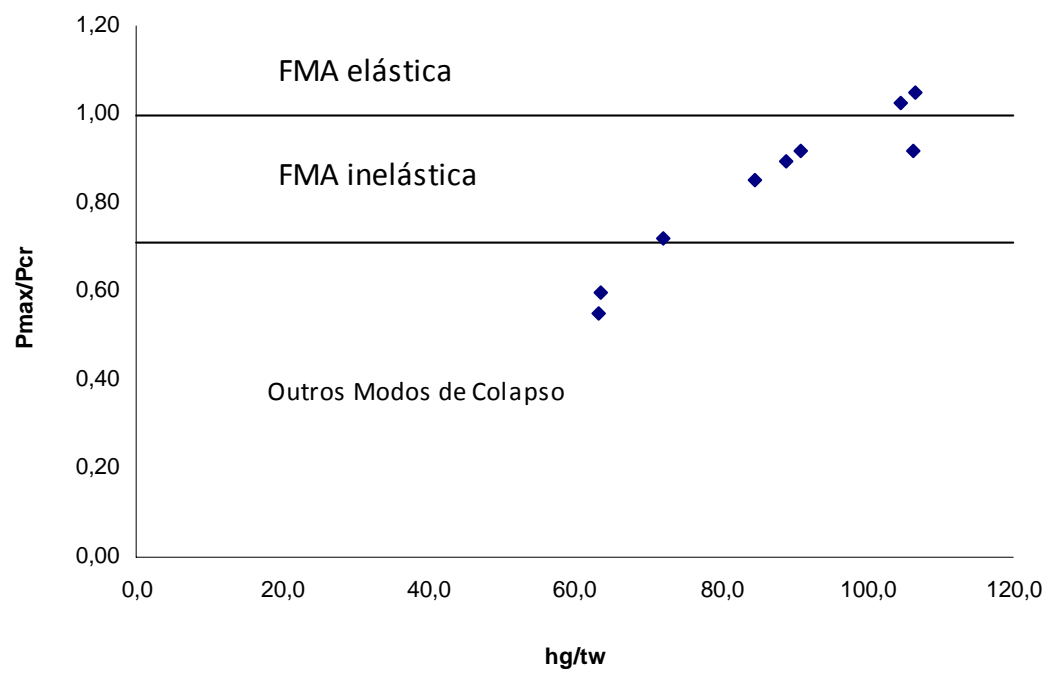

Figura 6.10 - Correlação entre esbeltez da alma $\left(h_{g} / t_{w}\right)$, relação $P_{\text {máx }} / P_{c r}$ e modos de colapso das vigas de padrão Peiner com chapa expansora, modeladas do subgrupo 2.1.

Observou-se que nas vigas casteladas sem chapa expansora, apenas aquelas com alma mais esbelta sofreram colapso por FMA. Já nas vigas com chapa expansora, como a chapa aumenta a esbeltez da alma, tanto as mais esbeltas quanto as intermediárias sofreram colapso pela instabilidade dos montantes de alma. Observa-se também, a partir dos resultados das análises, que a maioria das vigas que colapsaram por FMA sofreram intensa plastificação, como se pode ver na Figura 6.11. Na figura, as regiões em vermelho estão submetidas à tensão de escoamento do material. 


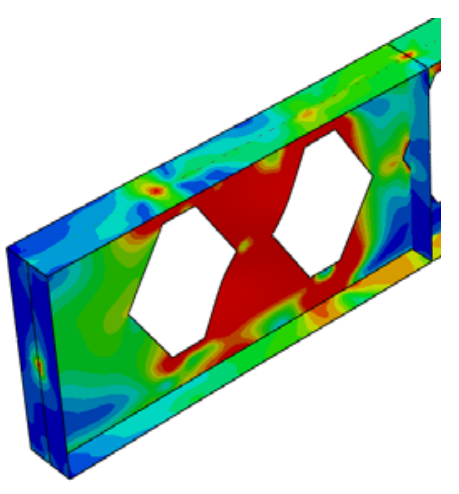

(a)

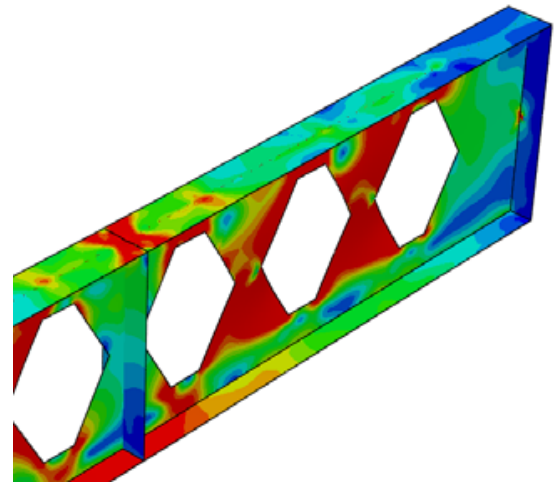

(b)

Figura 6.11 - Distribuição de tensões nas vigas: (a) W360x32,9_3000_CC2_AS (ver Tabela 5.8) e (b) W410x38,8_3000_CC1_AS (ver Täbela 5.5).

Observando-se as figuras anteriores, pode-se notar que a flambagem dos montantes quase sempre ocorre em regime inelástico $\left(P_{m a \dot{x}} / P_{c r}<1,0\right)$, mesmo nas vigas com alma esbelta. A flambagem elástica dos montantes de alma raramente ocorre e somente foi observada em vigas com alma esbelta e com chapa expansora.

Na Figura 6.12 é apresentada a carga de flambagem elástica do montante de alma das vigas do Grupo 4 e, na Figura 6.13, a carga última para essas mesmas vigas. Todas essas vigas estavam submetidas a uma carga concentrada no centro do vão. Em ambas as figuras a carga é expressa em função da relação $b_{w} / b$, do ângulo das aberturas e da presença de chapa expansora nas vigas. As chapas expansoras possuíam altura de $100 \mathrm{~mm}$.

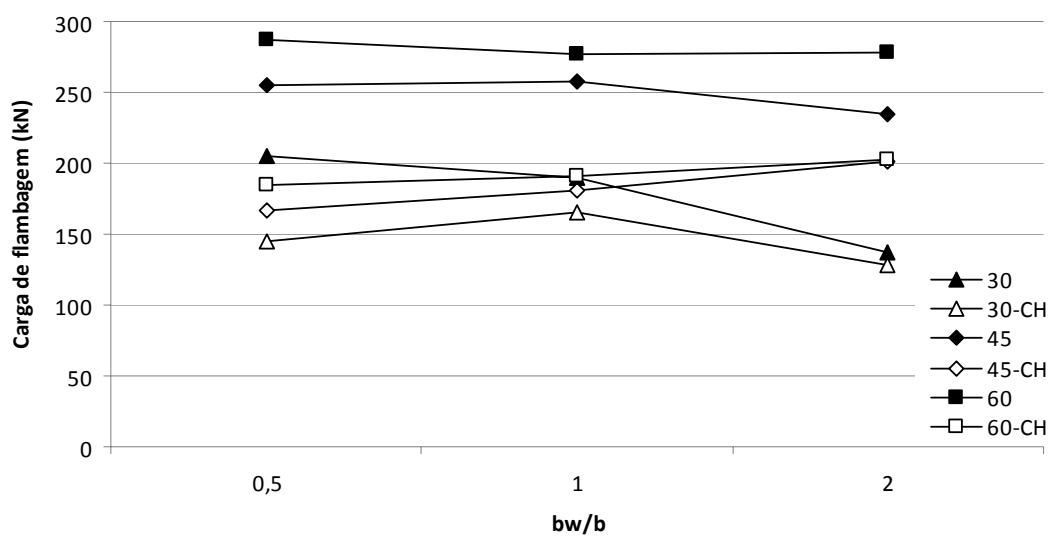

Figura 6.12 - Relação entre carga crítica e razão $b_{w} / b$ das vigas casteladas submetidas a carga concentrada no centro do vão, perfil W360 x 32,9 (Grupo 4). 


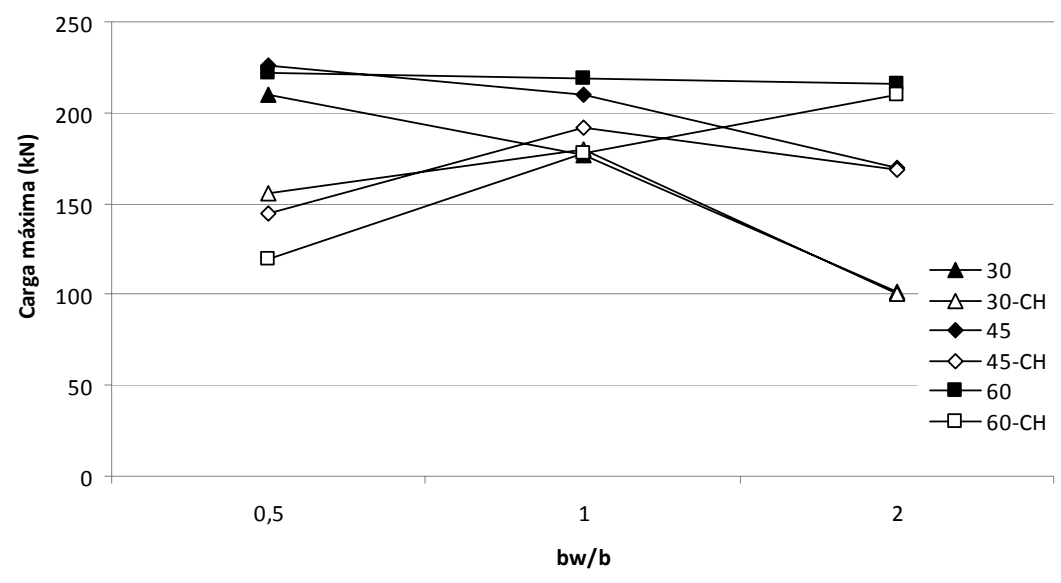

Figura 6.13 - Carga última de vigas casteladas submetidas a carga concentrada no centro do vão em relação à razão $b_{w} / b$, perfil W360 x 32,9 (Grupo 4).

Observa-se que a carga de FMA elástica é mais baixa nas vigas com chapa expansora, já que esses elementos causam um aumento da esbeltez dos montantes. Nota-se também, na Figura 6.13, que para as vigas com baixa relação $b_{w} / b$ a influência da chapa expansora é bastante significativa, negativamente, na capacidade última. Isso se deve ao fato da largura mínima do montante, $b_{w}$, ser reduzida, o que leva a uma alta relação $h_{o} / b_{w}$ quando se utiliza a chapa expansora, propiciando a ocorrência da FMA (ver item 3.2.5).

Por outro lado, nas vigas com a relação $b_{w} / b$ maior, a influência da chapa expansora na capacidade última é muito pequena, como se pode ver na Figura 6.13. O ângulo das aberturas interfere significativamente na capacidade última dessas vigas, isto porque essas vigas são mais susceptíveis a outros modos de colapso, com destaque para o mecanismo Vierendeel, que tende a ocorrer nas aberturas mais alongadas.

As mesmas considerações feitas para essas vigas podem ser feitas para as vigas submetidas a um carregamento distribuído, como pode ser visto na Figura 6.14 e na Figura 6.15. 


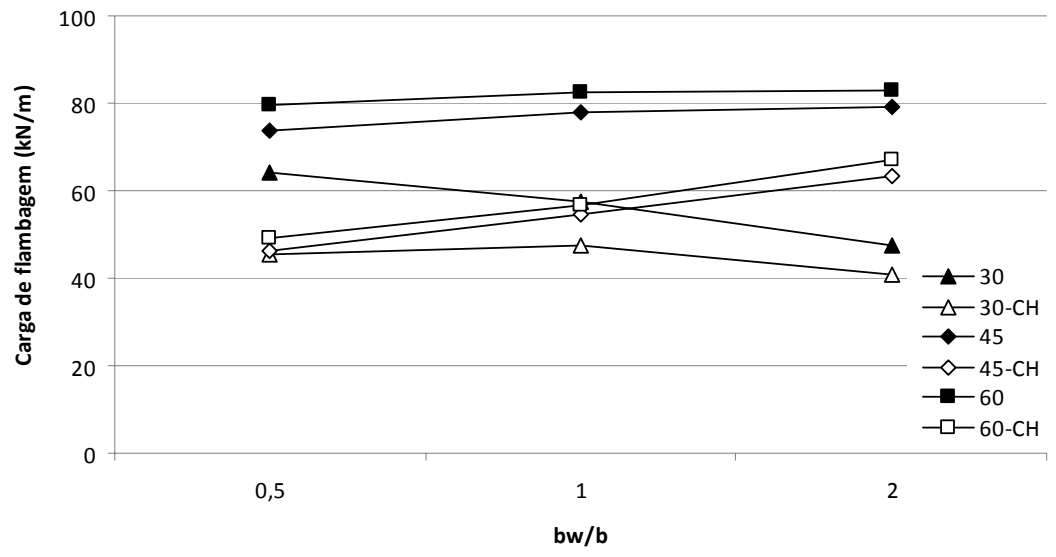

Figura 6.14 - Relação entre carga crítica e razão $b_{w} / b$ das vigas casteladas submetidas a carregamento uniformemente distribuído, perfil W360 x 32,9 (Grupo 4).

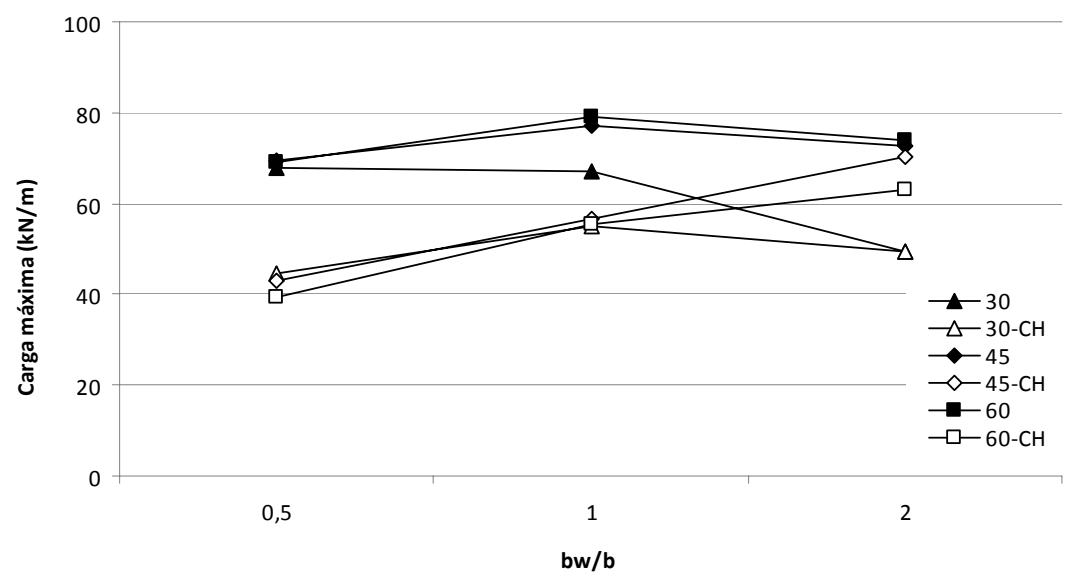

Figura 6.15 - Carga última de vigas casteladas submetidas a carregamento uniformemente distribuído em relação à razão $b_{w} / b$, perfil W360 x 32,9 (Grupo 4).

Os mesmos resultados, relacionando-se a carga de flambagem e a carga última com o ângulo da abertura, são apresentados nos gráficos da Figura 6.16 à Figura 6.19.

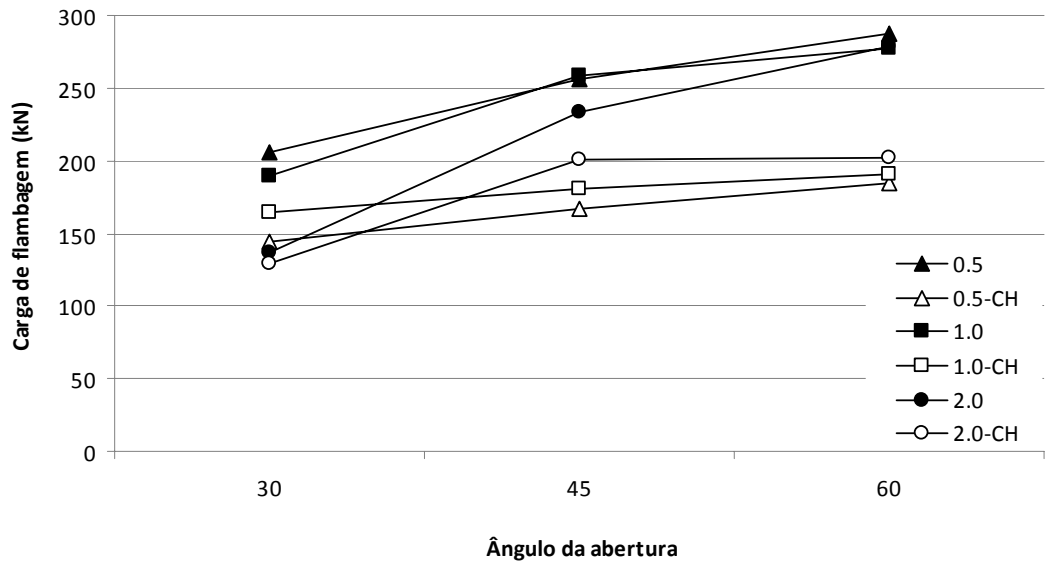

Figura 6.16 - Relação entre carga crítica e ângulo das aberturas nas vigas casteladas submetidas a carregamento concentrado no centro do vão, perfil W360 x 32,9 (Grupo 4). 


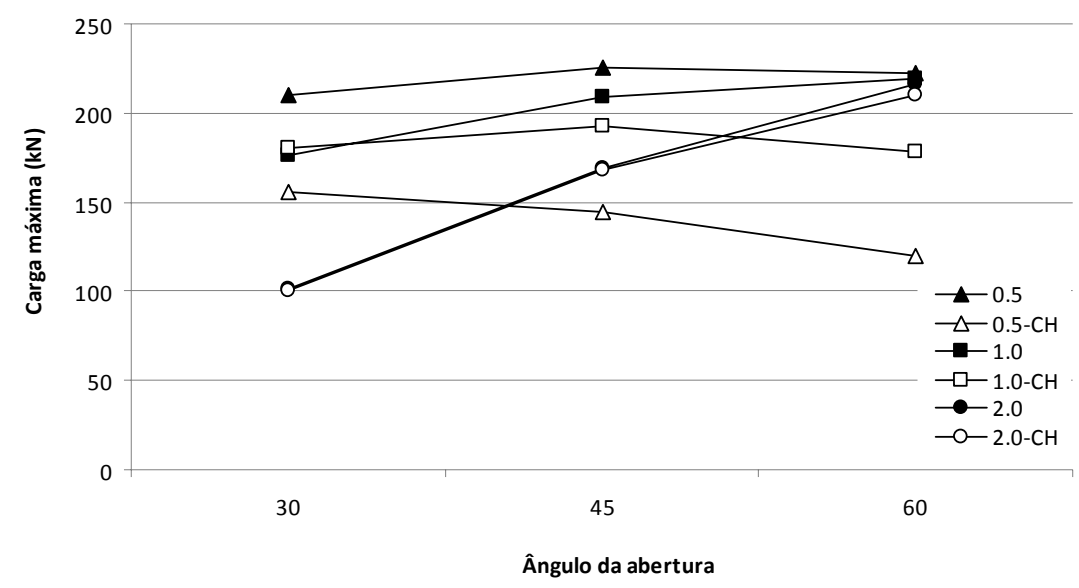

Figura 6.17 - Carga última de vigas casteladas submetidas a carregamento concentrado no centro do vão em relação ao ângulo das abertura, perfil W360 x 32,9 (Grupo 4).

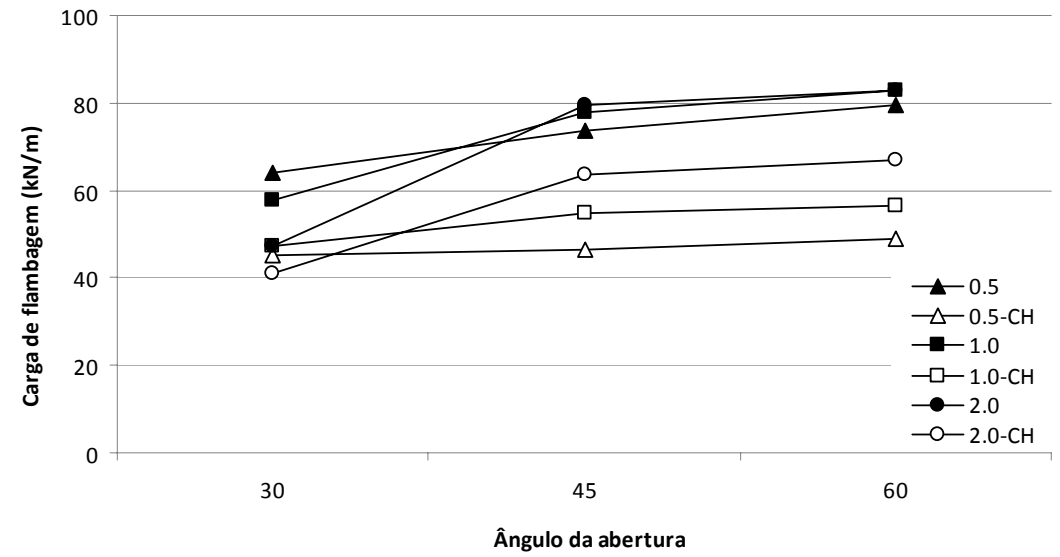

Figura 6.18 - Relação entre carga crítica e ângulo das aberturas nas vigas casteladas submetidas a carregamento uniformemente distribuído, perfil W360 x 32,9 (Grupo 4).

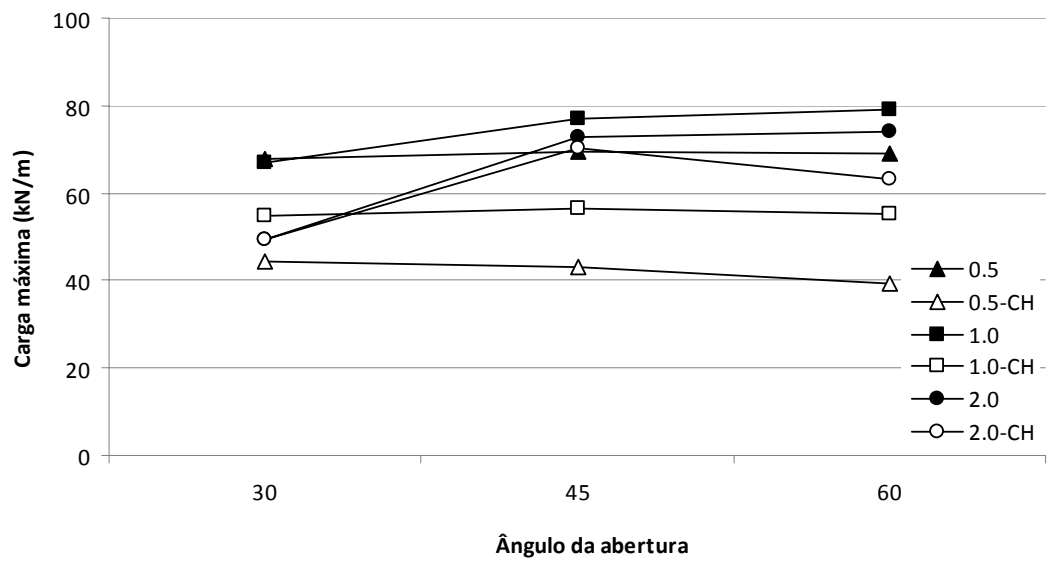

Figura 6.19 - Carga última de vigas casteladas submetidas a carregamento uniformemente distribuído em relação ao ângulo das aberturas, perfil W360 x 32,9 (Grupo 4). 
Observa-se dos gráficos da Figura 6.16 à Figura 6.19 que nas aberturas com ângulos maiores o efeito da chapa intermediária é mais notável, já que as vigas com essa geometria têm maior susceptibilidade à flambagem dos montantes (ver Figura 5.8 e Figura 5.9).

A seguir são apresentadas as curvas carga-deslocamento das vigas casteladas do Grupo 4 do estudo paramétrico, a fim de comparar o comportamento dessas vigas com diferentes geometrias de aberturas. Na Figura 6.20, na Figura 6.21 e na Figura 6.22 são apresentadas as curvas carga-deslocamento das vigas cujos alvéolos possuem lados inclinados com ângulo de $30^{\circ}, 45^{\circ}$ e $60^{\circ}$, respectivamente.

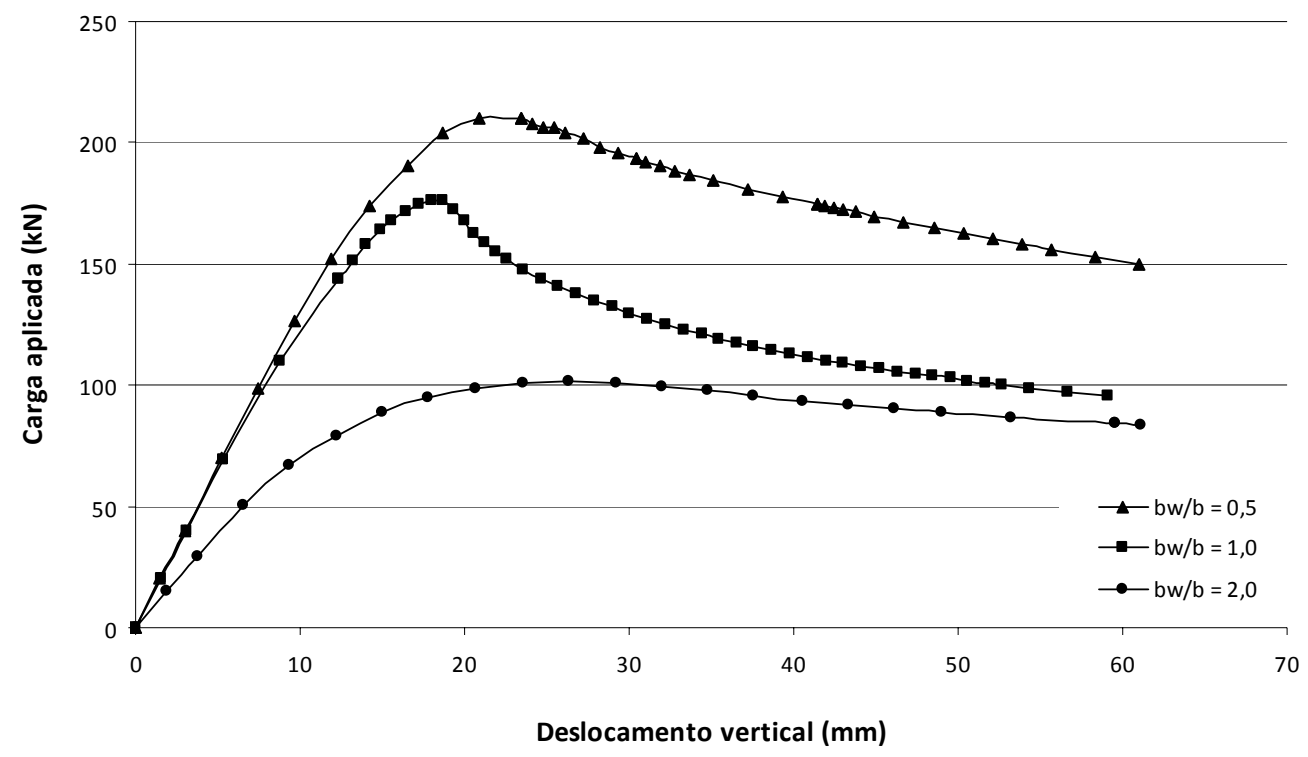

Figura 6.20 - Curva carga-deslocamento das vigas com ângulo do lado inclinado do alvéolo igual a $30^{\circ}$ (ver Figura 5.4) e submetidas a uma carga concentrada no centro do vão, perfil W360 x 32,9. 


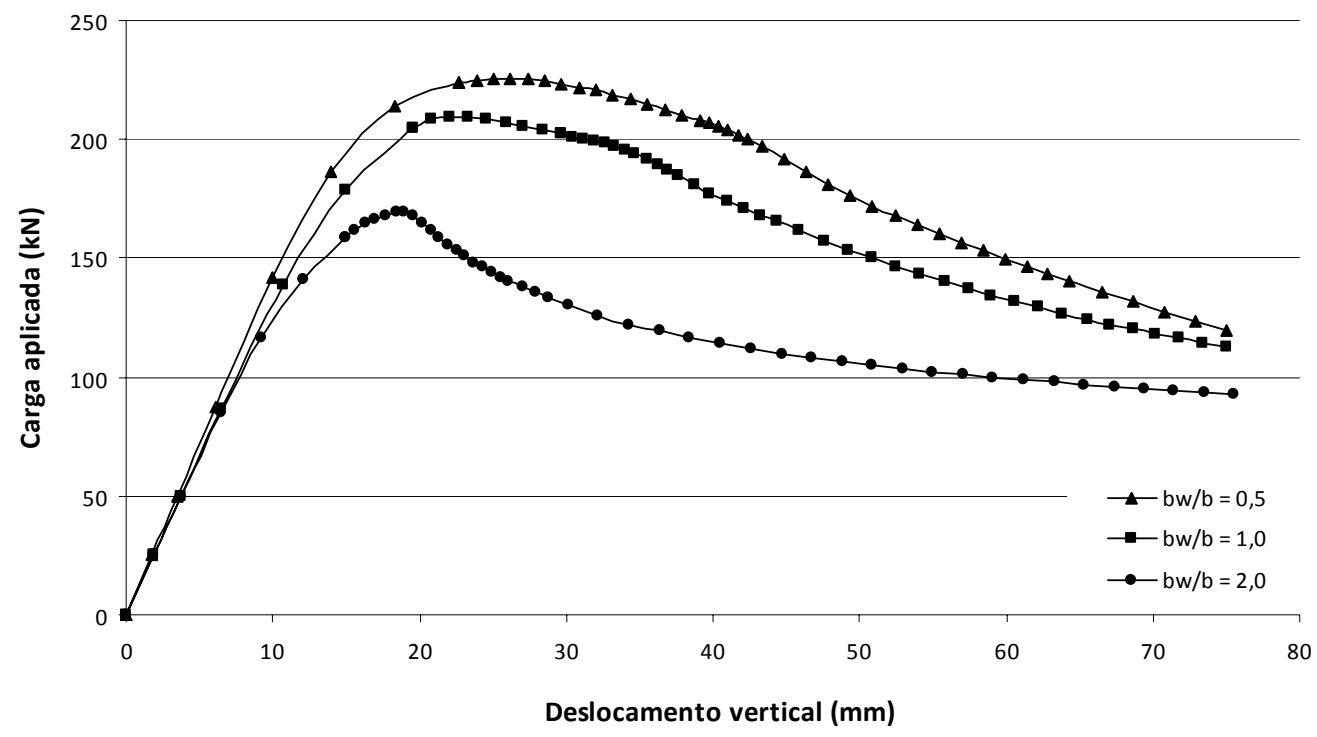

Figura 6.21 - Curva carga-deslocamento das vigas com ângulo do lado inclinado do alvéolo igual a $45^{\circ}$ (ver Figura 5.6) e submetidas a uma carga concentrada no centro do vão, perfil W360 x 32,9.

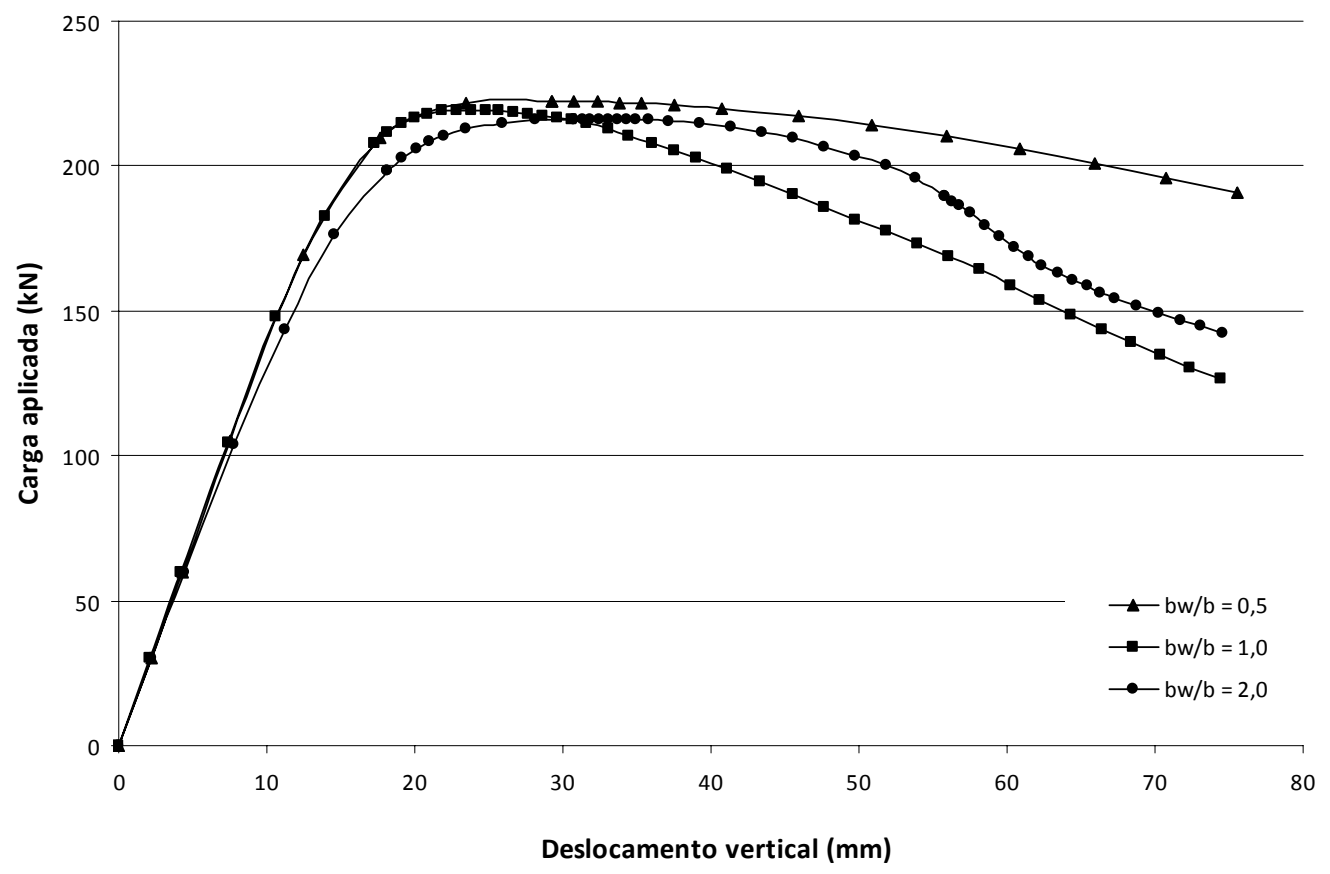

Figura 6.22 - Curva carga-deslocamento das vigas com ângulo do lado inclinado do alvéolo igual a $60^{\circ}$ (ver Figura 5.8) e submetidas a uma carga concentrada no centro do vão, perfil W360 x 32,9.

Observando-se as curvas da Figura 6.20, da Figura 6.21 e da Figura 6.22, nota-se que a relação $b_{w} / b$ tem influência na capacidade resistente e na rigidez das vigas, principalmente quando se trata das vigas cujas aberturas possuem menor ângulo de abertura. Nas vigas com ângulo de $30^{\circ}$ ou $45^{\circ}$, pode-se observar que tanto a rigidez como a capacidade resistente decrescem com o aumento da relação $b_{w} / b$. 
Na Figura 6.23, na Figura 6.24 e na Figura 6.25, as curvas carga-deslocamento são agrupadas para relação $b_{w} / b$ igual a $1 / 2,1$ e 2 , respectivamente.

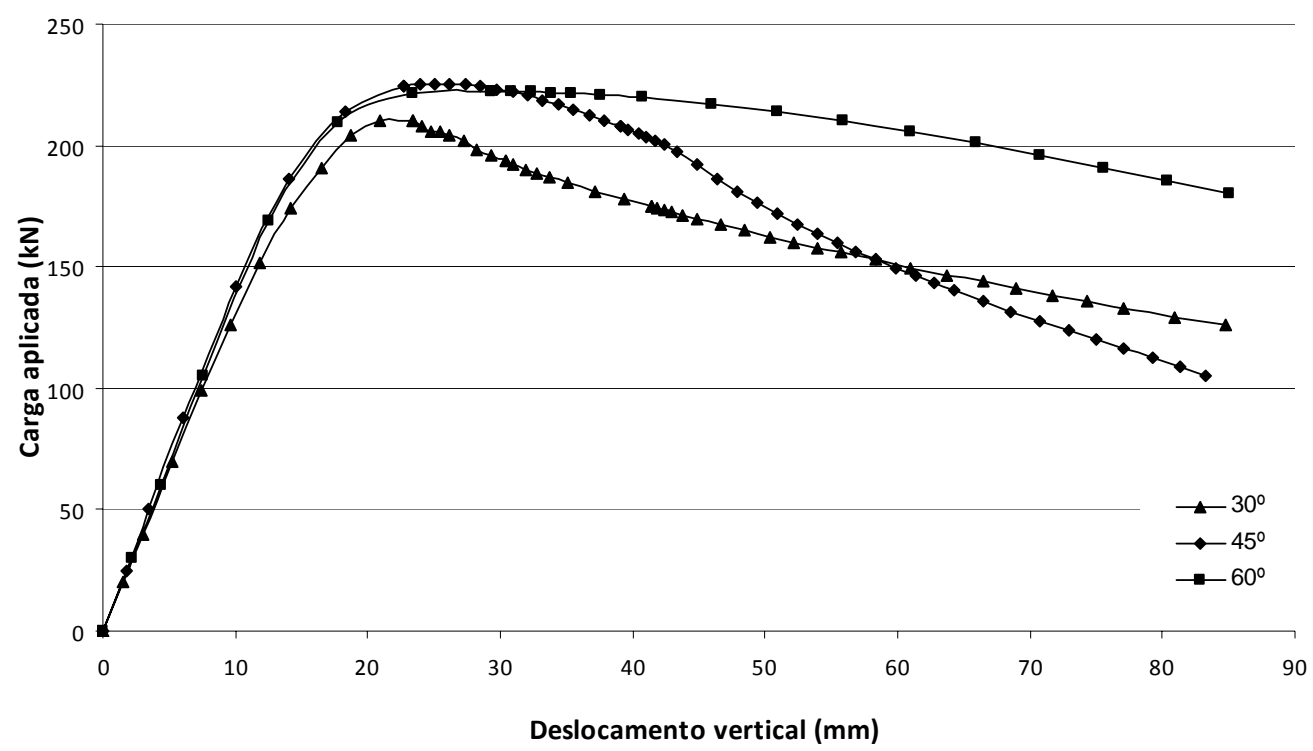

Figura 6.23 - Curva carga-deslocamento das vigas relação $b_{w} / b=0,5$ (ver Figura 5.4a, Figura 5.6a, Figura 5.8a) e submetidas a um carregamento concentrado no centro do vão, perfil W360 x 32,9.

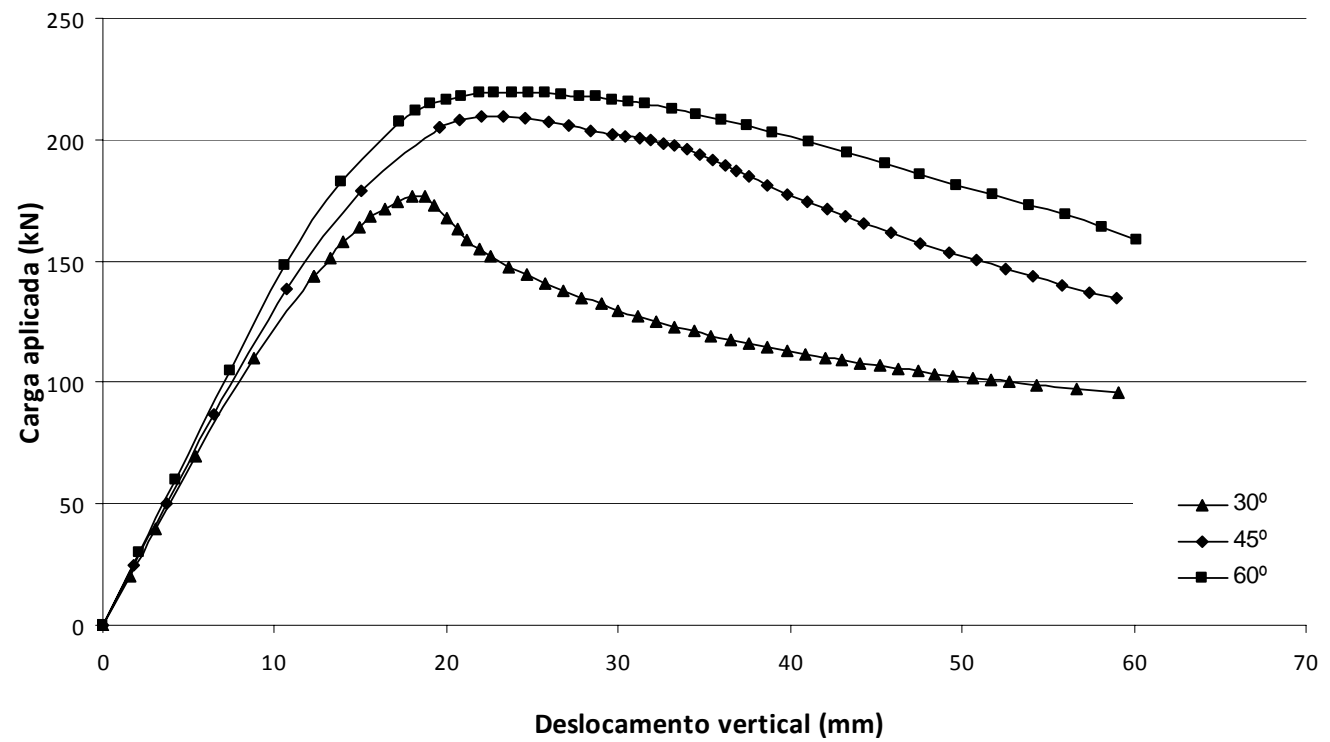

Figura 6.24 - Curva carga-deslocamento das vigas relação $b_{w} / b=1,0$ (ver Figura 5.4b, Figura 5.6b, Figura 5.8b) e submetidas a um carregamento concentrado no centro do vão, perfil W360 x 32,9. 


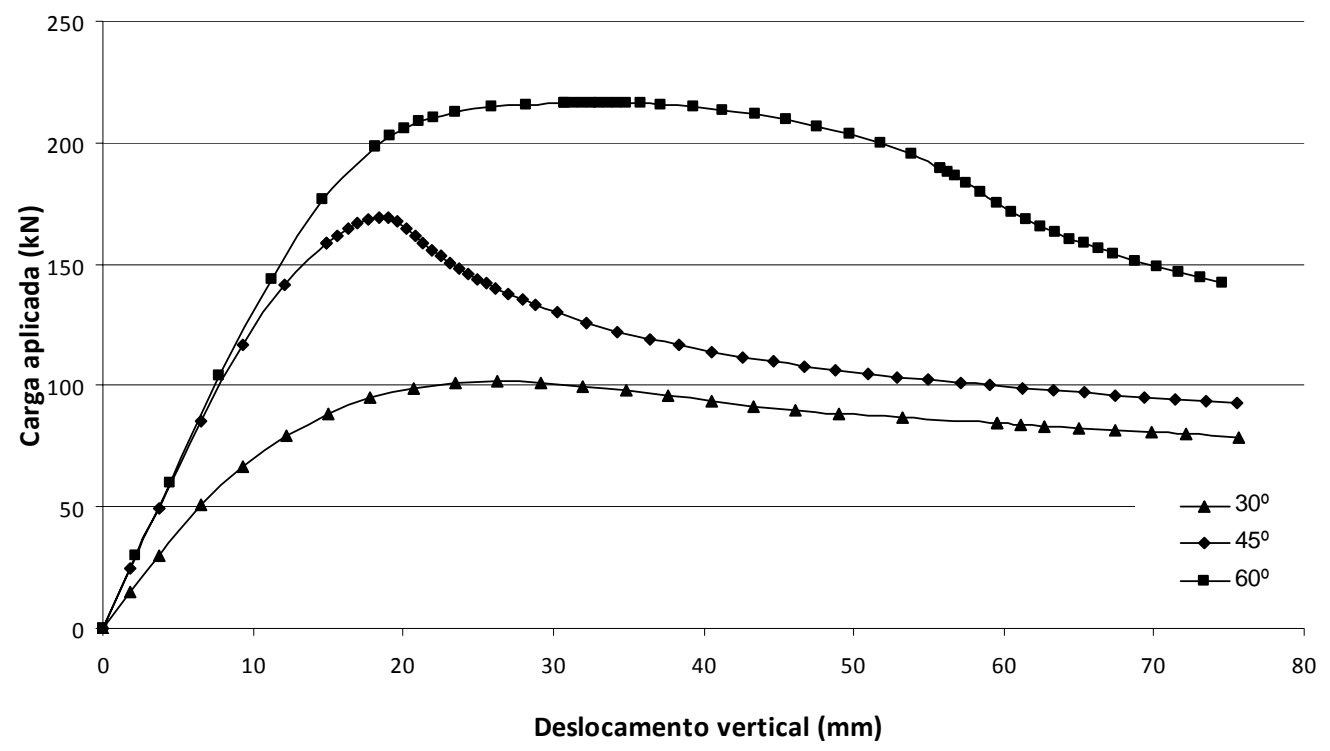

Figura 6.25 - Curva carga-deslocamento das vigas relação $b_{w} / b=2,0$ (ver Figura 5.4c, Figura 5.6c, Figura 5.8c) e submetidas a um carregamento concentrado no centro do vão, perfil W360 x 32,9.

Observando-se as curvas da Figura 6.23, da Figura 6.24 e da Figura 6.25, percebe-se que a capacidade resistente e a rigidez das vigas são também função do ângulo de abertura das mesmas. Nota-se que as vigas com aberturas mais inclinadas apresentam maior rigidez e resistência, principalmente naquelas com maior relação $b_{w} / b$.

Na Figura 6.26 e na Figura 6.27 são apresentadas a capacidade resistente das vigas casteladas nos padrões Anglo-Saxão e Peiner, com e sem a utilização de chapa expansora, em comparação com as vigas originais não-casteladas. 


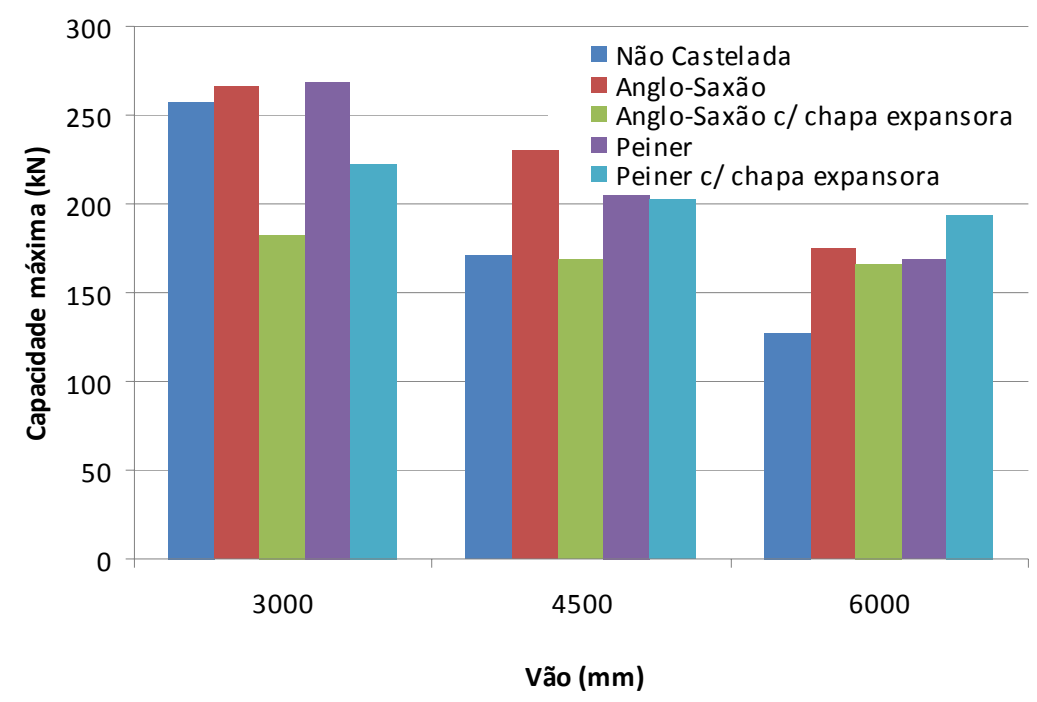

Figura 6.26 - Capacidade última das vigas submetidas a carregamento concentrado no centro do vão, perfil W360 x 32,9.

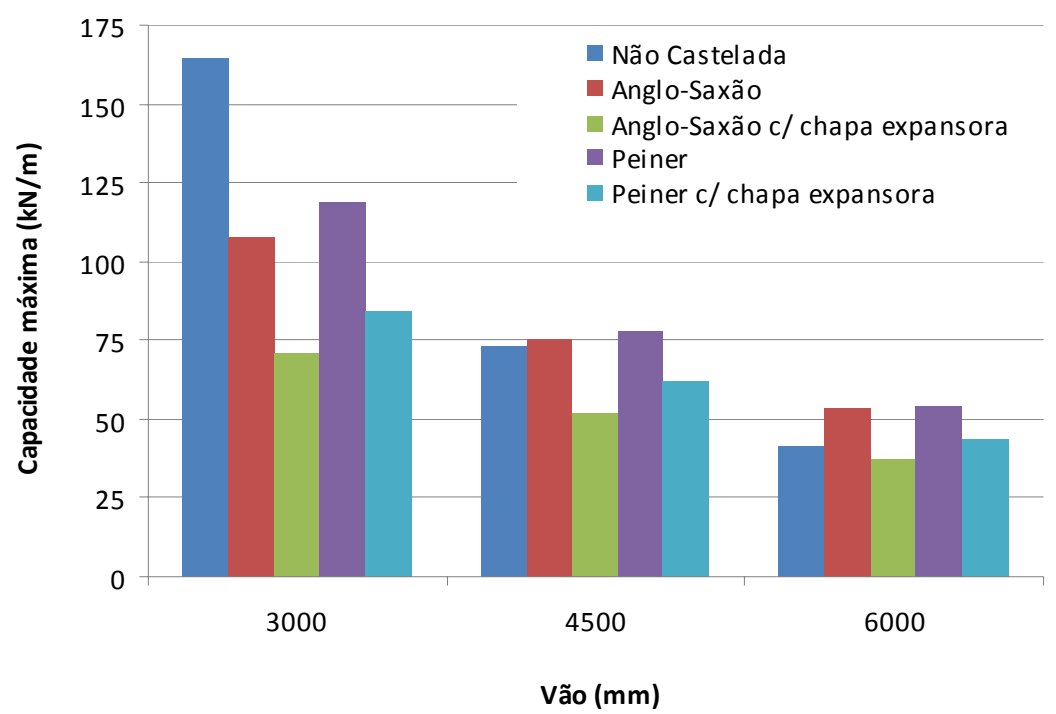

Figura 6.27 - Capacidade última das vigas submetidas a carregamento distribuído, perfil W360 x 32,9.

Observando os gráficos acima, nota-se que à medida que o vão das vigas aumenta, e a resistência à flexão passa a ter importância maior no comportamento, a expansão da viga conduz a uma maior capacidade resistente em relação à viga de alma cheia. Outra característica a ressaltar é que a introdução da chapa expansora em vigas muito curtas com alma esbelta resulta em redução da capacidade resistente. Isso se deve ao fato dessas vigas estarem sujeitas a grandes esforços de cisalhamento e muito susceptíveis à flambagem do montante de alma. 
Os gráficos apresentados na Figura 6.28 e na Figura 6.29 apresentam a capacidade máxima das vigas casteladas, comparando-se os padrões Anglo-Saxão e Peiner, com e sem chapa expansora, com vãos de 3000, 4500 e $6000 \mathrm{~mm}$, para os três diferentes tipos de carregamento modelados no estudo paramétrico (uma carga concentrada no centro do vão, $\mathrm{CC} 1$; duas cargas concentradas nos terços médios do vão, CC2; e carregamento uniformemente distribuído ao longo do vão, CD). Os resultados são apresentados nos gráficos em termos de momento fletor máximo e esforço cortante máximo resistentes, respectivamente.

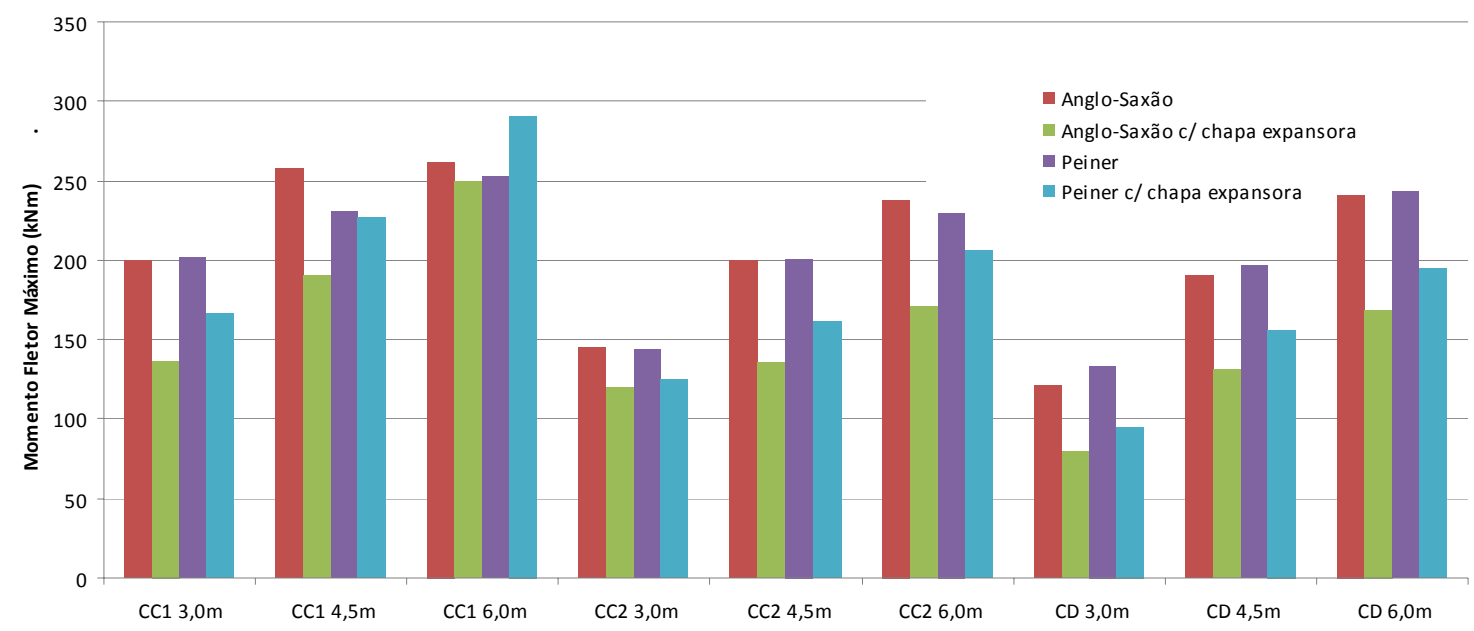

Figura 6.28 - Momento fletor máximo resistente das vigas com diferentes vãos e tipos de carregamento, perfil W360 x 32,9.

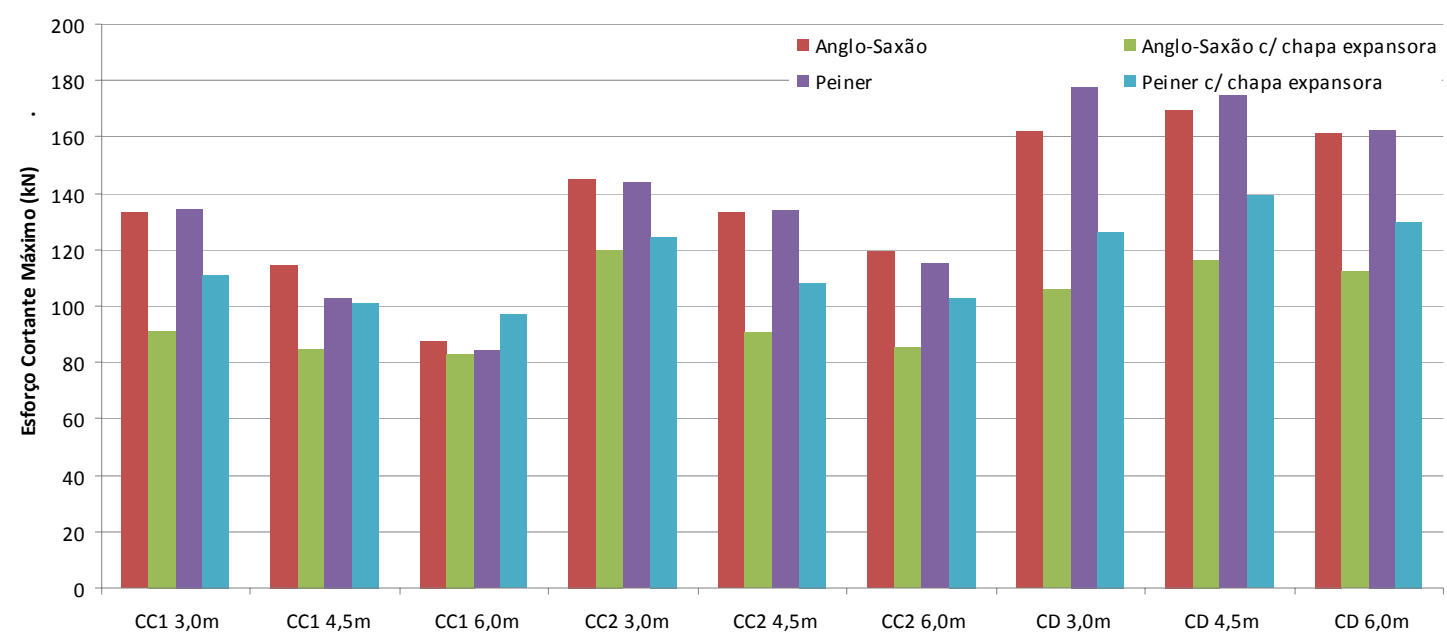

Figura 6.29 - Esforço cortante máximo das vigas com diferentes vãos e tipos de carregamento, perfil W360 x 32,9. 
Observando-se as figuras apresentadas, pode-se notar que, nas vigas casteladas formadas a partir de perfis com alma esbelta, a inserção de chapa expansora reduz a capacidade última na maior parte das vigas, principalmente quando estas têm vãos curtos. Nota-se também que a influência da chapa expansora é mais significativa nas vigas de padrão Anglo-Saxão, devido ao fato de, nestas vigas, a largura mínima do montante ser menor, e assim, mais susceptíveis a fenômenos de instabilidade dos montantes.

Para verificar a influência da altura do montante na capacidade resistente das vigas casteladas, foram modeladas vigas nos padrões Anglo-Saxão e Peiner, variando-se a altura da chapa expansora. Na Figura 6.30, mostra-se a comparação dos resultados.

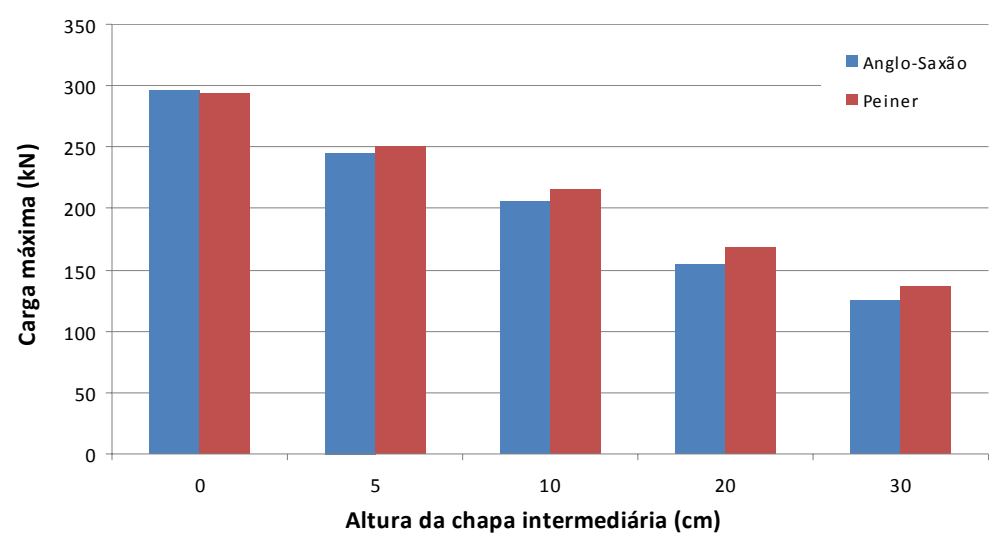

Figura 6.30 - Carga máxima nas vigas casteladas, em função da altura da chapa expansora, perfil W360 x 32,9.

Na Figura 6.30, observa-se que, como as vigas modeladas são originárias de um perfil com alma esbelta, quanto maior a altura da chapa expansora, maior a esbeltez da alma e, consequentemente, menor a carga crítica de flambagem. Comparando os padrões AngloSaxão e Peiner, pode-se perceber que as vigas do padrão Anglo-Saxão têm maior rigidez (a capacidade de carga é maior para as vigas com alma menos esbelta), e por outro lado tem maior susceptibilidade à FMA (a carga última é menor nas vigas com alma mais esbelta).

$\mathrm{Na}$ sequência são apresentadas curvas carga-deslocamento, comparando-se o comportamento das vigas casteladas nos padrões Anglo-Saxão e Peiner, com e sem a presença de chapa expansora, e das vigas não casteladas. Todas as vigas são feitas a partir do perfil W360 x 32,9 . 
$\mathrm{Na}$ Figura 6.31, comparou-se o comportamento das vigas com vão de três metros submetidas a uma carga concentrada no centro do vão. Pode-se notar que as vigas casteladas não apresentam nenhum ganho significativo de resistência e as vigas casteladas com chapa intermediária apresentam uma redução da capacidade resistente. Entretanto, pode-se perceber um acréscimo da rigidez das vigas casteladas em relação à viga original.

As mesmas considerações são válidas para as vigas submetidas a carregamento uniformemente distribuído ao longo do vão (Figura 6.32). Nestas vigas, ocorre a flambagem dos montantes de alma por compressão (ver item 3.2.5).

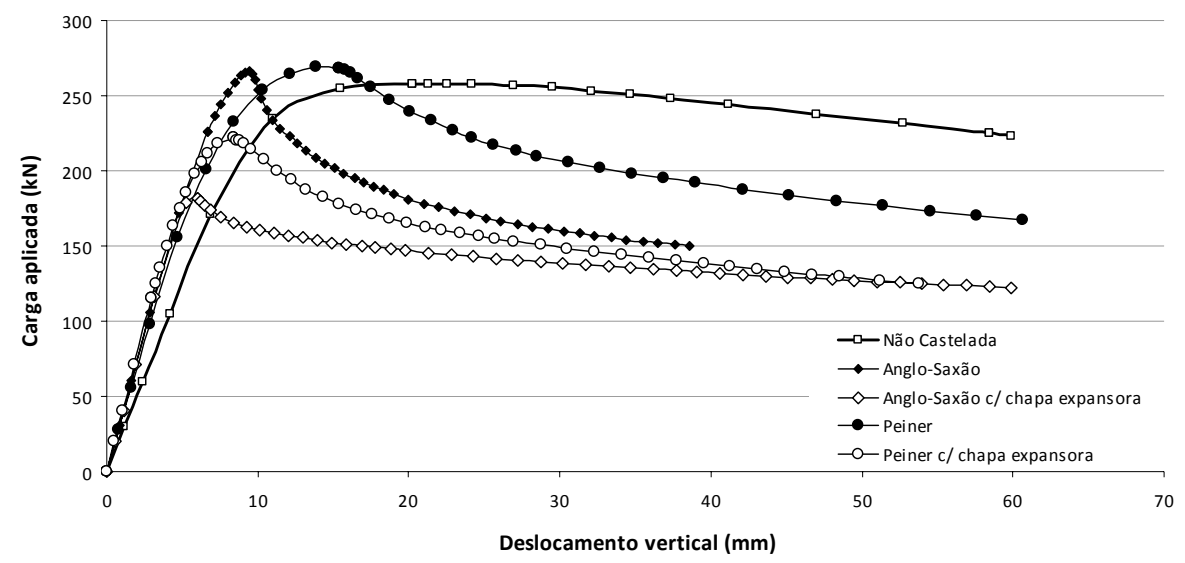

Figura 6.31 - Curva carga-deslocamento das vigas com vão de $3000 \mathrm{~mm}$ e submetidas a um carregamento concentrado no centro do vão, perfil W360 x 32,9.

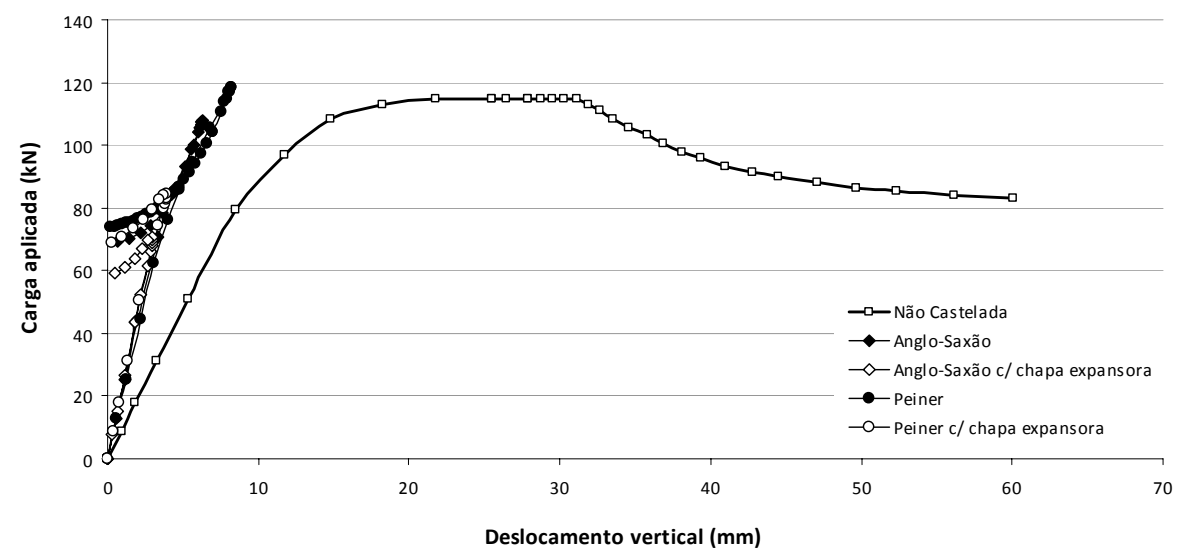

Figura 6.32 - Curva carga-deslocamento das vigas com vão de $3000 \mathrm{~mm}$ e submetidas a um carregamento distribuído ao longo do vão, perfil W360 x 32,9.

A reversão dos deslocamentos verticais, observada na Figura 6.32, se deve à flambagem dos montantes de alma por compressão (ver Figura 5.10). Os deslocamentos representados 
na figura foram obtidos em um ponto do modelo numérico situado no centro do vão, na altura da borda inferior do alvéolo. Na fase inicial do carregamento, à medida que a viga se deforma por flexão, enquanto a seção se mantém íntegra esse ponto sofre um deslocamento vertical crescente para baixo. A partir do momento em que a FMA tem início, a flexão dos montantes possibilita um deslocamento da mesa inferior em sentido contrário. Na fase póspico, os deslocamentos devidos à FMA se tornam maiores que os devidos à flexão.

Nos gráficos da Figura 6.33 e da Figura 6.34 apresentam-se as curvas carga-deslocamento das vigas com vão livre de $4500 \mathrm{~mm}$, submetidas a um carregamento concentrado no centro do vão e uniformemente distribuído, respectivamente. Nota-se um pequeno ganho de resistência nas vigas casteladas em relação à viga original, e nenhum ganho ou ainda perda quando se adiciona a chapa intermediária. Quanto à rigidez, entretanto, percebe-se um ganho significativo nas vigas casteladas em relação ao perfil original, e ainda um pequeno ganho adicional quando se acrescenta as chapas expansoras.

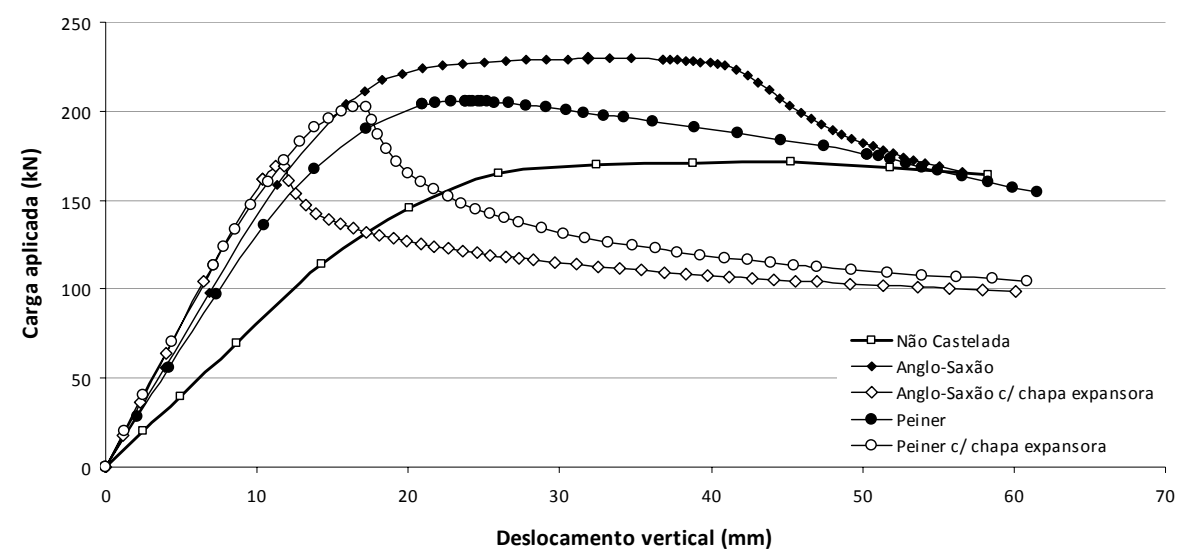

Figura 6.33 - Curva carga-deslocamento das vigas com vão de $4500 \mathrm{~mm}$ e submetidas a um carregamento concentrado no centro do vão, perfil W360 x 32,9. 


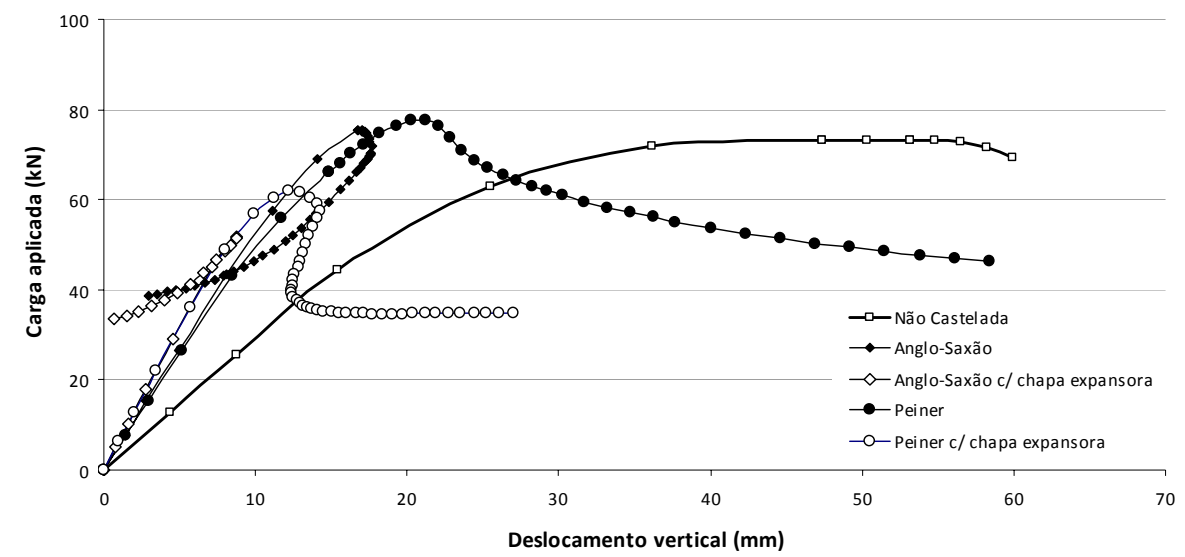

Figura 6.34 - Curva carga-deslocamento das vigas com vão de $4500 \mathrm{~mm}$ e submetidas a um carregamento distribuído ao longo do vão, perfil W360 x 32,9.

Sabe-se que em vigas com vãos mais longos, a influência da flexão no comportamento estrutural começa a ser significativo. Deste modo, um aumento na inércia reflete em acréscimo de capacidade resistente, motivo pelo qual as vigas casteladas mostram-se com resistência superior às vigas originais e a rigidez passa a ser consideravelmente maior. $\mathrm{O}$ deslocamento referente à carga última da viga castelada com chapa intermediária é significativamente menor que o da viga sem chapa, que por sua vez é bastante inferior ao da viga não-castelada. Na Figura 6.35 e na Figura 6.36 apresentam-se as curvas cargadeslocamento para as vigas com vão de $6000 \mathrm{~mm}$, submetidas a uma carga concentrada no centro do vão e a carga uniformemente distribuída ao longo do vão, respectivamente.

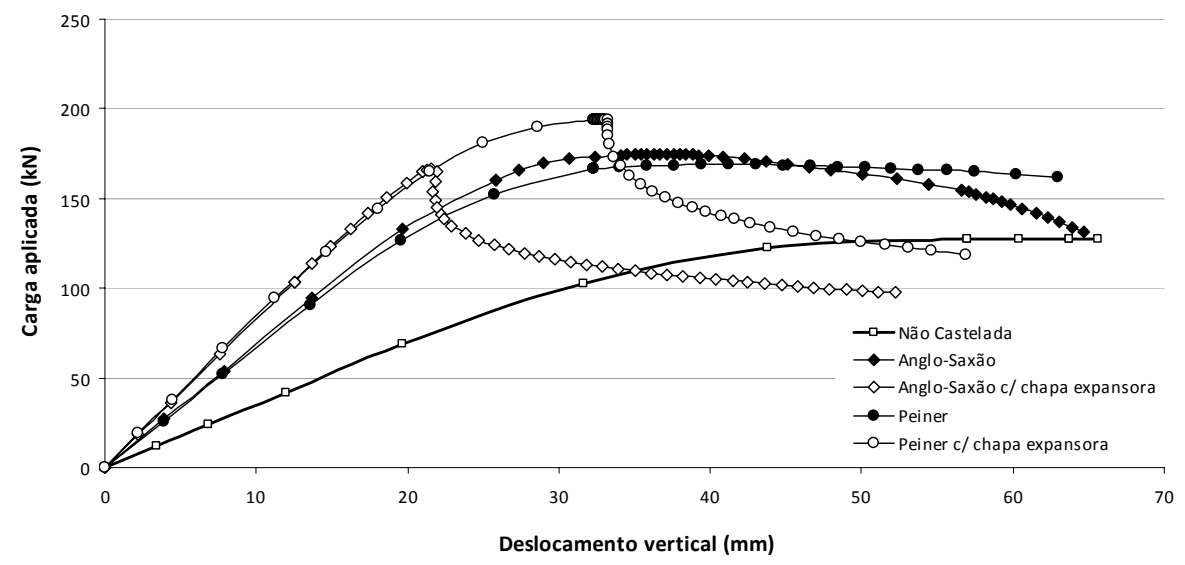

Figura 6.35 - Curva carga-deslocamento para vigas com vão de $6000 \mathrm{~mm}$ submetidas a uma carga concentrada no centro do vão, perfil W360 x 32,9. 


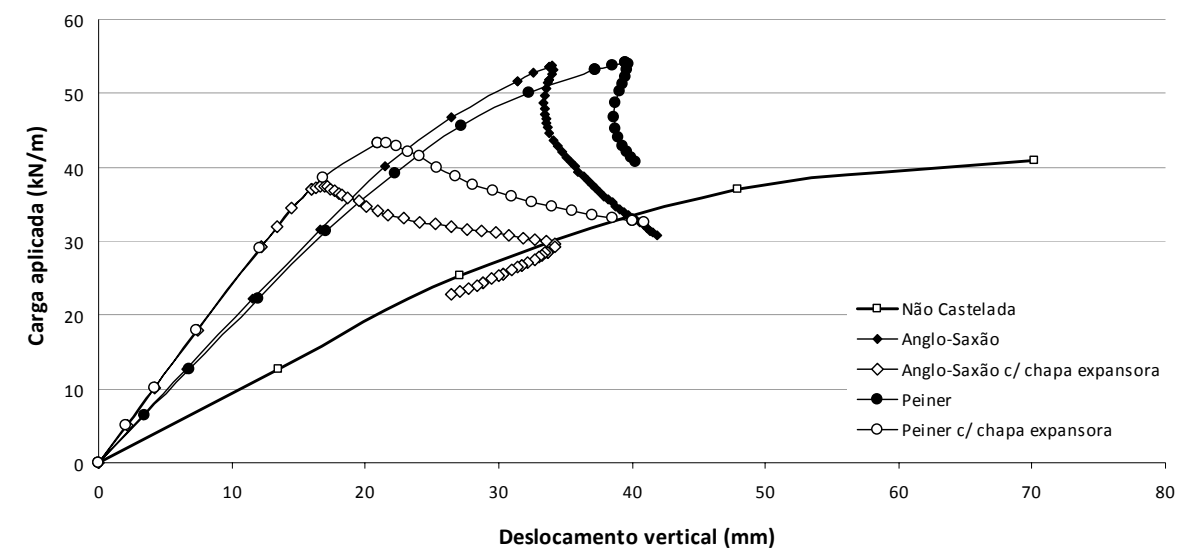

Figura 6.36 - Curva carga-deslocamento para vigas com vão de $6000 \mathrm{~mm}$ submetidas a carga distribuída ao longo do vão, perfil W360 x 32,9.

De um modo geral, pode-se perceber que o ganho de inércia obtido com o aumento da altura das vigas tem influência sobre a rigidez maior que sobre a capacidade resistente. Uma vez que o estudo paramétrico foi realizado principalmente com vigas cuja esbeltez da alma é grande, pode-se concluir que para estas vigas, a utilização da chapa expansora traz pouca contribuição na capacidade das vigas, exceto para o caso de vãos longos, quando se tornam críticos os estados limites de deslocamento excessivo. Observa-se também, nas curvas apresentadas, que as vigas casteladas no padrão Anglo-Saxão possuem rigidez ligeiramente superior à rigidez das vigas padrão Peiner.

Em vigas curtas com alma de pequena espessura, sujeitas a carregamento uniformemente distribuído, há uma tendência de ocorrer o colapso por flambagem do montante de alma próximo à região do apoio, em função da interação de tensões normais e de cisalhamento nessa região. Se a viga é muito curta, e o carregamento aplicado se aproxima da capacidade limite da peça, existe a possibilidade de ocorrer flambagem por compressão dos montantes de alma próximos ao centro do vão (Figura 5.10). Nesses casos, a presença usual de um enrijecedor de alma na região dos apoios produz um efeito favorável, contribuindo para que não ocorra flambagem dos montantes próximos ao apoio. Nas simulações realizadas, a introdução de um enrijecedor no centro do vão de vigas com essas características, evidenciou o efeito benéfico desse enrijecedor no sentido de aumentar a capacidade resistente da viga.

Na Figura 6.37 é apresentada a relação entre a carga última das vigas com enrijecedor no centro do vão e a carga última das vigas modeladas sem esse enrijecedor (cujo colapso se 
deu pela flambagem dos montantes de alma por compressão), onde as vigas A, B e C são as vigas apresentadas na Tabela 5.16, na ordem em que estão listadas, respectivamente.

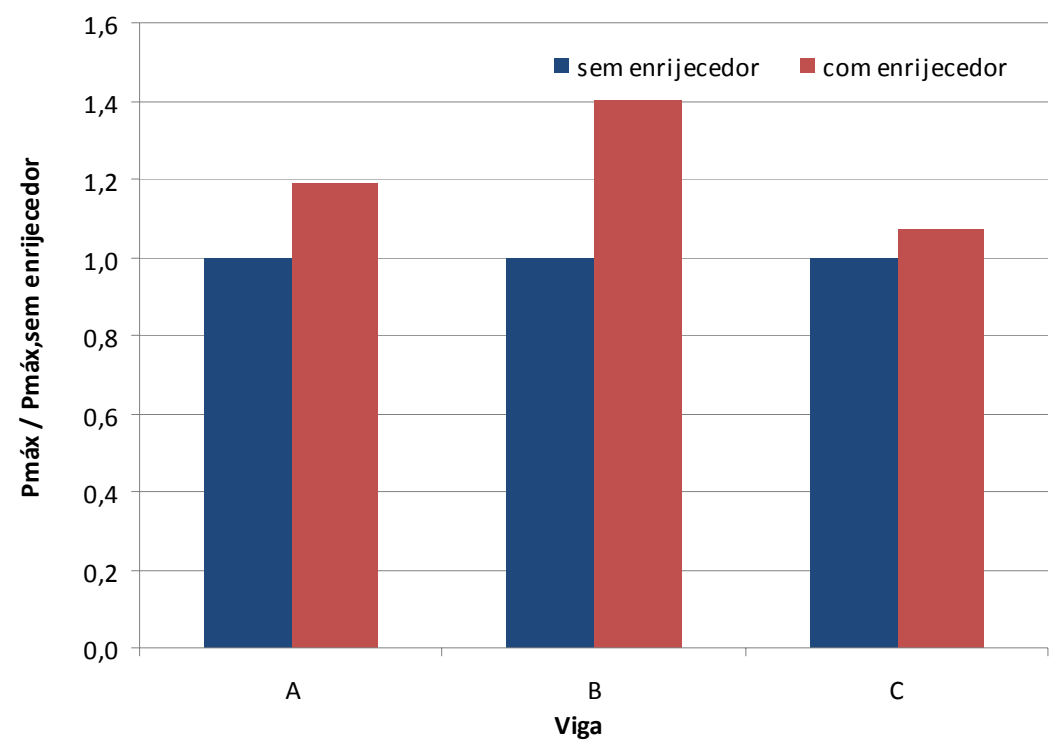

Figura 6.37 - Razão entre a carga última das vigas com enrijecedor e a carga última das vigas sem enrijecedor adicional (perfil W360 x 32,9).

$\mathrm{Na}$ Figura 6.38, na Figura 6.39 e na Figura 6.40 são mostradas as curvas cargadeslocamento dessas vigas a fim de comparar o comportamento das mesmas.

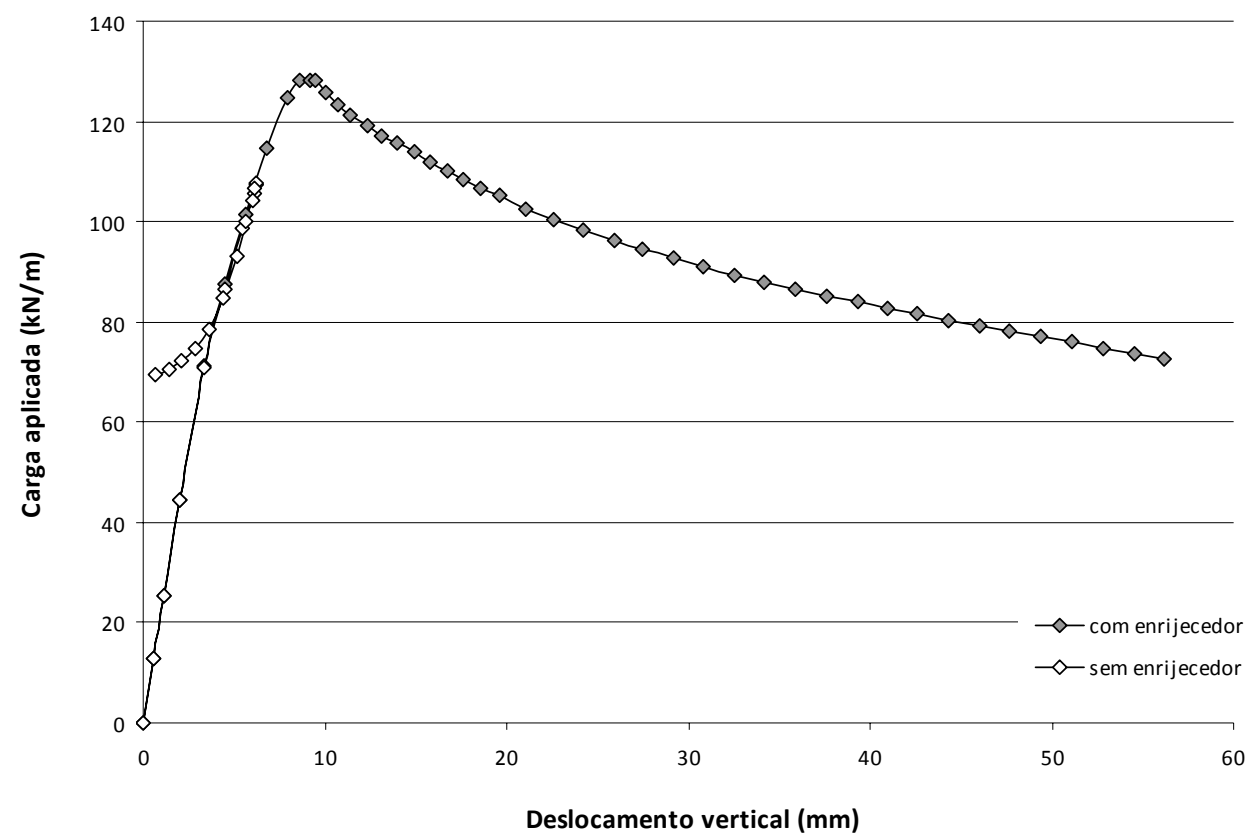

Figura 6.38 - Curva carga-deslocamento das vigas W360x32,9_3000_CD_AS (ver Tabela 5.8). 


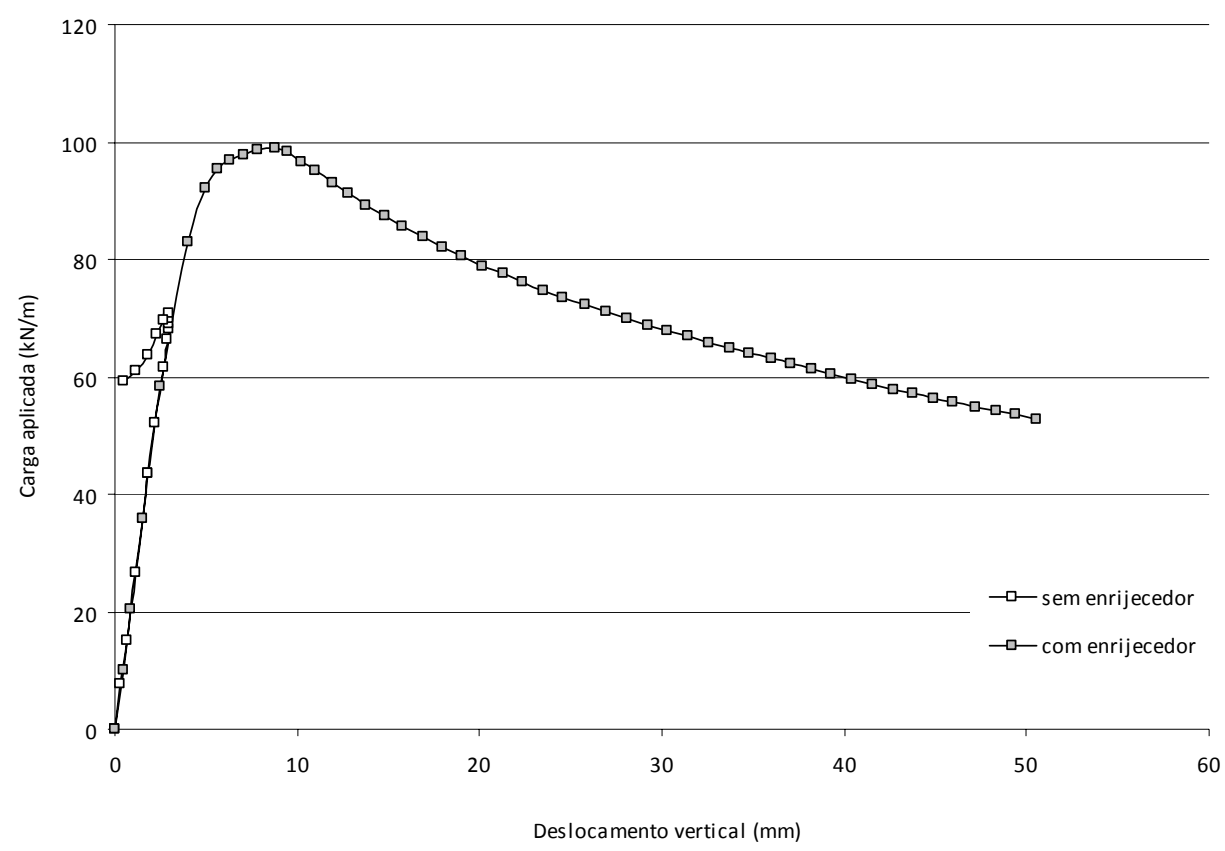

Figura 6.39 - Curva carga-deslocamento das vigas W360x32,9_3000_CD_AS-CH (ver Tabela 5.8).

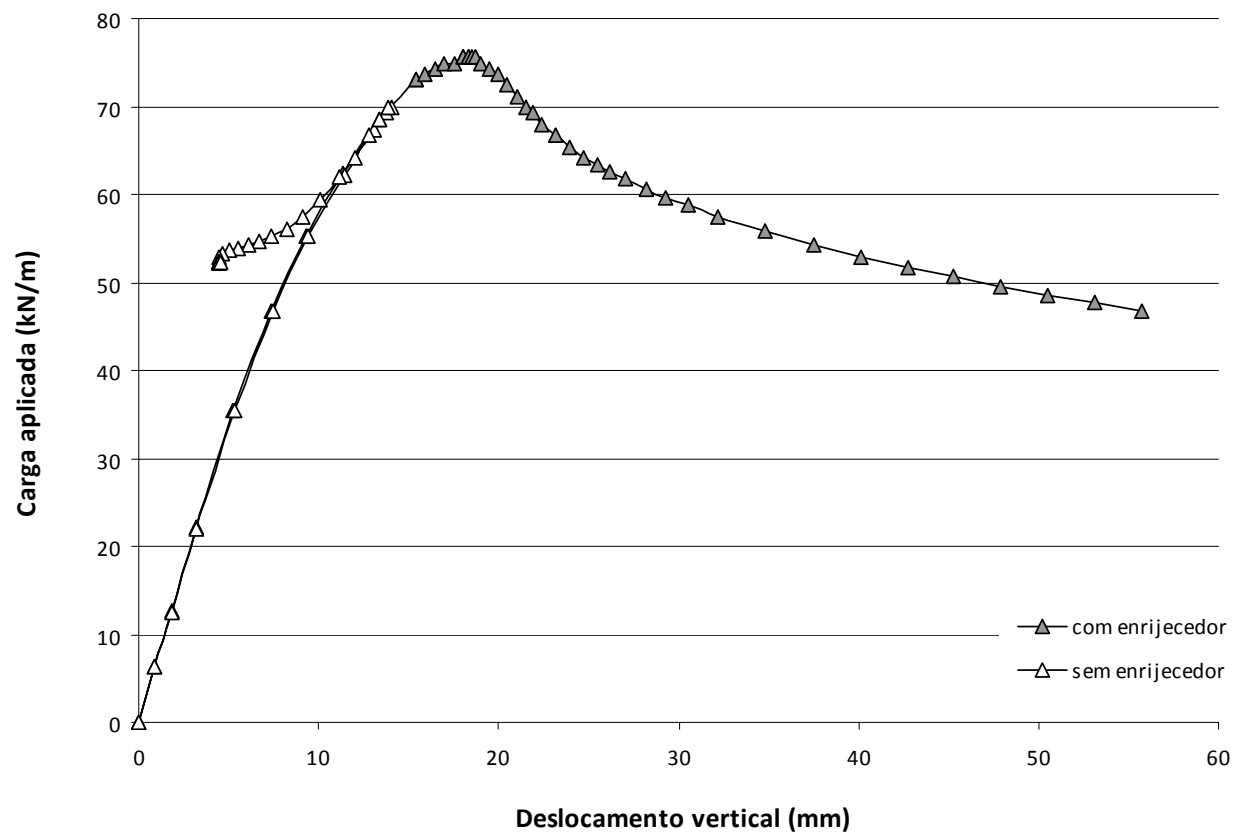

Figura 6.40 - Curva carga-deslocamento das vigas W360x32,9_4500_CD_45;2-CH (ver Tabela 5.10).

Observando-se as figuras anteriores, relacionadas ao enrijecedor de alma, nota-se que a introdução do enrijecedor não apenas modifica o modo de colapso da viga como também aumenta a sua capacidade resistente. 


\section{CONCLUSÕES}

\subsection{Conclusões gerais}

Neste trabalho, foi apresentado um modelo numérico pelo Método dos Elementos Finitos, elaborado no software ABAQUS, para o estudo do comportamento das vigas casteladas susceptíveis ao colapso por flambagem dos montantes de alma. As vigas foram modeladas no espaço tridimensional com elementos de casca.

Nas análises realizadas, foram consideradas não-linearidade material e não-linearidade geométrica da estrutura, admitindo-se um material com comportamento elastoplástico perfeito. Para que ocorresse a flambagem durante a análise, adotou-se uma imperfeição inicial igual a 1/2000 da altura total da viga castelada, associada ao modo de flambagem obtido na análise de flambagem elástica realizada previamente. 
Neste trabalho foi proposta e utilizada uma distribuição simplificada de tensões residuais, criada a partir da distribuição parabólica de Young. Na distribuição simplificada, as tensões são consideradas uniformes ao longo das mesas e ao longo da alma, de modo que a força resultante em cada elemento da seção é equivalente em ambas as distribuições.

Foram modeladas 13 vigas casteladas obtidas de resultados de programas experimentais, encontrados na literatura. Os resultados das modelagens mostraram boa concordância com os resultados experimentais. Embora o enfoque principal deste trabalho tenha sido o estudo das vigas com colapso por FMA, foram modeladas vigas com outros modos de colapso, para verificação da validade do modelo numérico. Os resultados mostraram que este modelo numérico reproduz bem o comportamento das vigas casteladas, tanto para estados limites de serviço, como para estados limites últimos, com uma representação adequada dos modos de colapso.

Na etapa de validação do modelo numérico pôde-se verificar que o modelo simplificado de tensões residuais, apresentado e utilizado neste trabalho, é válido e consistente, tendo em vista a concordância entre os resultados da modelagem numérica e resultados experimentais.

Após a validação do modelo numérico foi realizada uma avaliação do comportamento estrutural na forma de um estudo paramétrico, tendo como enfoque as vigas susceptíveis ao colapso por instabilidade dos montantes de alma.

Os resultados obtidos indicam que vigas casteladas de alma esbelta com vãos curtos apresentam pouco ou nenhum ganho de capacidade última em relação às vigas de alma cheia originais. A adição da chapa expansora reduz a capacidade última das vigas curtas. Nas vigas com vãos médios $\left(L \cong 10 d_{g}\right)$, observou-se que a adição das chapas expansoras produziu um pequeno ganho de capacidade resistente, uma vez que nessas vigas a ocorrência da flambagem do montante de alma é menos provável. $\mathrm{O}$ estudo paramétrico realizado não abrangeu as vigas longas $\left(L>20 d_{g}\right)$, onde a flexão e os deslocamentos determinam o dimensionamento. Espera-se que para essas vigas a contribuição das chapas expansoras seja mais significativa.

Apesar do pequeno ganho de capacidade resistente, as curvas carga-deslocamento mostraram significativo ganho de rigidez no comportamento das vigas casteladas em 
relação às vigas originais de alma cheia. Um acréscimo de rigidez adicional é obtido quando se empregam as chapas expansoras.

Comparando-se os resultados das vigas modeladas com diferentes geometrias de aberturas, observou-se um melhor comportamento das vigas, quanto à capacidade resistente e quanto à rigidez, quando as aberturas têm os lados inclinados com ângulo próximo de $60^{\circ}$, confirmando a configuração geométrica adotada ao longo de anos no cenário internacional, conforme os padrões Litzka, Peiner e Anglo-Saxão. Observou-se também uma melhoria no comportamento das vigas quando foi utilizada menor relação $b_{w} / b$, principalmente naquelas com baixo ângulo de abertura.

Os resultados das análises das vigas submetidas a carregamento uniformemente distribuído mostraram que as vigas curtas, principalmente, sofrem colapso por flambagem dos montantes de alma por compressão. Isso se dá pelo fato de o esforço cortante ser pequeno em relação à força de compressão sobre os montantes. Observou-se que os montantes próximos do centro do vão são os que mais sofrem com as deformações devidas à FMA por compressão. Constatou-se que a introdução de um enrijecedor de alma na região central da viga melhora consideravelmente seu desempenho estrutural, podendo elevar em até $40 \%$ sua capacidade resistente.

Uma das principais questões que motivou este trabalho estava relacionada ao comportamento de vigas casteladas fabricadas a partir de perfis laminados produzidos no Brasil, visto que alguns deles possuem almas com esbeltez superior àquelas dos perfis equivalentes utilizados na América do Norte e na Europa. Em função dos resultados obtidos, verificou-se que, em vigas casteladas de aço com vãos longos e carregamento distribuído, que representam a maioria dos casos correntes, a ocorrência da flambagem dos montantes de alma é quase sempre menos crítica que outros modos de colapso. Pode-se afirmar também que, nas vigas casteladas curtas, a flambagem dos montantes de alma é um modo de colapso importante e que ocorre, geralmente, em regime inelástico, mesmo nas vigas com alma esbelta. 


\subsection{Sugestões para trabalhos futuros}

Após a realização deste trabalho, uma série de questões pode ser levantada, o que torna necessário outras investigações, dentre as quais se podem citar as seguintes:

- realização de um estudo numérico, variando-se o índice de esbeltez do montante de alma com vistas à identificação dos valores chave da esbeltez que caracterizam a mudança dos regimes de plastificação, flambagem inelástica e flambagem elástica dos montantes de alma;

- realização de um estudo da distribuição de tensões residuais ao longo da alma das vigas alveolares, considerando as perturbações causadas pelo corte e soldagem desses perfis;

- modelagem de vigas cujo colapso se dá por flambagem dos montantes de alma por cisalhamento, adicionando enrijecedores nos montantes críticos, para avaliar as mudanças no comportamento da viga;

- modelagem de vigas susceptíveis ao colapso por flambagem do montante de alma, sem impedir a ocorrência de FLT, para estudar a interação entre os dois modos de flambagem;

- realização de uma campanha experimental, com o objetivo de confirmar o comportamento observado nos modelos numéricos para os perfis brasileiros com alma mais esbelta. 


\section{REFERÊNCIAS BIBLIOGRÁFICAS}

ABNT, NBR 8800. Projeto de Estruturas de Aço e de Estruturas Mistas de Aço e Concreto de Edifícios. Rio de Janeiro, 2008.

Abreu, L.M.P.; Fakury, R.H.; Castro e Silva, A.L.R. Determinação do momento fletor resistente à flambagem lateral com torção de vigas de aço celulares. CILAMCE 2010 - XXXI Iberian-Latin-American Congress on Computational Methods in Engineering: Argentina: 2010.

Aglan, A.A.; Qaqish, S. Plastic behavior of beams with mid-depth web openings. Engineering Journal American Institute of Steel Construction. 20-26; 1982.

Amayreh, L.; Saka, M.P. Failure load predictions of castellated beams using artificial neural networks. Asian Journal of Civil Engineering. 6:35-54; 2005.

Bailey, C. Indicative fire tests to investigate the behaviour of cellular beams protected with intumescent coatings. Fire Safety Journal. 39:689-709; 2004. 
Bathe, K-J; Finite Element Procedures. Estados Unidos: 1996.

Bezerra, E.M.; Fakury R.H.; Castro e Silva A.L.R.; Caldas R.B. Determinação do momento fletor resistente a flambagem lateral com torção de vigas de aço casteladas. XXXIV Jornadas Sudamericanas de Ingeniería Estructural: Argentina: 2010 .

Boyer, J.P. Castellated Beams - New Developments. AISC Engineering Journal. 104-108; 1964.

Castro e Silva, A.L.R. Análise numérica não-linear da flambagem local de perfis de aço estrutural submetidos à compressão uniaxial. Belo Horizonte, Brasil: Universidade Federal de Minas Gerais; 2006.

Cavalcante, O.R.O. Estudo das tensões na solda da alma de vigas de aço alveolares em estruturas mistas. Brasília, Brasil: Universidade de Brasília; 2005.

Chai, T.Y. Warping Behaviour of Cantilever Steel Beam With Openings. Malásia: Universiti Teknologi Malaysia; 2005.

Chung, K.F.; Liu, T.C.H.; Ko, A.C.H. Investigation on Vierendeel mechanism in steel beams with circular web openings. Journal of Constructional Steel Research. $57: 467-490 ; 2001$.

Cimadevilla, J.E.; Gutiérrez, E.M.; Rodríguez, J.A.V.; Vigas Alveoladas. A Coruna: Biblioteca Técnica Universitária; 2000.

Cunha, P.C. Comportamento crítico e pós-crítico de placas dobradas. Rio de Janeiro, Brasil: Pontifícia Universidade Católica do Rio de Janeiro; 2005.

Dabaon, M.A.; El-Naggar, M.I.; Yossef, N.M. Experimental and theoretical study of curved rolled and castellated composite beams. Alexandria Engineering Journal. 42:219-230; 2003.

Das, P.K.; Srimani, S.L. Handbook for the Design of Castellated Beams. Rotterdam: A. A. Balkema; 1986.

Delesques, R. Le calcul des poutres ajourées. Construction Métallique. 4:41-51; 1969.

Delesques, R. Stabilité des montants de poutres ajourées. Construction Métallique. 3:26$33 ; 1968$.

Demirdjian, S. Stability of Castellated Beam Webs. Montreal, Canadá: McGill University; 1999.

Dougherty, B.K. Buckling of web post in perforated beams. Journal of the Structural Division. 107:507-519; 1981.

Estrada, H.; Jimenez J.J.; Aguíniga F. Cost analysis in the design of open-web castellated beams. Proceedings of the 2006 Architectural Engineering National Conference, EUA; 2006. 
Faltus, F. Calculation of castellated girders. Acier-Stahl-Steel. 5:229-232; 1966.

Feldmann, M.; Müller, C.; Hechler, O.; et al. Final Report: Large web openings for service integration in composite floors: RFS-CT-2005-00037; 2006.

Galambos, A.R.; Hosain, M.U.; Speirs, W.G. Optimum expansion ratio of castellated steel beams. Engineering Optimization. 1:213-225; 1973.

Gemperle, C. Vereinfachte Vordimensionierung von Wabenträgern. Stahlbau. 76:530-536; 2007.

Gibson, J.E.; Jenkins W.M. An investigation of the stress and deflections in castellated beams. The Structural Engineer. 467-479; 1957.

Gomes, C.A.B. Resistência a compressão de perfis H laminados de abas paralelas. Ouro Preto; Brasil: Universidade Federal de Ouro Preto; 2006.

Grünbauer BV. Acessado em 26/01/2011. Web Page: http://www.grunbauer.nl/eng/waarom.htm.

Hennessey, J.M.; Hoffman, R.M.; Dinehart, D.W.; Gross, S.P.; Yost, J.R. Effect of cope geometry on the strength and failure behavior of open web expanded beams. Seventeenth ASCE Engineering Mechanics Conference. EUA; 2004.

Hibbitt, Karlsson e Sorensen. “ABAQUS Theory Manual”, Hibbitt, Karlsson \& Sorensen, Inc, EUA; 2009

Hoffman, R.M.; Dinehart, D.W.; Gross, S.P.; Yost, J.R. Analysis of stress distribution and failure behavior of cellular beams. Proceedings of the 2006 ANSYS Conference, EUA; 2006.

Kerdal, D.; Nethercot D.A. Failure modes for castellated beams. Journal of Constructional Steel Research. 295-315; 1984.

Knowles, P.R. Castellated beams. Proceedings of the Institution of Civil Engineers. 521$536 ; 1991$.

Kohnehpooshi, O.; Showkati, H. Numerical modeling and structural behavior of elastic castellated beams. European Journal of Scientific Research. 31:306-318; 2009.

Kolosowski, J. Stresses and deflections in castellated beams. The Structural Engineer. 42:19-24; 1964.

Lagaros, N.D.; Psarras, L.D.; Papadrakakis, M.; Panagiotou G. Optimum design of steel structures with web openings. Engineering Structures. 2008.

Lam, C. Lateral Buckling of Beams With Web Holes. Montreal, Canadá: McGill University; 1984.

Lawson, R.M.; Lim, J.; Hicks S.J.; Simms, W.I. Design of composite asymmetric cellular beams and beams with large web openings. Journal of Constructional Steel Research. 62:614-629; 2006. 
Lian, V.T.; Shanmugam, N.E. Design of horizontally curved plate girder webs containing circular openings. Thin-Walled Structures. 42:719-739; 2004.

Liu, T.C.H.; Chung, K.F. Steel beams with large web openings of various shapes and sizes: finite element investigations. Journal of Constructional Steel Research. 59:1159$1176 ; 2003$.

Lleonart, J. M. Geometría de los perfiles alveolares. Informes de la Construcción. 40:51$64 ; 1988$.

Lotfollahi-Yaghin, M.A.; Ahmadi H. Investigation of dynamic properties of cantilever castellated beams in comparison with plain-webbed beams using white noise excitation. World Applied Sciences Journal. 3:522-530; 2008.

Lourenço, P.B. Métodos computacionais da mecânica dos sólidos não-linear. Guimarães, Portugal: 1999.

Megharief, J.D. Behavior of Composite Castellated Beams. Montreal, Canada: McGill University; 1997.

Mohebkhah, A. The moment-gradient factor in lateral-torsional buckling on inelastic castellated beams. Journal of Constructional Steel Research. 60:1481-1494; 2004.

Mohebkhah, A.; Showkati, H. Bracing requirements for inelastic castellated beams. Journal of Constructional Steel Research. 61:1373-1386; 2005.

Nadjai, A.; Goodfellow, N.; Vassart ,O.; Ali, F.; Choi, S. Simple calculation method of composite cellular beams at elevated temperatures. Fifth International Conference on Structures in Fire: 551-559; 2008.

Nadjai, A.; Vassart, O.; Ali, F; Talamona, D.; Allam, A.; Hawes, M. Performance of cellular composite floor beams at elevated temperatures. Fire Safety Journal. 42:489-497; 2007.

Nethercot, D.A.; Kerdal, D. Lateral-torsional buckling of castellated beams. The Structural Engineer. 60B:53-61; 1982.

Radić, I.; Markulak D. Lateral buckling of castellated beams. Tehnički Vjesnik. 14:25-35; 2007.

Radić, I.; Markulak D.; Varevac D. Utjecaj vrste bočnih pridržanja na otpornost saćastih nosača na bočno-torzijsko izvijanje. Technical Gazette. 16:9-17; 2009.

Raftoyiannis, I.G.; Ioannidis, G.I. Deflection of castellated I-beams under transverse loading. Steel Structures. 6:31-36; 2006.

Redwood, R.G. Behaviour of composite castellated beams. Progress in Structural Engineering and Materials. 2:164-168; 2000.

Redwood, R.G.; Demirdjian, S. Castellated beam web buckling in shear. Journal of Structural Engineering. 124:1202-1207; 1998. 
Redwood, R.G.; Poumbouras, G. Analysis of composite beams with web openings. Journal of Structural Engineering. 110:1949-1958; 1984.

Rini, D.T. Critical behavior of long span cellular beams in fire. College Park, Estados Unidos: University of Maryland; 2006.

Rodrigues, F. Comportamento estrutural de vigas de aço com abertura na alma. Rio de Janeiro, Brasil: Universidade do Estado do Rio de Janeiro; 2007.

Showkati, H. Lateral-torsional buckling of castellated beams. Iranian Journal of Science \& Technology. 32:153-156; 2008.

Szalai, J.; Papp, F. A new residual stress distribution for hot-holled I-shaped sections. Journal of Constructional Steel Research. 845-861; 2005.

Tkalčević, V.; Džeba I.; Androić B. Proracun saćastih nosača prema Eurokodu 3. Građevinar. 58:709-716; 2006.

Toprac, A.A.; Cooke, B.R. An experimental investigation of open-web beams. 1-16; 1959.

Vassart, O.; Bouchair, A.; Muzeau, J-P.; Nadjai, A. Analytical model for the web post buckling in cellular beams under fire. Proceedings of the Fifth International Conference on Structures in Fire: 2008.

Westok. Accessado em 10/12/2010. Web Page: http://www.westok.co.uk.

Wong, V.B.; Burgess, I.; Plank, R. Behaviour of Composite Cellular Steel - Concrete Beams at Elevated Temperatures. Steel Structures. 9:29-37; 2009.

Zaarour, W.J. Web Buckling in Thin Webbed Castellated Beams. Montrel, Canadá: McGill University; 1995.

Zaarour, W.J.; Redwood, R.G. Web Buckling in Thin Webbed Castellated Beams. Journal of Structural Engineering. 860-866; 1996.

Zirakian, T.; Showkati H. Distortional buckling of castellated beams. Journal of Constructional Steel Research. 62:863-871; 2006. 